\title{
Effects of elevated temperature and eutrophication on tropical lagoon sponges
}

\section{SANDEEP SHIVRAM BEEPAT}

A thesis submitted to the Victoria University of Wellington in fulfilment of the requirements for the degree of Doctor of Philosophy

Victoria University of Wellington 
This thesis was conducted under the supervision of

\author{
Professor James J. Bell \\ (Primary Supervisor)
}

$\boldsymbol{\&}$

\title{
Professor Simon K. Davy \\ (Co-supervisor)
}

Victoria University of Wellington

Wellington, New Zealand 
This thesis is dedicated to the 'Supreme Enjoyer' 


\begin{abstract}
Coastal lagoons are important, but fragile ecosystems, which host diverse biological assemblages. However, these ecosystems are becoming increasingly exposed to anthropogenic stressors such as ocean warming and eutrophication. Sponges are important suspension feeders and are often important components of coastal lagoon communities. However, the impacts of anthropogenic stressors on lagoon-inhabiting sponges are poorly understood. This thesis examines the effects of elevated temperature and eutrophication on the physiological responses and temporal dynamics of three lagoon-inhabiting sponges, Neopetrosia chaliniformis, Amphimedon navalis and Spheciospongia vagabunda from Mauritius (western Indian Ocean). The effects of elevated temperature on A. navalis proteome dynamics and on the bentho-pelagic interactions of $S$. vagabunda were also explored.
\end{abstract}

In the first data chapter, I conducted a multifactorial experiment to investigate the short-term physiological responses of $N$. chaliniformis, A. navalis and S. vagabunda exposed to nine combinations of temperature and nitrate treatments for 14 days. Temperature treatments for this experiment were chosen based on the IPCC Representative Concentration Pathways, i.e. RCP6.0 $\left(+2{ }^{\circ} \mathrm{C}\right)$ and RCP8.5 $\left(+4{ }^{\circ} \mathrm{C}\right)$ projected for the year 2100 . Nitrate concentrations were increased to approximately two- and three-fold the actual nitrate concentrations in the lagoons where sponges were collected. After 14 days of exposure, the photosynthetic pigment concentrations, and effective quantum yield of the two photosynthetic species (N. chaliniformis and S. vagabunda), as well as the buoyant weight of all species declined significantly. The gross photosynthetic rates and $\mathrm{P}: \mathrm{R}$ ratios of $N$. chaliniformis and $S$. vagabunda also declined significantly, but the respiration rates of all species were significantly higher. The results from this chapter demonstrated that while lagoon-inhabiting sponges are susceptible to short term exposure to elevated temperatures, they are generally tolerant to elevated nitrate concentrations.

For my second data chapter, I conducted a four-week thermal tolerance experiment to investigate the physiological tolerance of these three sponges to elevated temperature. I also explored the proteomic responses of $A$. navalis to elevated temperature. The results showed that the physiology of $N$. chaliniformis and A. navalis were impacted over time, where after one-week of thermal exposure, both species experienced significant loss in buoyant weight and increases in pumping 
and holobiont oxygen consumption rates, respectively. In contrast, the bioeroding sponge $S$. vagabunda experienced an increase in buoyant weight over time and after a thermal exposure of two weeks, the effective quantum yield, pumping and holobiont oxygen consumption rates of this species appeared to stabilize, indicating the possible acclimation of this species to longer thermal exposure. A. navalis proteomic analysis after four weeks revealed significant changes in the expression of 50 proteins, which were mainly involved in oxidative stress, protein transport and cytoskeletal organization. These results demonstrate that medium- or long-term thermal experiments are more indicative of possible species-specificity and acclimation potential in sponges. Moreover, this study also demonstrates that thermal stress responses are also reflected at the proteome level and that a combination of physiology and proteomics can further enhance our understanding of stress mechanisms in sponges.

In my third data chapter, I aimed to assess the temporal variability in local distribution area (LDA), abundance and percentage cover of $N$. chaliniformis, A. navalis and $S$. vagabunda, respectively over a six- to eight-year period. I also aimed to explore the possible relationship between sea surface temperature (SST) and chlorophyll $a(\mathrm{Chl} a)$ concentration (used as a proxy for eutrophication), and temporal variability of these sponges. I found that while the LDA and percentage cover of $N$. chaliniformis decreased by $40.2 \%$ and $14.6 \%$, those of S. vagabunda increased by $135.1 \%$ and $23.3 \%$, respectively. No significant changes were observed in A. navalis LDA and percentage cover. A significant decline was seen in the abundance of $N$. chaliniformis and A. navalis, whereas a significant increase was noted for $S$. vagabunda abundance. $N$. chaliniformis and A. navalis abundance declines were likely due to a reduction in lagoonal coral cover, which often act as anchoring substrate for these sponges. The abundance of all species was significantly correlated with SST and Chl $a$ concentration, but the nature of these correlations was species-specific. These results showed that lagoon-inhabiting sponges demonstrate speciesspecific temporal dynamics, which are mostly driven by changes in seawater temperature.

For my final data chapter, I aimed to estimate the bacterial cell consumption, Chl $a$ uptake, net dissolved organic carbon uptake and net inorganic nutrient release of $S$. vagabunda when exposed to elevated seawater temperature. The results from this chapter indicated that the bacterial cell consumption and $S$. vagabunda bentho-pelagic interactions with the water column are relatively 
low compared to other shallow coastal sponges for which data are available. However, under future ocean warming scenarios RCP6.0 $\left(+2{ }^{\circ} \mathrm{C}\right)$ and RCP8.5 $\left(+4{ }^{\circ} \mathrm{C}\right)$, S. vagabunda bacterial cell consumption, net dissolved organic carbon uptake and net inorganic nutrient release would likely increase by $115 \%$ and $142 \%$, respectively. These results suggest that thermally tolerant lagooninhabiting sponges would likely have an enhanced bentho-pelagic role in future anthropogenicallyimpacted lagoons, although based on current abundance, $S$. vagabunda has limited bentho-pelagic interactions with the water column.

In summary, the results presented in this thesis demonstrate that the responses of lagoon-inhabiting sponges to elevated temperature are species-specific. While some species are thermally susceptible to elevated temperature, other species such as $S$. vagabunda may have a potential to acclimate to at least short-term thermal stress. Consequently, thermally-tolerant species could potentially have an increasing bentho-pelagic role in coastal lagoons under future climate change scenarios. The impacts of thermal stress in sponges can also occur at the proteome level, where cellular biological functions such as redox reactions, protein transport and cytoskeletal organization are significantly disrupted. Furthermore, elevated temperature can equally contribute to the temporal variability of some lagoon-inhabiting sponge species. In contrast, this study demonstrated that lagoon-inhabiting sponges are most likely tolerant to eutrophication. Given that sponges are important components of coastal lagoons, it is critically important to assess and incorporate their potential roles to the ecological functioning of anthropogenically-impacted coastal lagoons. 


\section{Acknowledgments}

First and foremost, I wish to thank my dear friend, Swami Paramananda for encouraging me to undertake this $\mathrm{PhD}$.

I wish to thank my supervisors Professor James J. Bell and Professor Simon K. Davy who have always provided invaluable guidance, advice, and support to me with this research project. I am very glad to have had the opportunity to learn from this amazing sponge-coral duo. I wish to thank James for always being around to advise, provide feedback and support me in all aspects of this project. I also thank Simon for his invaluable guidance for my project and for providing access to equipment from his lab. I highly appreciated the prompt positive attitude of both my supervisors towards me during my $\mathrm{PhD}$. It has certainly been a great pleasure for me to work with them.

Given that the fieldwork, sampling and physiological experiments of this thesis were all conducted in Mauritius, I wish to express my sincere gratitude to my brother Akhilesh and my partner Bhavna who have brought invaluable logistical support during all field trips and physiological experiments. It would have been impossible to conduct fieldwork and experiments without their assistance. They were informally the best research assistants I could ever have. A very special thanks goes to my parents who brought significant support in setting up a temporary experimental laboratory in Mauritius to conduct these experiments. This $\mathrm{PhD}$ would have been impossible without their infallible affection, moral, logistical, and financial support. I also wish to thank Suraj, Keeshan, Pravin and Krishan who have occasionally assisted me during my field trips and especially Dr. Kishore Boodhoo from the University of Mauritius who provided additional assistance and guidance in Mauritius. I am also grateful to Dr. Daniel Marie and Mr. C Samyan from the Mauritius Oceanography Institute for initially guiding me with the geolocations of Mauritian lagoon sponges.

I wish to sincerely thank all my peers, colleagues, and staff at VUW with whom I have been fortunate to share this journey with. I am grateful to Dr. Lisa Woods, who has consistently advised and guided me through the complex aspects of statistics and modelling. A special thank goes to the Bell Lab (Sponge Club 3.0) and most specifically to Valeria, Elizabeth, Benji, Nora, Megan, Albi, Valerio, Francesca, and Rama. I also wish to express my gratitude to Clint and Amir from the Davy Lab who have provided me with invaluable guidance and assistance in my proteomic 
work. I was fortunate to have such a positive, supportive, and friendly group around me in New Zealand. A huge thank goes to my scholarship advisors, Tim Lawther and Clemmie Newton from Victoria International who have constantly supported and advised me on all aspects of my scholarship/funding. They have ensured that my time in New Zealand was as swift as possible. My experience in New Zealand would have certainly been hard without the affection and support of my inseparable duo friends Vayouna and Khush. A special thanks also goes to my flat mates Tamlyn, Liam and Kayleigh.

Finally, I wish to express my sincere and utmost gratitude to my funding agency, the Ministry of Foreign Affairs and Trade of New Zealand (MFAT) who made this $\mathrm{PhD}$ possible through a New Zealand Commonwealth Doctoral Scholarship. I believe that I will remain in debt to Aotearoa and all New Zealanders as they have indirectly financially contributed to this $\mathrm{PhD}$. Thank you all and God Bless New Zealand. 


\section{Publications}

Chapters 2 and 4 of this thesis are based on two manuscripts published in Marine Environmental Research and Marine Biodiversity, respectively. Manuscripts for chapters 3 and 5 are currently in preparation.

\section{Chapter 2:}

Publication: Sandeep S. Beepat, Simon K. Davy, Lisa Woods, and James J. Bell (2020). Shortterm responses of tropical lagoon sponges to elevated temperature and nitrate. Marine Environmental Research, 157, 104922. https://doi.org/10.1016/j.marenvres.2020.104922

Conceptualization and Methodology: S. S. Beepat under the guidance of Prof. James J. Bell and Prof. Simon K. Davy.

Data collection: Sandeep S. Beepat.

Analysis: Sandeep S. Beepat under the guidance of Dr. Lisa Woods.

Writing and editing: Sandeep S. Beepat and edited by Prof. James J. Bell, Prof. Simon K. Davy, and Dr. Lisa Woods.

\section{Chapter 3:}

Publication: currently in preparation

Conceptualization and Methodology: S. S. Beepat under the guidance of Prof. James J. Bell, Prof. Simon K. Davy and Dr. Clinton A. Oakley.

Data collection: Sandeep S. Beepat.

Analysis: Sandeep S. Beepat under the guidance of Dr. Clinton A. Oakley.

Writing and editing: Sandeep S. Beepat and to be edited by Prof. James J. Bell, Prof. Simon K. Davy, Dr. Clinton A. Oakley.

\section{Chapter 4:}

Publication: Sandeep S. Beepat, Lisa Woods, Simon K. Davy, Khushboo Jhugroo, and James J. Bell (2020). Temporal variability in tropical lagoon sponges from Mauritius (Western Indian Ocean). Marine Biodiversity, 50(57). https://doi.org/10.1007/s12526-020-01079-3

Conceptualization and Methodology: Sandeep S. Beepat under the guidance of Prof. James J. Bell and Prof. Simon K. Davy. 
Data collection: Sandeep S. Beepat, satellite data acquired with the assistance of Ms. Khushboo Jhugroo.

Analysis: Sandeep S. Beepat under the guidance of Dr. Lisa Woods.

Writing and editing: Sandeep S. Beepat and edited by Prof. James J. Bell, Prof. Simon K. Davy, Dr. Lisa Woods and Ms. Khushboo Jhugroo.

\section{Chapter 5:}

Publication: currently in preparation

Conceptualization and Methodology: S. S. Beepat under the guidance of Prof. James J. Bell and Prof. Simon K. Davy.

Data collection: Sandeep S. Beepat.

Analysis: Sandeep S. Beepat.

Writing and editing: Sandeep S. Beepat and to be edited by Prof. James J. Bell and Prof. Simon K. Davy. 


\section{Table of contents}

Chapter 1: General Introduction...........................................................1

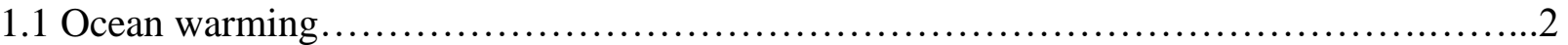

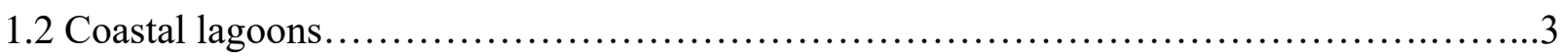

1.3 Ocean warming and eutrophication: major threats to coastal lagoons......................

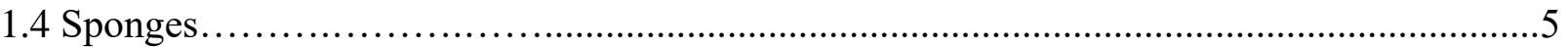

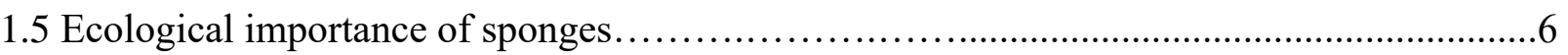

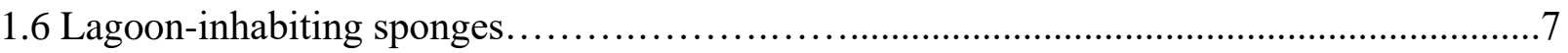

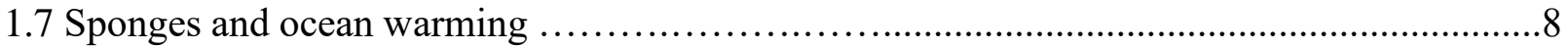

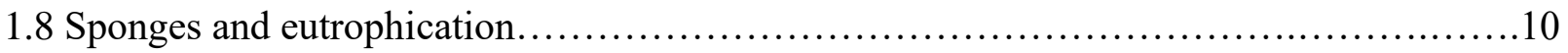

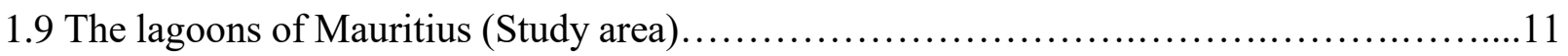

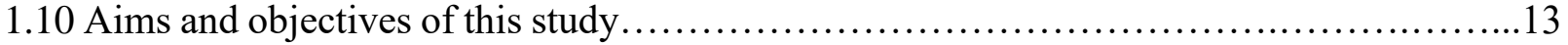

Chapter 2: Short-term responses of tropical lagoon sponges to elevated temperature and

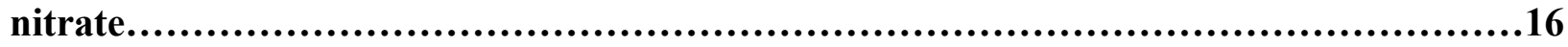

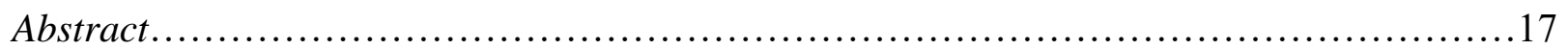

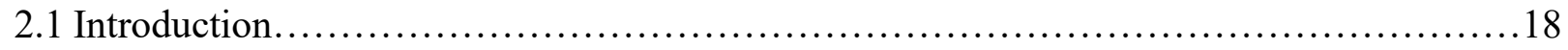

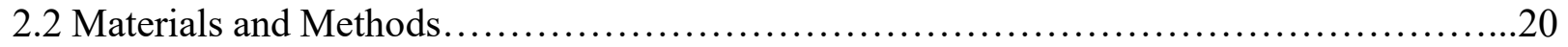

2.2.1 Study species.......................................................... 20

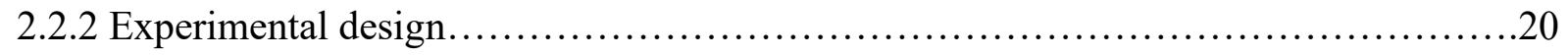

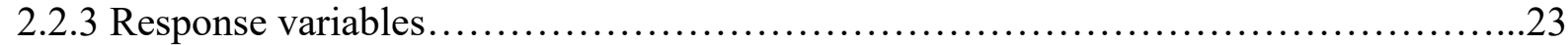

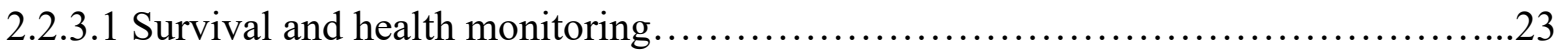

2.2.3.2 Photosynthetic pigment concentration.................................. 23

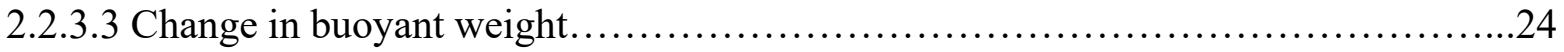

2.2.3.4 Effective quantum yield of PSII..........................................24

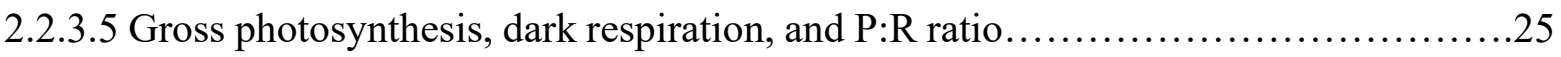

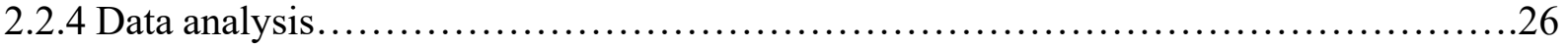

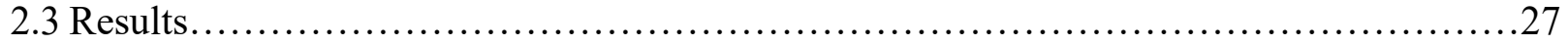

2.3.1 Sponge survival..................................................... 27

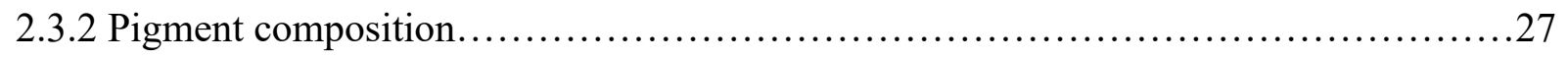

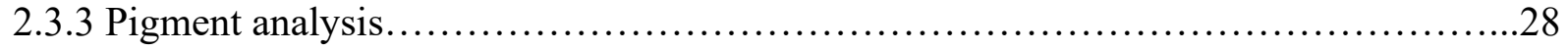


2.3.4 Change in buoyant weight....................................................

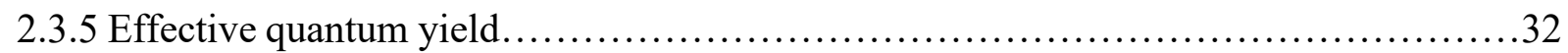

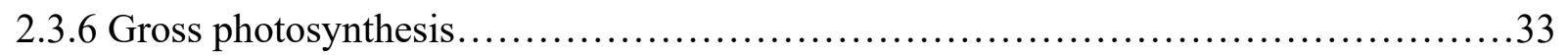

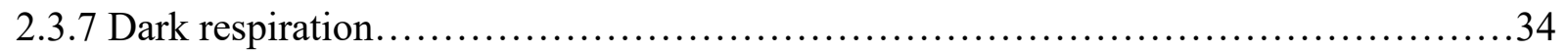

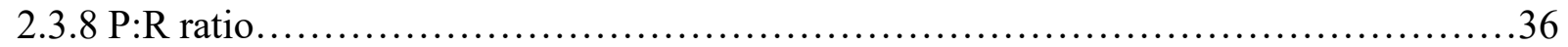

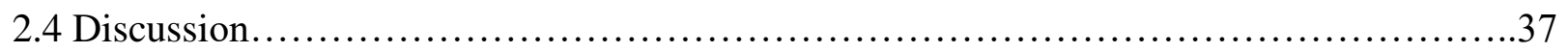

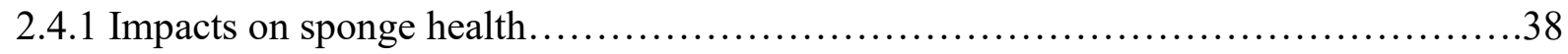

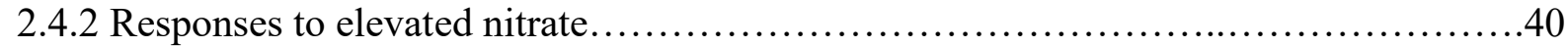

2.4.3 Ecological implications................................................41

2.5 Conclusions ...................................................................

Chapter 3: Physiological and proteomic responses of lagoon-inhabiting sponges to elevated temperature................................................................................43

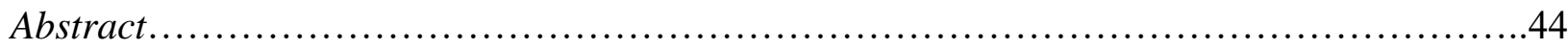

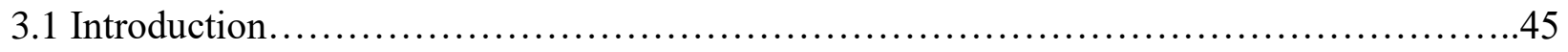

3.2 Materials and Methods........................................................... 47

3.2.1 Sponge collection......................................................47

3.2.2 Experimental design.................................................... 47

3.2.3 Physiological responses.................................................49

3.2.3.1 Buoyant weight.....................................................49

3.2.3.2 Effective quantum yield of PSII........................................49

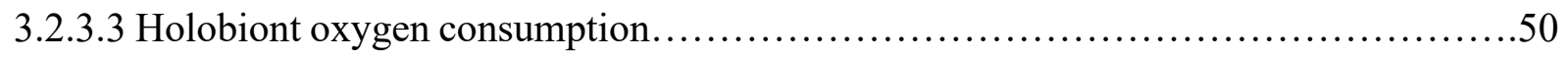

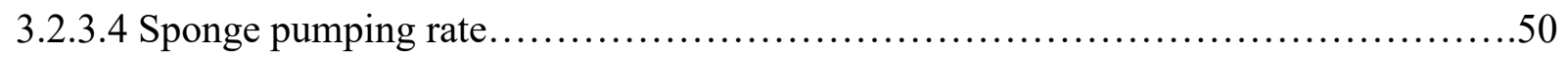

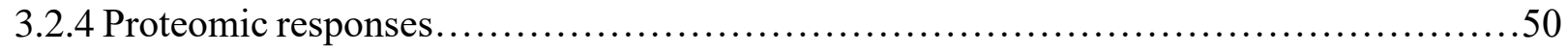

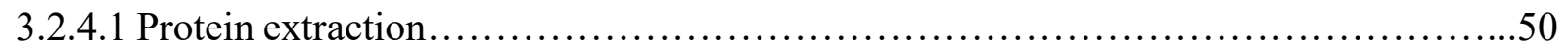

3.2.4.2 Liquid chromatography-tandem mass spectrometry...........................51

3.2.4.3 Protein identification and quantification..................................... 52

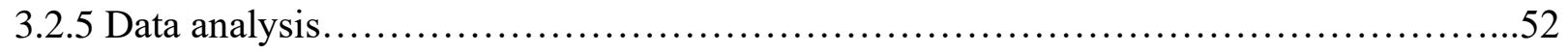

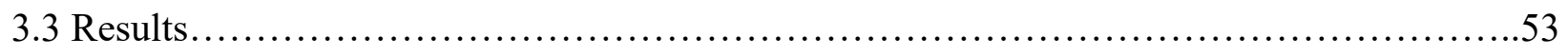

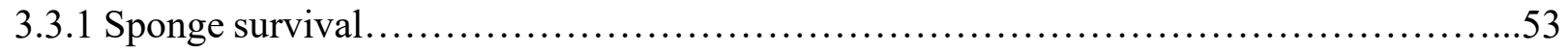

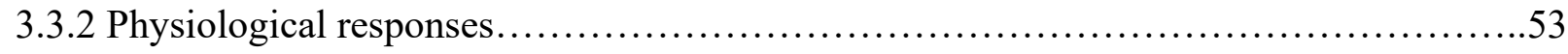




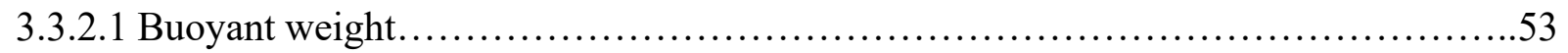

3.3.2.2 Effective quantum yield.................................................... 54

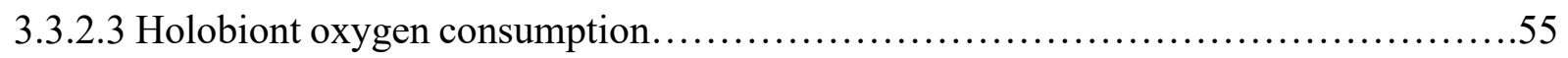

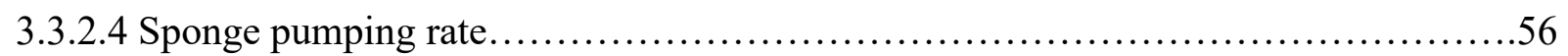

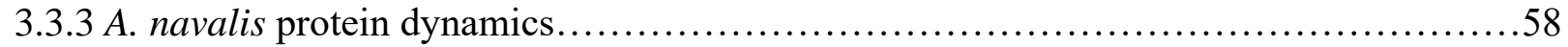

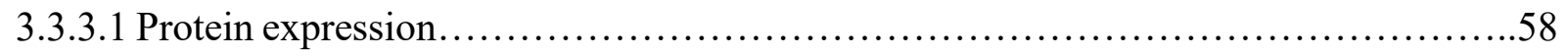

3.3.3.2 Effect of temperature on protein expression........................................59

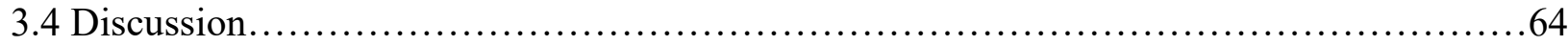

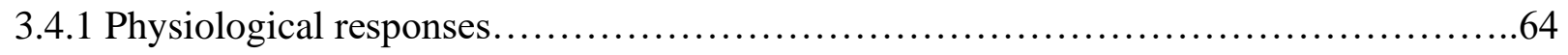

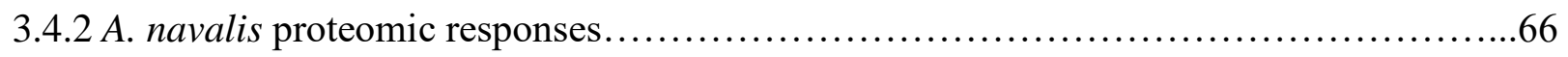

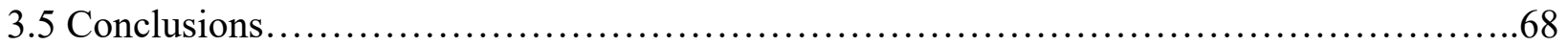

Chapter 4: Temporal variability in tropical lagoon-inhabiting sponges: effects of SST and Chl $a$ concentration..............................................................................70

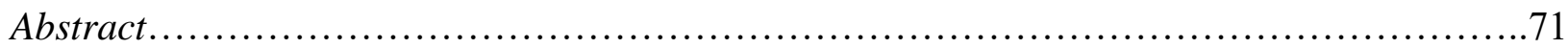

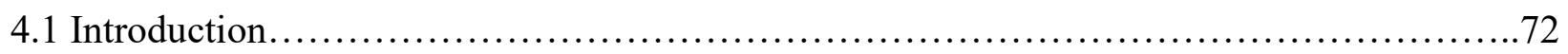

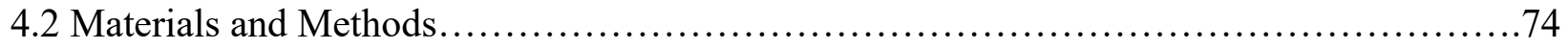

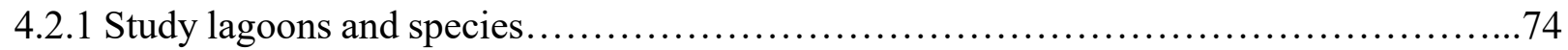

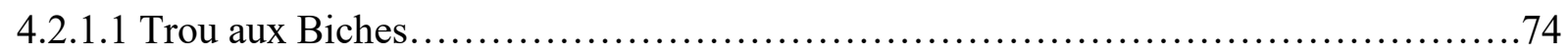

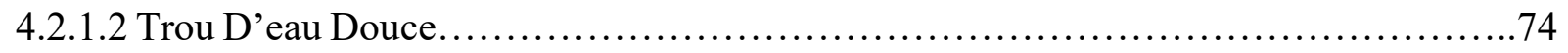

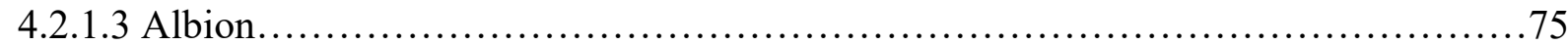

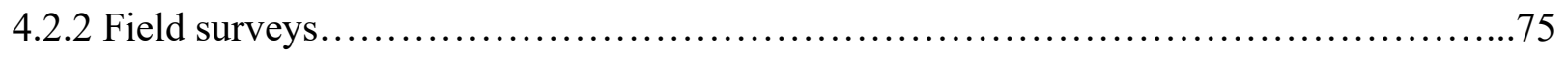

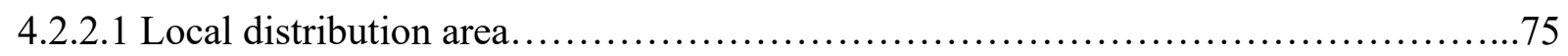

4.2.2.2 Sponge abundance and percentage cover........................................76

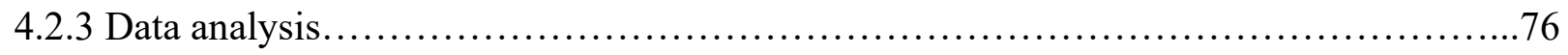

4.2.3.1 Temporal changes in abundance and percentage cover............................76

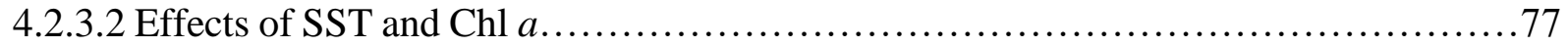

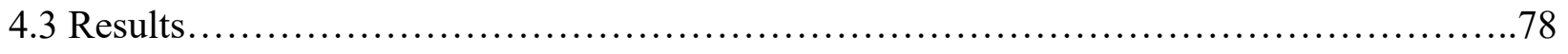

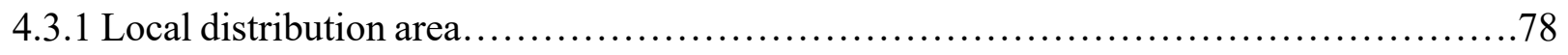

4.3.2 Temporal changes in abundance (number of patches) and percentage cover..............8 80

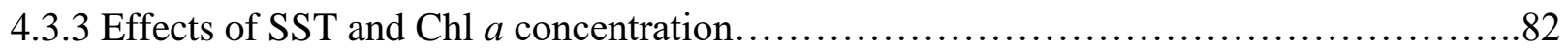




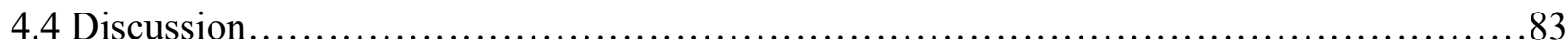

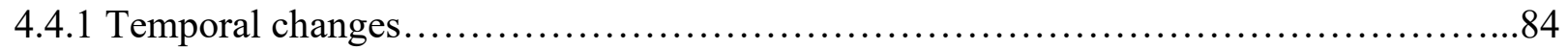

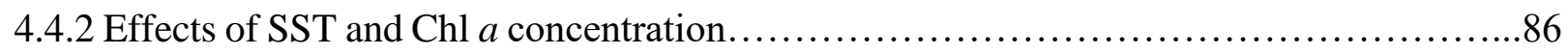

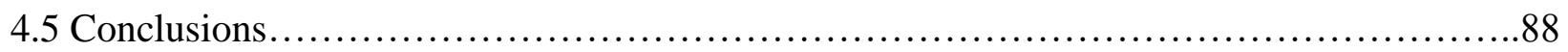

Chapter 5: Effect of elevated temperature on bentho-pelagic interactions of the sponge Spheciospongia vagabunda in a coastal lagoon............................................89

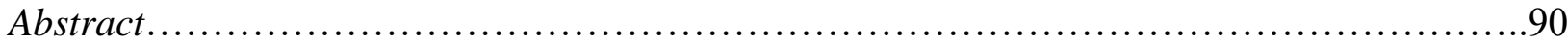

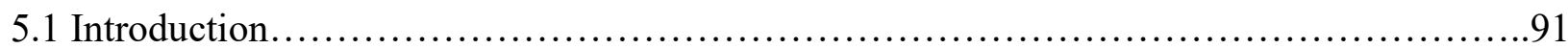

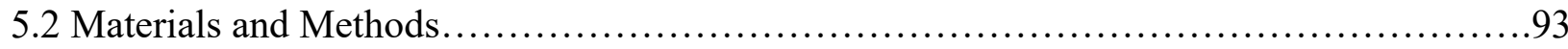

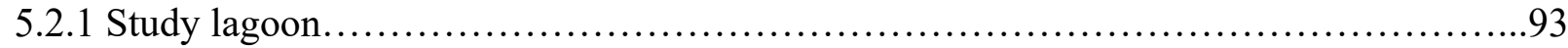

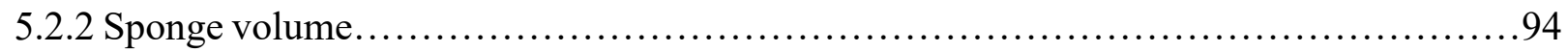

5.2.3 Thermal experiment design and S. vagabunda pumping rate..........................95

5.2.4 S. vagabunda organic matter and inorganic nutrient fluxes............................96

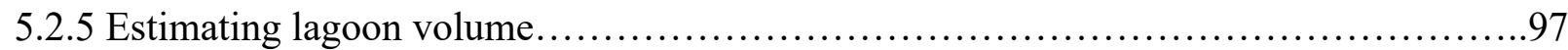

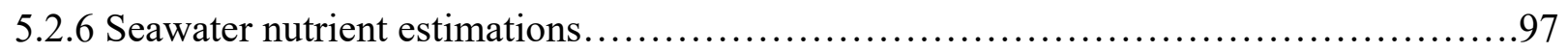

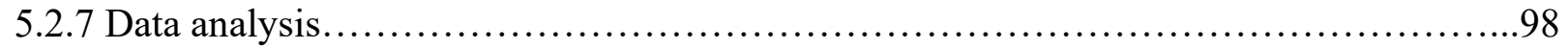

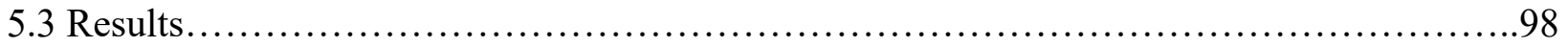

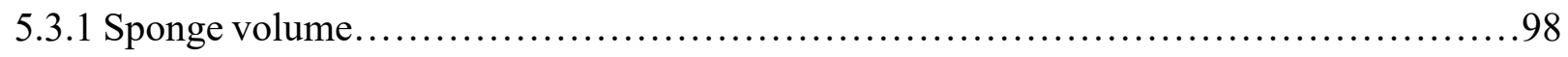

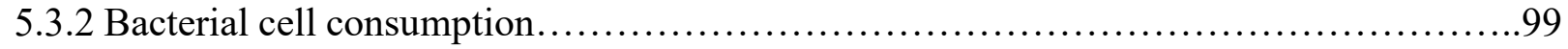

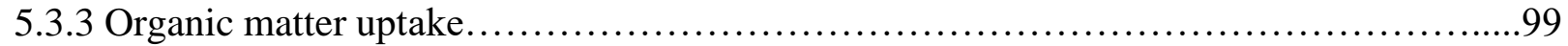

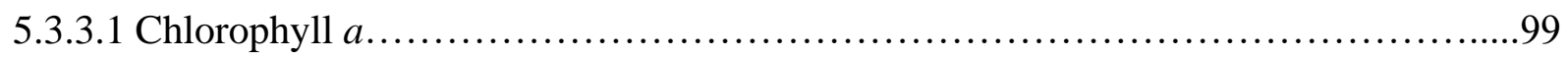

5.3.3.2 Dissolved organic carbon................................................. 100

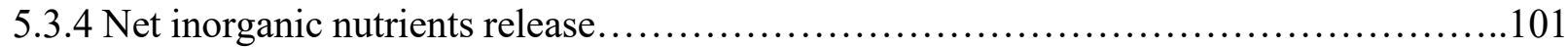

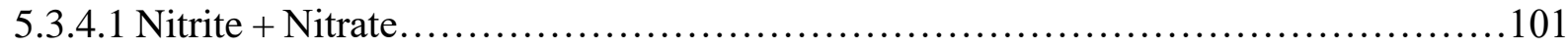

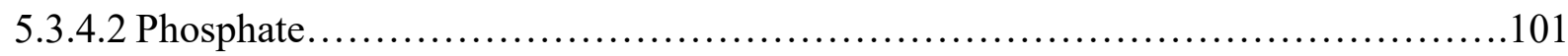

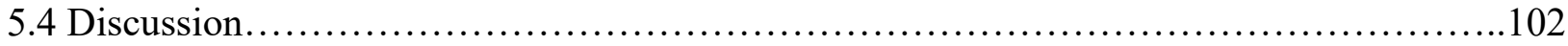

5.4.1 Net organic matter uptake in Albion Lagoon........................................ 103

5.4.2 Net inorganic nutrient contribution.............................................. 104

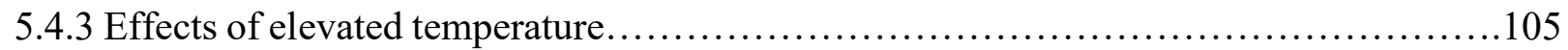

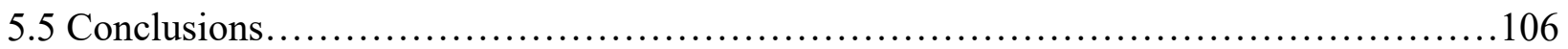




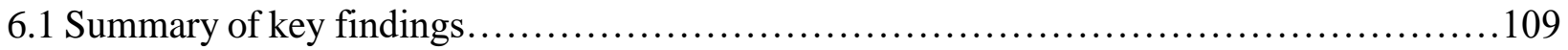

6.2 Lagoon-inhabiting sponges and thermal stress......................................111

6.3 Spheciospongia vagabunda: a persistent lagoon-inhabiting species.......................113

6.4 Implications for coastal lagoons........................................................ 114

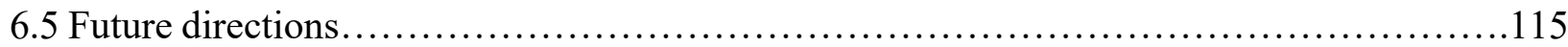

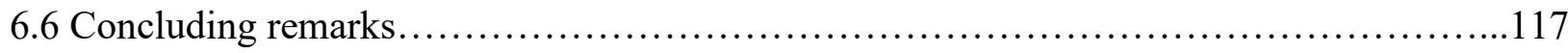

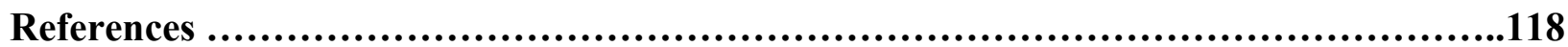

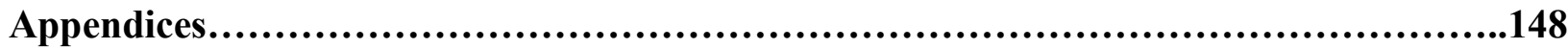

Appendix A......................................................................................149

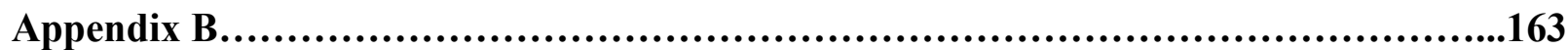

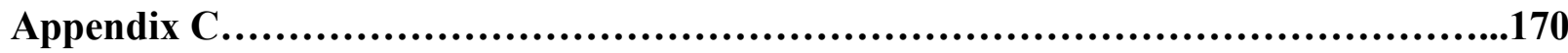

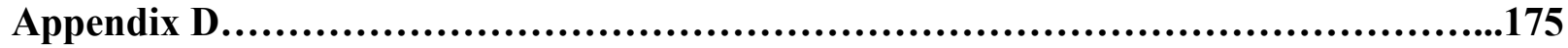




\section{List of Figures}

Fig. 1.1 Geography and temperature variations in Mauritius. A) Geographic location of Mauritius. Filled circles represent lagoons where sponges are known to occur. Source: Beepat (2015) and (Elliott et al., 2016a). B) Air and sea surface temperature variations from 2010 to 2020 in Mauritius. Temperature data retrieved from the National Oceanic and Atmospheric Administration (NOAA) database. (Data available at: https://www.noaa.gov/)

Fig. 1.2 General coastal lagoon topography around Mauritius (western Indian Ocean). Source:

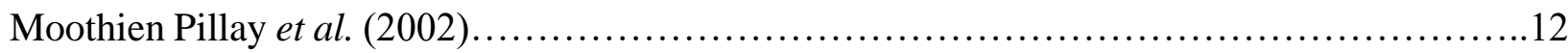

Fig. 2.1 Photosynthetic pigment concentrations of Neopetrosia chaliniformis, Amphimedon navalis and Spheciospongia vagabunda at T0. Pigments are coded as follows: Chl $a=$ chlorophyll $a, \mathrm{Chl} b=$ chlorophyll $b, \mathrm{Chl} c=$ chlorophyll $c$, Carotenoids = total carotenoids. (Note: Absence of detectable chlorophyll $c$ in $N$. chaliniformis). Values are mean $\mu \mathrm{g}$ pigment per gram of sponge

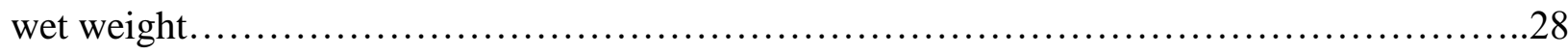

Fig. 2.2 Photosynthetic pigment concentration of Neopetrosia chaliniformis, Amphimedon navalis and Spheciospongia vagabunda in each treatment at T-end. (Note: Absence of detectable chlorophyll $c$ in $N$. chaliniformis). Values are mean $\mu$ g pigment per gram of sponge wet weight \pm SE

Fig. 2.3 Change in buoyant weight of A) Neopetrosia chaliniformis, B) Amphimedon navalis and C) Spheciospongia vagabunda in each treatment over time. $26{ }^{\circ} \mathrm{C} / 7.5 \mu \mathrm{M}$ nitrate, $\square 26{ }^{\circ} \mathrm{C} / 10.9$ $\mu \mathrm{M}$ nitrate, $\Delta 26{ }^{\circ} \mathrm{C} / 19.8 \mu \mathrm{M}$ nitrate, $\odot 28{ }^{\circ} \mathrm{C} / 7.5 \mu \mathrm{M}$ nitrate, $\square 28{ }^{\circ} \mathrm{C} / 10.9 \mu \mathrm{M}$ nitrate, $\Delta 28{ }^{\circ} \mathrm{C} /$ $19.8 \mu \mathrm{M}$ nitrate, $\odot 30{ }^{\circ} \mathrm{C} / 7.5 \mu \mathrm{M}$ nitrate, $\square 30^{\circ} \mathrm{C} / 10.9 \mu \mathrm{M}$ nitrate, $\Delta 30^{\circ} \mathrm{C} / 19.8 \mu \mathrm{M}$ nitrate. Values are mean per treatment \pm SE at each time point. $(n=6$ per treatment at each time point excluding mortalities). Note: scales on the y-axes differ between species. 
Fig. 2.4 Effective quantum yield of A) Neopetrosia chaliniformis and B) Spheciospongia vagabunda in each treatment over time. $\quad-26^{\circ} \mathrm{C} / 7.5 \mu \mathrm{M}$ nitrate, $\square 26^{\circ} \mathrm{C} / 10.9 \mu \mathrm{M}$ nitrate, $\Delta 26$ ${ }^{\circ} \mathrm{C} / 19.8 \mu \mathrm{M}$ nitrate, $\odot 28{ }^{\circ} \mathrm{C} / 7.5 \mu \mathrm{M}$ nitrate, $\square 28{ }^{\circ} \mathrm{C} / 10.9 \mu \mathrm{M}$ nitrate, $\Delta 28^{\circ} \mathrm{C} / 19.8 \mu \mathrm{M}$ nitrate, $-30{ }^{\circ} \mathrm{C} / 7.5 \mu \mathrm{M}$ nitrate, $\square 30{ }^{\circ} \mathrm{C} / 10.9 \mu \mathrm{M}$ nitrate, $\Delta 30^{\circ} \mathrm{C} / 19.8 \mu \mathrm{M}$ nitrate. Values are mean per treatment $\pm \mathrm{SE}$ at each time point. ( $\mathrm{n}=6$ per treatment at each time point excluding mortalities). Note: scales on the y-axes differ between species. .33

Fig. 2.5 Rates of gross photosynthesis of A) Neopetrosia chaliniformis and B) Spheciospongia vagabunda in each treatment over time. $.26{ }^{\circ} \mathrm{C} / 7.5 \mu \mathrm{M}$ nitrate, $\square 26^{\circ} \mathrm{C} / 10.9 \mu \mathrm{M}$ nitrate, $\Delta 26^{\circ} \mathrm{C} /$ $19.8 \mu \mathrm{M}$ nitrate, $\odot 28{ }^{\circ} \mathrm{C} / 7.5 \mu \mathrm{M}$ nitrate, $\boldsymbol{\nabla} 28^{\circ} \mathrm{C} / 10.9 \mu \mathrm{M}$ nitrate, $\Delta 28{ }^{\circ} \mathrm{C} / 19.8 \mu \mathrm{M}$ nitrate, $\bullet 30$ ${ }^{\circ} \mathrm{C} / 7.5 \mu \mathrm{M}$ nitrate, $\square 30{ }^{\circ} \mathrm{C} / 10.9 \mu \mathrm{M}$ nitrate, $\Delta 30{ }^{\circ} \mathrm{C} / 19.8 \mu \mathrm{M}$ nitrate. Values are mean per treatment $\pm \mathrm{SE}$ at each time point. ( $\mathrm{n}=6$ per treatment at each time point excluding mortalities). Note: scales on the y-axes differ between species. Values are mean per gram of sponge ash free weight $\pm \mathrm{SE}$ .34

Fig. 2.6 Rates of respiration of A) Neopetrosia chaliniformis, B) Amphimedon navalis and C) Spheciospongia vagabunda in each treatment over time. $226^{\circ} \mathrm{C} / 7.5 \mu \mathrm{M}$ nitrate, $\approx 26{ }^{\circ} \mathrm{C} / 10.9 \mu \mathrm{M}$ nitrate, $\Delta 26^{\circ} \mathrm{C} / 19.8 \mu \mathrm{M}$ nitrate, $\odot 28^{\circ} \mathrm{C} / 7.5 \mu \mathrm{M}$ nitrate, $\boldsymbol{\nabla} 28^{\circ} \mathrm{C} / 10.9 \mu \mathrm{M}$ nitrate, $\Delta 28^{\circ} \mathrm{C} / 19.8$ $\mu \mathrm{M}$ nitrate,, $30{ }^{\circ} \mathrm{C} / 7.5 \mu \mathrm{M}$ nitrate, $\square 30^{\circ} \mathrm{C} / 10.9 \mu \mathrm{M}$ nitrate, $\Delta 30{ }^{\circ} \mathrm{C} / 19.8 \mu \mathrm{M}$ nitrate. Values are mean per treatment $\pm \mathrm{SE}$ at each time point. $(\mathrm{n}=6$ per treatment at each time point excluding mortalities). Note: scales on the y-axes differ between species. Values are mean per gram of sponge ash free weight $\pm \mathrm{SE}$.

Fig. 2.7 P:R ratios of A) Neopetrosia chaliniformis and B) Spheciospongia vagabunda in each treatment over time. $.26{ }^{\circ} \mathrm{C} / 7.5 \mu \mathrm{M}$ nitrate, $\| 26^{\circ} \mathrm{C} / 10.9 \mu \mathrm{M}$ nitrate, $\Delta 26^{\circ} \mathrm{C} / 19.8 \mu \mathrm{M}$ nitrate, $.28{ }^{\circ} \mathrm{C} / 7.5 \mu \mathrm{M}$ nitrate, $\boldsymbol{\sigma} 28^{\circ} \mathrm{C} / 10.9 \mu \mathrm{M}$ nitrate, $\Delta 28^{\circ} \mathrm{C} / 19.8 \mu \mathrm{M}$ nitrate, $\odot 30^{\circ} \mathrm{C} / 7.5 \mu \mathrm{M}$ nitrate, $=30^{\circ} \mathrm{C} / 10.9 \mu \mathrm{M}$ nitrate, $\boldsymbol{\Delta} 30^{\circ} \mathrm{C} / 19.8 \mu \mathrm{M}$ nitrate. Values are mean per treatment $\pm \mathrm{SE}$ at each time point. ( $\mathrm{n}=6$ per treatment at each time point excluding mortalities). Note: scales on the y-axes differ between species. Values are mean per gram of sponge ash free weight \pm SE ..............36 
Fig. 3.1 Temperature fluctuations in treatment tanks during the experiments for A) Neopetrosia chaliniformis, B) Amphimedon navalis and C) Spheciospongia vagabunda. Note: scale on X-axes differ between species due to early mortalities of $N$. chaliniformis.

Fig. 3.2 Percentage change in buoyant weight of A) Neopetrosia chaliniformis, B) Amphimedon navalis and C) Spheciospongia vagabunda in response to elevated temperature. Values are mean percentage change per treatment $\pm \mathrm{SE}$ at each time-point $(\mathrm{n}=9$, excluding $N$. chaliniformis mortalities). Note: scale for the y-axes differ between species. .54

Fig. 3.3 Changes in effective quantum yield of A) Neopetrosia chaliniformis and B) Spheciospongia vagabunda in response to elevated temperature. Values are mean per treatment \pm $\mathrm{SE}$ at each time-point $(\mathrm{n}=9$, excluding $N$. chaliniformis mortalities)..... .55

Fig. 3.4 Holobiont oxygen consumption of A) Neopetrosia chaliniformis, B) Amphimedon navalis and C) Spheciospongia vagabunda in response to elevated temperature. Values are mean per gram of sponge ash free dry weight at each time point and represent mean per treatment $\pm \mathrm{SE}(\mathrm{n}=9$,

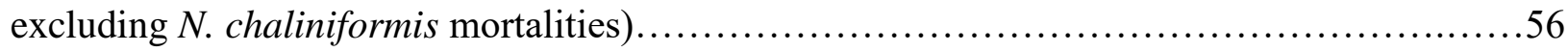

Fig. 3.5 Pumping rate of A) Neopetrosia chaliniformis, B) Amphimedon navalis and C) Spheciospongia vagabunda in response to elevated temperature. Values are mean per treatment \pm SE at each time-point $(\mathrm{n}=9$, excluding $N$. chaliniformis mortalities). Note: scale for the $\mathrm{y}$-axes differ between species due to species-specific pumping rate.............................57

Fig. 3.6 Venn diagram representing the distribution of the significantly expressed proteins from Amphimedon navalis between different temperature treatments. Numbers in brackets represent the number of proteins that were significantly were significantly higher $(\boldsymbol{\Delta})$ or lower $(\boldsymbol{\nabla}) \ldots \ldots \ldots \ldots 62$

Fig. 3.7 Heatmap showing the 50 differentially abundant proteins from Amphimedon navalis when exposed to $26^{\circ} \mathrm{C}, 28^{\circ} \mathrm{C}$ and $30^{\circ} \mathrm{C}$. Each row corresponds to a specific protein. Colour scale ranges from yellow (low abundance) to dark blue (high abundance). 
Fig. 4.1 The island of Mauritius (western Indian Ocean). Filled dots represent the study lagoons where sponge surveys were conducted. Map created in QGIS (QGIS Development Team, 2018). 75

Fig. 4.2 Bimonthly SST and Chl $a$ concentration means from Mauritius during the survey period. Satellite data retrieved from MODIS-Aqua satellite, Ocean color. (Data available at: https://oceancolor.gsfc.nasa.gov/13/). .78

Fig. 4.3 The local distribution areas (within each lagoon) of Neopetrosia chaliniformis (TAB), Amphimedon navalis (TDD) and Spheciospongia vagabunda (ALB) during the sponge monitoring period. GIS maps were created in QGIS (QGIS Development Team, 2018)....

Fig. 4.4 General linear model (GLM) fits showing temporal trends in sponge abundance (left) and percentage cover (right) of Neopetrosia chaliniformis (A \& B), Amphimedon navalis (C \& D) and Spheciospongia vagabunda (E \& F). Lines are indicative of linear fit for each sponge-dominated area. Area A, $\triangle$ Area B, - Area C, $\mathbf{0}$ Area D, + Area E, * $*$ Area F. Values are mean per area of occurrence \pm SE (grey shading) of the fit. ( $n=30$ per area per year). Note: scales on the axes differ between species.

Fig. 5.1 Map of Albion Lagoon (right). Maps on the left indicate the geographical position of the study lagoon in the western Indian Ocean and on the west coast of Mauritius. Map created in QGIS (QGIS Development Team, 2018)....

Fig. 5.2 Estimates of Spheciospongia vagabunda population bacterial cell consumption in Albion Lagoon at $26{ }^{\circ} \mathrm{C}, 28{ }^{\circ} \mathrm{C}$ and $30^{\circ} \mathrm{C}$. Values represent mean consumption rates per ml per hour...99

Fig. 5.3 The estimated range of A) Chl $a$ and B) net dissolved organic carbon (DOC) uptake by the Spheciospongia vagabunda population in Albion Lagoon at $26{ }^{\circ} \mathrm{C}, 28{ }^{\circ} \mathrm{C}$ and $30{ }^{\circ} \mathrm{C}$. Values represent log estimates of net organic matter uptake per hour 100 
Fig. 5.4 The estimated range of net A) nitrite + nitrate and B) phosphate release by the Spheciospongia vagabunda population in Albion Lagoon at $26{ }^{\circ} \mathrm{C}, 28{ }^{\circ} \mathrm{C}$ and $30{ }^{\circ} \mathrm{C}$. Values represent $\log$ estimates of net inorganic nutrient release per hour............................ 102

Fig. 6.1 Physiological, proteomic and population level responses of the lagoon-inhabiting sponges Neopetrosia chaliniformis, Amphimedon navalis and Spheciospongia vagabunda to elevated temperature and eutrophication. Arrows represent significant $(\uparrow)$ increase, $(\downarrow)$ decrease and $(\leftrightarrow)$ no change in responses. ( $\$$ ) represent significant negative and $(\dagger)$ significant positive effect of

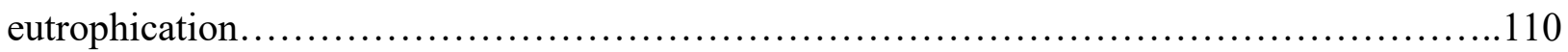




\section{List of Tables}

Table 2.1 Temperature and nitrate concentration in each treatment. Values are mean \pm SE over six weeks (combined values for all experiments for three sponge species). Individual temperature/nitrate fluctuations for each experiment can be found in Appendix A - Fig. A2.4.

Table 2.2 Percentage mortality of sponges during the experiment. Values are percentage mortalities per treatment for each species. Brackets represents time at which mortalities occurred

Table 2.3 Summary of general linear mixed models (GLMM) for the effects of temperature, nitrate and their combined effects on the change in buoyant weight, $\Delta \mathrm{F} / \mathrm{F}_{\mathrm{m}}$, gross photosynthetic and respiration rates and P:R ratio of Neopetrosia chaliniformis, Amphimedon navalis and Spheciospongia vagabunda. Significant values are shown in bold. ...

Table 3.1 Summary of general linear mixed models (GLMM) for the effects of time, temperature and their combined effects on buoyant weight, effective quantum yield ( $\Delta \mathrm{F} / \mathrm{F}_{\mathrm{m}}$ '), holobiont oxygen consumption and volume flow rate of Neopetrosia chaliniformis, Amphimedon navalis and Spheciospongia vagabunda. Significant values are shown in bold .58

Table 3.2 Most abundant proteins detected from Amphimedon navalis using a false discovery rate (FDR) of $2.5 \%$

Table 3.3 Differentially abundant proteins from Amphimedon navalis exposed to $26{ }^{\circ} \mathrm{C}, 28{ }^{\circ} \mathrm{C}$ and $30{ }^{\circ} \mathrm{C}$. An FDR threshold of 0.1 and log ratio (fold-change) of \pm 0.25 were used. and represent significantly more and less abundant, respectively. 'Proteins in cluster' indicate the number of identified proteins combined into each protein cluster.

Table 4.1 Model comparisons of the effects of SST and Chl $a$ concentration on the temporal abundance and percentage cover of Neopetrosia chaliniformis, Amphimedon navalis and 
Spheciospongia vagabunda. GLMMs were compared by the Akaike Information Criterion (AIC) scores. $\mathrm{n}=$ number of predictors. Models marked with an * represent the best model.............83

Table 5.1 Bacterial cell consumption, net organic matter uptake and net inorganic nutrient release estimates of $S$. vagabunda at $26^{\circ} \mathrm{C}, 28^{\circ} \mathrm{C}$ and $30^{\circ} \mathrm{C}$ in Albion Lagoon. Values are range estimates $( \pm \mathrm{SE})$ per litre sponge per hour based on the mean estimate fluxes of Spheciospngia vesparium reported by Valentine and Butler (2019).................................................97

Table 5.2 $\mathrm{Chl} a$, DOC, $\mathrm{NO}_{2}{ }^{-}+\mathrm{NO}_{3}{ }^{-}$and $\mathrm{PO}_{4}{ }^{3-}$ estimates in Albion Lagoon. Chl $a$ and $\mathrm{PO}_{4}{ }^{3-}$ estimations were taken from yearly concentrations reported in Ramessur et al. (2011) and Sadally et al. (2014) for the lagoon of Flic en Flac (i.e. nearest lagoon to Albion Lagoon) and $\mathrm{NO}_{2}{ }^{-}+\mathrm{NO}_{3}{ }^{-}$ concentrations were estimated (yearly) from the study of Bissembur et al. (2012) for Albion Lagoon. Values are mean estimates $( \pm \mathrm{SE})$ per litre ..................................... 98

Table 5.3. Organic matter and nutrient flux estimates of the Spheciospongia vagabunda population in Albion Lagoon at $26{ }^{\circ} \mathrm{C}, 28{ }^{\circ} \mathrm{C}$ and $30^{\circ} \mathrm{C}$. Values are percentage range estimates $( \pm \mathrm{SE}$ ) for $S$. vagabunda population (total sponge volume) per hour.................................... 102 


\section{Chapter 1:}

General Introduction 


\subsection{Ocean warming}

Human impacts, including the over overexploitation of resources, pollution and climate change are responsible for the degradation of marine ecosystems worldwide (Keller et al., 2009), with tropical habitats being considered as the most susceptible environments (Dillon et al., 2010; Saunders et al., 2014). In recent decades, numerous studies have described the susceptibility of tropical ecosystems, such as coral reefs (Hoegh-Guldberg et al., 2007; McClanahan et al., 2011), to carbon dioxide accumulation in the atmosphere. Carbon dioxide is one of the most important greenhouse gases present in the atmosphere (Farmer \& Cook, 2013). However, it is estimated that from the approximately 350 billion tons of carbon dioxide that has been emitted to the atmosphere, 25\% has been absorbed by the oceans so far (Canadell et al., 2007; Quéré et al., 2010; Heinze et al., 2015; Cao \& Zhang, 2017); thus the oceans are major natural anthropogenic carbon dioxide sinks (Landschützer et al., 2014). The uptake of heat energy trapped in carbon dioxide molecules has altered the physical dynamics of the oceans by increasing the temperature of oceanic surface layers (Abraham et al., 2013; Saba et al., 2016); carbon dioxide also strongly favors a reduction in the oceans' pH (ocean acidification). This ocean heating effect, commonly known as ocean warming influences oceanic processes such as ocean mixing (Manucharyan et al., 2011) and ocean current dynamics (Winton et al., 2013). Ocean warming also contributes to the depletion of oxygen in seawater (Shaffer et al., 2009) and hence also impacts fundamental ecological processes. According to the IPCC (2014), the global mean ocean surface temperature at some locations could increase between $0.3{ }^{\circ} \mathrm{C}$ (scenario RCP2.6) and $4.8^{\circ} \mathrm{C}$ (scenario RCP8.5) by the end of the $21^{\text {st }}$ century. As a result, this heating will directly impact the normal functioning of marine biological processes. For example, elevated seawater temperature has been responsible for severe coral bleaching events (Eakin et al., 2010; Hughes et al., 2017), disease outbreaks (Bruno et al., 2007; Clemente et al., 2014), mass mortalities (Decarlo et al., 2017) and shifts in species distribution patterns (Kleisner et al., 2017). However, while many studies have focused on the impacts of ocean warming on coral reefs, its impacts on shallow coastal water bodies such as estuaries and lagoons, are relatively less understood (Anthony et al., 2009; Pérez-Ruzafa et al., 2019). 


\subsection{Coastal lagoons}

Coastal lagoons are shallow water bodies that are separated from the open ocean by a barrier, but are at least intermittently connected to the ocean by one or more restricted inlets (Kjerfve, 1994; Chapman, 2012). These ecosystems represent approximately 13\% of the world's coastlines (Badcock \& Barnes, 1981) and are often soft-bottom environments that support multiple benthic habitats, such as seagrass beds, mudflats, mangroves and salt marshes. They are also highly productive ecosystems that serve as nursery grounds for many marine species and host a suite of marine organisms (Anthony et al., 2009). Species richness and composition within lagoons are often best explained by the levels of inlets connectivity to the open ocean (Pérez-Ruzafa et al., 2007b). In some regions, coastal lagoons provide important resources and functions, such as storm protection, fisheries and tourism (Gönenç \& Wolflin, 2005). For example, in the Mediterranean region, coastal lagoons are considered the most valuable coastal ecosystem mostly due to their rich biodiversity, which provide diverse resources to the local fishers (Ferrarin et al., 2014). The shallow nature and low flushing rates of coastal lagoons makes them naturally stressed ecosystems that are characterized by frequent and dynamic environmental changes, such as fluctuations in salinity, sedimentation, temperature and nutrient inputs (Kjerfve, 1994; Kennish \& Paerl, 2010). However, the biological and ecological impacts of anthropogenic stressors on these ecosystems are more speculative than supported by evidence (Pérez-Ruzafa et al., 2019). Therefore, further comprehensive scientific studies are needed to better understand the consequences of climate change and other stressors on coastal lagoons.

\subsection{Ocean warming and eutrophication: major threats to coastal lagoons}

Air temperature over land masses increases at a higher rate compared to air temperature over the oceans (Lambert et al., 2011). Therefore, due to their proximity with land masses, seawater temperature within coastal lagoons are likely to increase under future climate change scenarios (Harley et al., 2006; Lloret et al., 2008). As heat energy accumulates within the partially enclosed water body and with limited mixing with the open ocean, lagoon ecosystems are strongly influenced by elevated seawater temperature (Anthony et al., 2009; Tagliapietra et al., 2011; Ferrarin et al., 2014). For example, projection models for the Curonian lagoon (Baltic Sea) predict an increase in salinity from 1.4 to $2.6 \mathrm{ppt}$ by 2100 resulting from seawater evaporation (Jakimavičius et al., 2018) and the habitat suitability for the clam Ruditapes philippinarum in the 
lagoon of Venice will be highly susceptible to elevated seawater temperature resulting from anthropogenic activities (Canu et al., 2010). Temperature has an important role in the normal functioning of biological processes and is critically important for living organisms. However, unlike the open ocean, lagoon-inhabiting organisms are more likely to be living near their thermal tolerance limits as they are subjected to frequent and wider environmental variations (Coles et al., 1976; Somero, 2010). Therefore, an increase in seawater temperature within coastal lagoons will most likely have major impacts on lagoon-inhabiting species (Tomanek \& Somero, 1999; Lloret et al., 2008) because temperature shifts outside an organism's optimal temperature range could disrupt basic physiological processes such as respiration, growth and subsequently affect the survival of existing populations (Pörtner \& Farrell, 2008). As a result, the resiliency of lagoon ecosystems to elevated temperature in the future will likely depend on the acclimation and potential adaptation of existing lagoon-inhabiting species to thermal stress (Pörtner \& Gutt, 2016).

Due to their proximity to land masses, coastal lagoons are also recipient of excess nutrients runoff from precipitation, sewage and agricultural fertilizers (Taylor et al., 1995). According to Nixon (1982, 1995), the combination of low flushing rates and terrestrial nutrient inputs make coastal lagoons high primary production zones, which can lead to phytoplankton blooms, oxygen depletion and eutrophication. The depletion of oxygen due to the decomposition of lagooninhabiting vegetation has previously been reported in Venice, Italy (Tagliapietra et al., 2011) and eutrophication-impacted lagoons have also been reported in the USA (Glibert et al., 2014) and along the Mediterranean coast (Padedda et al., 2019). While some lagoons can potentially selfregulate the effects of eutrophication through top-down control over phytoplankton (Pérez-Ruzafa et al., 2002, 2005), the impacts of excess nutrients on lagoon-inhabiting species is not well understood, especially in Small Island Developing States (SIDS) where urban development and intensive agriculture are mostly concentrated along the coast. Many benthic communities, such as sponges or other cnidarians, are often nutrient limited (Rands et al., 1993; D'Angelo \& Wiedenmann, 2014). For example, elevated nutrient concentrations can potentially decrease the resiliency of corals to bleaching events (Wiedenmann et al., 2012) and reduce coral calcification and fertilization rates (Fabricius, 2005), suggesting that eutrophication could potentially have catastrophic impacts on lagoon-inhabiting benthic organisms. 
The combined effects of elevated temperature and eutrophication is known to have negative effects on lagoon-inhabiting benthic communities because the combination of these stressors can accelerate hypoxic events or phytoplankton blooms (Lloret et al., 2008; Anthony et al., 2009; Grenz et al., 2017). Bintz et al. (2003) demonstrated that the combination of elevated seawater temperature and excess nutrients was the main cause of rapid declines in lagoon plant communities in Ninigret and Point Judith lagoons (Rhode Island, USA). Furthermore, the combined effects of both stressors were also reported to cause significant increases in phytoplankton biomass in Peri lagoon, South Brazil (Hennemann \& Petrucio, 2010). Benthic communities, such as coral reefs (Heron et al., 2016; Kenneth, 2016) and seagrasses (Marbà \& Duarte, 2010; Repolho et al., 2017), are known to be susceptible to these combined stressors. However, the stress responses of benthic organisms might be taxon specific. For example, Bell et al. (2013) proposed that some coral reefs could potentially shift to sponge-dominated reefs, as sponges appear to be more resilient to environmental changes when compared to calcifying organisms (Bell et al., 2018). While the populations of susceptible organisms could potentially decrease within coastal lagoons due to anthropogenic stressors such as ocean warming and eutrophication, it is likely that other resilient taxonomic groups could thrive in these ecosystems as a result of space availability. However, this will likely depend on the drivers of abundance and environmental tolerance of these taxonomic groups in these ecosystems.

\subsection{Sponges}

Sponges are one of the most ancient and primitive organisms living in our oceans (Müller, 2003). They are classified into four major classes within the phylum Porifera namely: Calcarea, Hexactinellida, Homoscleromorpha and Desmospongiae, with the latter representing the most diverse and abundant group (Hooper et al., 2002). According to Van Soest et al. (2012), approximately 11,000 sponge species have been described so far, yet due to taxonomical complexities and uncertainties, only 8,500 species are considered to be valid. Sponges have very simple multicellular body structures and do not possess any internal body organs. They are generally composed of three layers of cells: the pinacoderm (external layer), the choanoderm (internal layer) and the mesohyl (middle layer). The sponge's mesohyl section is most often associated with an organic skeleton made of spongin fibers and/or spicules (Bergquist, 2001). Most sponges are immobile marine invertebrates and are commonly found attached to a substrate. They 
are suspension feeding organisms, mostly feeding on dissolved organic carbon (DOC), nano- and picoplankton as well as heterotrophic bacteria from the water column (Reiswig, 1971b; Riisgård et al., 1993), although several species can also be phototrophic due to their associations with photosymbionts such as cyanobacteria and dinoflagellates (Cheshire \& Wilkinson, 1991; Taylor et al., 2007). The feeding ability of sponges relies on the presence of specialized flagellated cells that help them to draw water into a complex system of internal canals within the sponge, where water is usually pumped in through multiple tiny pores known as the ostia and expelled through other larger openings known as oscules. Water flow within sponges also brings in oxygen for respiration and contributes to waste removal from their internal canals. The reproductive mechanisms of sponges are mostly species-specific and can be both sexual and asexual (Wulff, 1991; Maldonado \& Riesgo, 2008). The presence of specialized cells unique to sponges called archaeocytes has provided sponges with the ability to heal rapidly after minor damage (Müller et al., 1999). This is in addition to the various chemical and structural defensive mechanisms, which have evolved in sponges to protect them from predation (Pawlik et al., 1995; Hooper et al., 2002; Hill et al., 2005; Rohde \& Schupp, 2011). The simple physiological functioning of sponges and their ability to adapt to multiple external disturbances through evolution have made the Poriferans one of the most historically persistent phyla in our oceans (Zhang \& Pratt, 1994).

\subsection{Ecological importance of sponges}

Sponges have major ecological roles in the marine environment (Diaz \& Rützler, 2001; Wulff, 2001; Bell, 2008). They can filter large volumes of water and their exceptional filtering capabilities makes them important nutrient links between the benthos and the open water column (Reiswig, 1971a; Riisgård et al., 1993; Yahel et al., 2005; Ludeman et al., 2017). As a result, sponges have been reported to contribute to complex biogeochemical processes, such as carbon cycling (Maldonado et al., 2012; Mueller et al., 2014; Cathalot et al., 2015), nitrogen cycling (Jiménez \& Ribes, 2007; Fiore et al., 2013), silicate cycling (Maldonado et al., 2005; Chu et al., 2011) and phosphorus cycling (Maldonado et al., 2012; Colman, 2015). Recent studies have demonstrated that sponges contribute greatly to the marine top-down (Pawlik et al., 2013) and bottom-up (Lesser \& Slattery, 2013) processes where they can convert and redistribute DOC into organic matter in the water column via sponge-cell turnover (Rix et al., 2016; Rix et al., 2018). de Goeij et al. (2013) also demonstrated that sponges can retain Dissolved Organic Matter (DOM) in nutrient-poor 
waters, hence providing other reef fauna with a source of nutrients. This process, known as the 'sponge-loop', was further supported by Rix et al. (2016) who reported that coral mucus also fuels a loop in both warm-water and cold-water environments, thus creating a trophic link between corals and sponges. More recently, Rix et al. (2018) suggested that the sponge loop is facilitated by sponge-associated fauna and thereby promote benthic productivity, although McMurray et al. (2018) proposed that other pathways such as retaining assimilated carbon as biomass may exist in some sponge species by which sponges may fuel nutrients to higher trophic levels.

Sponges also have an important bioeroding role on coral reefs where they contribute to the balance between calcification and erosion rates (Rützler, 1975; Schönberg et al., 2017). They contribute to the breakdown of dead coral skeletons and other calcium carbonate structures into sediments, whereby part of the ingested carbonate is dissolved in the process (Pomponi, 1979; Calcinai et al., 2007). Many sponges are also major habitat providers for diverse macroinvertebrate groups, such as polychaetes and crustaceans (Bacescu, 1971; Wendt et al., 1985; Koukouras et al., 1996), and are also host to diverse microbial communities including bacteria and archaea (Taylor et al., 2007; Webster \& Taylor, 2012), although macroinvertebrate and microbial communities associated with sponges are often species-specific. Despite their key multifunctional roles in marine ecosystems, sponges have often been largely overlooked in many ecological monitoring programmes and biodiversity assessments. This is most likely due to the taxonomical difficulties and uncertainties surrounding sponge identification (Bell, 2007). However, while studies reporting on the ecology of reef sponges have gained some momentum in the past two decades, investigations on lagooninhabiting sponges have remained comparatively restrained (Barnes, 2009).

\subsection{Lagoon-inhabiting sponges}

Sponges are found in all aquatic ecosystems (Van Soest et al., 2012) and some species can be dominant within coastal lagoons (Corriero et al., 2007; Longo et al., 2015). The New Caledonian (Levi et al., 1998) and south Italian lagoons (Longo et al., 2015) for example, are host to multiple sponge species. In the Caribbean region, lagoon-inhabiting sponges are known to have significant roles in contributing to spatial competition, epizoism and endobioses with macrofaunal communities (Butler et al., 1995; Rützler, 2012). Furthermore, according to Picton (1995), shallow-water sponges also maintain the nutrient balance in nutrient-deprived reefs and mangroves 
through inter- and intracellular photosynthetic symbionts. Unlike many other benthic organisms, some sponge species have developed a range of strategies to adapt to shallow soft-bottom ecosystems, such as lagoons and estuaries. To colonize the soft-bottom substratum, some species such as Spheciospongia vagabunda often incorporate foreign materials such as sand or debris in their body structure (Levi et al., 1998). This strategy enables them to reinforce their spongin skeletons and/or spicules whereby they can firmly anchor themselves in the bottom substratum (Illan \& Abelson, 1995; Cerrano et al., 2002, 2004, 2007) and therefore contribute in bioerosion and substrate stabilization. Furthermore, other species such as Biemna ehrenbergi (Illan \& Abelson, 1995), have also developed special morphological adaptations that could mitigate

clogging (sediment settlement) of their aquiferous systems. Other mechanisms developed by shallow-water sponges subjected to sedimentation include water flow reversal (Simpson, 1984) and production of mucus (Bannister et al., 2012), although these strategies have not been reported from lagoon-inhabiting species.

Studies on lagoon-inhabiting sponges have mostly been reported from the Mediterranean (Mercurio et al., 2006; Corriero et al., 2007; Longo et al., 2015) and Caribbean regions (Cerrano et al., 2004; Rützler, 2012; Wall et al., 2012) and until now, there are only a few studies available from other geographical locations. According to Bell et al. (2015), there is currently a lack of information on the global conservation status of sponges worldwide. Therefore, it is critically important to conduct baseline ecological investigations to facilitate future monitoring and identify anthropogenic impacts on sponges (Bell et al., 2017a). Wulff (2006b) also highlighted the need for regular monitoring of sponge variability due to rapid changes in abundance and biomass, which is particularly relevant to future climate change impacts. Since ocean warming is most likely to have a greater impact on coastal lagoons (Anthony et al., 2009), its potential impacts on lagooninhabiting sponges are yet to be thoroughly investigated.

\subsection{Sponges and ocean warming}

The impacts of ocean warming on sponges has gained increasing interest in the past decade (Duckworth et al., 2012; Fang et al., 2013; Bennett et al., 2017), although sponge-specific studies related to climate change remain fewer compared to other taxa such as corals (Bell et al., 2018). The thin pinacoderm cell layer is the only layer separating a sponge and its immediate environment 
and this theoretically make sponges susceptible to physico-chemical changes in seawater (Bergquist, 2001). However, multiple studies suggest that sponges are generally more resilient to environmental changes compared to other benthic taxa (Duckworth et al., 2012; Bell et al., 2013; Kelmo et al., 2013; Vicente et al., 2015). For example, Schönberg and Suwa (2007) demonstrated that the sponge Cliona orientalis has the ability to displace its microbial symbionts within the host hence, protecting them from external stress factors; a mechanism unknown to other benthic taxa. Sponges are also thought to be generally more tolerant to ocean warming and ocean acidification than corals (Bell et al., 2013, 2018; Bennett et al., 2017). As a result, an increase in sponge abundance on bleached coral reefs has been reported in several locations, such as in the Mexican Pacific (Carballo et al., 2013) and Caribbean (Chaves-Fonnegra et al., 2018) seas.

The responses of sponges to elevated seawater temperature are often species-specific (Bennett $e t$ al., 2017; Strand et al., 2017; Bell et al., 2018) and while some sponge species are known to be resilient to temperature changes, other species are physiologically vulnerable to thermal stress (Pantile \& Webster, 2011; Kelmo et al., 2013). For example, the sponge Cliona celata has been reported to be resistant to elevated temperature of up to $5{ }^{\circ} \mathrm{C}$ (Miller et al., 2010; Duckworth et al., 2012). Likewise, Vicente (2015) also reported the thermal tolerance of the sponge Mycale grandis from Hawaii at temperature maxima of $25.6^{\circ} \mathrm{C}$ (i.e. approximately $4{ }^{\circ} \mathrm{C}$ higher than ambient temperature). In contrast, some species are less tolerant to thermal stress (Bell et al., 2018). For example, a temperature increase of $2-4{ }^{\circ} \mathrm{C}$ during the summer was likely responsible for the mass mortality of sponges in the Mediterranean (Cerrano et al., 2000). The reef sponge Rhopaloeides odorabile has been reported to have a strict thermal threshold tolerance (Pantile \& Webster, 2011) and when exposed to a temperature increase of $6{ }^{\circ} \mathrm{C}$, adult $R$. odorabile lose their dominant culturable symbionts and express stress-inducible genes (Webster et al., 2008; Pantile \& Webster, 2011). Lopez-Legentil et al. (2008) also demonstrated that the sponge Xestospongia muta expressed a higher level of heat stress protein (Hsp70) leading to mortality when exposed to an elevated seawater temperature of $+2{ }^{\circ} \mathrm{C}$ and $+10{ }^{\circ} \mathrm{C}$, respectively. However, the different responses of sponges to thermal stress could be due to differences in ecological and physiological features of species at different life stages (Webster et al., 2013; Guzman \& Conaco, 2016). For example, Webster et al. (2013) reported that $R$. odorabile larvae could withstand seawater temperatures of up to $36^{\circ} \mathrm{C}$ but, adult specimens are thermally limited to $32{ }^{\circ} \mathrm{C}$. At present, multiple studies have 
reported on the impacts on elevated temperature on reef sponges (Massaro et al., 2012; Schönberg et al., 2017; Ramsby et al., 2018), and there are currently few investigations with regards to lagoon-inhabiting sponges. According to Bell and Carballo (2017), approximately 69 studies have been conducted on the impact of climate change on sponges from 1989 to 2016, yet further investigations from other geographical locations are required to better understand climate changeinduced impacts on sponges on a global scale. As a result, additional studies are necessary to understand the responses of lagoon-inhabiting species exposed to climate change.

\subsection{Sponges and eutrophication}

There are currently very few studies describing the impacts of eutrophication on sponges. Previous studies suggest that reef sponges are generally tolerant to excess nutrients (Gochfeld et al., 2012; Simister et al., 2012; Luter et al., 2014), although the decline of sponge populations in Florida Bay (USA) was attributed to exceptionally strong cyanobacterial blooms that occurred as a result of increased nutrients (Butler et al., 1995). Field studies conducted on the Grand Cayman (Rose \& Risk, 1985) and Barbados reefs in the Caribbean Sea (Holmes, 2000) showed that bioeroding clionid sponges such as Cliona delitrix and Cliona c.f vastifica are often more abundant in nutrient enriched waters. Similarly, lab-based experiments made on Cymbastela concentrica (Roberts et al., 2006), Aplysina cauliformis (Gochfeld et al., 2012), R. odorabile (Simister et al., 2012) and Cymbastela stipitata (Luter et al., 2014) also indicate that reef sponges are not physiologically impacted by elevated nutrient levels, although the exposure of these sponges to excess nutrients were generally less than one week (12 h- 7 days) and different nutrient-enriched media were used across those experimental studies. With the exception of the studies by Simister et al. (2012) and Webb et al. (2017), no investigations have considered the combined effects of climate change and eutrophication on sponges and, at present, our knowledge on sponge-nutrient interactions related to climate change remains fairly limited. Lagoon ecosystems being subjected to both temperature and nutrient variations, it is increasingly important to investigate the combined effects of these stressors on lagoon-inhabiting sponges to better understand any potential impacts on existing lagoon sponge populations. 


\subsection{The lagoons of Mauritius (Study area)}

Mauritius $\left(20^{\circ} 34^{\prime} \mathrm{S}, 57^{\circ} 55^{\prime} \mathrm{E}\right)$ is an archipelago situated in the western Indian Ocean, approximately $2000 \mathrm{~km}$ east from the main African continent (Fig. 1.1A). Yearly temperature distribution over the island is characterized by a mean maximum of $31^{\circ} \mathrm{C}$ along the coastal areas during summer and a mean minimum temperature of about $14{ }^{\circ} \mathrm{C}$ on the high ground during winter. However, the relatively small temperature variation $\left( \pm 4{ }^{\circ} \mathrm{C}\right)$ is sufficient to cause a well-marked difference in the season (Fig 1.1B). Diurnal air temperature variations vary from $6-7.5^{\circ} \mathrm{C}$ on the high grounds, and from $6.5-10{ }^{\circ} \mathrm{C}$ along the coast (Boojhawon et al., 2010). The average sea surface temperature in the region varies from $22-27^{\circ} \mathrm{C}$ depending on season (Daby, 1994). The island of Mauritius has a surface land mass of $2040 \mathrm{~km}^{2}$ and a coastline of approximately $300 \mathrm{~km}$. It is surrounded by faltering fringing coral reefs, leading to approximately $243 \mathrm{~km}^{2}$ of discontinuous lagoons bearing multiple inlets and links with the open ocean (Fagoonee, 1990; Daby, 2003). The average depths of Mauritian lagoons range from 1-4 m and lagoon widths range from 1-8 km from the shoreline (Fagoonee, 1990). Water currents within lagoons are usually minimal $\left(0.01-0.15 \mathrm{~ms}^{-1}\right)$ and are mostly influenced by tides and lagoon inlets (Daby, 2006), although longshore currents across the lagoons are relatively frequent.
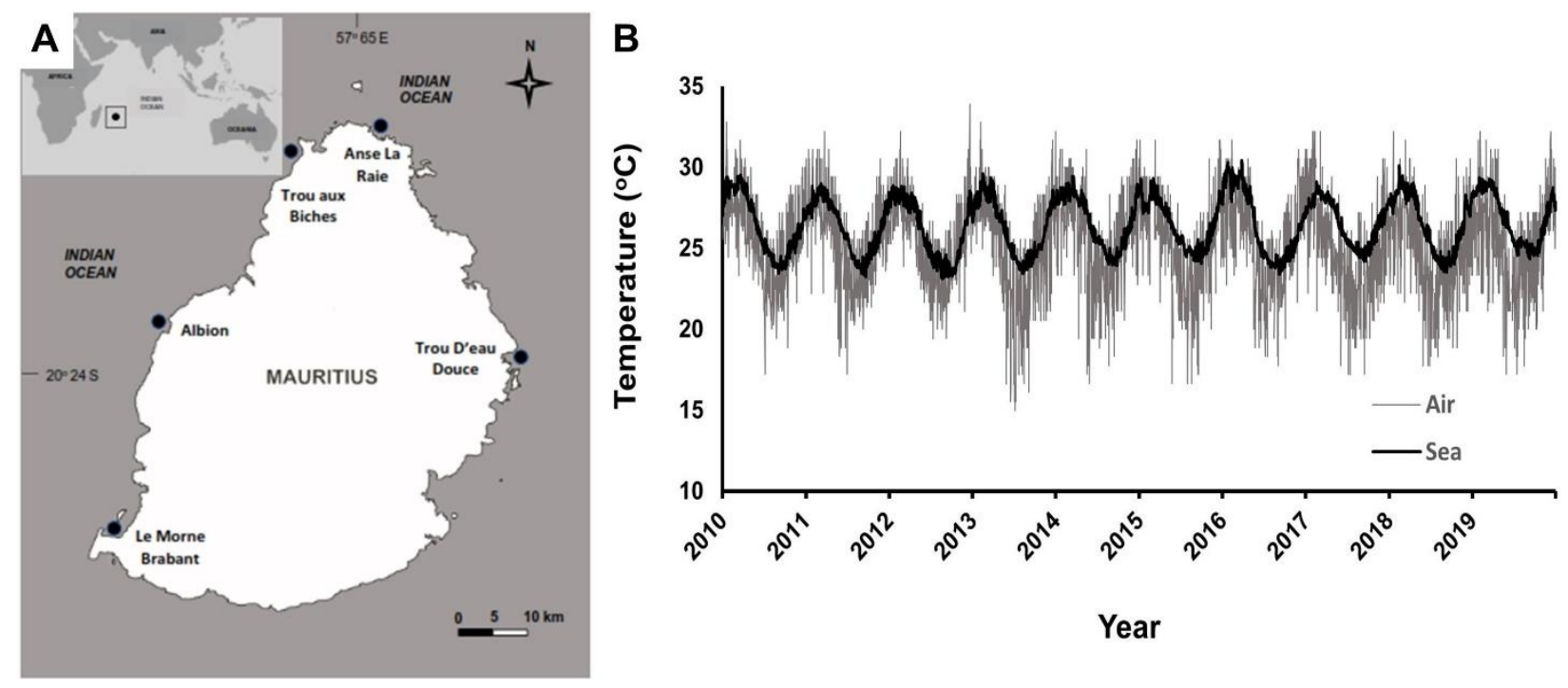

Fig. 1.1 Geography and temperature variations in Mauritius. A) Geographic location of Mauritius. Filled circles represent lagoons where sponges are known to occur. Source: Beepat (2015) and (Elliott et al., 2016a). B) Air and sea surface temperature variations from 2010 to 2020 in Mauritius. Temperature data retrieved from the National Oceanic and Atmospheric Administration (NOAA) database. (Data available at: https://www.noaa.gov/). 
The lagoons of Mauritius are topographically shallow at both extremities with a middle post-reef depression (Fig. 1.2), which is slightly deeper (Moothien Pillay et al., 2002). The lagoon floor at these middle depressions are mostly composed of fine sand, coarse gravel, and fragments of corals. As experienced in many island states, Mauritian lagoons are also subjected to nutrients inputs both from agricultural activities as well as from submarine groundwater discharges (Povinec et al., 2012). Nutrient run-off from land and underwater seepage have been reported to influence the seagrass biomass at some lagoons (Daby, 2003). Nutrients concentrations within lagoons are however variable and are subjected to seasonal change with highest peaks occurring during summer (Ramessur, 2013). The lagoon post-reef depressions of Mauritius also accommodate multiple habitats such as coral patches, seagrass beds and sponge patches (Fagoonee, 1990; Turner \& Klaus, 2005; Daby, 2006; Beepat, 2015). However, while the distribution and ecology of coral reefs in these lagoons have been studied over the past two decades (Turner et al., 2000; MoothienPillay et al., 2002; Turner \& Klaus, 2005), the biodiversity and ecology of lagoon-inhabiting sponges have been widely overlooked, although several studies have explored the bioactive potentials of Mauritian sponges (Wah et al., 2006; Beedessee et al., 2012, 2015).

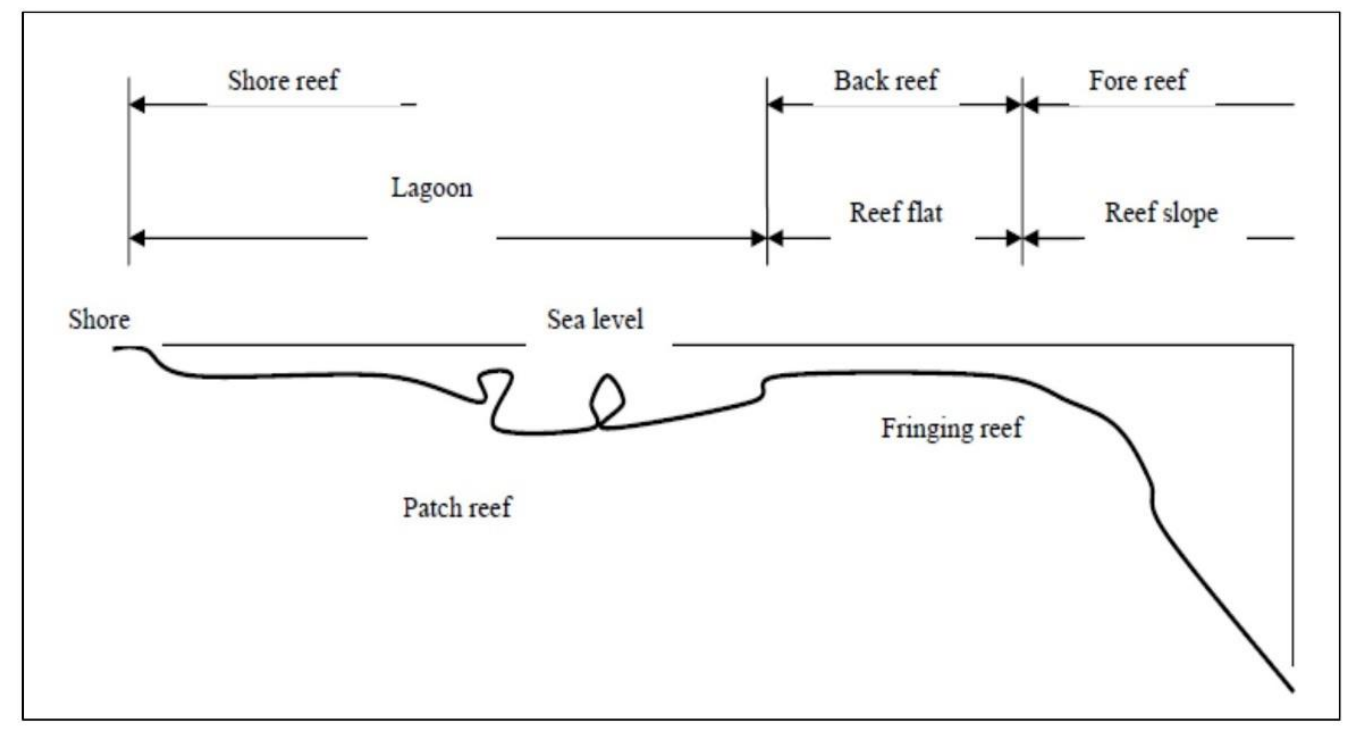

Fig. 1.2 General coastal lagoon topography around Mauritius (western Indian Ocean). Source: Moothien Pillay et al. (2002)

The presence of sponge patches in the post-reef depression zone of Trou aux Biches lagoon $\left(20^{\circ}\right.$ $01^{\prime} \mathrm{S}, 57^{\circ} 33^{\prime}$ E) was reported for the first time by Appadoo et al. (2011). Following this study, Beepat (2015) further reported the presence of additional sponge assemblages at other lagoons 


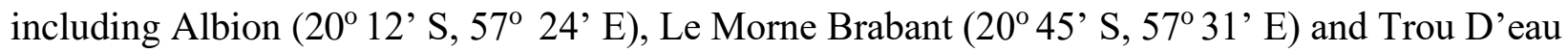
Douce $\left(20^{\circ} 14^{\prime} \mathrm{S}, 57^{\circ} 47^{\prime} \mathrm{E}\right)$, and partially described the ecology of sponges at these lagoons. The lagoon-inhabiting sponges of Mauritius do not usually occur in off-reef locations, except for Spheciospongia incontans where the population distribution of this species occurs at a depth range of 1-26 m (Wah et al., 2006). To date, reported lagoon-inhabiting sponge species from Mauritius include Terpios hoshinota, S. inconstans, Amphimedon navalis, Haliclona (reneira) debilis, Neopetrosia chaliniformis (previously known as Neopetrosia exigua) and S. vagabunda with the latter being the most abundant and common species around the island (Appadoo et al., 2011; Beepat, 2015; Elliott et al., 2016b).

Ocean warming and eutrophication have been reported to have major ecological impacts on Mauritian coral reefs (Thomassin et al., 1998; Hardman, 1999; McClanahan et al., 2005; MattanMoorgawa et al., 2014). Yet, the impacts of these stressors on the lagoon sponge assemblages have never been investigated. While the coral reefs of Mauritius are already significantly affected by anthropogenic stressors (McClanahan et al., 2014), it is becoming increasingly important to investigate the potential effects of these stressors on lagoon-inhabiting sponge assemblages to better understand ecological implications at the community level.

\subsection{Aims and objectives of this study}

The overall aim of this thesis is to investigate the effects of elevated seawater temperature as well as its combined effect with excess nutrients on tropical lagoon-inhabiting sponges. The specific objectives of this thesis are divided into four main data chapters with the following aims:

I. Assessing the short-term physiological responses of lagoon-inhabiting sponges to elevated temperature and excess nitrate concentration.

In this chapter (chapter 2), three common lagoon-inhabiting sponge species, namely $N$. chaliniformis, A. navalis and S. vagabunda were exposed to nine combined treatments of elevated temperature based on the IPCC (2014) Representative Concentration Pathways, RCP6.0 and RCP8.5 and excess nitrate concentrations (approximately 2- and 3-fold ambient levels) for 14 days through a multi-factorial lab-based experiment. Changes in pigment concentrations, buoyant weight, effective quantum yield of photosystem (PS) II (for Chl $a$-containing species only), gross 
photosynthesis, respiration and photosynthesis to respiration (P:R) ratio were regularly assessed to determine the short-term physiological responses of these sponges to the combined effects of elevated temperature and excess nitrate concentrations.

\section{Determining the physiological and proteomic responses of lagoon-inhabiting sponges exposed} to elevated temperature.

For chapter 3, thermal tolerance lab-based experiments were conducted on $N$. chaliniformis and A. navalis and $S$. vagabunda. Sponges were exposed to elevated temperatures of $+2{ }^{\circ} \mathrm{C}$ and $+4{ }^{\circ} \mathrm{C}$, respectively, for an extended period of four weeks after an acclimation of one week. Changes in physiological responses including buoyant weight, holobiont oxygen consumption and pumping rates were assessed at weekly intervals. At the end of the experiment, sponge tissue samples from A. navalis only were collected and compared to controls to explore the effects of elevated temperature on the protein expression (i.e. biological functions at the cellular level) of this species.

III. Investigating the temporal variability of lagoon-inhabiting sponges $\mathrm{N}$. chaliniformis, A. navalis and $\mathrm{S}$. vagabunda and explore whether temporal changes are correlated with sea surface temperature and chlorophyll a concentration.

In this chapter (chapter 4), using previously collected and new in situ data, the temporal changes in local distribution area, sponge abundance and percentage cover of $N$. chaliniformis, A. navalis and $S$. vagabunda were assessed in their respective lagoon of occurrence over a period of 6-8 years (depending on species). Using satellite (MODIS-Aqua) data corresponding to the specific sponge survey periods, the correlations between sponge temporal variability and sea surface temperature and chlorophyll a ( $\mathrm{Chl} a$ ) concentration (used as a proxy for eutrophication) were explored to determine whether the temporal variability of lagoon-inhabiting sponges were species-specific.

$I V$. Estimating the effects of elevated temperature on the bentho-pelagic interactions of the lagooninhabiting sponge Spheciospongia vagabunda in a shallow coastal lagoon.

For this final data chapter (chapter 5), a combination of laboratory-based thermal tolerance experimental data from Chapter 3 and in situ data from Chapter 4 was used to investigate the possible effects of elevated temperature on the bacterial cell consumption and nutrient fluxes i.e. $\mathrm{Chl} a$ and net DOC uptake and the net release of nitrate + nitrite $\left(\mathrm{NO}_{2}{ }^{-}+\mathrm{NO}_{3}{ }^{-}\right)$and phosphate 
$\left(\mathrm{PO}_{4}{ }^{3-}\right)$ of $S$. vagabunda in a shallow coastal lagoon. Since the bentho-pelagic fluxes of $S$. vagabunda could not be specifically investigated, the bentho-pelagic fluxes of another lagooninhabiting sponge Spheciospongia vesparium from the Caribbean was used to model the bacterial cell consumption and, net organic matter uptake and net inorganic nutrient release of $S$. vagabunda in the lagoon. 


\section{Chapter 2:}

Short-term responses of tropical lagoon sponges to elevated temperature and nitrate 


\begin{abstract}
Sponges are often important components of coastal lagoons, however their responses to anthropogenic stressors remain poorly understood. In this chapter, the short-term physiological responses of three lagoon sponges, Neopetrosia chaliniformis, Amphimedon navalis and Spheciospongia vagabunda from Mauritius (western Indian Ocean) were tested, to nine temperature and nitrate combinations for 14 days. Physiological responses measured were changes in photosynthetic pigment concentrations ( $\mathrm{Chl} a, b, c$ and total carotenoids), buoyant weight, effective quantum yield of photosystem (PS) II $\left(\Delta \mathrm{F} / \mathrm{F}_{\mathrm{m}}\right.$ ') for Chl $a$-containing species, gross photosynthetic rate, respiration rate and gross photosynthesis to respiration $(P: R)$ ratio. The results presented in this chapter demonstrate that after 14 days exposure, elevated seawater temperature resulted in significant physiological responses in all species, but there was generally little negative effect of elevated nitrate (except for changes in buoyant weight). At the end of the experiment, the buoyant weight of all three species were significantly reduced, while for the two chlorophyll $a$ containing species, $N$. chaliniformis and $S$. vagabunda, $\Delta \mathrm{F} / \mathrm{F}_{\mathrm{m}}$, photosynthetic pigment concentrations, gross photosynthetic rate and $\mathrm{P}: \mathrm{R}$ ratio were also significantly reduced when compared to the controls. Dark respiration rates were significantly higher in all three species at elevated temperature. While these lagoon sponges appeared to be impacted by elevated seawater temperature, the results from this chapter also demonstrate that these species are generally physiologically tolerant to excess nitrate concentrations.
\end{abstract}




\subsection{Introduction}

Tropical coastal lagoons are naturally stressed ecosystems and are highly vulnerable to the impacts of increased sea surface temperature and land-based pollution (Nixon, 1995; Lloret et al., 2008). The shallow semi-enclosed nature of coastal lagoons, which is characterized by low flushing rates, makes them susceptible to heat accumulation (Anthony et al., 2009). They also receive excess nutrients originating from terrestrial sources, which can lead to oxygen depletion or phytoplankton blooms, i.e. eutrophication (Taylor et al., 1995). In some lagoons, excess nutrients such as phosphates and nitrates can also promote overgrowth of macroalgae reducing light availability (Herbert, 1999). As a result, organisms living in coastal lagoons are commonly exposed to the combined impacts of elevated temperature and eutrophication (Lloret et al., 2008; Grenz et al., 2017). Elevated temperature and excess nutrients can have catastrophic impacts on coastal benthic communities and the combination of both stressors often results in large-scale population declines (Bintz et al., 2003; Hughes et al., 2003; Ezzat et al., 2016; Zaneveld et al., 2016). As tropical coastal lagoon organisms likely live near to their thermal tolerance limits, additional exposure to abiotic stressors may lead to reduced physiological performance or mortality (Somero, 2010). While the combined effects of elevated temperature and nutrients have been investigated in corals (Ezzat et al., 2016; Zaneveld et al., 2016), their potential impacts on other benthic taxa, such as sponges, are currently poorly understood.

Sponges have been proposed as potential winners under future climate scenarios (Bell et al., 2013, 2018; Kelmo et al., 2013). However, while sponges appear to be generally tolerant to ocean acidification (OA), many species experience physiological stress when subjected to elevated temperature (Bell et al., 2018). For example, the sponge Rhopaloeides odorabile has a very strict thermal threshold range of $3-5{ }^{\circ} \mathrm{C}$ and when exposed to an increase of $5{ }^{\circ} \mathrm{C}$ for seven days, it exhibits reduced filtering efficiency and pumping rates (Massaro et al., 2012). Changes in bioerosion rate (Schoenberg et al., 2017) have also been reported from the sponge Cliona orientalis when exposed to a $2.7{ }^{\circ} \mathrm{C}$ temperature increase, along with a significant reduction in photochemical efficiency when subjected to a thermal stress of $5{ }^{\circ} \mathrm{C}$ for eight days (Ramsby et al., 2018). 
In contrast to temperature, both in situ and field observations suggest that excess nutrients have no negative physiological impacts on sponges (Rose \& Risk, 1985; Holmes, 2000; Simister et al., 2012). For example, no significant change was reported in net photosynthesis, bioerosion rate and buoyant weight when Cliona caribbaea was subjected to a three-fold increase $(32 \mu \mathrm{mol} / \mathrm{kg})$ of RPMI 1640 medium for seven days (Webb et al., 2017). Furthermore, the reproductive status (i.e. number of larvae, eggs and sperm), growth and chlorophyll $a$ (Chl $a$ ) concentration of the sponge Cymbastela concentrica was unaffected when subjected to elevated nitrate/phosphate concentrations (Roberts et al., 2006). Finally, laboratory-based and in situ experiments have reported that the microbial symbionts of the sponges $R$. odorabile (Simister et al., 2012), Cymbastela stipitata (Luter et al., 2014) and Aplysina cauliformis (Gochfeld et al., 2012) are not significantly altered when exposed to elevated concentrations of fertilizers such as Thrive ${ }^{\circledR}$ and Osmocote ${ }$ for short periods, although several shallow water sponges may heavily rely on their associated photosymbionts to obtain their energy (Wilkinson, 1983; Thomas et al., 2016). While most studies report on the impacts of nutrients on reefs sponges, there are currently no reports on these effects on lagoon-inhabiting sponges, which are likely exposed to higher nutrient levels.

To date, most studies have focused on the individual effects of elevated temperature or excess nutrients on sponge physiology, and investigations on the combined effects of both stressors on sponges are scarce (but see Simister et al., 2012). Webb et al. (2017) investigated the combined effects of ocean acidification and excess nutrients on the sponge $C$. caribbaea and found that the physiology of this species is more likely to be influenced by OA than by eutrophication. The combined effects of elevated temperature and eutrophication have only been reported for the Great Barrier Reef sponge $R$. odorabile, which was subjected to a combination of elevated temperature up to $4{ }^{\circ} \mathrm{C}$ greater than ambient temperature and a nine-fold increase in nutrient levels (Simister $e t$ $a l ., 2012)$. After seven days of exposure to the combined stressors, no changes were found in the symbiotic bacterial, eukaryotic and archaeal community structure of the sponge. However, no other studies have considered physiological responses of sponges to the combined effects of elevated temperature and nutrients.

In this chapter, a multi-factorial experiment was conducted to investigate the short-term physiological responses of three lagoon-inhabiting sponges (Neopetrosia chaliniformis, 
Amphimedon navalis and Spheciospongia vagabunda) to the effects of increased temperature based on the IPCC (2014) Representative Concentration Pathways (RCP6.0 and RCP8.5) and elevated nitrate levels ranging from 7.5 $\mu \mathrm{M}$ (ambient) to $19.8 \mu \mathrm{M}$. Sponges were exposed to nine different treatment combinations for 14 days and changes in sponge photosynthetic pigment concentration, buoyant weight, effective quantum yield of PS II (light-adapted only), gross photosynthesis, dark respiration and P:R ratio were assessed during the experiment. This chapter therefore aims to determine whether lagoon sponges are physiologically tolerant to the combined effects of elevated temperature and excess nitrate levels.

\subsection{Materials and Methods}

\subsubsection{Study species}

The sponges Neopetrosia chaliniformis and Amphimedon navalis occur mostly on dead corals in

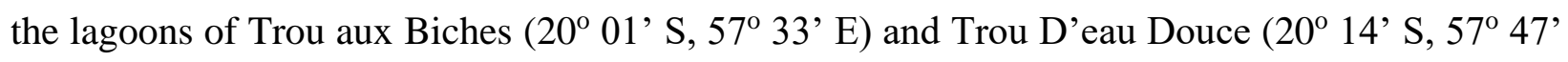
E) respectively, at a depth range of 0.5 - $2 \mathrm{~m}$ (Appadoo et al., 2011; Beepat, 2015). In contrast, the sponge Spheciospongia vagabunda is a burrowing species, which occurs at a depth range of 0.5 $1.5 \mathrm{~m}$ on the west coast of Albion ( $\left.20^{\circ} 12^{\prime} \mathrm{S}, 57^{\circ} 24^{\prime} \mathrm{E}\right)$, where it is often found on the soft-bottom substratum of the lagoon. However, S. vagabunda sometimes also grows on coral rubble (Beepat et al., 2013). While $N$. chaliniformis and S. vagabunda harbor some phototrophic symbionts, such as cyanobacteria (Levi, 1998; Thacker, 2005; Thomas et al., 2016), there are currently no studies considering the ecology or microbial associations of A. navalis (see Appendix A - section A2.1). These species are the most common and abundant species occurring in Mauritian lagoons (Appadoo et al., 2011; Beepat et al., 2013, 2015), which makes them good models to investigate the effects of elevated temperature and nutrients on lagoon sponges.

\subsubsection{Experimental design}

Specimens of $N$. chaliniformis, A. navalis and S. vagabunda were collected separately during low tide in July, August and September 2018, respectively when natural temperature variation is minimal around Mauritius. Genetically distinct sponges of size 4-8 cm were collected attached to a fragment of their respective substrate (except for $N$. chaliniformis, for which substrate-free sponges were available) to avoid any damage to the sponge's tissue. For S. vagabunda, only

sponges attached to dead coral or coral rubble were collected. Sponges were transported for 20 
min in seawater-containing polystyrene boxes to a laboratory facility, where they were immediately placed in $10 \mathrm{~L}$ aquaria of freshly collected seawater at the ambient temperature of 26 ${ }^{\circ} \mathrm{C}$ (approximate seawater temperature at collection sites) and kept under ambient light conditions. Three consecutive experiments were conducted (one experiment per species) where sponges were first left to acclimatize for 7 days prior to the start of each experiment. Acclimation tanks were aerated with individual aquarium oxygen pumps and unfiltered seawater was manually replaced at $12 \mathrm{~h}$ intervals to ensure adequate food supply to the sponges. Tanks were covered with a lightshade cloth and maintained under natural light conditions with a maximum irradiance (Photosynthetically Active Radiation; PAR) of approximately $450 \mu \mathrm{mol}$ photons $\mathrm{m}^{-2} \mathrm{~s}^{-1}$, corresponding to the irradiance at $0.5 \mathrm{~m}$ at 12:00 hr at Trou aux Biches at low tide on a clear day. PAR at Trou aux Biches was measured using a Pulse Amplitude Modulated (PAM) fluorometer (red LED Diving PAM, Walz, Germany).

Manipulative experiments were conducted separately for each species from July to September 2018. The experimental design consisted of 18 treatment tanks (two replicate tanks of $10 \mathrm{~L}$ for each treatment combination). Treatment tanks were individually heated with a $100 \mathrm{~W}$ aquarium heater and fitted with an aquarium oxygen pump to ensure oxygen influx and water circulation. Each treatment tank contained four live sponges. Three sponges in each treatment tank were exclusively used for physiological measurements ( $n=6$ per treatment), while the additional sponge in each treatment tank ( $\mathrm{n}=2$ per treatment) was sacrificed at the end of the experiment (T-end) for photosynthetic pigment analysis. Prior to the experiment, the average pumping rate of each species was assessed to estimate the turnover of seawater per day (see Appendix A - section A2.2). Given that the maximum pumping rate was estimated as $0.089 \pm 0.04 \mathrm{ml} \mathrm{s}^{-1}$, nitrate-treated seawater was pre-heated for each treatment and water in the treatment tanks was manually replaced at $12 \mathrm{~h}$ intervals, ensuring food availability and that on average the water in the tanks was recirculated no more than three times through the sponges. Nitrate-treated seawater was prepared using the commercial liquid soluble fertilizer CAN-17 (NPK: 17-0-0 and trace elements, Atlantica Agricola, Alicante, Spain) following initial experimental trials (see Appendix A - section A2.3) to test for any negative effects of the fertilizer on sponge health. Three separate $20 \mathrm{~L}$ tanks were used to heat nitrate-treated seawater daily to their respective temperatures. 
A total of nine combined temperature/nitrate treatments were used for the experiment, with the control treatment being $26{ }^{\circ} \mathrm{C} / 7.5 \mu \mathrm{M}$, representing the mean seawater temperature and nitrate level on the date of collection (see Table 2.1). For each species, sponges were exposed to the treatments for 14 days after the acclimation period of 7 days. Temperature levels were selected based on the (IPCC, 2014) Sea Surface Temperature (SST) prediction scenarios for 2100 at RCP6.0 (+2 $\left.{ }^{\circ} \mathrm{C}\right)$ and RCP8.5 $\left(+4{ }^{\circ} \mathrm{C}\right)$, relative to current ambient temperature $\left(26^{\circ} \mathrm{C}\right)$. Nitrate concentration was adjusted to approximately 2-fold $(10.9 \mu \mathrm{M})$ and 3-fold $(19.8 \mu \mathrm{M})$ the nitrate concentration recorded in July $2018(7.5 \mu \mathrm{M})$. According to The Mauritius Government Gazette (1999), nitrate levels within the lagoons of Mauritius are often less than $3.2 \mu \mathrm{M}$, although nutrients levels in Mauritian lagoons often fluctuate from $3.2 \mu \mathrm{M}$ to $30 \mu \mathrm{M}$ due to the presence of underground freshwater seepage in some locations around the island (Ramessur et al., 2011; Povinec et al., 2012). Temperature data loggers (Onset Hobo, MA, USA) were used to monitor temperature fluctuations in treatment tanks at six-hour intervals. Nitrate levels were monitored daily with a digital Pinpoint nitrate monitor (American Marine Inc. Ridgefield, CT, USA). Additional water samples (triplicate) were randomly collected from each treatment tank and analyzed at the Department of Chemistry, Faculty of Science, University of Mauritius to confirm $\mathrm{NO}_{3}{ }^{-}$concentrations by spectrophotometric methods (Narayana \& Sunil, 2009). PAR measurements in the laboratory were measured at 12:00 hr using the red light Diving PAM.

Table 2.1 Temperature and nitrate concentration in each treatment. Values are mean \pm SE over six weeks (combined values for all experiments for three sponge species). Individual temperature/nitrate fluctuations for each experiment can be found in Appendix A - Fig. A2.4.

\begin{tabular}{|c|c|c|c|}
\hline Treatment & Temp $\left({ }^{\circ} \mathrm{C}\right)$ & $\mathrm{NO}_{3}^{-}(\mu \mathrm{M})$ & PAR $\left(\mu \mathrm{mol}\right.$ photons $\left.\mathrm{m}^{-2} \mathrm{~s}^{-1}\right)$ \\
\hline $\begin{array}{c}26^{\circ} \mathrm{C} / 7.5 \mu \mathrm{M} \text { nitrate } \\
\text { (control) }\end{array}$ & $26.09 \pm 0.81$ & $7.41 \pm 0.06$ & $473 \pm 11.31$ \\
\hline $26{ }^{\circ} \mathrm{C} / 10.9 \mu \mathrm{M}$ nitrate & $25.93 \pm 0.69$ & $11.65 \pm 0.52$ & $455 \pm 9.58$ \\
\hline $26{ }^{\circ} \mathrm{C} / 19.8 \mu \mathrm{M}$ nitrate & $26.12 \pm 0.77$ & $19.54 \pm 0.31$ & $469 \pm 11.01$ \\
\hline $28^{\circ} \mathrm{C} / 7.5 \mu \mathrm{M}$ nitrate & $28.14 \pm 0.27$ & $7.71 \pm 0.13$ & $459 \pm 12.63$ \\
\hline $28^{\circ} \mathrm{C} / 10.9 \mu \mathrm{M}$ nitrate & $28.01 \pm 0.09$ & $10.71 \pm 0.26$ & $435 \pm 9.54$ \\
\hline $28^{\circ} \mathrm{C} / 19.8 \mu \mathrm{M}$ nitrate & $28.12 \pm 0.29$ & $20.02 \pm 0.41$ & $467 \pm 12.36$ \\
\hline $30^{\circ} \mathrm{C} / 7.5 \mu \mathrm{M}$ nitrate & $30.15 \pm 0.31$ & $7.53 \pm 0.24$ & $465 \pm 10.23$ \\
\hline $30{ }^{\circ} \mathrm{C} / 10.9 \mu \mathrm{M}$ nitrate & $29.91 \pm 0.51$ & $10.68 \pm 0.43$ & $427 \pm 14.25$ \\
\hline $30{ }^{\circ} \mathrm{C} / 19.8 \mu \mathrm{M}$ nitrate & $30.21 \pm 0.42$ & $19.69 \pm 0.78$ & $436 \pm 10.04$ \\
\hline
\end{tabular}




\subsubsection{Response variables}

Physiological responses of sponges were measured over 14 days at T0, T1, T4, T7, T10 and T14. Response variables measured during the experiment were changes in buoyant weight (loss/gain in buoyant weight), effective quantum yield of PS II, gross photosynthetic rate, P:R ratio (Chl $a$ containing species only) and dark respiration rate.

\subsubsection{Survival and health monitoring}

Sponge survival and health were monitored daily before and during the experiment. Sponges showing any visual signs of disease (significant change in colour or formation of a white film) were immediately removed from their treatment tanks to avoid contamination of other sponges.

\subsubsection{Photosynthetic pigment concentration}

Triplicate sponge surface tissue samples (from each sacrificed sponge in each treatment tank) were collected at T0 (Day 0) and T-end (day when sponge mortality was first recorded) to determine any change in photosynthetic pigment concentration over the course of the experiment. Differences in pigment concentration (chlorophylls $a, b$, and $c$, and total carotenoids) were determined following the methods described by Pineda et al. (2016) to estimate any change in prokaryotic and eukaryotic photosymbionts. $50 \mathrm{mg}$ of frozen sponge tissue were cut into pieces of approximately $1 \mathrm{~mm}^{3}$, macerated and placed in $1.5 \mathrm{ml}$ vials. A $1 \mathrm{ml}$ aliquot of $95 \%$ ethanol was added, and the mixture was vigorously mixed using a Tissuelyser (Tissuelyser LT, Qiagen Inc, CA, USA) for 5 $\min$. The mixture was centrifuged at $10,000 \mathrm{x}$ g for $5 \mathrm{~min}$ and $700 \mu 1$ of the supernatant were transferred into a new vial. One $\mathrm{ml}$ of $95 \%$ ethanol was added and mixed again for $5 \mathrm{~min}$. After centrifuging at 10,000 $\mathrm{x}$ g for $5 \mathrm{~min}$, approximately $700 \mu \mathrm{l}$ of the extract were recovered and used for absorbance measurements. Using $95 \%$ ethanol as a blank, $300 \mu \mathrm{l}$ of each extract were placed into a 96-well microplate and the absorbance at 470, 632, 649, 665 and $750 \mathrm{~nm}$ was measured on a Perkin Elmer EnSpire 2300 multimode plate reader (PerkinElmer, Inc. Waltham, MA, USA). Using the blank-corrected absorbance readings minus the absorbance at a wavelength of $750 \mathrm{~nm}$,

concentrations of chlorophylls $a, b$ and $c$ and total carotenoids were calculated using the standard equations of Lichtenthaler (1987) and Ritchie (2008), but with a correction factor of 1.1021 as follows: 
$\operatorname{Chl} a\left(\mu \mathrm{g} \mathrm{ml}^{-1}\right)=\left[\left(-0.9394 \times \mathrm{E}_{632}\right)+\left(-4.2774 \times \mathrm{E}_{649}\right)+\left(13.3914 \times \mathrm{E}_{665}\right)\right] / 1.1021$

$\operatorname{Chl} b\left(\mu \mathrm{g} \mathrm{ml}^{-1}\right)=\left[\left(-4.0937 \times \mathrm{E}_{632}\right)+\left(25.6865 \times \mathrm{E}_{649}\right)+\left(-7.3430 \times \mathrm{E}_{665}\right)\right] / 1.1021$

$\operatorname{Chl} c\left(\mu \mathrm{g} \mathrm{ml}^{-1}\right)=\left[\left(28.5073 \times \mathrm{E}_{632}\right)+\left(-9.9940 \times \mathrm{E}_{649}\right)+\left(-1.9749 \times \mathrm{E}_{665}\right)\right] / 1.1021$

Total carotenoids $\left(\mu \mathrm{g} \mathrm{ml}^{-1}\right)=\left[\left(\left(1000 \times \mathrm{E}_{470}\right) / 1.1021\right)-(2.13 \times \mathrm{Chl} a)-(97.64 \times \mathrm{Chl} b)\right] / 209$

The correction factor (microplate path-length) was calculated according to the formula of Warren (2008), using a volume of $300 \mu \mathrm{l}$ of $95 \%$ ethanol as the solvent (blank) and $300 \mu \mathrm{l}$ of sponge extract at a specified wavelength $(632 \mathrm{~nm})$. Pigment concentrations were normalized to wet weight using the formula:

[Pigment concentration $\left(\mu \mathrm{g} \mathrm{ml}^{-1}\right) \times$ extraction volume $\left.(\mathrm{ml})\right] /$ wet weight $(\mathrm{g})$

\subsubsection{Change in buoyant weight}

Buoyant weight was measured with a digital scale (Scout STX422, Ohaus, USA) following the methods of Osinga et al. (1999) at each time point. Briefly, an underhanging plastic container was attached to the bottom hook of the digital scale and the apparatus being placed over the tank on a tripod ensuring that the underhanging container was always immersed in the treatment tank. Sponges were placed on the underhanging container and the buoyant weight was measured. Buoyant weight was calculated by subtracting the weight of the underhanging container from the combined weight of the sponge and the container. The loss in sponge buoyant weight for all sponges was then estimated as the loss or gain in weight in grams per day.

\subsubsection{Effective quantum yield of PSII $\left(\Delta F / F_{m}{ }^{\prime}\right)$}

A red light diving Pulse Amplitude Modulated (PAM) fluorometer (Walz, Germany) was used to measure the effective quantum yield of PSII (Genty-parameter) of sponges (except for A. navalis where the fluorescent signal was too low to be detected by the Diving PAM). Differences in $\Delta F / F_{m}$ ' were used as a proxy for the photosynthetic efficiency of the photosynthetic symbionts during the experiment. Due to the low photosynthetic fluorescence of $N$. chaliniformis and S. vagabunda, the electronic signal gain of the Diving PAM was set to 5 and the Auto-Zero setting (background signal) was used to reduce noise. Other PAM settings used for each measurement were: detection of PAR, saturation pulse intensity (8) and the intensity of the measuring light (8). The apparatus was pre-calibrated against a quantum sensor Li-Cor (LI -190). A $10 \mathrm{~mm}$ rubber spacer was 
positioned on the end of the $5.5 \mathrm{~mm}$ (active diameter) fibre optic probe to ensure consistent distance between the sponge and the optic sensor. For each sponge, two measurements at different locations on the sponge but facing the same directions were taken at every time point.

The saturated pulse method of PS II was used to determine $\Delta F / F_{m}$, whereby a weak red light $(0.15$ $\mu \mathrm{mol}$ photons $\mathrm{m}^{-2} \mathrm{~s}^{-1}$ ) was first emitted to determine the initial fluorescence ( $\mathrm{F}$, fluorescence before saturating pulse is applied) of the sponge-associated photosymbionts. Maximum fluorescence was determined by the emission of a strong pulse of white light $\left(>10000 \mu \mathrm{mol}\right.$ photons $\left.\mathrm{m}^{-2} \mathrm{~s}^{-1}\right)$ for 0.8 s to fully saturate $\left(\mathrm{F}_{\mathrm{m}}\right.$, light-adapted maximum fluorescence) the PS II acceptors (Schreiber et al., 1995; Klughhammer \& Schreiber, 2008). $\Delta \mathrm{F} / \mathrm{F}_{\mathrm{m}}$ ' was measured under natural light conditions (between 11: 00 and 12: $00 \mathrm{hr}$ ) and was calculated using the equation of Schreiber et al. (1995).

$$
\text { Effective quantum yield }\left(\frac{\Delta \mathrm{F}}{F m^{\prime}}\right)=\frac{F m^{\prime}-F}{F m^{\prime}}
$$

\subsubsection{Gross photosynthesis, dark respiration, and P:R ratio}

Net photosynthesis and dark respiration rates were measured in cylindrical $100 \mathrm{ml}$ acrylic respiration chambers fitted with an oxygen probe and a temperature probe. Gross photosynthesis rate was calculated as: net photosynthetic rate + dark respiration rate. A magnetic stir bar to generate water movement was positioned at the base of the chamber and the sponge in the main chamber was separated from the stir bar with a mesh disc. The plastic lids of the chambers were tightly fixed with rubber bungs bearing two holes for the fiber optic oxygen and temperature probes of the dissolved oxygen (DO) meter (PreSens, Fibrox 3, Germany). The DO meter was calibrated each day by placing the probes in $100 \%$ and $0 \%$ oxygen saturated seawater. $100 \%$ oxygenated seawater was prepared by bubbling air through the seawater for $10 \mathrm{~min}$, while $0 \%$ oxygen saturated seawater was achieved by adding sodium sulphite $(1 \mathrm{~g} / 100 \mathrm{ml}$ seawater). The respiration chambers were placed in thermal water baths to ensure a stable temperature.

For sponge respiration, chambers containing sponges were darkened for at least 5 min before measurements commenced, to inhibit photosynthesis (Biggerstaff et al., 2015). One chamber filled with only seawater was treated similarly; this acted as a control for any electrode drift or respiration from micro-organisms in the seawater (Gatti et al., 2002). For both measurements, oxygen levels were recorded every minute for approximately half an hour to assess gross photosynthesis and 
respiration rates following an incubation of 5-10 mins. A short incubation time was used as sponges did not stop pumping after being placed in the chamber. Measurements were ended prematurely if oxygen saturation dropped below $70 \%$ to minimize stress to the sponge. PAR was approximately $450 \mu \mathrm{mol}$ photons $\mathrm{m}^{-2} \mathrm{~s}^{-1}$. Gross photosynthesis and respiration measurements were standardized to sponge dry weight (ash-free) using a conversion ratio of $0.29 \pm 0.02$ ( $N$. chaliniformis), $0.39 \pm 0.04$ (A. navalis) and $0.38 \pm 0.09$ (S. vagabunda). Conversion ratios were calculated by first measuring the buoyant weight of ten sponges of each species. The sponges were dried overnight in an oven at $60{ }^{\circ} \mathrm{C}$, weighed and then ashed at $450{ }^{\circ} \mathrm{C}$ for $4 \mathrm{~h}$ to determine their ash free dry weight. The buoyant weight to tissue dry weight ratios were then calculated for each species. This conversion method was used as sponges during the experiment could not be sacrificed for dry weight or ash free measurements. Gross photosynthesis to respiration ratio (P:R ratio) was calculated based on a daily budget of 12 hours of sunlight (photosynthesis) and 24 hours respiration (Wilkinson, 1983).

\subsubsection{Data analysis}

Statistical analyses were performed by SPSS v.24 (SPSS Statistics for Windows, IBM Inc) and PRIMER v.6 with the PERMANOVA extension (Plymouth Marine Laboratory, Plymouth, UK). For pigment analysis, a two-way PERMANOVA was used to test the effects of temperature and nitrate on sponge pigment concentration at T-end. Pigment data were log $(x+1)$ transformed and resemblance matrices were constructed with Euclidean distances for fixed factors (temperature and nitrate levels). Post hoc pairwise comparisons (based on permutations) were used to determine significant differences between treatments (Appendix A - Table A2.5a-d). General linear mixed models (GLMMs) were used to analyze the effects of the stressors on sponge physiological responses, with fixed effects being temperature and nitrate. All models were fitted with sponge replicate and tanks as random effects. Tank effect was considered in all models to address pseudoreplication (nested design). Models were built using data when all sponges were alive from T0 (Day 0) and T-end (day when first sponge mortality was recorded). Shapiro-Wilk tests indicated that response variable data were not normally distributed. Continuous data were therefore $\log$ $(\mathrm{x}+1)$ transformed and $\Delta \mathrm{F} / \mathrm{Fm}$ ' data were arcsine-square root transformed prior to statistical analyses. For $S$. vagabunda, continuous data were square-root transformed, as the oxygen consumption rate for this species was very low. Due to early mortalities of all S. vagabunda in the 
$30{ }^{\circ} \mathrm{C} / 19.8 \mu \mathrm{M}$ nitrate treatment on Day 4 , response data for this specific treatment were removed from their respective GLMMs and results of this treatment for $S$. vagabunda were excluded from comparative pairwise descriptions. Post hoc pairwise comparisons (with Sidak applied correction) were conducted for significant results to determine significant differences and the results are listed in Appendix A - Tables A2.6a-e. Only significant response variables observed at T-end are described below.

\subsection{Results}

\subsubsection{Sponge survival}

The percentage sponge survival differed among species, with Neopetrosia chaliniformis being the most sensitive species to the effects of elevated temperature and nitrate (Table 2.2). Nine $N$. chaliniformis sponges exposed to $28{ }^{\circ} \mathrm{C}$ died after eight days and all sponges exposed to $30{ }^{\circ} \mathrm{C}$ died after 12 days, irrespective of nitrate concentration. However, no mortalities were recorded at $26{ }^{\circ} \mathrm{C}$ irrespective of nitrate level. For Amphimedon navalis, five sponges exposed to $30{ }^{\circ} \mathrm{C} / 7.5 \mu \mathrm{M}$ nitrate, four sponges exposed to $30{ }^{\circ} \mathrm{C} / 10.9 \mu \mathrm{M}$ nitrate, and five sponges exposed to $30{ }^{\circ} \mathrm{C} / 19.8$ $\mu \mathrm{M}$ nitrate died after 10,11 and 13 days, respectively. No mortalities were recorded for A. navalis exposed to $26{ }^{\circ} \mathrm{C}$ and $28{ }^{\circ} \mathrm{C}$, irrespective of nitrate level. Spheciospongia vagabunda mortality only occurred in the $30{ }^{\circ} \mathrm{C} / 19.8 \mu \mathrm{M}$ nitrate treatment, with all six sponges exposed to this treatment dying after 4 days.

Table 2.2 Percentage mortality of sponges during the experiment. Values are percentage mortalities per treatment for each species. Brackets represents time at which mortalities occurred.

\begin{tabular}{cccc}
\cline { 2 - 4 } & & \% Mortality & \\
\hline Treatment & Neopetrosia chaliniformis & Amphimedon navalis & Spheciospongia vagabunda \\
\hline $26^{\circ} \mathrm{C} / 7.5 \mu \mathrm{M}$ nitrate & - & - & - \\
$26^{\circ} \mathrm{C} / 10.9 \mu \mathrm{M}$ nitrate & - & - & - \\
$26^{\circ} \mathrm{C} / 19.8 \mu \mathrm{M}$ nitrate & - & - & - \\
$28^{\circ} \mathrm{C} / 7.5 \mu \mathrm{M}$ nitrate & 50 (Day 12) & - & - \\
$28^{\circ} \mathrm{C} / 10.9 \mu \mathrm{M}$ nitrate & 50 (Day 12) & - & - \\
$28^{\circ} \mathrm{C} / 19.8 \mu \mathrm{M}$ nitrate & 50 (Day 12) & 83 (Day 10) & - \\
$30^{\circ} \mathrm{C} / 7.5 \mu \mathrm{M}$ nitrate & 100 (Day 8$)$ & 66 (Day 11) & 100 (Day 4$)$ \\
$30^{\circ} \mathrm{C} / 10.9 \mu \mathrm{M}$ nitrate & 100 (Day 8$)$ & 83 (Day 13$)$ & \\
$30^{\circ} \mathrm{C} / 19.8 \mu \mathrm{M}$ nitrate & 100 (Day 8$)$ & &
\end{tabular}




\subsubsection{Pigment composition}

The initial photosynthetic pigment composition of each species was determined from the sacrificed sponge tissue samples collected at the start of the experiment (T0). Carotenoids were major constituents of pigments across all species although, Chl $a$ was the most abundant pigment found in N. chaliniformis and S. vagabunda (Fig. 2.1). N. chaliniformis contained higher concentrations of Chl $a$, Chl $b$ and carotenoids than did A. navalis and S. vagabunda. Carotenoids were the main pigments found in A. navalis. In contrast, S. vagabunda contained relatively low concentrations of Chl $b$ and Chl $c$.

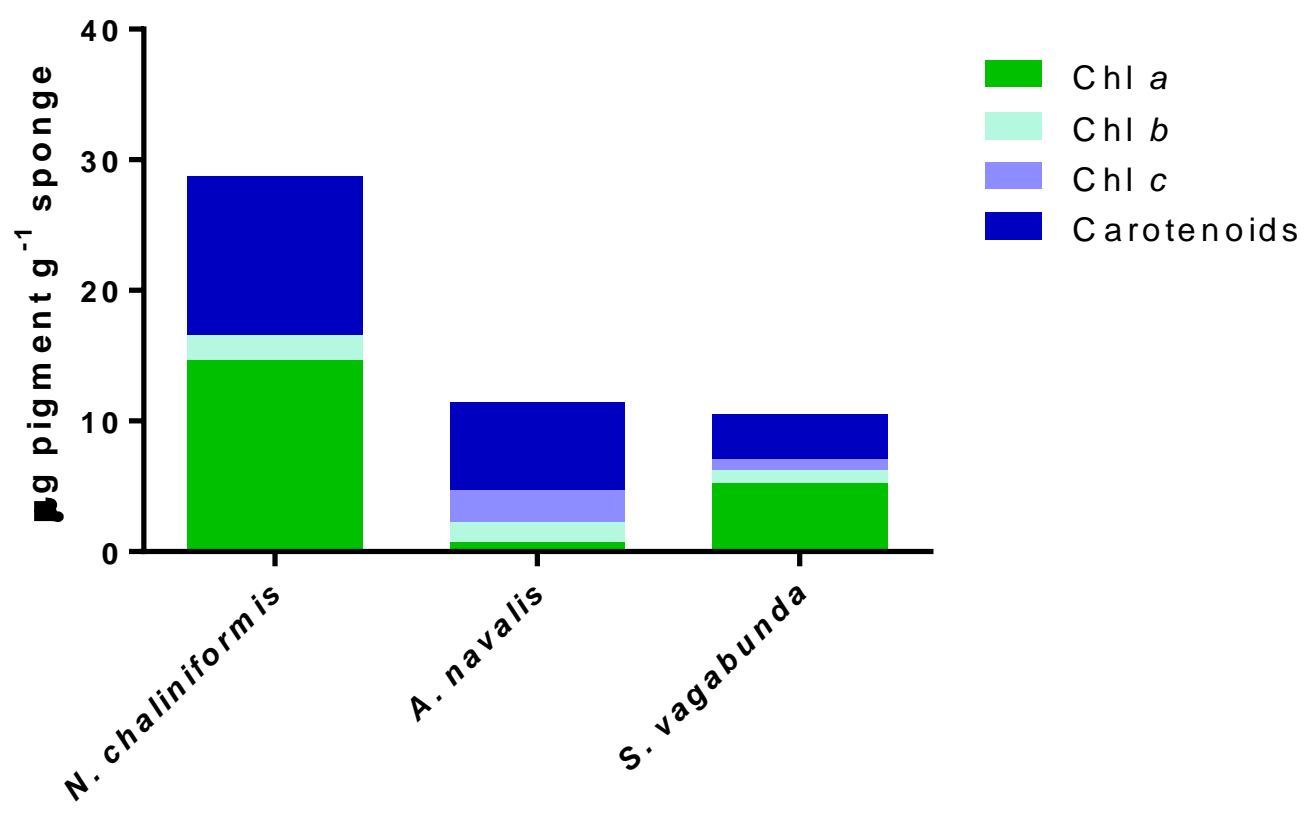

Fig. 2.1 Photosynthetic pigment concentrations of Neopetrosia chaliniformis, Amphimedon navalis and Spheciospongia vagabunda at T0. Pigments are coded as follows: Chl $a=$ chlorophyll $a, \mathrm{Chl} b=$ chlorophyll $b, \mathrm{Chl} c=$ chlorophyll $c$, Carotenoids = total carotenoids. (Note: Absence of detectable chlorophyll $c$ in $N$. chaliniformis). Values are mean $\mu \mathrm{g}$ pigment per gram of sponge wet weight.

\subsubsection{Pigment analysis}

The Chl $a$ concentration of $N$. chaliniformis was significantly affected by temperature (Pseudo$\left.\mathrm{F}_{(2,47)}=3.656, \mathrm{p}=0.038\right)$ and the interaction of nitrate with temperature (Pseudo- $\mathrm{F}_{(4,47)}=4.567, \mathrm{p}$ 
$=0.001$; Table A2.5a). At 7.5 $\mu \mathrm{M}$ nitrate, $\mathrm{Chl} a$ concentration was significantly lower at $30{ }^{\circ} \mathrm{C}$ relative to $26{ }^{\circ} \mathrm{C}(\mathrm{p}=0.003)$ and at $19.8 \mu \mathrm{M}$ nitrate, $\mathrm{Chl} a$ concentration was significantly lower at $28{ }^{\circ} \mathrm{C}$ than to $26{ }^{\circ} \mathrm{C}(\mathrm{p}=0.031$; Fig. 2.2; Table A2.5b). Chl $b$ concentration of $N$. chaliniformis was significantly affected by temperature only $\left(\right.$ Pseudo- $\mathrm{F}_{(2,47)}=3.836, \mathrm{p}=0.021$; Table A2.5a). At $10.9 \mu \mathrm{M}$ nitrate, $\mathrm{Chl} b$ concentration significantly decreased at $30{ }^{\circ} \mathrm{C}$ compared to $28{ }^{\circ} \mathrm{C}(\mathrm{p}=$ 0.031 ) and at $28{ }^{\circ} \mathrm{C}$ compared to $26^{\circ} \mathrm{C}$ ( $\mathrm{p}=0.003$; Fig. 2.2; Table A2.5b). Total carotenoids in $N$. chaliniformis were significantly influenced by temperature $\left(\right.$ Pseudo- $\left.\mathrm{F}_{(2,47)}=11.677, \mathrm{p}=0.001\right)$, nitrate $\left(\right.$ Pseudo- $\left.\mathrm{F}_{(2,47)}=8.061, \mathrm{p}=0.002\right)$ and the interaction of both stressors $\left(\right.$ Pseudo- $\mathrm{F}_{(4,47)}=$ 14.687, $\mathrm{p}=0.001$; Fig 2.2; Table A2.5a), indicating that the effect of temperature varied with nitrate concentration. Significant declines were seen at $30{ }^{\circ} \mathrm{C}$ compared to $26^{\circ} \mathrm{C}$ at all nitrate levels ( $\mathrm{p}<0.05$ ) and at $10.9 \mu \mathrm{M}$ nitrate and $19.8 \mu \mathrm{M}$ nitrate, total carotenoids were significantly lower at $28{ }^{\circ} \mathrm{C}$ compared to $26^{\circ} \mathrm{C}(\mathrm{p}=0.003$ and 0.016 , respectively; Table A2.5b).

For Spheciospongia vagabunda, Chl a concentration was significantly affected by temperature (Pseudo- $\left.\mathrm{F}_{(2,37)}=11.104, \mathrm{p}=0.001\right)$, nitrate $\left(\right.$ Pseudo- $\left.\mathrm{F}_{(2,37)}=9.104, \mathrm{p}=0.001\right)$, and the interaction of both factors (Pseudo- $\mathrm{F}_{(4,37)}=11.664, \mathrm{p}=0.001$; Table A2.5a), with nitrate levels causing some variations in the effect of temperature. At $7.5 \mu \mathrm{M}$ nitrate, $\mathrm{Chl} a$ concentration was significantly lower at $30{ }^{\circ} \mathrm{C}$ compared to $28^{\circ} \mathrm{C}(\mathrm{p}=0.028)$ and $26^{\circ} \mathrm{C}(\mathrm{p}=0.039)$ and at $28{ }^{\circ} \mathrm{C}$ compared to 26 ${ }^{\circ} \mathrm{C}(\mathrm{p}=0.019)$. At $19.8 \mu \mathrm{M}$ nitrate, $\mathrm{Chl} a$ concentration significantly declined at $30{ }^{\circ} \mathrm{C}$ compared to $28{ }^{\circ} \mathrm{C}(\mathrm{p}=0.028)$ and $26{ }^{\circ} \mathrm{C}(\mathrm{p}=0.029$; Fig. 2.2; Table A2.5d). Chl $b$ concentration in $S$. vagabunda was significantly affected by temperature $\left(\right.$ Pseudo- $\left.\mathrm{F}_{(2,37)}=2.491, \mathrm{p}=0.047\right)$ and the interaction of temperature and nitrate $\left(\right.$ Pseudo- $\mathrm{F}_{(4,37)}=3.464, \mathrm{p}=0.002$; Table A2.5a) only. At $19.8 \mu \mathrm{M}$ nitrate, $\mathrm{Chl} b$ concentration was significantly lower at $30{ }^{\circ} \mathrm{C}$ than $28{ }^{\circ} \mathrm{C}(\mathrm{p}=0.035)$ and $26{ }^{\circ} \mathrm{C}\left(\mathrm{p}=0.031\right.$;). A significant decrease was also seen at $28{ }^{\circ} \mathrm{C}$ compared to $26{ }^{\circ} \mathrm{C}$ at $19.8 \mu \mathrm{M}$ nitrate $\left(\mathrm{p}=0.015\right.$; Fig. 2.2; Table A2.5d). Temperature $\left(\right.$ Pseudo- $\left.\mathrm{F}_{(2,37)}=18.65, \mathrm{p}=0.001\right)$, nitrate $\left(\right.$ Pseudo- $\left.\mathrm{F}_{(2,37)}=6.37, \mathrm{p}=0.002\right)$ and the interaction of both stressors (Pseudo- $\mathrm{F}_{(4,37)}=14.692, \mathrm{p}=$ 0.001; Table A2.5a) significantly affected total carotenoids of $S$. vagabunda. At $7.5 \mu \mathrm{M}$ nitrate total carotenoids were significantly lower at $30{ }^{\circ} \mathrm{C}$ compared to $28{ }^{\circ} \mathrm{C}(\mathrm{p}=0.028)$ and at $28{ }^{\circ} \mathrm{C}$ compared to $26{ }^{\circ} \mathrm{C}(\mathrm{p}=0.004)$. At $19.8 \mu \mathrm{M}$ nitrate, total carotenoids were significantly lower at $30{ }^{\circ} \mathrm{C}$ than at $28{ }^{\circ} \mathrm{C}$ and $26{ }^{\circ} \mathrm{C}(\mathrm{p}=0.027$ and 0.029 , respectively; Fig. 2.2; Table S5d). No 
significant changes in pigment concentration were seen in A. navalis at T-end (Fig. 2.2; Table A2.5a).

Neopetrosia chaliniformis
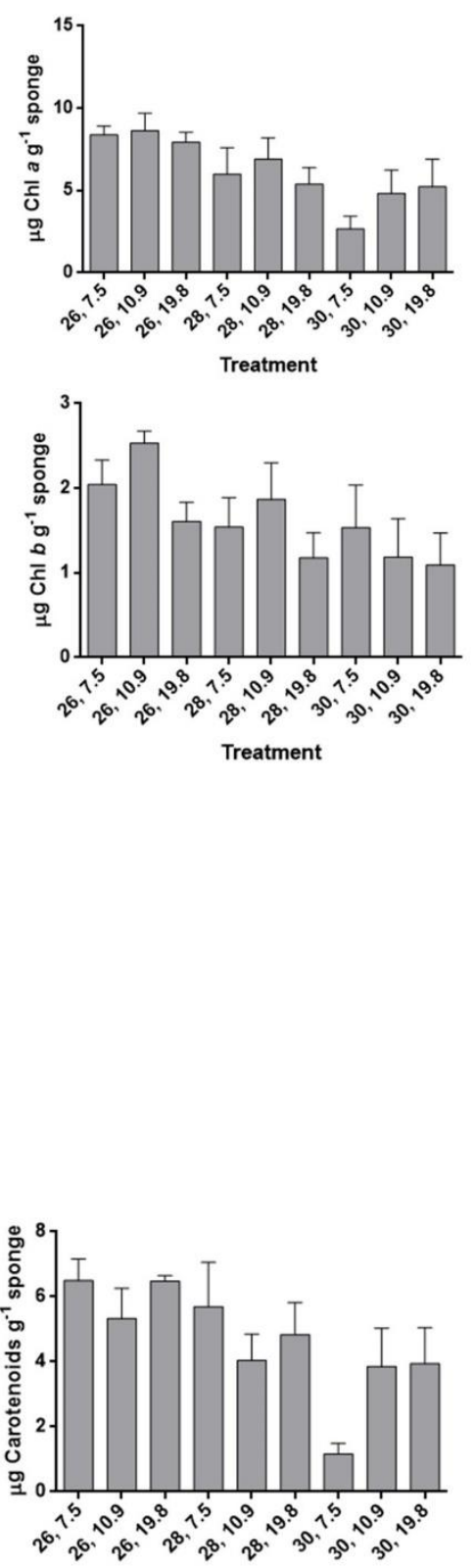

Treatment
Amphimedon navalis
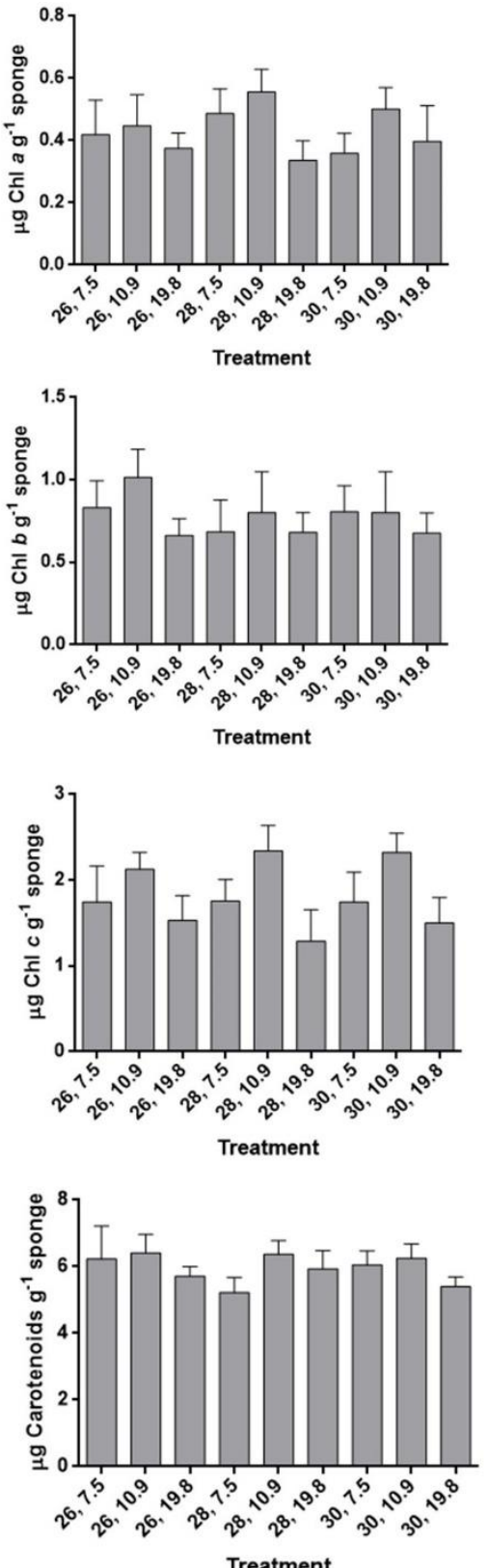

Spheciospongia vagabunda
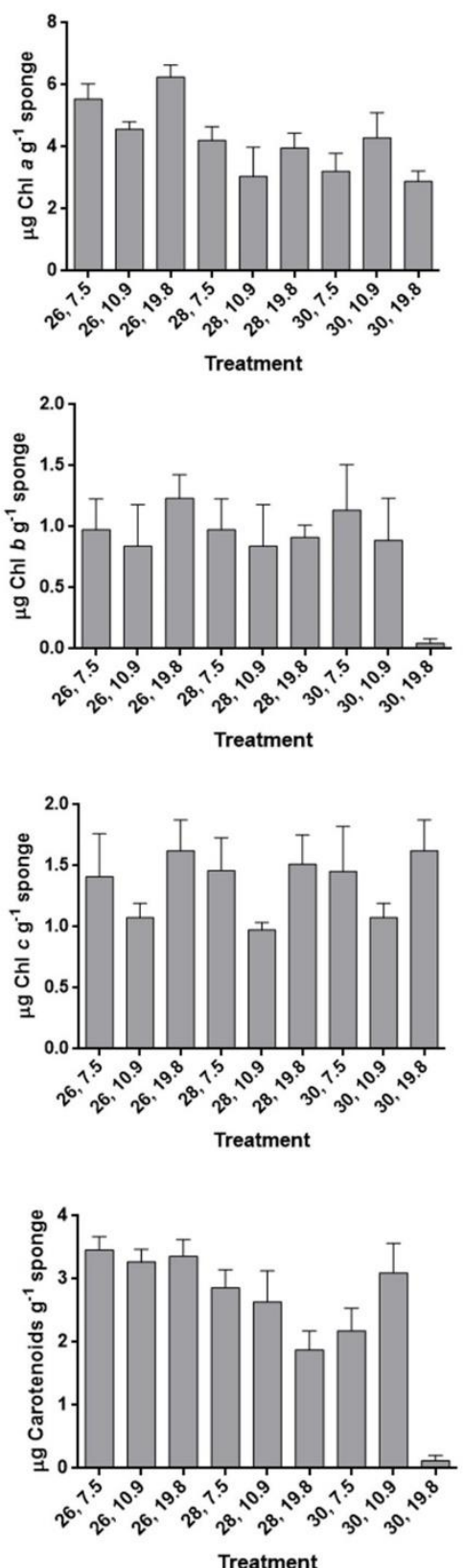

Fig. 2.2 Photosynthetic pigment concentration of Neopetrosia chaliniformis, Amphimedon navalis and Spheciospongia vagabunda in each treatment at T-end. (Note: Absence of detectable chlorophyll $c$ in $N$. chaliniformis). Values are mean $\mu$ g pigment per gram of sponge wet weight \pm SE. 


\subsubsection{Change in buoyant weight}

The buoyant weight of $N$. chaliniformis was significantly affected by temperature $\left(\mathrm{F}_{(2,45)}=29.162\right.$, $\mathrm{p}<0.001)$ and nitrate $\left(\mathrm{F}_{(2,45)}=3.446, \mathrm{p}=0.034\right.$; Fig. 2.3A; Table 2.3). Significant declines in buoyant weight were seen at $7.5 \mu \mathrm{M}$ nitrate $(\mathrm{p}<0.001)$ and $19.8 \mu \mathrm{M}$ nitrate $(\mathrm{p}<0.001)$ between $30{ }^{\circ} \mathrm{C}$ and $28^{\circ} \mathrm{C}$, and significant decreases were also seen at $10.9 \mu \mathrm{M}$ nitrate $(\mathrm{p}<0.001)$ and 19.8 $\mu \mathrm{M}$ nitrate $(\mathrm{p}<0.001)$ between $28^{\circ} \mathrm{C}$ and $26^{\circ} \mathrm{C}$. Buoyant weight also significantly decreased at $30{ }^{\circ} \mathrm{C}$ compared to $26^{\circ} \mathrm{C}$ at all nitrate levels ( $\mathrm{p}<0.001$; Table A2.6a).

For A. navalis, buoyant weight was significantly affected by temperature $\left(\mathrm{F}_{(2,44)}=16.224, \mathrm{p}<\right.$ $0.001)$, nitrate $\left(\mathrm{F}_{(2,44)}=10.626, \mathrm{p}<0.001\right)$ and the interaction of both stressors $\left(\mathrm{F}_{(4,45)}=2.819, \mathrm{p}=\right.$ 0.036; Fig. 2.3B; Table 2.3). At the end of the experiment, buoyant weight had significantly declined at $28^{\circ} \mathrm{C}$ relative to $26^{\circ} \mathrm{C}$ at $10.9 \mu \mathrm{M}$ nitrate $(\mathrm{p}<0.001)$ and $19.8 \mu \mathrm{M}$ nitrate $(\mathrm{p}<0.001)$. Buoyant weight was also significantly lower at $30{ }^{\circ} \mathrm{C}$ than $26{ }^{\circ} \mathrm{C}$ at all nitrate levels $(\mathrm{p}<0.001$; Table A2.6a).

Buoyant weight of $S$. vagabunda was significantly influenced by temperature $\left(\mathrm{F}_{(2,47)}=14.561, \mathrm{p}\right.$ $<0.001)$, nitrate $\left(\mathrm{F}_{(2,47)}=7.473, \mathrm{p}=0.002\right)$ and the interaction between the two stressors $\left(\mathrm{F}_{(3,47)}=\right.$ 9.260, p < 0.001; Fig. 2.3C; Table 2.3), indicating that the effect of temperature was dependent on time and nitrate levels. At $7.5 \mu \mathrm{M}$ nitrate, buoyant weight significantly declined at $30{ }^{\circ} \mathrm{C}$ relative to $28^{\circ} \mathrm{C}(\mathrm{p}=0.005)$ and $26^{\circ} \mathrm{C}(\mathrm{p}<0.001)$. A significant decline in $S$. vagabunda buoyant weight was also observed at $28{ }^{\circ} \mathrm{C}$ compared to $26^{\circ} \mathrm{C}$ at all nitrate levels ( $<<0.05$; Table A2.6a). 

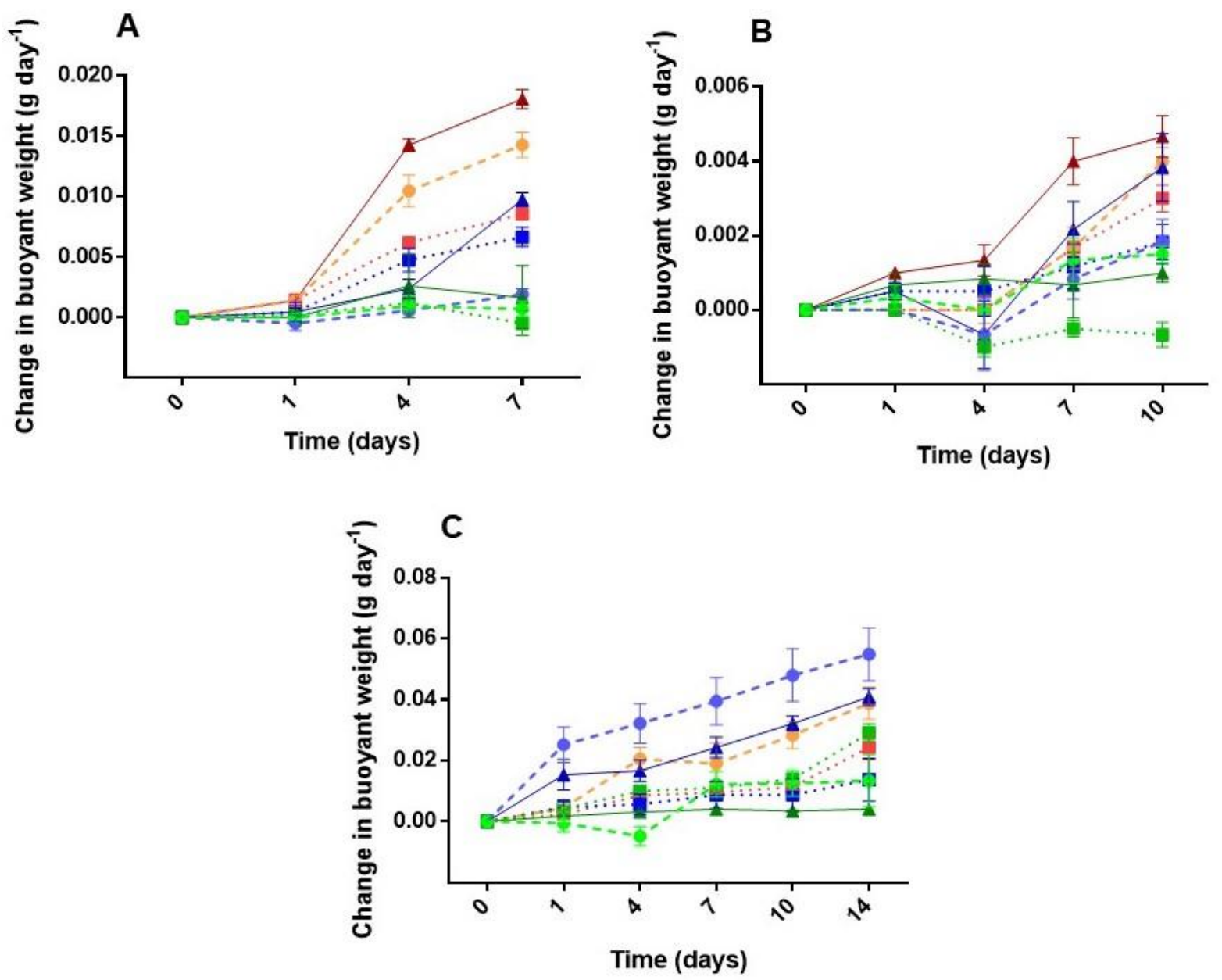

Fig. 2.3 Change in buoyant weight of A) Neopetrosia chaliniformis, B) Amphimedon navalis and C) Spheciospongia vagabunda in each treatment over time. $26^{\circ} \mathrm{C} / 7.5 \mu \mathrm{M}$ nitrate, $\square 26^{\circ} \mathrm{C} / 10.9$ $\mu \mathrm{M}$ nitrate, $\Delta 26{ }^{\circ} \mathrm{C} / 19.8 \mu \mathrm{M}$ nitrate, ${ }^{\circ} 28{ }^{\circ} \mathrm{C} / 7.5 \mu \mathrm{M}$ nitrate, $\boldsymbol{\nabla} 28{ }^{\circ} \mathrm{C} / 10.9 \mu \mathrm{M}$ nitrate, $\boldsymbol{\Delta} 28{ }^{\circ} \mathrm{C} /$ $19.8 \mu \mathrm{M}$ nitrate, $\odot 30{ }^{\circ} \mathrm{C} / 7.5 \mu \mathrm{M}$ nitrate, $\square 30^{\circ} \mathrm{C} / 10.9 \mu \mathrm{M}$ nitrate, $\Delta 30^{\circ} \mathrm{C} / 19.8 \mu \mathrm{M}$ nitrate. Values are mean per treatment $\pm S E$ at each time point. $(n=6$ per treatment at each time point excluding mortalities). Note: scales on the y-axes differ between species.

\subsubsection{Effective quantum yield}

$\Delta \mathrm{F} / \mathrm{F}_{\mathrm{m}}$ ' of $N$. chaliniformis was significantly affected by temperature only $\left(\mathrm{F}_{(2,45)}=78.084, \mathrm{p}<\right.$ 0.001; Fig. 2.4A; Table 2.3). N. chaliniformis $\Delta \mathrm{F} / \mathrm{F}_{\mathrm{m}}$ ' significantly declined at $30{ }^{\circ} \mathrm{C}$ compared to $28^{\circ} \mathrm{C}(\mathrm{p}<0.05)$ and $26^{\circ} \mathrm{C}(\mathrm{p}<0.05)$ at all nitrate levels. At $\mathrm{T}$-end, a significant decrease in $\Delta \mathrm{F} / \mathrm{F}_{\mathrm{m}}{ }^{\prime}$ was also seen at $28{ }^{\circ} \mathrm{C}$ compared to $26^{\circ} \mathrm{C}$ at all nitrate levels ( $\mathrm{p}<0.05$; Table A2.6b). 
For $S$. vagabunda, $\Delta \mathrm{F} / \mathrm{F}_{\mathrm{m}}$ ' declined significantly with increasing temperature only $\left(\mathrm{F}_{(2,47)}=\right.$ 204.043, p < 0.001; Fig. 2.4B; Table 2.3). Significant declines in $\Delta F / F_{m}$ ' were seen at $30^{\circ} \mathrm{C}$ relative to $28^{\circ} \mathrm{C}$ and $26^{\circ} \mathrm{C}$ when exposed to both $7.5 \mu \mathrm{M}$ nitrate ( $\mathrm{p}<0.001$ for both comparisons) and 10.9 $\mu \mathrm{M}$ nitrate ( $\mathrm{p}<0.001$ for both comparisons). At $10.9 \mu \mathrm{M}$ nitrate and $19.8 \mu \mathrm{M}$ nitrate, $\Delta \mathrm{F} / \mathrm{F}_{\mathrm{m}}{ }^{\prime}$ significantly declined between $28^{\circ} \mathrm{C}$ and $26^{\circ} \mathrm{C}(\mathrm{p}=0.007$ and $<0.001$, respectively; Table A2.6b). Due to the low concentration of $\mathrm{Chl} a$ in A. navalis, $\Delta \mathrm{F} / \mathrm{F}_{\mathrm{m}}$ ' of this species was not be determined.
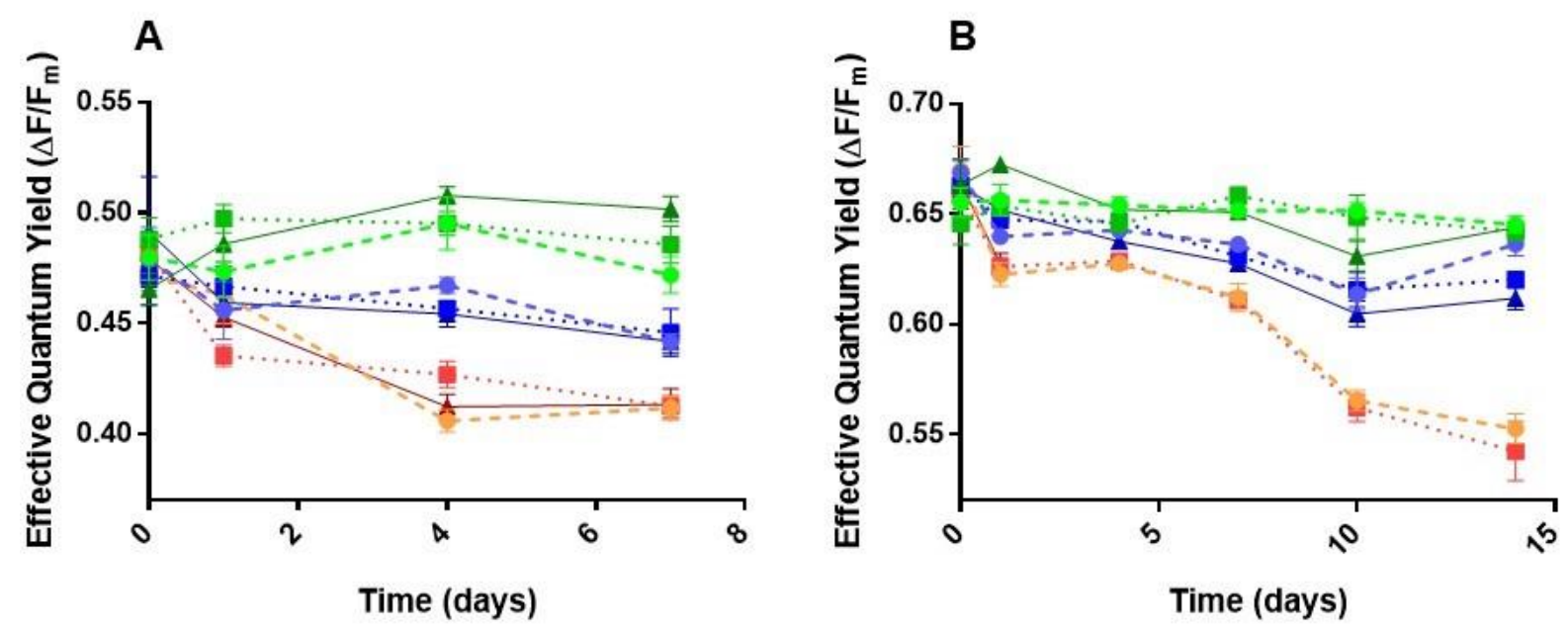

Fig. 2.4 Effective quantum yield of A) Neopetrosia chaliniformis and B) Spheciospongia vagabunda in each treatment over time. $\quad 26{ }^{\circ} \mathrm{C} / 7.5 \mu \mathrm{M}$ nitrate, $\square 26^{\circ} \mathrm{C} / 10.9 \mu \mathrm{M}$ nitrate, $\Delta 26$ ${ }^{\circ} \mathrm{C} / 19.8 \mu \mathrm{M}$ nitrate, $\odot 28{ }^{\circ} \mathrm{C} / 7.5 \mu \mathrm{M}$ nitrate, $\square 28{ }^{\circ} \mathrm{C} / 10.9 \mu \mathrm{M}$ nitrate, $\Delta 28^{\circ} \mathrm{C} / 19.8 \mu \mathrm{M}$ nitrate, - $30{ }^{\circ} \mathrm{C} / 7.5 \mu \mathrm{M}$ nitrate, $\square 30{ }^{\circ} \mathrm{C} / 10.9 \mu \mathrm{M}$ nitrate, $\Delta 30{ }^{\circ} \mathrm{C} / 19.8 \mu \mathrm{M}$ nitrate. Values are mean per treatment $\pm \mathrm{SE}$ at each time point. ( $\mathrm{n}=6$ per treatment at each time point excluding mortalities). Note: scales on the y-axes differ between species.

\subsubsection{Gross photosynthesis}

The gross photosynthetic rate of $N$. chaliniformis was significantly affected by temperature only $\left(\mathrm{F}_{(2,45)}=5.124, \mathrm{p}=0.031\right.$; Fig. 2.5A; Table 2.3). At $19.8 \mu \mathrm{M}$ nitrate, gross photosynthesis significantly decreased at $30{ }^{\circ} \mathrm{C}$ compared to $28{ }^{\circ} \mathrm{C}(\mathrm{p}=0.009)$ and $26{ }^{\circ} \mathrm{C}(\mathrm{p}=0.026$; Table A2.6c).

For $S$. vagabunda, gross photosynthetic rate decreased significantly with increasing temperature only $\left(\mathrm{F}_{(2,47)}=24.998, \mathrm{p}<0.001\right.$; Fig. $2.5 \mathrm{~B}$; Table 2.3$)$. At $7.5 \mu \mathrm{M}$ nitrate, gross photosynthetic rate was significantly lower at $30^{\circ} \mathrm{C}$ than $28^{\circ} \mathrm{C}(\mathrm{p}=0.004)$. Gross photosynthetic rate also significantly decreased at $30{ }^{\circ} \mathrm{C}$ compared to $28^{\circ} \mathrm{C}$ at $7.5 \mu \mathrm{M}$ nitrate $(\mathrm{p}=0.004)$ and $10.9 \mu \mathrm{M}$ nitrate $(\mathrm{p}<0.001)$. 
Gross photosynthetic rate was also significantly lower at $28{ }^{\circ} \mathrm{C}$ than $26{ }^{\circ} \mathrm{C}$ at $19.8 \mu \mathrm{M}$ nitrate $(\mathrm{p}=$ 0.002; Table A2.6c).
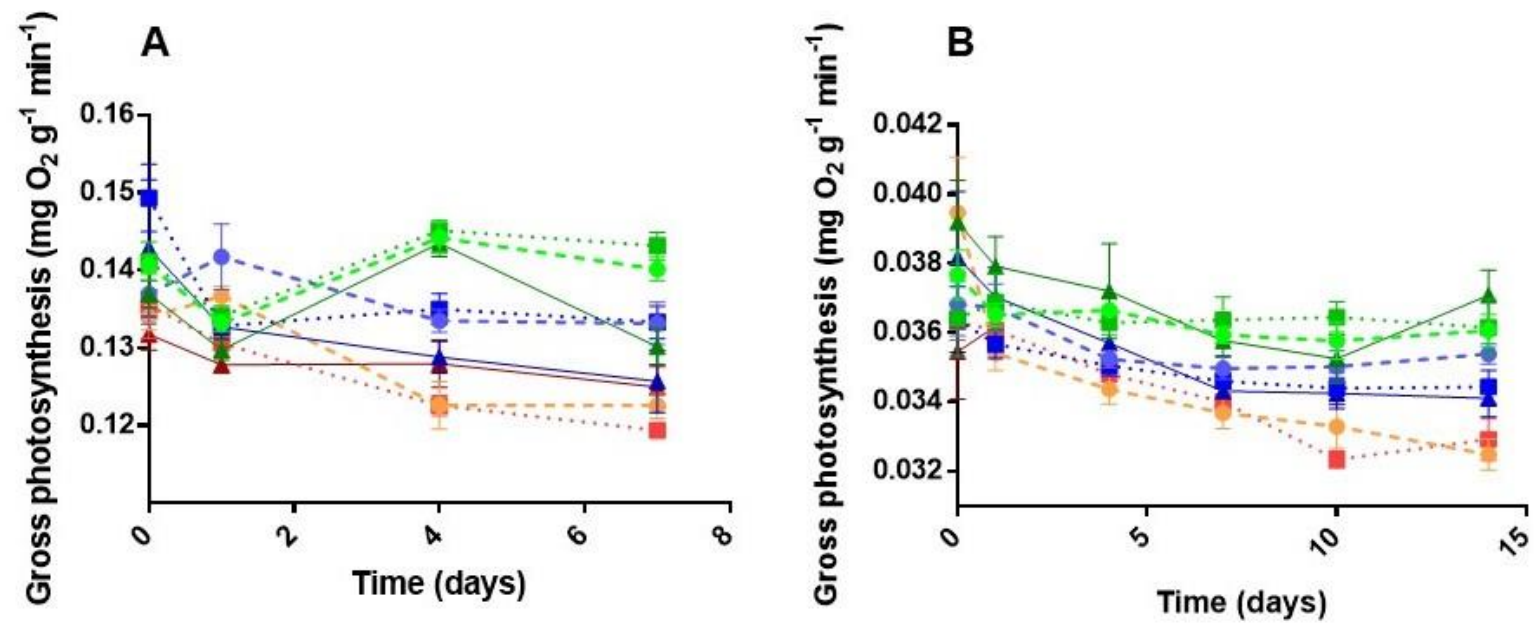

Fig. 2.5 Rates of gross photosynthesis of A) Neopetrosia chaliniformis and B) Spheciospongia vagabunda in each treatment over time. $\odot 26^{\circ} \mathrm{C} / 7.5 \mu \mathrm{M}$ nitrate, $-26{ }^{\circ} \mathrm{C} / 10.9 \mu \mathrm{M}$ nitrate, $\Delta 26{ }^{\circ} \mathrm{C} /$ $19.8 \mu \mathrm{M}$ nitrate, $\odot 28^{\circ} \mathrm{C} / 7.5 \mu \mathrm{M}$ nitrate, $\boldsymbol{\nabla} 28^{\circ} \mathrm{C} / 10.9 \mu \mathrm{M}$ nitrate, $\boldsymbol{\Delta} 28{ }^{\circ} \mathrm{C} / 19.8 \mu \mathrm{M}$ nitrate, $\diamond 30$ ${ }^{\circ} \mathrm{C} / 7.5 \mu \mathrm{M}$ nitrate, $\square 30{ }^{\circ} \mathrm{C} / 10.9 \mu \mathrm{M}$ nitrate, $\Delta 30{ }^{\circ} \mathrm{C} / 19.8 \mu \mathrm{M}$ nitrate. Values are mean per treatment $\pm \mathrm{SE}$ at each time point. ( $\mathrm{n}=6$ per treatment at each time point excluding mortalities). Note: scales on the y-axes differ between species. Values are mean per gram of sponge ash free weight \pm SE .

\subsubsection{Dark Respiration}

The respiration rate of $N$. chaliniformis increased significantly with increasing temperature $\left(\mathrm{F}_{(2,45)}\right.$ $=25.651, \mathrm{p}<0.001$; Fig. 2.6A; Table 2.3). Respiration rate was significantly higher at $30{ }^{\circ} \mathrm{C}$ than $26{ }^{\circ} \mathrm{C}$ at all nitrate levels $(\mathrm{p}<0.05)$ and $28^{\circ} \mathrm{C}$ at $7.5 \mu \mathrm{M}$ nitrate $(\mathrm{p}=0.033)$ and $10.9 \mu \mathrm{M}$ nitrate $(\mathrm{p}$ $=0.045)$. Significant increases were also observed at $28{ }^{\circ} \mathrm{C}$ compared to $26^{\circ} \mathrm{C}$ at $10.9 \mu \mathrm{M}$ nitrate $(\mathrm{p}=0.002)$ and $19.8 \mu \mathrm{M}$ nitrate $(\mathrm{p}<0.001 ;$ Table A2.6d).

A. navalis' respiration rate was significantly affected by temperature $\left(\mathrm{F}_{(2,44)}=15.543, \mathrm{p}=0.001\right)$; Fig. 2.6B; Table 2.3). Respiration rate was significantly higher at $28{ }^{\circ} \mathrm{C}$ than $26{ }^{\circ} \mathrm{C}$ in both the 10.9 $\mu \mathrm{M}$ nitrate and $19.8 \mu \mathrm{M}$ nitrate treatments $(\mathrm{p}=0.001$ and 0.009$)$. A similar trend was observed at $30{ }^{\circ} \mathrm{C}$ compared to $26{ }^{\circ} \mathrm{C}$ in both the $10.9 \mu \mathrm{M}$ nitrate $(\mathrm{p}<0.001)$ and $19.8 \mu \mathrm{M}$ nitrate $(\mathrm{p}=0.002$; Table A2.6d) treatments. 
S. vagabunda's respiration rate significantly increased with increasing temperature only $\left(\mathrm{F}_{(2,47)}=\right.$ 61.453, p < 0.001; Fig. 2.6C; Table 2.3). Respiration rate was significantly higher at $30^{\circ} \mathrm{C}$ than 28 ${ }^{\circ} \mathrm{C}$ for the two lower nitrate treatments $(7.5 \mu \mathrm{M}, \mathrm{p}=0.004$ and $10.9 \mu \mathrm{M}, \mathrm{p}=0.007)$ and $26{ }^{\circ} \mathrm{C}$ for these same treatments $(7.5 \mu \mathrm{M}, \mathrm{p}<0.001$ and $10.9 \mu \mathrm{M}, \mathrm{p}<0.001)$. At T-end, respiration rate was also significantly higher at $28{ }^{\circ} \mathrm{C}$ than $26^{\circ} \mathrm{C}$ at all nitrate levels ( $\mathrm{p}<0.05$; Table $\left.\mathrm{A} 2.6 \mathrm{~d}\right)$.
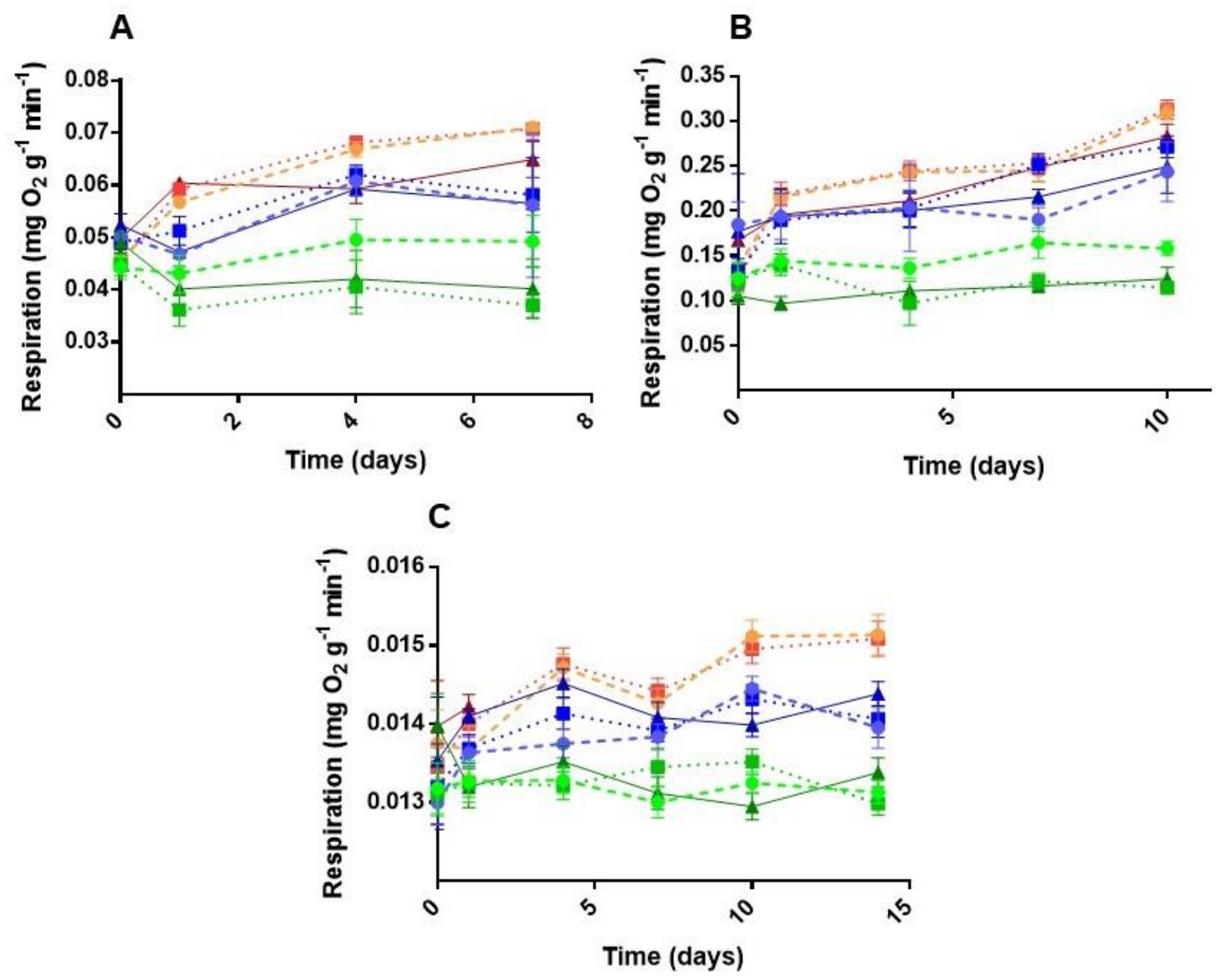

Fig. 2.6 Rates of respiration of A) Neopetrosia chaliniformis, B) Amphimedon navalis and C) Spheciospongia vagabunda in each treatment over time. $226^{\circ} \mathrm{C} / 7.5 \mu \mathrm{M}$ nitrate, $\square 26^{\circ} \mathrm{C} / 10.9 \mu \mathrm{M}$ nitrate, $\Delta 26^{\circ} \mathrm{C} / 19.8 \mu \mathrm{M}$ nitrate, $\bullet 28^{\circ} \mathrm{C} / 7.5 \mu \mathrm{M}$ nitrate, $\sim 28^{\circ} \mathrm{C} / 10.9 \mu \mathrm{M}$ nitrate, $\Delta 28^{\circ} \mathrm{C} / 19.8$ $\mu \mathrm{M}$ nitrate, $\diamond 30{ }^{\circ} \mathrm{C} / 7.5 \mu \mathrm{M}$ nitrate, $\square 30{ }^{\circ} \mathrm{C} / 10.9 \mu \mathrm{M}$ nitrate, $\Delta 30{ }^{\circ} \mathrm{C} / 19.8 \mu \mathrm{M}$ nitrate. Values are mean per treatment \pm SE at each time point. $(n=6$ per treatment at each time point excluding mortalities). Note: scales on the y-axes differ between species. Values are mean per gram of sponge ash free weight \pm SE. 


\subsection{8 $\mathrm{P}: \mathrm{R}$ ratio}

The P:R ratio of $N$. chaliniformis was significantly affected by temperature $\left(\mathrm{F}_{(2,45)}=27.669, \mathrm{p}<\right.$ 0.001; Fig. 2.7A; Table 2.3). At T- end, the P:R ratio of $N$. chaliniformis was $1.40-1.70$ at $26^{\circ} \mathrm{C}$, 1.08-1.40 at $28{ }^{\circ} \mathrm{C}$ and $0.95-1.04$ at $30{ }^{\circ} \mathrm{C}$ irrespective of nitrate concentration. The P:R ratio was significantly lower at $30{ }^{\circ} \mathrm{C}$ than $26^{\circ} \mathrm{C}$ at all nitrate levels ( $<<0.05$ ). At $7.5 \mu \mathrm{M}$ nitrate and 19.8 $\mu \mathrm{M}$ nitrate, the $\mathrm{P}: \mathrm{R}$ ratio was also significantly lower at $30{ }^{\circ} \mathrm{C}$ than $28{ }^{\circ} \mathrm{C}(\mathrm{p}=0.003$ and 0.025 , respectively). $N$. chaliniformis $\mathrm{P}: \mathrm{R}$ ratio also significantly declined at $28{ }^{\circ} \mathrm{C}$ relative to $26{ }^{\circ} \mathrm{C}$ at $10.9 \mu \mathrm{M}$ nitrate $(\mathrm{p}=0.001$; Table A2.6e).

The P:R ratio of $S$. vagabunda was significantly influenced by temperature only $\left(\mathrm{F}_{(2,47)}=11.642\right.$, $\mathrm{p}<0.001$; Fig. 2.7B; Table 2.3). At T-end, the P:R ratio of $S$. vagabunda ranged between 1.371.39 at $26{ }^{\circ} \mathrm{C}, 1.19-1.27$ at $28{ }^{\circ} \mathrm{C}$ and remained under 1.09 at $30{ }^{\circ} \mathrm{C}$ irrespective of nitrate concentration. At T-end, the P:R ratio was significantly lower at $28{ }^{\circ} \mathrm{C}$ than $26{ }^{\circ} \mathrm{C}$ at all nitrate levels ( $p<0.05$; Table S4n). The P:R ratio for this species was also significantly lower at $30{ }^{\circ} \mathrm{C}$ than at both $28{ }^{\circ} \mathrm{C}$ and $26{ }^{\circ} \mathrm{C}$ at all nitrate levels ( $p<0.05$; Table A2.6e).
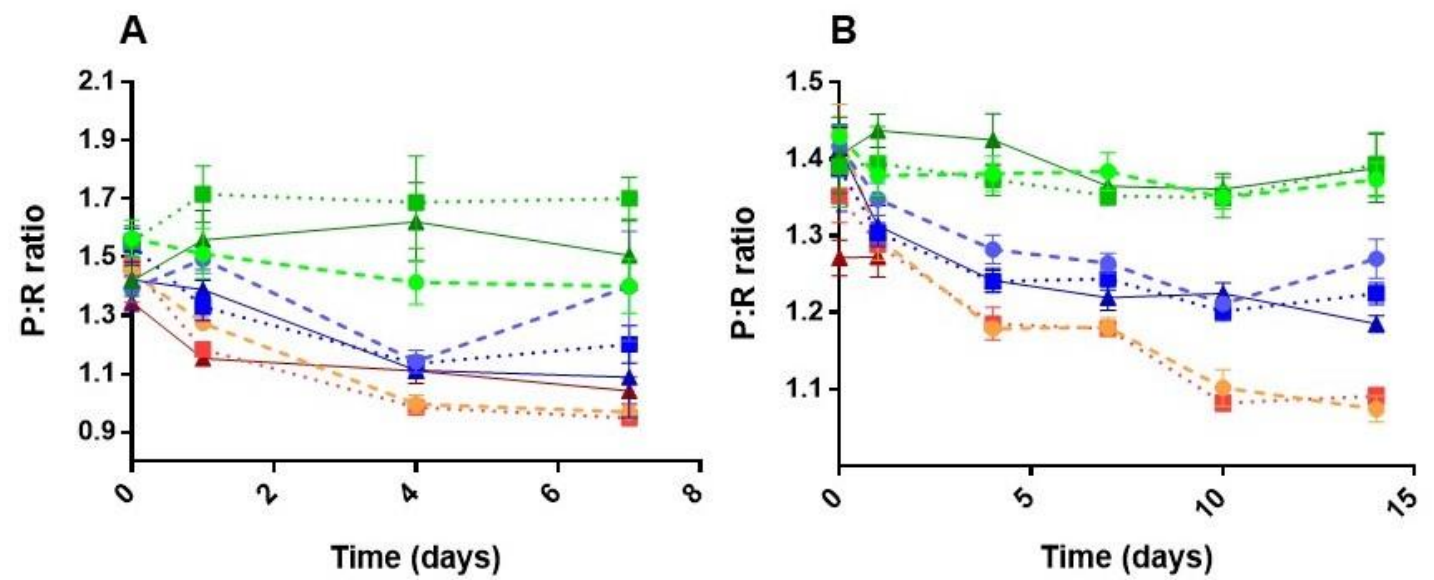

Fig. 2.7 P:R ratios of A) Neopetrosia chaliniformis and B) Spheciospongia vagabunda in each treatment over time. $.26{ }^{\circ} \mathrm{C} / 7.5 \mu \mathrm{M}$ nitrate, $\| 26^{\circ} \mathrm{C} / 10.9 \mu \mathrm{M}$ nitrate, $\Delta 26^{\circ} \mathrm{C} / 19.8 \mu \mathrm{M}$ nitrate, $-28{ }^{\circ} \mathrm{C} / 7.5 \mu \mathrm{M}$ nitrate, $\boldsymbol{\square} 28^{\circ} \mathrm{C} / 10.9 \mu \mathrm{M}$ nitrate, $\Delta 28^{\circ} \mathrm{C} / 19.8 \mu \mathrm{M}$ nitrate, $\odot 30^{\circ} \mathrm{C} / 7.5 \mu \mathrm{M}$ nitrate, $=30^{\circ} \mathrm{C} / 10.9 \mu \mathrm{M}$ nitrate, $\Delta 30^{\circ} \mathrm{C} / 19.8 \mu \mathrm{M}$ nitrate. Values are mean per treatment $\pm \mathrm{SE}$ at each time point. ( $\mathrm{n}=6$ per treatment at each time point excluding mortalities). Note: scales on the y-axes differ between species. Values are mean per gram of sponge ash free weight \pm SE. 
Table 2.3 Summary of general linear mixed models (GLMM) for the effects of temperature, nitrate and their combined effects on the change in buoyant weight, $\Delta \mathrm{F} / \mathrm{F}_{\mathrm{m}}$, gross photosynthetic and respiration rates and P:R ratio of Neopetrosia chaliniformis, Amphimedon navalis and Spheciospongia vagabunda. Significant values are shown in bold.

\begin{tabular}{|c|c|c|c|c|c|}
\hline \multirow[t]{2}{*}{ Fixed Effects } & \multicolumn{5}{|c|}{ Responses } \\
\hline & $\begin{array}{c}\text { Buoyant } \\
\text { weight (g) }\end{array}$ & $\Delta \mathbf{F} / \mathbf{F}_{\mathbf{m}}$, & $\begin{array}{l}\text { Gross photosynthesis } \\
\left(\mathrm{mg} \mathrm{O}_{2} \mathrm{~g}^{-1} \mathrm{~min}^{-1}\right)\end{array}$ & $\begin{array}{l}\text { Respiration (mg } \\
\left.\mathrm{O}_{2} \mathrm{~g}^{-1} \mathrm{~min}^{-1}\right) \\
\end{array}$ & $\begin{array}{l}P: R \\
\text { ratio }\end{array}$ \\
\hline \multicolumn{6}{|c|}{ Neopetrosia chaliniformis } \\
\hline Temp & $<0.001$ & $<0.001$ & $\mathbf{0 . 0 3 1}$ & $<0.001$ & $<0.001$ \\
\hline Nitrate & $\mathbf{0 . 0 3 4}$ & 0.514 & 0.477 & 0.832 & 0.610 \\
\hline Temp * Nitrate & 0.064 & 0.714 & 0.755 & 0.537 & 0.438 \\
\hline \multicolumn{6}{|c|}{ Amphimedon navalis } \\
\hline Temp & $<0.001$ & - & - & $<0.001$ & - \\
\hline Nitrate & $<0.001$ & - & - & 0.612 & - \\
\hline Temp * Nitrate & 0.036 & - & - & 0.737 & - \\
\hline \multicolumn{6}{|c|}{ Spheciospongia vagabunda } \\
\hline Temp & $<0.001$ & $<0.001$ & $<0.001$ & 0.001 & $<0.001$ \\
\hline Nitrate & 0.002 & 0.163 & 0.054 & 0.123 & 0.108 \\
\hline Temp * Nitrate & $<0.001$ & 0.327 & 0.525 & 0.896 & 0.176 \\
\hline
\end{tabular}

\subsection{Discussion}

This chapter explores the short-term responses of three lagoon sponge species exposed to the combined effects of elevated temperature and nitrate concentration. Manipulative experiments demonstrate that lagoon sponges are directly influenced by elevated seawater temperature, but not by elevated nitrate (except for buoyant weight). The combined effect of temperature/nitrate resulted in a decline in photosynthetic pigments ( $\mathrm{Chl} a$ and $\mathrm{Chl} b$ ) in Neopetrosia chaliniformis and Spheciospongia vagabunda; in contrast, no significant decline in pigment concentration was reported for Amphimedon navalis. All species experienced a significant loss in buoyant weight in response to elevated temperature. The $\Delta \mathrm{F} / \mathrm{F}_{\mathrm{m}}$ ' of PSII, gross photosynthetic rate and P:R ratio of $N$. chaliniformis and $S$. vagabunda exposed to $28{ }^{\circ} \mathrm{C}$ and $30^{\circ} \mathrm{C}$ declined significantly compared to the controls. Significant increases in respiration rate were also observed for all species at elevated temperature. However, excess nitrate generally had little impact on the sponges, indicating that elevated nutrients may not be harmful to lagoon sponges as compared to elevated temperature. 


\subsubsection{Impacts on sponge health}

Photosynthetic pigments in sponges are generally associated with photosymbionts (Wilkinson, 1978; Thacker \& Freeman, 2012); Chl $a$-containing photosymbionts are sometimes major constituents of the sponge-bacterial biomass (Thacker \& Freeman, 2012). Here, an increase in temperature of $2-4{ }^{\circ} \mathrm{C}$ and its interaction with nitrate caused a significant decline in photosynthetic pigments (except for Chl $c$ ) in $N$. chaliniformis and S. vagabunda. Wilkinson (1983) suggested that a decline in sponge-associated photosynthetic pigments (most specifically $\mathrm{Chl} a$ ) correlates with reduced photosynthetic functioning of associated photosymbionts, potentially resulting in reduced energetic resources for the sponge host. For example, in the Mediterranean, a breakdown in the sponge-cyanobacterial symbiosis of Ircinia fasciculata resulted in massive die-offs as a result of thermal exposure in the summer (Cebrian et al., 2011). In this chapter, the decline in $\Delta \mathrm{F} / \mathrm{F}_{\mathrm{m}}$ ' (by approximately $15 \%$ ) observed by the end of the experiment for $N$. chaliniformis and $S$. vagabunda supports earlier studies showing reduced functioning of the PSII reaction center in the chloroplasts of sponge-associated photosymbionts at elevated temperatures (Bennett et al., 2017; Ramsby et al., 2018). Some sponges have the ability to photoacclimate when transferred to lowlight from high-light conditions (Beer \& Ilan, 1998; Biggerstaff et al., 2015). While partial decline in $\Delta \mathrm{F} / \mathrm{F}_{\mathrm{m}}$ ' observed here might be attributed to potential photoacclimation in response to the treatment conditions when $N$. chaliniformis and $S$. vagabunda were brought to the laboratory, the results here suggest that the declines in photosynthetic pigments observed in these two species are likely associated with photosynthetic dysfunction of the associated phototrophic prokaryotic and eukaryotic microbes. This is because, in addition to declines in $\Delta \mathrm{F} / \mathrm{F}_{\mathrm{m}}$, significant declines in Chl $a$, Chl $b$ and total carotenoid concentrations as well as significant declines in buoyant weight in both $N$. chaliniformis and S. vagabunda were also noted.

The impacts of elevated temperature on sponge photosynthetic symbionts are usually speciesspecific (Miller et al., 2010; Pita et al., 2013; Bennett et al., 2018; Ramsby et al., 2018). For example, while no significant loss of pigment was reported in thermally-stressed Cliona celata (Miller et al., 2010) and I. fasciculata (Pita et al., 2013), a 35\% decline in Chl a concentration was observed when the sponge Cliona orientalis was exposed to a $3{ }^{\circ} \mathrm{C}$ thermal stress (Ramsby et al., 2018). Chl $a$ concentration in the reef sponges Carteriospongia foliascens and Cymbastela 
coralliophila also declined when they were exposed to an increase in temperature of $4^{\circ} \mathrm{C}$ and reduced $\mathrm{pH}$ of 7.1 (Bennett et al., 2018).

In contrast, excess nutrients including nitrate are generally thought to have little impact on spongeassociated Chl $a$ concentration (Roberts et al., 2006; Luter et al., 2014; Gochfeld et al., 2012). For example, no significant decline in $\mathrm{Chl} a$ was observed when the sponge Cymbastela concentrica was subjected to excess nutrients (Roberts et al., 2006) and no significant change in eukaryotic bacterial communities was seen when the sponge Rhopaloeides odorabile was subjected to the combined effects of elevated temperature and nutrients (Simister et al., 2012). While the photosynthetic pigment results reported here are consistent with previous findings, no strong evidence for an effect of elevated nitrate on sponge-associated photosynthetic pigment concentrations could be found and it is likely that the pigment declines in $N$. chaliniformis and $S$. vagabunda were mostly driven by elevated temperature.

Increased respiration rates in sponges are often attributed to environmental stress (Bennett et al., 2017; Strand et al., 2017; Ramsby et al., 2018). Here, at higher temperature treatments, the respiration rate of all sponges significantly increased at T-end compared to the controls. While there is currently limited literature on the impacts of eutrophication on sponge respiration, the results reported in this chapter are consistent with the study of Webb et al. (2017), who reported no significant impact of eutrophication on the respiration rate of Cliona caribbaea. In contrast, increased respiration is commonly reported in thermally-stressed sponges. For example, GBR (Cheshire et al., 1995) and Mediterranean (Coma, 2002) sponges have been reported to consume more oxygen in summer seasons. Furthermore, under experimental conditions, Ramsby et al. (2018) demonstrated that the sponge $C$. orientalis consumed $47 \%$ more oxygen when subjected to a thermal increase of $6{ }^{\circ} \mathrm{C}$. Here, it was noted that elevated temperature was the main cause of increased oxygen consumption in all species with no significant change in respiration rate occurring due to excess nitrate or the interaction between both factors.

The long-term survival of a species can be compromised when it is exposed to anthropogenic stressors and under prolonged stress, certain species are likely to experience functional constraints (Pörtner \& Farrell, 2008). According to Fang et al. (2014), increased oxygen consumption in 
sponges might be due to an increase in the rate of carbon fixation by the hosts' symbionts to meet metabolic demands. For example, under stress, the energy required for growth and reproduction may be reallocated within the organism to support other basic physiological functions such as filtration/feeding (Riisgård et al., 1993) and respiration (Hadas et al., 2008). In addition, to maintain cellular homeostasis in response to stress, sponges may activate additional protective processes, such as cellular damage repair, and the induction of antioxidants and heat-shock proteins (Guzman \& Conaco, 2016). Similarly, the reduction in buoyant weight and the decline in gross photosynthetic rate under thermal stress in all species are symptomatic of physiological dysfunction.

\subsubsection{Responses to elevated nitrate}

The physiological and cellular mechanisms leading to metabolic changes in sponges are relatively unknown. While most marine invertebrates are negatively affected by anthropogenic stressors (Pörtner \& Farrell, 2008), several sponge species are relatively tolerant to stressors such as reduced pH (Goodwin et al., 2014; Bennett et al., 2017) or excess nutrients (Gochfeld et al., 2012; Simister et al., 2012; Luter et al., 2014). Here, elevated nitrate appeared to have little negative impact as compared to elevated temperature on all species. These findings are consistent with other studies performed on reef sponges (Gochfeld et al., 2012; Luter et al., 2014). Significant nitrate effects were only seen on sponge buoyant weight and carotenoid concentration. The symbiotic association between sponges and their microbial symbionts appears to be tolerant to excess nitrate but not elevated temperature. For example, no significant change in archaeal and bacterial compositions was seen in $R$. odorabile exposed to combined elevated temperature and nutrients (Simister et al., 2012). Similarly, no significant change in symbiotic algal growth (measured through Chl $a$ concentration) was seen in C. concentrica (Roberts et al., 2006), and no significant change in the sponge-cyanobacterial symbiosis was reported in Aplysina cauliformis when exposed to excess

nutrients (Gochfeld et al., 2012). While the mechanism explaining the effect of elevated nitrate on thermally-stressed lagoon sponges remains unknown, it is possible that excess nutrients alone could be beneficial to some sponge-associated symbionts, thus counterbalancing the negative effects of elevated temperature. Unlike corals and cnidarians, which are reported to restrict access of nutrients to their associated zooxanthellae (Rands et al., 1993; D’Angelo \& Wiedenmann, 2014), photosynthetic symbiotics associated with sponges, as well as the hosts themselves, do not 
appear to be nutrient limited (Roberts et al., 2006; Gochfeld et al., 2012). As a result, excess nutrients alone are less likely to impact sponges and their associated symbionts.

\subsubsection{Ecological implications}

Lagoon benthic organisms, including sponges, are thought to be specifically adapted to these habitats since they are often subjected to frequent dynamic environmental changes (Vernberg, 1982; Cerrano et al., 2004). However, as coastal lagoons are subjected to the cumulative effects of anthropogenic stressors, such as elevated temperature, ocean acidification and eutrophication, the persistence, survival and population size of many lagoon species are likely to be under threat (Anthony et al., 2009). Given that sponges generally have limited dispersal potential (Maldonado \& Young, 1996) and that coastal lagoons are spatially-limited environments with low flow regimes (Kjerfve, 1994), lagoon sponges like other lagoon-specific species are generally confined to these environments (Pérez-Ruzafa \& Marcos-Diego, 1992). Therefore, under prolonged anthropogenic stress, some lagoon species may experience population declines (Ponti et al., 2011). Being important filter feeding organisms, sponges provide an important link between the benthos and pelagic ecosystems (Reiswig, 1971a; Rix et al., 2016). As a result, declines in lagoon sponge populations may potentially result to secondary ecological impacts on coastal lagoon ecosystems. However, the responses of sponges to anthropogenic stressors are often species-specific (Bell et $a l ., 2018)$ and, further investigations on combined anthropogenic effects on other lagoon-specific species are required to enhance our understanding on the physiological responses of lagoon sponges.

\subsection{Conclusions}

Sponges are an important component of benthic lagoon communities (Longo et al., 2015), and are often poorly understood. While there is increasing evidence that some coral reef sponges are potentially more resilient to anthropogenic stressors than others (Bell et al., 2013, 2018), the results here demonstrate that some tropical lagoon species might not be resilient to a $2-4{ }^{\circ} \mathrm{C}$ future temperature increase. In contrast, lagoon-inhabiting sponges are most likely to be tolerant to elevated nitrate concentrations. While it is likely that the sponge species studied here are potentially adapted to environmental fluctuations, as they are regularly exposed to seasonal nutrient-fluctuations (Ramessur et al., 2011; Sadally et al., 2014), further inter-seasonal long-term 
investigations are required to understand the physiological responses of lagoon sponges to these combined stressors. The results here also highlight the importance of understanding the responses of benthic communities in lagoon ecosystems, specifically in Small Island Developing States where development is mostly concentrated along the coast, to better implement of future mitigation and conservation strategies. 


\section{Chapter 3:}

Physiological and proteomic responses of lagoon-inhabiting sponges to elevated temperature 


\begin{abstract}
Lagoon-inhabiting organisms are often exposed to elevated temperatures. However, the thermal responses of lagoon-inhabiting sponges are relatively unknown. This chapter reports on the physiological responses of three lagoon-inhabiting sponges, Neopetrosia chaliniformis, Amphimedon navalis and Spheciospongia vagabunda, as well as the proteomic responses of $A$. navalis to elevated seawater temperatures of $+2{ }^{\circ} \mathrm{C}$ (RCP6.0) and $+4{ }^{\circ} \mathrm{C}(\mathrm{RCP} 8.5)$ relative to an ambient temperature of $26^{\circ} \mathrm{C}$ for four weeks. Physiological observations demonstrate that, after one week of thermal exposure, the buoyant weights of $N$. chaliniformis and A. navalis significantly declined, but the buoyant weight of S. vagabunda did not. In N. chaliniformis and S. vagabunda, the effective quantum yield $\left(\Delta \mathrm{F} / \mathrm{F}_{\mathrm{m}}{ }^{\prime}\right)$ of photosystem (PS) II also experienced a significant decline after one week of thermal exposure. Sponge pumping rates and holobiont oxygen consumption rates (except for $S$. vagabunda) experienced a significant increase. Interestingly, $S$. vagabunda did not experience significant physiological changes after two weeks of thermal exposure, suggesting that this species may have undergone acclimation to elevated temperature. Proteomic analysis of $A$. navalis revealed 50 differentially abundant proteins at the end of the experiment, of which $72 \%$ were significantly upregulated. Changes in protein expression was most pronounced in sponges exposed to a temperature increase of $+4{ }^{\circ} \mathrm{C}$, where 43 proteins were differentially expressed. Thermal stress in A. navalis induced upregulation of proteins involved in oxidative stress (14\% of the total differentially expressed proteins), cytoskeletal organisation (16\%), protein transport (12\%) and signal transduction (6\%), although downregulation was apparent for some proteins involved in protein transport. These results suggest that the response of lagoon-inhabiting sponges to thermal stress is species-specific. While $N$. chaliniformis and A. navalis are directly impacted by prolonged thermal stress, the bioeroding sponge $S$. vagabunda can potentially acclimate to elevated seawater temperature. The proteome analysis of $A$. navalis demonstrates that thermal stress can also induce disruption of cellular homeostasis in thermally-susceptible a sponge species.
\end{abstract}




\subsection{Introduction}

Coastal lagoons are highly productive semi-enclosed ecosystems that are important habitats for many organisms (Kennish \& Paerl, 2010). However, these ecosystems are often exposed to environmental changes related to climate change (Anthony et al., 2009; Chapman, 2012). Coastal lagoons are usually high-irradiance ecosystems, and their shallow topography, combined with their low flushing rates, make them particularly susceptible to ocean warming (Kennish, 2016; Pérez-Ruzafa et al., 2019). As a result, lagoon-inhabiting benthic communities are often directly impacted by elevated seawater temperatures (Lloret et al., 2008; Anthony et al., 2009). For example, lagoon-inhabiting corals around tropical Pacific islands have experienced significant bleaching when exposed to elevated temperatures (Hoegh-Guldberg et al., 2011). The biological and ecological consequences of climate change on lagoon-inhabiting organisms are poorly understood. Therefore, understanding the thermal responses of non-conspicuous, but important lagoon-inhabiting taxa, such as sponges, is becoming increasingly important.

The effects of elevated temperature on sponges are thought to be species-specific (see review Bell et al., 2018). While some sponges are known to be tolerant of elevated temperatures, other species are susceptible to thermal stress (Bell et al., 2018). For example, Massaro et al. (2012) reported reduced sponge pumping rates, filtration rates and a modification in the basic feeding behaviour of the sponge Rhopaloeides odorabile when exposed to an increase of $3{ }^{\circ} \mathrm{C}$ for 16 days. Achlatis et al. (2017) reported extensive bleaching, lower bioerosion rates and mortality when $C$. orientalis was exposed to an increase of $2.7{ }^{\circ} \mathrm{C}$ above maximum monthly mean temperatures for 10 weeks. In recent decades, multiple studies have investigated the physiological responses of sponges to elevated temperature. However, responses at the cellular level have been relatively poorly studied (Lopez-Legentil et al., 2008; Pantile \& Webster, 2011; Webster et al., 2013).

Molecular responses of thermally-stressed sponges were initially reported by Bachinski et al. (1997), who described reduced glutathione S-transferase and glutathione concentrations (both involved in cell peroxide metabolism) and expression of the heat-stress protein Hsp70 (a chaperone for protein folding) in the sponge Suberites domuncula after a thermal exposure of $+10{ }^{\circ} \mathrm{C}$ for 30 min. Subsequently, increased Hsp70 expression was also reported in thermally- 
stressed Geodia cydonium (Krasko et al., 1997) and Xestospongia muta (Lopez-Legentil et al., 2008). Thermally-induced molecular responses in sponges have mostly been documented for the reef sponge $R$. odorabile (Pantile \& Webster, 2011; Fan et al., 2013; Webster et al., 2013). Changes in gene expression, such as for actin (cytoskeletal arrangements), ubiquitin conjugating enzyme, elongation factor-Tu (protein synthesis/degradation), calmodulin, (signal transduction) and ferritin (oxidative stress) were reported after a thermal exposure of $0.5-2{ }^{\circ} \mathrm{C}$ for three days (Pantile \& Webster, 2011; Webster et al., 2013).

Molecular stress responses in sponges have mainly focused on gene expression dynamics (Webster et al., 2013; Guzman \& Conaco, 2016). To date, no attempt has been made to explore sponge-stress responses at the proteomic level, although Tyers and Mann (2003) suggested that a proteomic approach could potentially provide a better understanding of the changes in functional behaviour of an organism. While gene expression is based on mRNA transcript counts, protein abundance is a function of transcription rates, the availability of amino acids and ribosomes, protein degradation rates and other post-translational processes, and the mRNA (Cho, 2007; Buccitelli \& Selbach, 2020). Therefore, proteomics can confirm the presence and abundance of the potentially expressed mRNA within the cell of an organism (Cox \& Mann, 2007) and can further completement functional genomic approaches at both cellular and organismal levels (Tyers \& Mann, 2003). According to Liu et al. (2012), such approaches can potentially provide novel information on the functional behaviour of the host's physiology or symbiont communities in response to environmental change. Functional processes such as aerobic nitrification, and transportation and degradation of halogenated compounds have previously been reported for the microbiomes of the sponges Cymbastela concentrica (Liu et al., 2012) and Aplysina aerophoba (Chaib De Mares et al., 2018), using metaproteomic approaches. Given that sponges are likely to be exposed to elevated temperature under future climate change scenarios, it is essential to identify whether thermally-induced physiological and cellular changes could yield novel insights into the responses of sponges to environmental stress.

The sponges Neopetrosia chaliniformis, Amphimedon navalis and Spheciospongia vagabunda are common lagoon inhabiting species from the Western Indian Ocean and have been reported to be physiologically susceptible to short-term ( 2 weeks) elevated temperatures (see Chapter 2 ). This 
chapter investigates the physiological responses of these three lagoon-inhabiting sponges, exposed to temperatures of $+2{ }^{\circ} \mathrm{C}$ and $+4{ }^{\circ} \mathrm{C}$ (IPCC, 2014) above the ambient temperature $\left(26^{\circ} \mathrm{C}\right)$ over an extended period of 4 weeks. Changes in a range of physiological parameters, including buoyant weight, effective quantum yield ( $\Delta \mathrm{F} / \mathrm{F}_{\mathrm{m}}$ ') of photosystem (PS) II of chlorophyll $a$-containing species (i.e. N. chaliniformis and S. vagabunda), holobiont oxygen consumption (i.e. respiration) and sponge pumping rates were measured at weekly time-points. At the end of the experiment, the protein expression dynamics of $A$. navalis were also compared to the controls at the start of the experiment to identify thermally-induced functional changes at the proteomic level.

\subsection{Materials and Methods}

\subsubsection{Sponge collection}

Neopetrosia chaliniformis, Amphimedon navalis and Spheciospongia vagabunda specimens of size 4-10 cm were collected from the lagoons of Trou aux Biches (20 01' S, 57 33' E), Trou

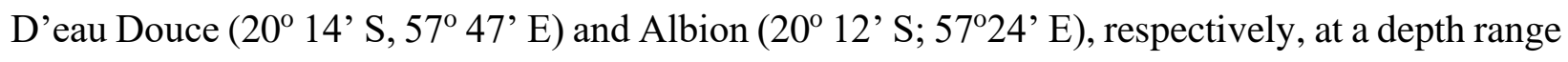
of $0.5-2 \mathrm{~m}$ depending on species. Approximately $45 \mathrm{~min}$ after collection, sponges were transported to a laboratory facility in polystyrene boxes and transferred to $10 \mathrm{~L}$ tanks of freshly collected seawater at an ambient temperature of $26^{\circ} \mathrm{C}$ (average seawater temperature at collection sites). Light conditions in the laboratory facility were maintained at a maximum irradiance of approximately $450 \mu \mathrm{mol}$ photons $\mathrm{m}^{-2} \mathrm{~s}^{-1}$, which corresponds to the irradiance at $0.5 \mathrm{~m}$ in Trou aux Biches lagoon. A shad cloth was used to reduce maximum Photosynthetically Active Radiation (PAR) in the tanks. PAR in the laboratory was monitored using a Pulse Amplitude Modulated (PAM) fluorometer (red LED Diving PAM, Walz, Germany).

\subsubsection{Experimental design}

Thermal experiments were conducted separately for each species during November/December 2017 and 2018. Experiments were conducted in summer to minimize thermal stress to sponges. Tanks were supplied with individual aquarium heaters and were aerated using aquarium oxygen pumps. Food supply for sponges was maintained by manually replacing unfiltered freshly collected seawater at 12-h intervals, based on prior sponge pumping rate calculations for each species. Sponge pumping rates for each species were estimated to determine the volume of water that each species would recycle per day. For each species, sponges were acclimatized for one week 
(acclimation week) prior to the start of the temperature-stress experiment (see Chapter 2 - Section 2.2.2). A four-week thermal exposure period was used, where the total length of the thermal experiment for each species was five weeks including the acclimation week.

Three temperature treatments $\left(26,28\right.$ and $30^{\circ} \mathrm{C}$, range $\left.\pm 0.5^{\circ} \mathrm{C}\right)$ were chosen based on the IPCC (2014) SST prediction scenarios for 2100 using the Representative Concentration Pathways RCP6.0 $\left(+2{ }^{\circ} \mathrm{C}\right)$ and RCP8.5 $\left(+4{ }^{\circ} \mathrm{C}\right)$ relative to the current ambient seawater temperature in Mauritius during the summer $\left(26{ }^{\circ} \mathrm{C}\right)$. The experimental design consisted of a total of nine treatment tanks (i.e. three replicate tanks for each temperature treatment) with a holding capacity of $10 \mathrm{~L}$, with each tank containing a total of five live sponges. Three sponges from each tank (i.e. $\mathrm{n}=9$ per temperature treatment) were exclusively used to assess physiological changes over time (see Section 3.2.3). During the A. navalis thermal tolerance experiment, the remaining two sponges ( $\mathrm{n}=6 \mathrm{per}$ temperature treatment) were sacrificed at the end of the experiment for proteomic expression dynamics (see Section 3.2.4). Each treatment tank was supplied with a $100 \mathrm{~W}$ aquarium heater, and air pumps were used to ensure oxygen supply and water circulation. Three $20 \mathrm{~L}$ tanks were used to pre-heat seawater daily and pre-heated seawater was manually replaced at $12 \mathrm{~h}$ intervals. Temperature loggers (Onset, Hobo, MA, USA) were used to monitor temperature fluctuations in the treatment tanks at $3 \mathrm{~h}$ intervals (Fig. 3.1). Each treatment tank was covered with a shade cloth to keep maximum PAR measurements to approximately $450 \mu$ mol photons $\mathrm{m}^{-2} \mathrm{~s}^{-1}$. Sponge survival and health were monitored daily and sponges showing any signs of disease (necrosis or formation of white film) were immediately removed from their respective treatment tanks (Bennett et al., 2017; Bates \& Bell, 2018). Physiological responses were measured at weekly time-points (T0, T1, T2, T3 and T4) for four weeks after the acclimation week. 

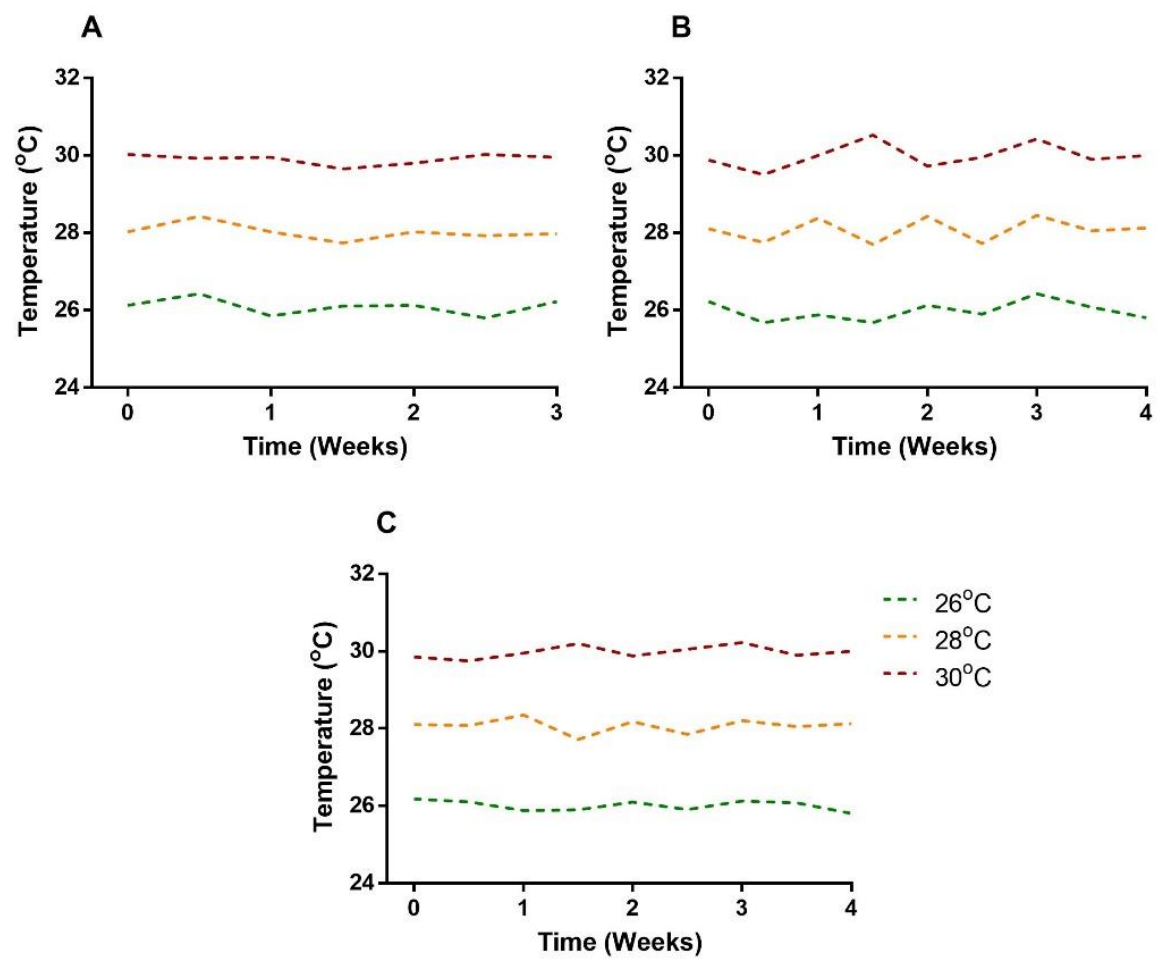

Fig. 3.1 Temperature fluctuations in treatment tanks during the experiments for A) Neopetrosia chaliniformis, B) Amphimedon navalis and C) Spheciospongia vagabunda. Note: scale on x-axes differ between species due to early mortalities of $N$. chaliniformis.

\subsubsection{Physiological responses}

\subsubsection{Buoyant weight}

The buoyant weight of each sponge was measured weekly following the methods of Osinga et al. (1999). Buoyant weight was measured using a digital scale (Scout STX422, Ohaus, USA) as described in Chapter 2 (Section 2.2.3.3).

\subsubsection{Effective quantum yield of PSII}

Effective quantum yield of PSII ( $\left.\Delta \mathrm{F} / \mathrm{F}_{\mathrm{m}}{ }^{\prime}\right)$ of $N$. chaliniformis and $S$. vagabunda was measured using a red LED diving Pulse Amplitude Modulated (PAM) fluorometer (Walz, Germany) and used to measure photosynthetic performance of the sponges (Lemloh et al., 2009). Measurements were taken following the methods and settings described in Chapter 2 (Section 2.2.3.4). 


\subsubsection{Holobiont oxygen consumption}

Holobiont (sponge + symbionts) oxygen consumption (i.e. respiration) was measured in cylindrical 100-mL acrylic respiration chambers following the methods described in Chapter 2 (Section 2.2.3.5), using a dissolved oxygen meter (PreSens, Fibrox 3, Germany) under ambient light conditions (PAR, $430-450 \mu \mathrm{mol}$ photons $\mathrm{m}^{-2} \mathrm{~s}^{-1}$ ). To reduce any significant temperature drift during measurements, respiration chambers were placed in thermal water baths. The oxygen concentration in one empty chamber filled with seawater from the host's tank was measured to control for any electrode drift or respiration from potential micro-organisms in the tank water (Gatti et al., 2002). Holobiont oxygen consumption rate was recorded across a total of $30 \mathrm{~min}$. Measurements were ended prematurely if the oxygen concentration fell below $70 \%$ of the original concentration (100\%), to reduce any anoxic stress to the sponge (Biggerstaff et al., 2015). Oxygen consumption measurements were standardized to sponge ash-free dry weight using the conversion ratio described in Chapter 2 (Section 2.2.3.5).

\subsubsection{Sponge pumping rate}

Sponge pumping rates were measured following the methods of Massaro et al. (2012). Briefly, a ruler was vertically attached to the bottom of a transparent 2 L glass beaker and the target sponge was carefully transferred into the beaker with the osculum facing upwards. Approximately $1 \mathrm{~mL}$ of fluorescein dye was carefully released at the base of the sponge using a syringe and the exhaled dye movement from the sponge's osculum was recorded. In situations where the sponge's osculum could not be placed facing upwards in the beaker (i.e. the sponge osculum was horizontal), the glass beaker was placed on graph paper and the exhaled horizontal movement of the dye was recorded on video from the top of the beaker and analyzed. The pumping rate was calculated by measuring the time taken for the fluorescein dye to travel a known distance from the osculum opening to a specific distance on the ruler/graph paper. Pumping rate $\left(\mathrm{ml} \mathrm{s}^{-1}\right)$ was then multiplied by the cross-sectional area of the sponge's osculum.

\subsubsection{Proteomic responses}

\subsubsection{Protein extraction}

Protein dynamics were assessed for A. navalis only. Proteomic responses could not be investigated for $N$. chaliniformis and S. vagabunda due to the lack of genetic resources (i.e. protein library) for 
these species. At the end of the thermal experiment (T4), sacrificed A. navalis sponges ( $\mathrm{n}=6$ per treatment; two sponges from each tank) were frozen at $-20{ }^{\circ} \mathrm{C}$ for proteome analysis. Prior to peptide extraction, sponge samples were kept overnight in $99.5 \%$ ethanol at $-20{ }^{\circ} \mathrm{C}$ to remove any excess pigments associated with the sponge. Peptides were prepared using a modified method of Oakley et al. (2016) with the sodium deoxycholate (SDC) in-solution digestion method. Samples were homogenized for $30 \mathrm{~s}$ using a tissue homogenizer (Thermo Fisher Scientific Inc., USA) and incubated at $85{ }^{\circ} \mathrm{C}$ for $20 \mathrm{~min}$ in $5 \% \mathrm{SDC}$, followed by adding $1 \% \beta$-mercaptoethanol (BME) to the solution to denature proteins. SDC and residual pigments were extracted from the solution via ethyl acetate phase transfer (Yeung \& Stanley, 2010) and cell debris was removed by centrifugation at $10,000 \times \mathrm{g}$ for $2 \mathrm{~min}$. Lysates were processed using a modified method of the filter-aided sample preparation from Wiśniewski et al. (2009). Lysates were transferred to $0.5 \mathrm{ml}$ Amicon Ultra centrifugal units (Sigma-Aldrich, MO, USA), centrifuged at 14,000 × g for 15 min, mixed with $380 \mu \mathrm{l}$ of $50 \mathrm{mM}$ Tris buffer and centrifuged again. A subsample of $100 \mu \mathrm{g}$ was alkylated using $50 \mathrm{mM}$ acrylamide, incubated at room temperature for $20 \mathrm{~min}$ and digested with 2 $\mu \mathrm{g}$ trypsin at $37^{\circ} \mathrm{C}$ for $12-18$ hours. Formic acid (0.1\%) was added to terminate trypsin digestion and precipitate any remaining SDC. The peptide solution was centrifuged at $16,000 \times \mathrm{g}$ for $2 \mathrm{~min}$ to pellet the SDC precipitate. Peptides were then desalted using 50\% and 30\% acetonitrile (ACN) and resuspended in $0.1 \%$ formic acid at $37^{\circ} \mathrm{C}$ for $30 \mathrm{~min}$. Protein extraction at all steps was performed using low protein-binding tubes and high-performance liquid chromatography-grade water. Protein and peptide concentrations were assessed by bound dye fluorescence (Qubit, Thermo Fisher Scientific Inc., USA).

\subsubsection{Liquid chromatography-tandem mass spectrometry}

Peptide separation was conducted on an Acclaim PepMap C18, $3100 \AA$ column (Thermo Scientific, Auckland, New Zealand) and a liquid chromatogram system (Ultimate 3000, Dionex, Sunnyvale, CA), using a 75 min linear gradient from 5\% to $35 \%$ buffer B (buffer A: $0.1 \%$ formic acid; buffer B: $80 \%$ acetonitrile, $0.1 \%$ formic acid) at $300 \mathrm{~nL} \mathrm{~min}{ }^{-1}$. Peptide ionization was conducted by $1.8 \mathrm{kV}$ electrospray and assessed using an Orbitrap Fusion Lumos Tribrid mass spectrometer (Thermo Scientific). The acquisition of precursor mass spectra was performed using the following specifications: 120,000 resolution, rejecting single-charged ions, enabled quadrupole isolation with an automatic gain target of $7.0 \mathrm{e} 5$ and maximum injection time of $50 \mathrm{~ms}$. Higher- 
energy collision dissociation was used to fragment the 20 most intense precursor spectra and analysis was performed in the ion trap (automatic gain target and maximum injection time set at 5.0e3 and $300 \mathrm{~ms}$, respectively).

\subsubsection{Protein identification and quantification}

The Andromeda search algorithm in MaxQuant was used for protein identification (Cox et al., 2014) against the genome of the sponge Amphimedon queenslandica (Srivastava et al., 2010) in UniProtKB (UniProt Consortium, 2018). Trypsin digestion with a maximum of two missed cleavages was assumed. The carbamidomethylation of cysteine was assumed as a fixed modification, and oxidation of methionine and acetylation of the protein n-terminus were both assumed as variable modifications. Peptide tolerances for first and main searches were $20 \mathrm{ppm}$ and $4.5 \mathrm{ppm}$, respectively, and for ion trap MS2 search, a mass tolerance of 0.5 Da was used. Protein quantification was made using label-free quantification (LFQ). Searches were performed with a false discovery rate (FDR) of $2.5 \%$ and a minimum of two peptides per protein were required for identification. Protein annotations were matched using the web-based tool QuickGo (Binns et al., 2009) in UniProtKB.

\subsubsection{Data analysis}

Statistical analyses for physiological responses were performed using SPSS v.24 (SPSS Statistics for Windows, IBM Inc, NY, USA). General linear mixed models (GLMMs) were used to test the fixed effects of time and temperature on the sponge's physiological response. For N. chaliniformis, models were built from the start of the experiment (T0) to the day when sponge mortality was first recorded (T3). To account for pseudo-replication (nested design), all models were fitted with sponge replicates and tanks as random effects. Physiological response data were $\log (\mathrm{x}+1)$ transformed. For each model, post hoc pairwise comparisons with Sidak applied correction were conducted to assess significant differences between the treatments at each time-point (see Appendix B - Table B3.1a-d).

Proteomic data were analyzed using PolySTest (Schwämmle et al., 2020) and the bioinformatics software Perseus v.1.6.13.0 (Tyanova \& Cox, 2018). Proteomic data were first filtered for possible contaminants and reverse identifications. The resulting database was then $\log _{2}$-transformed. 
Principal Components Analysis (PCA) plot was constructed using the filtered $\log _{2}$-transformed database. The Miss test was used to assess the effects of elevated temperature on A. navalis protein expression. Miss test was used because it simultaneously tests for missingness and feature protein abundance, therefore rescuing otherwise discarded data (Schwämmle et al., 2020). An FDR threshold of 0.1 and $\log$-ratio thresholds of \pm 0.25 were used to defined statistically significant proteins (See Appendix B - Table B3.2).

\subsection{Results}

\subsubsection{Sponge survival}

Sponge mortality occurred exclusively with Neopetrosia chaliniformis. All N. chaliniformis specimens (100\%) exposed to $30{ }^{\circ} \mathrm{C}$ died after three weeks (T3) and $44 \%$ exposed to $28{ }^{\circ} \mathrm{C}$ died during the last week of the experiment (T4). In contrast, no mortality was recorded for this species in the control treatment. No mortality was recorded for Amphimedon navalis and Spheciospongia vagabunda in any treatment.

\subsubsection{Physiological responses}

\subsubsection{Buoyant weight}

$N$. chaliniformis buoyant weight was significantly affected by temperature $\left(\mathrm{F}_{(2,55)}=31.933, \mathrm{p}<\right.$ $0.001)$ and there was an effect of temperature over time $\left(\mathrm{F}_{(6,55)}=28.148, \mathrm{p}<0.001\right.$; Fig. 3.2A; Table 3.1). At T-end, the buoyant weight of $N$. chaliniformis declined by $5-0.15 \%$ at $28{ }^{\circ} \mathrm{C}$, and $6.67-19 \%$ at $30{ }^{\circ} \mathrm{C}$, whereas at $26^{\circ} \mathrm{C} N$. chaliniformis buoyant weight increased by $2.77-10 \% . N$. chaliniformis buoyant weight significantly declined at both $30^{\circ} \mathrm{C}$ and $28{ }^{\circ} \mathrm{C}$ relative to $26{ }^{\circ} \mathrm{C}(\mathrm{p}<$ 0.05; Table B3.1a).

The buoyant weight of $A$. navalis significantly decreased with elevated temperature $\left(\mathrm{F}_{(2,68)}=\right.$ 43.652, $\mathrm{p}<0.001)$ and over time $\left(\mathrm{F}_{(8,68)}=28.199, \mathrm{p}<0.001\right.$; Fig. 3.2B; Table 3.1). At T-end, $A$. navalis buoyant weight declined from $0.77-2.33 \%$ at $28{ }^{\circ} \mathrm{C}$, and $1.22-5.33 \%$ at $30{ }^{\circ} \mathrm{C}$. However, in the control treatment, the buoyant weight of this species increased by 0.83-2.33\%. Buoyant weight was significantly lower in the higher temperature treatments relative to the controls $(\mathrm{p}<$ 0.05; Table B3.1a). No significant change in buoyant weight was seen for S. vagabunda across treatment, although buoyant weight increased over time ( $\mathrm{p}>0.05$; Fig. 3.2C; Table 3.1). 


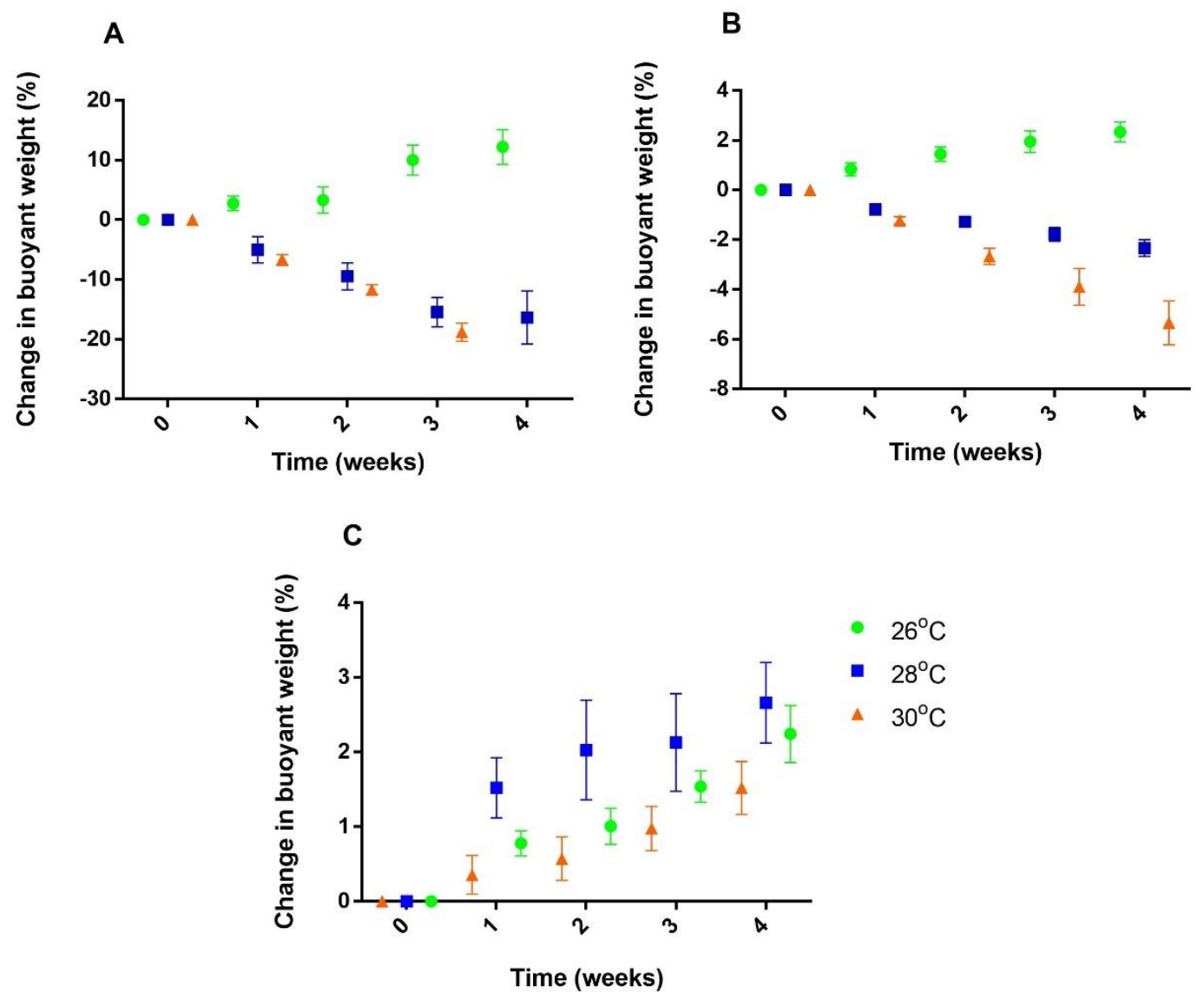

Fig. 3.2 Percentage change in buoyant weight of A) Neopetrosia chaliniformis, B) Amphimedon navalis and C) Spheciospongia vagabunda in response to elevated temperature. Values are mean percentage change per treatment $\pm \mathrm{SE}$ at each time-point $(\mathrm{n}=9$, excluding $N$. chaliniformis mortalities). Note: scale for the y-axes differ between species.

\subsubsection{Effective quantum yield}

$N$. chaliniformis $\Delta \mathrm{F} / \mathrm{F}_{\mathrm{m}}$ ' was significantly affected by elevated temperature $\left(\mathrm{F}_{(2,57)}=68.562, \mathrm{p}<\right.$ $0.001)$ and across time $\left(\mathrm{F}_{(6,57)}=22.583, \mathrm{p}<0.001 ; \mathrm{Fig}\right.$. 3.3A; Table 3.1). N. chaliniformis $\Delta \mathrm{F} / \mathrm{F}_{\mathrm{m}}$ ' at T-end was 0.505-0.541 in the control, 0.361-0.410 at $28{ }^{\circ} \mathrm{C}$ and $0.289-0.331$ at $30{ }^{\circ} \mathrm{C} . \Delta \mathrm{F} / \mathrm{F}_{\mathrm{m}}{ }^{\prime}$ in this species significantly declined at $30^{\circ} \mathrm{C}$ and $28^{\circ} \mathrm{C}$ relative to the control ( $\mathrm{p}<0.05$; Table B3.1b). A significantly lower $\Delta \mathrm{F} / \mathrm{F}_{\mathrm{m}}$ ' was also observed at $30{ }^{\circ} \mathrm{C}$ compared to $28{ }^{\circ} \mathrm{C}$ ( $\mathrm{p}<0.05$; Table B.3.1b).

S. vagabunda $\Delta \mathrm{F} / \mathrm{F}_{\mathrm{m}}$ ' was significantly affected by temperature $\left(\mathrm{F}_{(2,72)}=240.64, \mathrm{p}<0.001\right)$ and there was an effect of temperature over time $\left(\mathrm{F}_{(8,72)}=32.894, \mathrm{p}<0.001\right.$; Fig. 3.3B; Table 3.1). At 
T-end, $\Delta \mathrm{F} / \mathrm{F}_{\mathrm{m}}$ ' of this species was $0.625-0.703$ at $26^{\circ} \mathrm{C}, 0.510-0.586$ at $28{ }^{\circ} \mathrm{C}$ and $0.485-0.568$ at $30{ }^{\circ} \mathrm{C} . \Delta \mathrm{F} / \mathrm{F}_{\mathrm{m}}$ ' was significantly lower at both elevated temperatures compared to the control $(\mathrm{p}<$ 0.05; Table B3.1b).
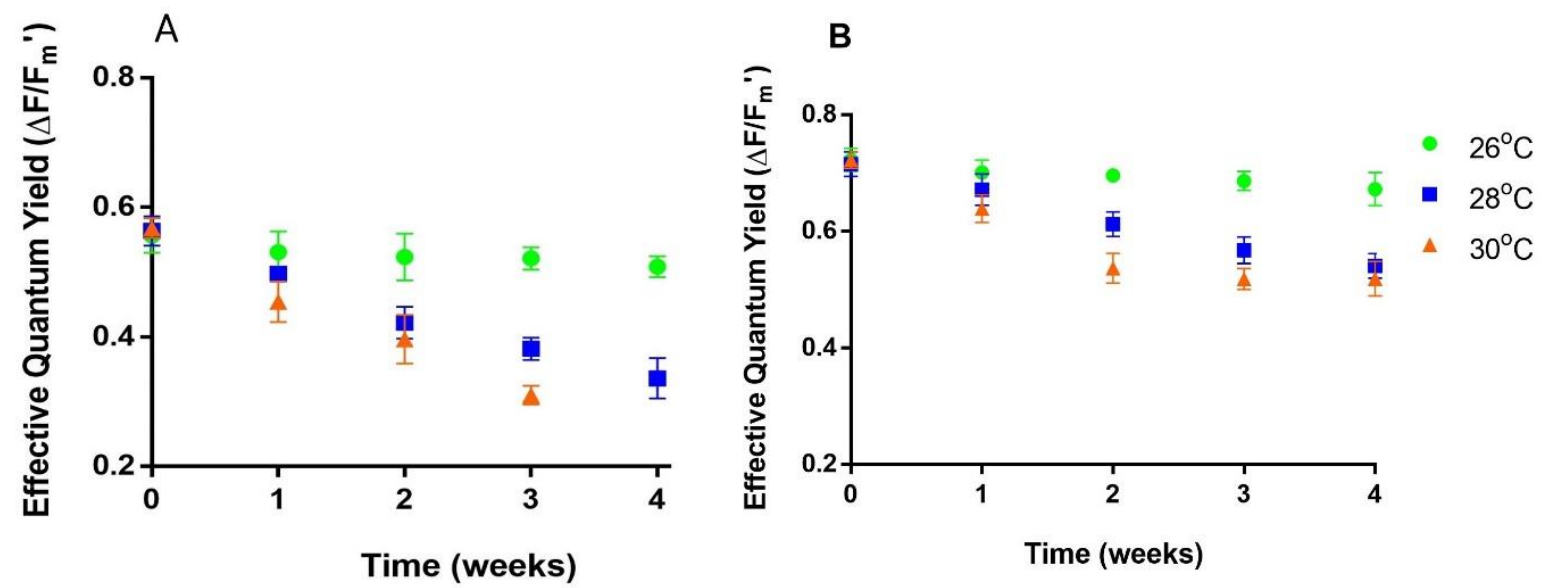

Fig. 3.3 Changes in effective quantum yield of A) Neopetrosia chaliniformis and B) Spheciospongia vagabunda in response to elevated temperature. Values are mean per treatment \pm $\mathrm{SE}$ at each time-point ( $\mathrm{n}=9$, excluding $N$. chaliniformis mortalities).

\subsubsection{Holobiont oxygen consumption}

$N$. chaliniformis oxygen consumption rate was significantly influenced by temperature $\left(\mathrm{F}_{(2,57)}=\right.$ $17.834, \mathrm{p}<0.001)$ and there was an effect of temperature over time $\left(\mathrm{F}_{(6,57)}=21.892, \mathrm{p}<0.001\right.$; Fig. 3.4A; Table 3.1). At T-end, $N$. chaliniformis oxygen consumption rate was $0.055-0.118 \mathrm{mg}$ $\mathrm{O}_{2} \mathrm{~g}^{-1} \mathrm{~min}^{-1}$ in the control, 0.071-0.0162 $\mathrm{mg} \mathrm{O}_{2} \mathrm{~g}^{-1} \mathrm{~min}^{-1}$ at $28^{\circ} \mathrm{C}$, and 0.136-0.196 $\mathrm{mg} \mathrm{O}_{2} \mathrm{~g}^{-1} \mathrm{~min}^{-}$ ${ }^{1}$ at $30^{\circ} \mathrm{C}$. The oxygen consumption rate of this species was significantly higher at both $30^{\circ} \mathrm{C}$ and $28^{\circ} \mathrm{C}$ relative to the controls $(\mathrm{p}<0.05$; Table B3.1c).

A. navalis, oxygen consumption rates significantly increased with elevated temperature $\left(\mathrm{F}_{(2,75)}=\right.$ 5.958, $\mathrm{p}<0.001)$ and across time $\left(\mathrm{F}_{(8,75)}=47.904, \mathrm{p}<0.001\right.$; Fig. 3.4B; Table 3.1). At T-end, A. navalis oxygen consumption rate was $0.089-0.121 \mathrm{O}_{2} \mathrm{~g}^{-1} \mathrm{~min}^{-1}$ for the control, 0.110-0.145 $\mathrm{O}_{2} \mathrm{~g}^{-1}$ $\min ^{-1}$ at $28{ }^{\circ} \mathrm{C}$, and $0.139-0.204 \mathrm{O}_{2} \mathrm{~g}^{-1} \mathrm{~min}^{-1}$ at $30{ }^{\circ} \mathrm{C}$. Oxygen consumption for this species was significantly higher at $28^{\circ} \mathrm{C}$ and $30^{\circ} \mathrm{C}$ versus $26^{\circ} \mathrm{C}(\mathrm{p}<0.05$; Table B3.1c). No significant change was seen in S. vagabunda oxygen consumption rate between any treatments ( $p>0.05$; Fig. 3.4C; Table 3.1). 

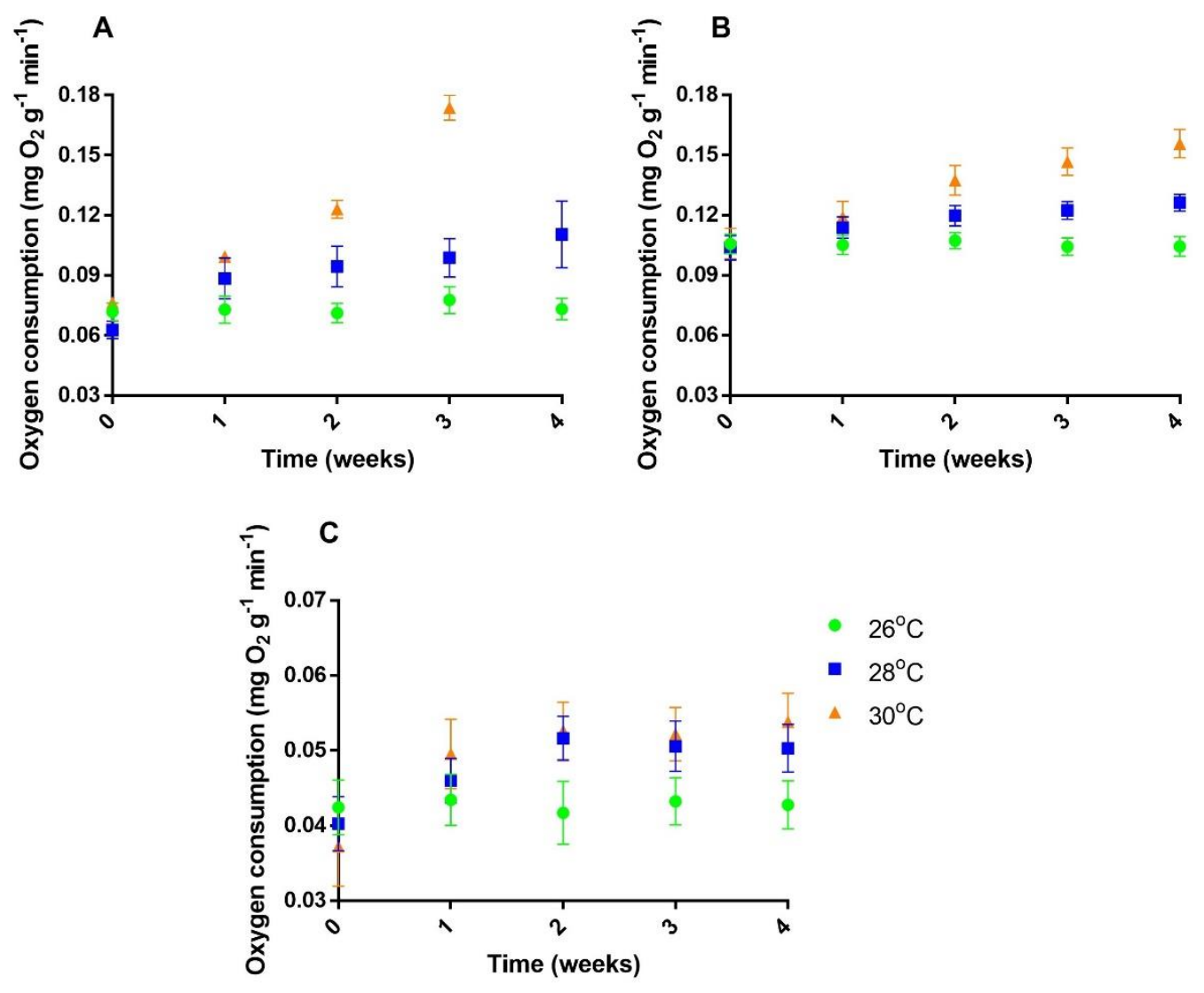

Fig. 3.4 Holobiont oxygen consumption of A) Neopetrosia chaliniformis, B) Amphimedon navalis and C) Spheciospongia vagabunda in response to elevated temperature. Values are mean per gram of sponge ash free dry weight at each time point and represent mean per treatment $\pm \mathrm{SE}(\mathrm{n}=9$, excluding $N$. chaliniformis mortalities).

\subsubsection{Sponge pumping rate}

$N$. chaliniformis pumping rate was significantly affected by temperature $\left(\mathrm{F}_{(2,56)}=16.345, \mathrm{p}<\right.$ 0.001) and over time $\left(\mathrm{F}_{(6,56)}=14.277, \mathrm{p}=0.001\right.$; Fig. 3.5A; Table 3.1). At T-end, $N$. chaliniformis pumping rate was $0.050-0.091 \mathrm{ml} \mathrm{s}^{-1}$ at $26^{\circ} \mathrm{C}, 0.189-0.236 \mathrm{ml} \mathrm{s}^{-1}$ at $28{ }^{\circ} \mathrm{C}$, and $0.260-0.314 \mathrm{ml} \mathrm{s}^{-1}$ at $30{ }^{\circ} \mathrm{C}$. The pumping rate of this species was significantly higher at both elevated temperatures relative to the control $(\mathrm{p}<0.05$; Table $\mathrm{B} 3.1 \mathrm{~d})$.

A. navalis pumping rate significantly increased with elevated temperature $\left(\mathrm{F}_{(2,73)}=38.366, \mathrm{p}<\right.$ $0.001)$ and over time $\left(\mathrm{F}_{(8,73)}=45.396, \mathrm{p}<0.001\right.$; Fig. 3.5B; Table 3.1). A. navalis pumping rate at 
T-end was $0.070-0.120 \mathrm{ml} \mathrm{s}^{-1}$ at the control temperature, $0.150-0.180 \mathrm{ml} \mathrm{s}^{-1}$ at $28{ }^{\circ} \mathrm{C}$, and 0.160 $0.230 \mathrm{ml} \mathrm{s}^{-1}$ at $30{ }^{\circ} \mathrm{C}$. A. navalis pumping rate was significantly higher at both elevated temperatures relative to the control $(\mathrm{p}<0.05$; Table B3.1d).

S. vagabunda pumping rate was significantly affected by temperature $\left(\mathrm{F}_{(2,77)}=29.862, \mathrm{p}<0.001\right)$ and time $\left(\mathrm{F}_{(8,77)}=6.559, \mathrm{p}<0.001\right.$; Fig. 3.5C; Table 3.1). Pumping rate at T-end for this species was $0.067-1.428 \mathrm{ml} \mathrm{s}^{-1}$ in the control temperature, $0.173-0.333 \mathrm{ml} \mathrm{s}^{-1}$ at $28{ }^{\circ} \mathrm{C}$, and $0.200-0.420 \mathrm{ml}$ $\mathrm{s}^{-1}$ at $30{ }^{\circ} \mathrm{C}$. S. vagabunda pumping rate was significantly higher at both elevated temperatures relative to the control ( $\mathrm{p}<0.05$, Table B3.1d).
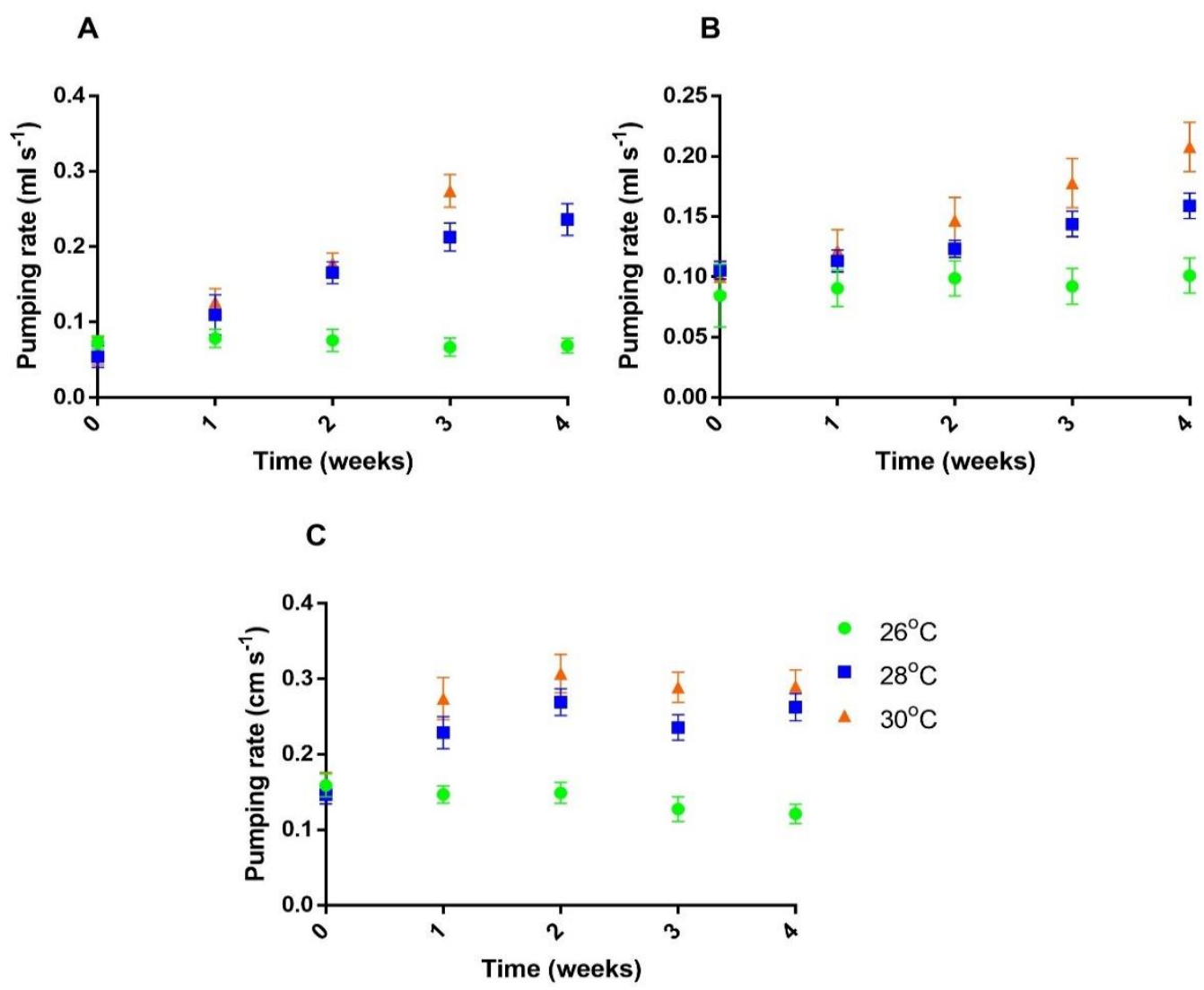

Fig. 3.5 Pumping rate of A) Neopetrosia chaliniformis, B) Amphimedon navalis and C) Spheciospongia vagabunda in response to elevated temperature. Values are mean per treatment \pm SE at each time-point $(\mathrm{n}=9$, excluding $N$. chaliniformis mortalities). Note: scale for the $\mathrm{y}$-axes differ between species due to species-specific pumping rate. 
Table 3.1 Summary of general linear mixed models (GLMM) for the effects of time, temperature and their combined effects on buoyant weight, effective quantum yield $\left(\Delta \mathrm{F} / \mathrm{F}_{\mathrm{m}}{ }^{\prime}\right)$, holobiont oxygen consumption and pumping rate of Neopetrosia chaliniformis, Amphimedon navalis and Spheciospongia vagabunda. Significant values are shown in bold.

\begin{tabular}{|c|c|c|c|c|}
\hline \multirow[t]{2}{*}{ Fixed Effects } & \multicolumn{4}{|c|}{ Physiological responses } \\
\hline & $\begin{array}{l}\text { Buoyant weight } \\
\text { (g) }\end{array}$ & $\Delta F / F_{m}$ & $\begin{array}{l}\mathrm{O}_{2} \text { consumption } \\
\left(\mathrm{mg} \mathrm{O}_{2} \mathrm{~g}^{-1} \mathrm{~min}^{-1}\right)\end{array}$ & $\begin{array}{l}\text { Pumping rate } \\
\quad\left(\mathrm{ml} \mathrm{s}^{-1}\right)\end{array}$ \\
\hline & \multicolumn{4}{|c|}{ Neopetrosia chaliniformis } \\
\hline Time & $<0.001$ & $<0.001$ & $<0.001$ & $<0.001$ \\
\hline Temp & $<0.001$ & $<0.001$ & $<0.001$ & $<0.001$ \\
\hline \multirow[t]{2}{*}{ Time*Temp } & $<0.001$ & $<0.001$ & $<0.001$ & $<0.001$ \\
\hline & \multicolumn{4}{|c|}{ Amphimedon navalis } \\
\hline Time & $<0.001$ & - & $<0.001$ & $<0.001$ \\
\hline Temp & $<0.001$ & - & 0.008 & $<0.001$ \\
\hline \multirow[t]{2}{*}{ Time*Temp } & $<0.001$ & - & $<0.001$ & $<0.001$ \\
\hline & \multicolumn{4}{|c|}{ Spheciospongia vagabunda } \\
\hline Time & 0.070 & $<0.001$ & 0.201 & $<0.001$ \\
\hline Temp & 0.576 & $<0.001$ & 0.895 & $<0.001$ \\
\hline Time*Temp & 0.578 & $<0.001$ & 0.511 & $<0.001$ \\
\hline
\end{tabular}

\subsubsection{A. navalis protein dynamics}

\subsubsection{Protein expression}

A. navalis proteomic analysis yielded a total of 814 identified proteins. The most abundant proteins were representative of cellular compartments such as the cytoskeleton/microtubules, membranes, ribosome, and nucleosome. The molecular and biological functions of the twenty-five most abundant proteins based on their respective Gene Ontology (GO) annotations are described in Table 3.2. 
Table 3.2 Most abundant proteins detected from Amphimedon navalis using a false discovery rate (FDR) of $2.5 \%$.

\begin{tabular}{|c|c|c|c|}
\hline $\begin{array}{c}\text { UniprotKB } \\
\text { Accession number }\end{array}$ & Protein annotation & Molecular function & Biological function \\
\hline A0A1X7VST2 & $\begin{array}{l}\text { Uncharacterized (Actin } \\
\text { family) }\end{array}$ & ATP binding & Cytoskeletal organisation \\
\hline A0A1X7VM44 & Tubulin beta chain & GTP and nucleotide binding & Cytoskeletal organization \\
\hline A0A1X7U5Q4 & $\begin{array}{c}\text { Uncharacterized (Gelsolin-like } \\
\text { domain protein) }\end{array}$ & Actin filament binding & Cytoskeletal organisation \\
\hline A0A1X7VHU9 & $\begin{array}{c}\mathrm{NAD}(\mathrm{P}) \mathrm{H} \text { oxidase }\left(\mathrm{H}_{2} \mathrm{O}_{2}\right. \\
\text { forming })\end{array}$ & $\begin{array}{l}\text { Calcium and heme binding / } \\
\text { oxidoreductase activity }\end{array}$ & Oxidation-reduction process \\
\hline A0A1X7UUJ9 & $40 \mathrm{~S}$ ribosomal protein $\mathrm{S} 8$ & Structural constituent of ribosome & Translation \\
\hline A0A1X7V9A9 & Clathrin heavy chain & Clathrin light chain binding & Protein transport \\
\hline A0A1X7VLR9 & Histone $\mathrm{H} 4$ & DNA binding & DNA-template transcription \\
\hline A0A1X7UXJ8 & $\begin{array}{l}\text { Uncharacterized (alpha-actinin } \\
\text { family) }\end{array}$ & Calcium and actin ion binding & Cytoskeletal organization \\
\hline A0A1X7VL10 & ATP synthase subunit beta & ATP and nucleotide binding & Protein transport \\
\hline A0A1X7V9W5 & $\begin{array}{l}\text { HATPase_c domain- } \\
\text { containing protein }\end{array}$ & ATP and nucleotide binding & Protein folding \\
\hline A0A1X7V3W4 & $\begin{array}{l}\text { Uncharacterized (HSP70 } \\
\text { family) }\end{array}$ & ATP and nucleotide binding & Protein folding \\
\hline A0A1X7VSH2 & $\begin{array}{l}\text { Uncharacterized (Myosin } \\
\text { family) }\end{array}$ & $\begin{array}{c}\text { Actin and ATP binding / Motor } \\
\text { activity }\end{array}$ & Cytoskeletal organisation \\
\hline A0A1X7VNW3 & Catalase & Heme and metal ion binding & Oxidation-reduction process \\
\hline A0A1X7VRP4 & $\begin{array}{l}\text { Histone domain-containing } \\
\text { protein (Histone } 2 \mathrm{~B} \text { family) }\end{array}$ & DNA binding & DNA folding \\
\hline A0A1X7VAN2 & Calmodulin & Calcium and metal ion binding & Calcium-mediated signaling \\
\hline A0A1X7V1A0 & $\begin{array}{l}\text { Uncharacterized protein } \\
\text { (HSP60 family) }\end{array}$ & ATP and nucleotide binding & Protein folding \\
\hline A0A1X7V0I1 & $60 \mathrm{~S}$ ribosomal protein L40 & Structural constituent of ribosome & Translation \\
\hline A0A1X7UPB4 & Tubulin alpha chain & GTP binding & Cytoskeletal organisation \\
\hline A0A1X7TRT9 & Uncharacterized & - & - \\
\hline A0A1X7UQ10 & Tubulin alpha chain & GTP and nucleotide binding & Cytoskeletal organisation \\
\hline A0A1X7UKV7 & $\begin{array}{c}\text { Uncharacterized } \\
\text { (mitochondrial carrier family) }\end{array}$ & Transmembrane transporter activity & Protein transport \\
\hline A0A1X7V5G1 & Uncharacterized & GTP binding & - \\
\hline A0A1X7UIL6 & $\begin{array}{l}\text { Uncharacterized (ATPase } \\
\text { alpha/beta chains family) }\end{array}$ & $\begin{array}{l}\text { ATP and nucleotide binding / } \\
\text { proton-transporting ATP synthase } \\
\text { activity (rotational mechanism) }\end{array}$ & Protein transport \\
\hline A0A1X7VWH7 & $\begin{array}{l}\text { ADF-H domain-containing } \\
\text { protein }\end{array}$ & Actin binding & Cytoskeletal organisation \\
\hline
\end{tabular}

\subsubsection{Effect of temperature on protein expression}

From the 814 expressed proteins, 50 proteins were differentially abundant when exposed to elevated temperature (FDR < 0.1). PCA analysis revealed that similarities between protein expressions were mostly grouped among temperature treatments, except for sponges exposed to $30{ }^{\circ} \mathrm{C}$, where three samples were significantly dispersed (Fig. B.3.1). 72\% of the differentially expressed proteins (i.e. 36 proteins) were significantly more abundant while the remaining $28 \%$ were significantly less abundant at T4 (Table 3.3). Protein enrichment was mostly found for 
proteins involved in cytoskeletal organization (eight proteins), oxidative stress (seven proteins) and protein translation (three proteins). In contrast, significant decline in protein abundance was mostly apparent for proteins involved in transportation (four proteins) and protein catabolism (two proteins). Of the 50 differentially abundant proteins, 10 proteins (listed as 'Others') were uncharacterized with no GO annotation.

Table 3.3 Differentially abundant proteins from Amphimedon navalis exposed to $26{ }^{\circ} \mathrm{C}, 28{ }^{\circ} \mathrm{C}$ and $30{ }^{\circ} \mathrm{C}$. An FDR threshold of 0.1 and $\log$ ratio (fold-change) of \pm 0.25 were used. $\boldsymbol{\Delta}$ and represent significantly more and less abundant, respectively. 'Proteins in cluster' indicate the number of identified proteins combined into each protein cluster.

\begin{tabular}{|c|c|c|c|c|c|c|}
\hline $\begin{array}{c}\text { UniprotKB } \\
\text { Accession number }\end{array}$ & Protein annotation & $\begin{array}{l}\text { Proteins } \\
\text { in cluster }\end{array}$ & $\begin{array}{c}\text { Log- } \\
\text { ratio } \\
26^{\circ} \mathrm{C} \text { vs } \\
28^{\circ} \mathrm{C} \\
\end{array}$ & $\begin{array}{c}\text { Log- } \\
\text { ratio } \\
26^{\circ} \mathrm{C} \text { vs } \\
3^{\circ} \mathrm{C} \\
\end{array}$ & $\begin{array}{c}\text { Log- } \\
\text { ratio } \\
\mathbf{2 8}^{\circ} \mathrm{C} \text { vs } \\
\mathbf{3 0}^{\circ} \mathrm{C} \\
\end{array}$ & $\begin{array}{c}\text { Number of } \\
\text { unique } \\
\text { peptides }\end{array}$ \\
\hline \multicolumn{7}{|c|}{$\begin{array}{l}\text { Oxidation-reduction process (Oxidative stress) } \\
\end{array}$} \\
\hline A0A1X7V4C4 & Aldedh domain-containing protein & 2 & $2.42 \boldsymbol{\Delta}$ & $0.71 \boldsymbol{\Delta}$ & -1.70 & 3 \\
\hline I1GFQ7 & Ferritin & 2 & $2.40 \boldsymbol{\Delta}$ & $2.05 \boldsymbol{\Delta}$ & -0.34 & 4 \\
\hline A0A1X7SUN1 & VOC domain-containing protein & 2 & 0.94 & $1.54 \boldsymbol{\Delta}$ & 0.59 & 2 \\
\hline A0A1X7VNW3 & Catalase (Heme cofactor) & 2 & 0.62 & $0.92 \boldsymbol{\Delta}$ & $0.30 \boldsymbol{\Delta}$ & 7 \\
\hline A0A1X7VQL2 & $\begin{array}{l}\text { Uncharacterized (Thioredoxin-like } \\
\text { superfamily) }\end{array}$ & 1 & 0.32 & $2.00 \boldsymbol{\Delta}$ & $1.68 \boldsymbol{\Delta}$ & 1 \\
\hline A0A1X7UNX4 & $\begin{array}{l}\text { Uncharacterized (Glutathione S- } \\
\text { transferase superfamily) }\end{array}$ & 1 & -0.23 & 3.31 & $3.54 \boldsymbol{\Delta}$ & 1 \\
\hline A0A1X7T3Q9 & E1_dh domain-containing protein & 2 & -0.41 & $1.98 \boldsymbol{\Delta}$ & $2.39 \boldsymbol{\Delta}$ & 2 \\
\hline A0A1X7VJL6 & Peroxiredoxin & 1 & -1.34 & $-2.51 \nabla$ & -1.16 & 2 \\
\hline A0A1X7U633 & $\begin{array}{c}\text { Cytochrome } c \text { domain-containing } \\
\text { protein }\end{array}$ & 2 & -2.35 & $-4.19 \nabla$ & $-1.83 \nabla$ & 3 \\
\hline A0A1X7V4Y0 & $\begin{array}{l}\text { Proton-translocating NAD }(\mathrm{P})(+) \\
\text { transhydrogenase }\end{array}$ & 1 & $-2.37 \nabla$ & $-2.01 \nabla$ & 0.36 & 8 \\
\hline \multicolumn{7}{|c|}{ Protein transport } \\
\hline A0A1X7U4A4 & $\begin{array}{l}\text { Protein kinase domain-containing } \\
\text { protein }\end{array}$ & 1 & $1.51 \boldsymbol{\Delta}$ & $1.50 \boldsymbol{\Delta}$ & -0.01 & 1 \\
\hline A0A1X7UVI1 & $\begin{array}{l}\text { Protein kinase domain-containing } \\
\text { protein }\end{array}$ & 1 & 1.13 & $1.82 \boldsymbol{\Delta}$ & 0.69 & 3 \\
\hline A0A1X7VH72 & $\begin{array}{l}\text { Uncharacterized (inositol } \\
\text { phosphokinase family) }\end{array}$ & 1 & $0.84 \boldsymbol{\Delta}$ & $1.11 \boldsymbol{\Delta}$ & 0.27 & 2 \\
\hline A0A1X7V114 & $\begin{array}{l}\text { Vacuolar protein sorting- } \\
\text { associated protein } 11 \text { homolog }\end{array}$ & 1 & 0.70 & $1.47 \boldsymbol{\Delta}$ & 0.77 & 3 \\
\hline A0A1X7UHM1 & Ras-related protein Rab-14 & 1 & 0.36 & $0.50 \boldsymbol{\Delta}$ & 0.13 & 6 \\
\hline A0A1X7VLI5 & $\begin{array}{l}\text { Protein kinase domain-containing } \\
\text { protein }\end{array}$ & 1 & 0.16 & $2.16 \boldsymbol{\Delta}$ & $2.00 \boldsymbol{\Delta}$ & 1 \\
\hline A0A1X7VL10 & ATP synthase subunit beta & 1 & $-0.48 \nabla$ & -0.39 & 0.09 & 14 \\
\hline A0A1X7VVN1 & $\begin{array}{l}\text { Uncharacterized (ABC } \\
\text { transporter-like family) }\end{array}$ & 1 & $-0.82 \nabla$ & $-1.26 \nabla$ & $-0.43 \nabla$ & 0 \\
\hline A0A1X7VJC1 & Uncharacterized (DUOXA family) & 1 & $-2.98 \nabla$ & -1.99 & 0.98 & 2 \\
\hline A0A1X7VXP7 & Uncharacterized (SNF7 family) & 1 & $-3.35 \nabla$ & $-3.93 \nabla$ & -0.57 & 2 \\
\hline
\end{tabular}




\begin{tabular}{|c|c|c|c|c|c|c|}
\hline $\begin{array}{c}\text { UniprotKB } \\
\text { Accession number }\end{array}$ & Protein annotation & $\begin{array}{l}\text { Proteins } \\
\text { in cluster }\end{array}$ & $\begin{array}{c}\text { Log- } \\
\text { ratio } \\
26^{\circ} \mathrm{C} \text { vs } \\
28^{\circ} \mathrm{C}\end{array}$ & $\begin{array}{c}\text { Log- } \\
\text { ratio } \\
26^{\circ} \mathrm{C} \text { vs } \\
30^{\circ} \mathrm{C} \\
\end{array}$ & $\begin{array}{c}\text { Log- } \\
\text { ratio } \\
28^{\circ} \mathrm{C} \text { vs } \\
3^{\circ} \mathrm{C} \\
\end{array}$ & $\begin{array}{c}\text { Number of } \\
\text { unique } \\
\text { peptides }\end{array}$ \\
\hline \multicolumn{7}{|c|}{ Cytoskeletal organization } \\
\hline A0A1X7UKK7 & Costars domain-containing protein & 1 & $4.11 \boldsymbol{\Delta}$ & $3.33 \mathbf{\Delta}$ & -0.78 & 2 \\
\hline A0A1X7VU79 & Fascin & 1 & $3.20 \bar{\Delta}$ & 0.62 & -2.58 & 3 \\
\hline A0A1X7UPB4 & Tubulin alpha chain & 1 & $1.31 \boldsymbol{\Delta}$ & $3.80 \boldsymbol{\Delta}$ & 2.48 & 2 \\
\hline A0A1X7UIF6 & $\begin{array}{l}\text { F-actin-capping protein subunit } \\
\text { beta }\end{array}$ & 1 & 0.78 & 0.36 & $-0.41 \boldsymbol{\nabla}$ & 5 \\
\hline A0A1X7V1D4 & Tubulin alpha chain & 1 & $0.52 \boldsymbol{\Delta}$ & $1.11 \boldsymbol{\Delta}$ & $0.59 \boldsymbol{\Delta}$ & 3 \\
\hline A0A1X7U6V8 & $\begin{array}{l}\text { Septin-type G domain-containing } \\
\text { protein }\end{array}$ & 2 & $0.50 \boldsymbol{\Delta}$ & 0.04 & $0.55 \boldsymbol{\Delta}$ & 6 \\
\hline A0A1X7VTE3 & $\begin{array}{c}\text { Uncharacterized (small GTPase } \\
\text { family) }\end{array}$ & 1 & 0.48 & $0.46 \boldsymbol{\Delta}$ & -0.02 & 9 \\
\hline A0A1X7UXJ8 & $\begin{array}{c}\text { Uncharacterized (alpha-actinin } \\
\text { family) }\end{array}$ & 1 & $0.46 \boldsymbol{\Delta}$ & $0.45 \boldsymbol{\Delta}$ & -0.01 & 20 \\
\hline A0A1X7V9U2 & $\begin{array}{c}\text { Uncharacterized (WASH complex, } \\
\text { subunit strumpellin) }\end{array}$ & 1 & 0.34 & $1.99 \boldsymbol{\Delta}$ & $1.64 \boldsymbol{\Delta}$ & 2 \\
\hline A0A1X7U0F7 & PDZ domain-containing protein & 1 & -1.04 & $-1.38 \nabla$ & -0.34 & 2 \\
\hline \multicolumn{7}{|c|}{ Signal transduction } \\
\hline A0A1X7VAN2 & Calmodulin & 3 & $0.50 \boldsymbol{\Delta}$ & $1.18 \boldsymbol{\Delta}$ & $0.68 \boldsymbol{\Delta}$ & 3 \\
\hline A0A1X7UI48 & Histidine-tRNA ligase & 1 & $-0.78 \nabla$ & $-2.94 \nabla$ & -2.16 & 3 \\
\hline A0A1X7VIG0 & $\begin{array}{l}\text { ADP-ribosylation factor } 6 \text { (Arf } \\
\text { family) }\end{array}$ & 1 & -2.51 & $-2.82 \nabla$ & -0.30 & 3 \\
\hline \multicolumn{7}{|c|}{ Protein translation } \\
\hline A0A1X7VB92 & $\begin{array}{c}\text { Aspartate-tRNA ligase } \\
\text { cytoplasmic }\end{array}$ & 1 & $2.05 \boldsymbol{\Delta}$ & $2.88 \boldsymbol{\Delta}$ & 0.83 & 3 \\
\hline A0A1X7V8E5 & $\begin{array}{l}\text { Uncharacterized (Universal } \\
\text { ribosomal protein S8 family) }\end{array}$ & 1 & 1.59 & $4.70 \boldsymbol{\Delta}$ & 3.10 & 3 \\
\hline A0A1X7V0I1 & $\begin{array}{c}\text { Ubiquitin - 60S ribosomal protein } \\
\text { L40 }\end{array}$ & 6 & $0.82 \boldsymbol{\Delta}$ & $1.00 \boldsymbol{\Delta}$ & 0.18 & 5 \\
\hline \multicolumn{7}{|c|}{\begin{tabular}{|l} 
\\
\end{tabular} Protein catabolism } \\
\hline A0A1X7VN30 & Proteasome subunit beta & 2 & $3.04 \boldsymbol{\Delta}$ & $4.96 \boldsymbol{\Delta}$ & $1.92 \Delta$ & 2 \\
\hline A0A1X7VGM8 & Palmitoyl-protein hydrolase 1 & 1 & $-1.55 \nabla$ & -1.53 & 0.02 & 8 \\
\hline A0A1X7VV07 & $\begin{array}{l}\text { Sulfatase domain-containing } \\
\text { protein }\left(\mathrm{Ca}^{2+} \text { Cofactor }\right)\end{array}$ & 1 & $-2.02 \nabla$ & $-2.96 \nabla$ & $-0.93 \nabla$ & 0 \\
\hline \multicolumn{7}{|c|}{ Metabolic process } \\
\hline A0A1X7VEB3 & $\begin{array}{l}\text { Adenosylhomocysteinase }\left(\mathrm{NAD}^{+}\right. \\
\text {cofactor) }\end{array}$ & 1 & $1.24 \boldsymbol{\Delta}$ & $4.48 \boldsymbol{\Delta}$ & $3.24 \boldsymbol{\Delta}$ & 4 \\
\hline \multicolumn{7}{|c|}{ (a) } \\
\hline A0A1X7SVR6 & Uncharacterized & 4 & $3.77 \boldsymbol{\Delta}$ & $5.15 \Delta$ & 1.38 & 1 \\
\hline A0A1X7VMX7 & $\begin{array}{l}\text { Septin-type G domain containing } \\
\text { protein }\end{array}$ & 1 & 2.15 & $4.16 \boldsymbol{\Delta}$ & 2.01 & 2 \\
\hline A0A1X7SMT9 & Uncharacterized & 1 & $1.02 \boldsymbol{\Delta}$ & $1.78 \boldsymbol{\Delta}$ & 0.76 & 1 \\
\hline A0A1X7VLW9 & $\begin{array}{l}\text { Transket_pyr domain-containing } \\
\text { protein }\left(\mathrm{Co}^{2+} \text { and } \mathrm{Mg}^{2+} \text { cofactor }\right)\end{array}$ & 1 & 0.88 & $0.40 \boldsymbol{\Delta}$ & -0.48 & 4 \\
\hline A0A1X7V015 & $\begin{array}{l}\text { DUF3504 domain-containing } \\
\text { protein }\end{array}$ & 1 & 0.86 & $2.32 \boldsymbol{\Delta}$ & 1.46 & 1 \\
\hline A0A1X7SJZ1 & Uncharacterized & 3 & 0.62 & $1.25 \boldsymbol{\Delta}$ & 0.63 & 1 \\
\hline A0A1X7SYB4 & Uncharacterized & 1 & 0.61 & $1.55 \bar{\Delta}$ & 0.94 & 1 \\
\hline A0A1X7U869 & $\begin{array}{l}\text { Store-operated calcium entry- } \\
\text { associated regulatory factor }\end{array}$ & 1 & 0.58 & $1.38 \boldsymbol{\Delta}$ & 0.80 & 1 \\
\hline A0A1X7VNC8 & $\begin{array}{l}\text { Uncharacterized (RNA helicase } \\
\text { family) }\end{array}$ & 1 & -0.04 & $1.47 \boldsymbol{\Delta}$ & 1.51 & 3 \\
\hline A0A1X7T7Q1 & Uncharacterized & 2 & -1.44 & $-2.28 \nabla$ & -0.83 & 2 \\
\hline
\end{tabular}


The Miss test revealed that differences in protein abundance were most pronounced in sponges exposed to $30{ }^{\circ} \mathrm{C}$ relative to the controls, where 43 proteins were differentially abundant (33 proteins were significantly highly abundant and 10 proteins were significantly less abundant) at the end of the experiment. For sponges exposed to $28^{\circ} \mathrm{C}, 25$ proteins were differentially expressed in comparison to the controls. Seventeen proteins were significantly more abundant and eight were significantly least abundant. On the other hand, fifteen proteins were differentially expressed at 30 ${ }^{\circ} \mathrm{C}$ relative to $28{ }^{\circ} \mathrm{C}$, of which eleven were highly abundant and four less abundant (Fig. 3.6). Tubulin alpha chain, calmodulin, proteasome subunit beta and adenosylhomocysteinase were significantly more abundant, whereas uncharacterized ( $\mathrm{ABC}$ transporter-like family) and sulfatase domain-containing protein were significantly less abundant between all comparative treatments.

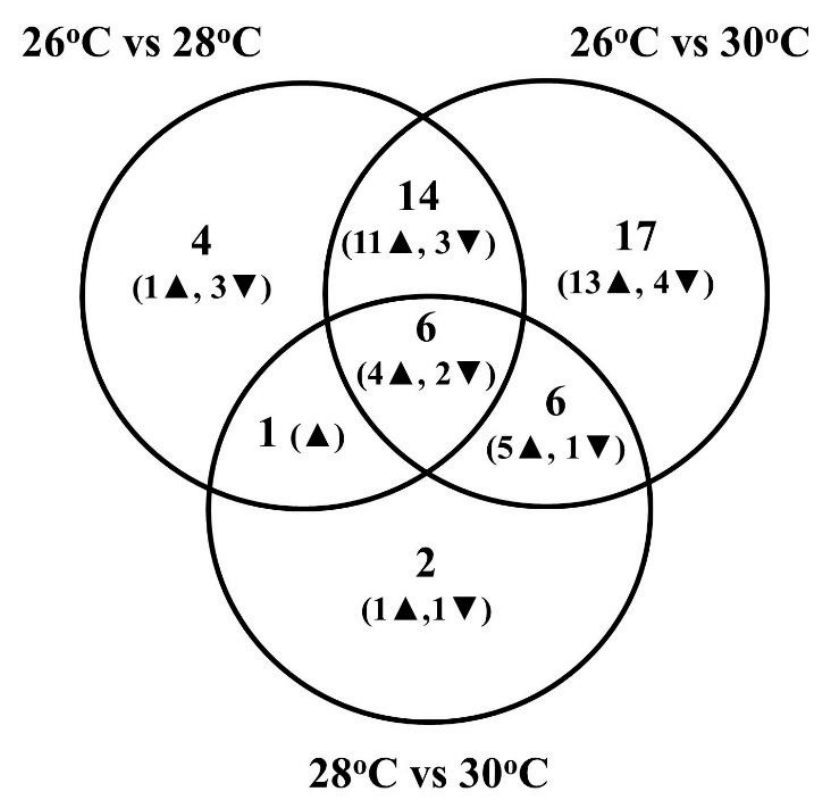

Fig. 3.6 Venn diagram representing the distribution of the significantly expressed proteins from Amphimedon navalis between different temperature treatments. Numbers in brackets represent the number of proteins that were significantly higher $(\boldsymbol{\Lambda})$ or lower $(\boldsymbol{\nabla})$. 


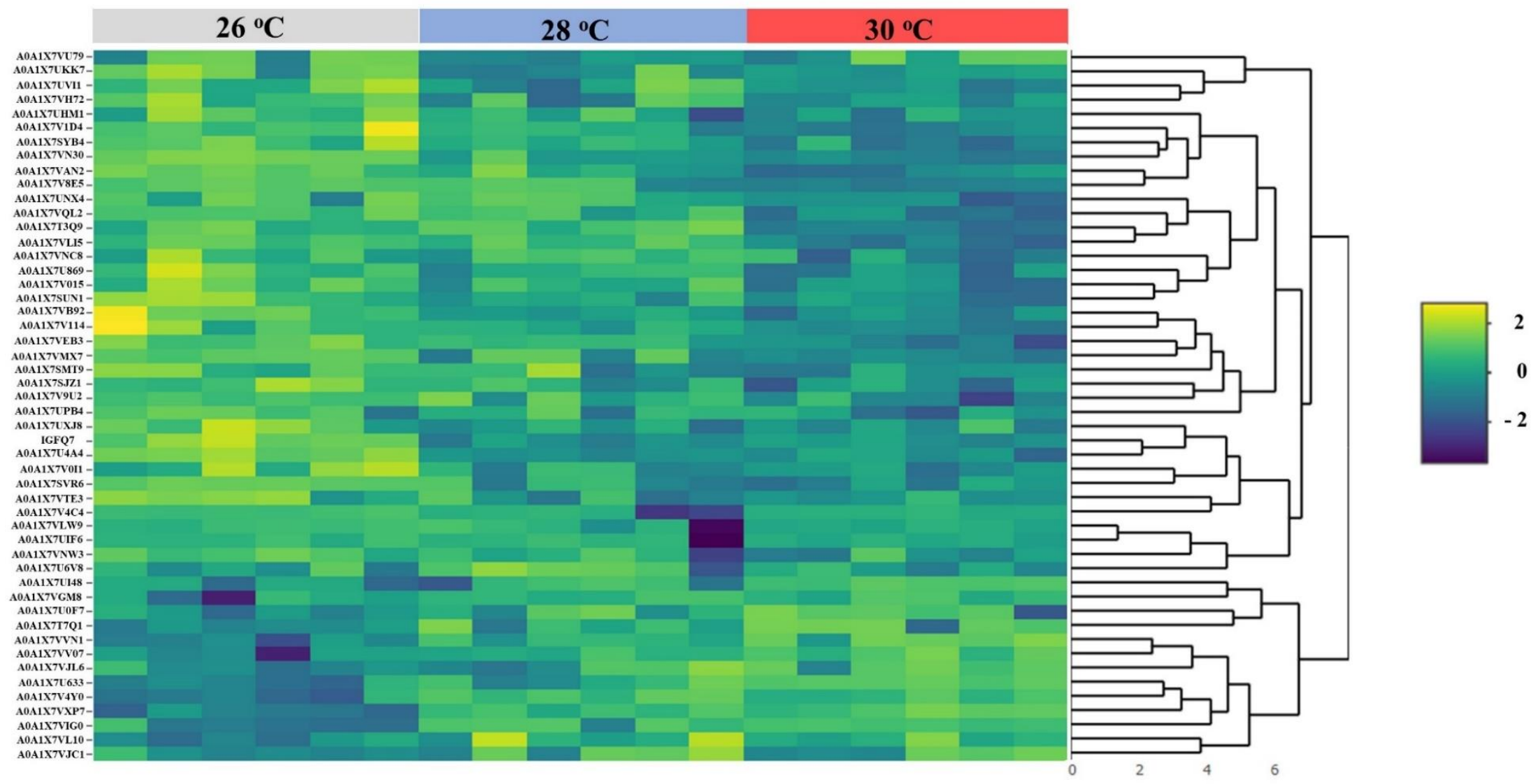

Fig. 3.7 Heatmap showing the 50 differentially abundant proteins from Amphimedon navalis when exposed to $26{ }^{\circ} \mathrm{C}, 28{ }^{\circ} \mathrm{C}$ and $30{ }^{\circ} \mathrm{C}$. Each row corresponds to a specific protein. Colour scale ranges from yellow (low abundance) to dark blue (high abundance). 


\subsection{Discussion}

Lagoon-inhabiting organisms are often exposed to elevated temperatures (Anthony et al., 2009). Yet, the thermal responses of lagoon-inhabiting sponges, which are often important components of coastal lagoons are poorly understood. This chapter explored the physiological responses of three sponge species and the proteomic responses of one lagoon-inhabiting sponge from the Western Indian Ocean. At the physiological level, the buoyant weight of Neopetrosia chaliniformis and Amphimedon navalis significantly declined after one-week of thermal exposure. $N$. chaliniformis and Spheciospongia vagabunda $\Delta \mathrm{F} / \mathrm{F}_{\mathrm{m}}$ ' also declined significantly when exposed to elevated temperature. The pumping rates of all species and the holobiont oxygen consumption (i.e. respiration) of $N$. chaliniformis and A. navalis increased significantly by the end of the experiment. In contrast to $N$. chaliniformis and A. navalis, the physiological responses of $S$. vagabunda did not change significantly after two weeks of thermal exposure, suggesting that this species may acclimate to elevated seawater temperature within this timeframe. A. navalis proteomic analysis revealed that 50 proteins, which are mostly involved in oxidation-reduction, protein transport and cytoskeletal organization processes, were differentially expressed after four weeks of elevated temperature. While most of the differentially expressed proteins were significantly enriched at elevated temperature, some proteins such as ATP synthase subunit beta (protein transport) and sulfatase domain-containing protein (protein catabolism) were significantly downregulated.

\subsubsection{Physiological responses}

Thermal stress in sponges can often lead to a reduced photochemical efficiency $\left(\Delta \mathrm{F} / \mathrm{F}_{\mathrm{m}}{ }^{\prime}\right)$ of the host's associated photosymbionts. This has previously been reported for the Great Barrier Reef sponges Cymbastela coralliophila (Bennett et al., 2017) and Cliona orientalis (Schönberg et al., 2008; Ramsby et al., 2018). In the present study, the decline in $\Delta \mathrm{F} / \mathrm{F}_{\mathrm{m}}{ }^{\prime}$ for $N$. chaliniformis and $S$. vagabunda was clearly visible after the first week of the experiment. However, while the results for $N$. chaliniformis and A. navalis presented here were relatively coherent with the short-term (two weeks) experimental results reported in Chapter 2, it is interesting to note that, S. vagabunda $\Delta \mathrm{F} / \mathrm{F}_{\mathrm{m}}$ ' appeared to remain relatively stable (except for sponges exposed to 28 ${ }^{\circ} \mathrm{C}$ ) after a thermal exposure of two weeks. This indicated the possible acclimation of $S$. vagabunda photosynthetic performance under prolonged thermal exposure. While the acclimatory mechanisms of $S$. vagabunda was not investigated in this study, it is likely that this species was acclimated to higher temperatures in situ, when thermal tolerance experiments of 
this chapter were initiated in February. Seasonal adaptations of shallow water sponges have previously been reported by Elvin (1976) and seasonal characteristics of S. vagabunda have previously been reported by (Beepat et al., 2013). Given that the combined thermaleutrophication experiments in Chapter 2 were conducted in October (end of winter) and that the present experiments were carried out in February (summer), the thermal responses of this species could potentially be season-specific. However, additional inter seasonal monitoring of S. vagabunda physiological responses would be required to confirm this hypothesis. Under environmental stress, some clionid sponges, such as $C$. orientalis have the ability to shift their associated symbionts into deeper tissues for protection (Schönberg \& Suwa, 2007; Fang et al., 2016). While this hypothesis was not investigated in the present study, it is possible that such a mechanism may exist in $S$. vagabunda. In addition to cyanobacteria, $S$. vagabunda also hosts dinoflagellate symbionts (Levi et al., 1998). Therefore, under thermal stress, it is possible that S. vagabunda may shift its associated cyanobacteria into deeper tissues and rely on its associated dinoflagellate symbionts for its energetic demands to account for any loss of associated cyanobacteria.

The impacts of elevated temperature on sponge pumping rate have previously been reported for the sponges Halichondria panicea, Haliclona urceolus (Riisgård et al., 1993) and Rhopaloeides odorabile (Massaro et al., 2012). While Riisgård et al. (1993) reported a significant increase in pumping rate in thermally-stressed sponges, Massaro et al. (2012) reported a significant decline in pumping rate. This suggests that changes in sponge pumping rate may be species-specific. Given that sponges are reliant on their pumping ability for feeding and oxygen demand (Vogel, 1977; Hadas et al., 2008; Leys et al., 2011), there exists a correlation between sponge pumping rate and holobiont oxygen consumption rate for all species (see Table B3.3). According to Hadas et al. (2008), approximately $75 \%$ of the oxygen consumed by sponges is used for the host's maintenance and pumping activity, while the remaining 25\% is used for other physiological activities. Thomassen and Riisgård (1995) also suggested that there is a strong relationship between sponge growth rate and sponge respiration. When exposed to elevated temperature, $N$. chaliniformis and A. navalis may utilize most of their energy uptake for maintaining basic physiological activities such as respiration as a response to thermal stress, with less energy allocated to growth. However, some studies suggest that there is potentially no direct correlation between elevated temperature and sponge growth (Duckworth et al., 2012; Vicente et al., 2015). For example, Duckworth et al. (2012) reported no significant change in the growth rate of six Caribbean sponges when exposed to a 
combination of elevated temperature and reduced $\mathrm{pH}$ for 24 days, and a similar response was also reported for the sponge Mycale grandis (Vicente et al., 2015). In the present study, while the results for $S$. vagabunda buoyant weight were consistent with the findings of Duckworth et al. (2012) and Vicente et al. (2015), the significant reduction of buoyant weight for $N$. chaliniformis and A. navalis over the course of the experiment indicates that $N$. chaliniformis and $A$. navalis are greatly impacted by increased temperature.

The physiological trends reported in the present study demonstrate that the responses of lagooninhabiting sponges are species-specific and partially support the earlier findings reported in Chapter 2. However, in contrast to $N$. chaliniformis and A. navalis, the bioeroding sponge $S$. vagabunda appears to have the potential to acclimate to elevated temperature, with the most striking difference being reflected in the change in buoyant weight (Fig. 3.2). Similarly, $S$. vagabunda $\Delta \mathrm{F} / \mathrm{F}_{\mathrm{m}}$ ', holobiont oxygen consumption and pumping rate after two weeks of thermal exposure remained relatively stable until the end of the experiment (Figs. 3.3 - 3.5). This contrast between the results presented here and the results reported in Chapter 2 demonstrates that short-term thermal-tolerance experiments for some sponge species could possibly be less informative than longer-terms ones, and that after a prolonged stress exposure some species could potentially acclimate to elevated temperature. Therefore, additional medium- and long-term experimental investigations are necessary to demonstrate the acclimatory capacity of sponges to temperature change.

\subsubsection{A. navalis proteomic responses}

Cellular mechanisms in response to thermal stress have previously been reported for some sponges (Lopez-Legentil et al., 2008; Pantile \& Webster, 2011; Webster et al., 2013). For example, using gene-expression patterns, Pantile and Webster (2011) and Webster et al. (2013) demonstrated that the reef sponge $R$. odorabile experienced significant downregulation in multiple genes involved in protein folding and cytoskeletal arrangement when exposed to elevated temperature of up to $+5{ }^{\circ} \mathrm{C}$ for 15 days. Guzman and Conaco (2016) also showed that a three-day thermal exposure of up to $+5{ }^{\circ} \mathrm{C}$ increased the expression of heat shock proteins, antioxidants and genes involved in signal transduction in the sponge Haliclona tubifera. The present study demonstrates that cellular mechanisms in response to thermal stress can also be expressed in sponges at the proteome level. Thermal stress in A. navalis resulted in the significant upregulation of multiple proteins that are mostly involved in oxidative stress, 
protein transport, and cytoskeletal arrangement, although proteins were also differentially expressed in functions such as signal transduction, protein translation and protein catabolism.

Proteomic analysis provided clear evidence of oxidative stress in thermally-stressed A. navalis. This resulted in the upregulation of multiple antioxidant enzymatic proteins such as aldehd, catalase and glutathione-S-transferase (Table 3.3). The upregulation of these enzymatic proteins suggests an increase in detoxification processes to counteract the dissociation of amino acids by reactive oxygen species (ROS). ROS can be stimulated by heat stress (Belhadj Slimen et al., 2014) and are often responsible for cellular damage (Ray et al., 2012). They have been reported in multiple marine organisms (Lesser, 2006) and the genetic upregulation of such enzymes as a response to oxidative stress has previously been reported in thermally-stressed sponges (Bachinski et al., 1997; Pantile \& Webster, 2011; Guzman \& Conaco, 2016). The upregulation of these enzymes in parallel with the upregulation of redox proteins, including ferritin and thioredoxin, suggests that A. navalis cells may have experienced hypoxic conditions when exposed to elevated temperature. The downregulation of cytochrome $c$ proteins, which are reported to dissociate in the presence of increased ROS concentrations in the cell, may also indicate changes in cellular detoxification processes (Petrosillo et al., 2001). Consequently, the increase in holobiont oxygen consumption noted in A. navalis may likely be a response to the oxidative stress being induced at the cellular level of the sponge.

Thermal stress also significantly increased the production of proteins related to cytoskeletal organization in A. navalis. The highest fold-changes in protein expression were observed in coastars-related protein, fascin and tubulin alpha-related proteins (Table 3.3). These proteins are involved in cell motility (Pang et al., 2010) and the maintenance of cell shape, and provide mechanical resistance to cell deformation in the cytoskeleton complex (Herrmann et al., 2007). Therefore, the increase in cytoskeletal activity observed here in A. navalis is likely related to the loss of biomass (buoyant weight) of this sponge, which could indicate a decline in cellular health at higher temperatures. This is further supported by the upregulation of fascin and septin type-G, which are involved in cell morphological alterations (Yamashiro et al., 1998) and cell division (Bridges \& Gladfelter, 2015), respectively. Tubulins are important components of the cytoskeleton complex and are involved in the formation and movement of cilia and flagella (Mohri et al., 2012). Given that sponges rely on the movement of flagellated cells for pumping and respiration, the increase in A. navalis pumping rate is most likely associated with the upregulation of multiple tubulin alpha chain proteins (Green \& Dove, 1984). 
Interestingly, the enrichment of some proteins, such as proteasome subunit beta (protein catabolism), ubiquitin (protein translation) and calmodulin (signal transduction), is consistent with previous thermal-stress studies performed on corals (Downs et al., 2000; DeSalvo et al., 2010; Huang et al., 2018). The enrichment of calmodulin, for example, has been reported in thermally-stressed Galexea astreata (Huang et al., 2018). Upregulation of calmodulin expression suggests a possible disruption in $\mathrm{Ca}^{2+}$ homeostasis, which could lead to disrupted cell proliferation (Berchtold \& Villalobo, 2014). Being a multifunctional protein, calmodulin can be involved in both signal transduction and cytoskeletal organization (Desrivières et al., 2002), and it mediates multiple intracellular processes such as apoptosis and the immune response (Koga \& Kawakami, 2018). As a result, the upregulation of proteins such as proteasome subunit beta and ubiquitin, which are involved in intracellular proteolysis processes, was not surprising. These proteins are expressed during both cellular and physiological disorders (Schwartz \& Ciechanover, 2009), and have been documented in thermally-stressed Monstastraea faveolata (Downs et al., 2000) and Acropora palmata (DeSalvo et al., 2010), respectively. The significant upregulation of proteasome subunit beta and ubiquitin proteins in the present study suggests that $A$. navalis cells were likely subjected to an increased concentration of degraded or misfolded proteins at elevated temperature.

The proteomic responses of $A$. navalis reported here are partially consistent with the gene expression studies of Pantile and Webster (2011), Webster et al. (2013) and Guzman and Conaco (2016). However, it is interesting to note that the expression dynamics of some specific proteins reported for A. navalis differed from the gene expression of $R$. odorabile and $H$. tubifera. For example, while thermal stress reduced the abundance of mRNA genes, such as calmodulin, ubiquitin and actin-relates proteins, in R. odorabile (Pantile \& Webster, 2011; Webster et al., 2013), these proteins were clearly upregulated in thermally-stressed A. navalis. Furthermore, while both $R$. odorabile and $H$. tubifera experienced significant upregulation in heat shock chaperones such as Hsp70 or Hsp90, no such upregulation was observed in $A$. navalis. This variability in cellular biological functions may be attributed to the different temperature treatments used in the different studies. While the experiments of Webster et al. (2013) and Guzman and Conaco (2016) were designed with thermal increases of $4-5{ }^{\circ} \mathrm{C}$, the temperature increase in the present study was restricted to an increase of $2-4{ }^{\circ} \mathrm{C}$. However, given that sponge physiological responses to elevated temperature are often species-specific (Bell et al., 2018), this species-specificity may possibly be reflected at the cellular level. The 
hypothesis that cellular responses in sponges might be species-specific highlights the need to conduct additional in-depth multi-species proteomic investigations on the potential impacts of climate change on marine sponges. Furthermore, the high number of unidentified proteins reported in the present study, which was due to the phylogenetic distance between sponges and mammalian model organisms, highlights the need for better gene characterization in marine sponges.

\subsection{Conclusions}

Lagoon-inhabiting sponges are exposed to multiple environmental stressors related to climate change. This chapter demonstrates that, similar to reef sponges (Bell et al., 2018), some lagooninhabiting sponges such as $N$. chaliniformis and A. navalis are physiologically susceptible to elevated temperature. However, the results of this chapter also show that bioeroding sponges such as S. vagabunda could have the potential to acclimate to prolonged periods of elevated temperature, as suggested by Schönberg et al. (2017). This demonstrates that the acclimatory responses of lagoon-inhabiting sponges to elevated temperature are likely species-specific. The proteomic responses of $A$. navalis also revealed that the impacts of elevated temperature on sponges are reflected at cellular functional levels, where multiple biological functions such as oxidation-reduction process, protein transport and cytoskeletal organization are significantly affected. As a result, the incorporation of proteomic data with physiological observations could greatly enhance our understanding of the environmental tolerance of sponges. 
Chapter 4:

Temporal variability in tropical lagoon-inhabiting sponges: effects of SST and $\mathrm{Chl} a$ concentration 


\begin{abstract}
Coastal lagoons are subjected to complex abiotic interactions that result in strong spatiotemporal variability of lagoon-inhabiting communities. Sponges are important components of coastal lagoons, yet their temporal variability is poorly understood. This chapter investigates the temporal variability in local distribution area (LDA), abundance (number of patches) and percentage cover of three lagoon-inhabiting sponge species: Neopetrosia chaliniformis, Amphimedon navalis and Spheciospongia vagabunda from Mauritius in the Western Indian Ocean, over a six- to eight-year period (depending on species). The correlations between two known drivers of sponge temporal patterns, sea surface temperature (SST) and chlorophyll $a$ (Chl a) concentration, were also explored. After the survey, the total LDA and percentage cover of $N$. chaliniformis decreased by $40.2 \%$ and $14.6 \%$, respectively, whereas total LDA and percentage cover of S. vagabunda increased by $135.1 \%$ and $23.3 \%$, respectively. No significant changes were seen in the total LDA and percentage cover of A. navalis. While the abundance of $N$. chaliniformis and A. navalis declined over the study period, the abundance of $S$. vagabunda increased. SST and Chl $a$ concentration were significantly correlated with temporal changes in the abundance of all species, although correlations were species-specific. However, no significant correlations were seen between the environmental parameters and changes in sponge percentage cover, except between SST and N. chaliniformis percentage cover. The results presented in this chapter demonstrate that lagoon sponges show species-specific patterns in temporal variability and, while some species may potentially become locally extinct over the next few decades, if trends continue other species may become more abundant or may remain stable.
\end{abstract}




\subsection{Introduction}

Coastal lagoons are highly productive, semi-enclosed water bodies that are characterized by dynamic environmental conditions (Kjerfve, 1994). Being only partially connected to the open ocean and with low-flushing rates, coastal lagoons are increasingly becoming susceptible to anthropogenic stressors, such as ocean warming (Anthony et al., 2009) and eutrophication (Nixon, 1995). However, while lagoon-inhabiting species are likely adapted to these dynamic environments (Vernberg, 1982; Taylor et al., 1995), lagoon-specific communities are thought to experience marked temporal changes due to the complex natural abiotic interactions that characterize these ecosystems (Pérez-Ruzafa et al., 2007a). For example, plankton, zoobenthos and meiobenthos exhibit significant spatio-temporal variation in Greek lagoons as a result of environmental perturbations (Nicolaidou et al., 2005). Lagoon species are thought to be confined to these ecosystems because, in addition to their adaptation to these environments, they are also influenced by interspecific competition (Peterson, 1979). As a result, it is important to investigate the temporal variability of lagoon-inhabiting communities to enable possible anthropogenic impacts on these communities to be distinguished from natural patterns of variability. Temporal changes within lagoon benthic communities have mostly been reported for macrophytes (Pérez-Ruzafa et al., 2008; Christia et al., 2018) and corals (Adjeroud et al., 2019; Muko et al., 2019), while the temporal variation of other important lagoon-inhabiting taxa, such as sponges, are less understood. Given the ecological importance of sponges in marine ecosystems (Bell, 2008) and the vulnerability of coastal lagoons to anthropogenic stress (Anthony et al., 2009; Brito et al., 2011), it is important to understand the temporal variability of lagoon-specific sponge populations and identify possible drivers of such changes.

The temporal variability of sponges has previously been described from the Caribbean (Zea, 1994; Wulff, 2006a), Indo-Pacific (Biggerstaff et al., 2017; Rovellini et al., 2019), tropical Atlantic (Kelmo et al., 2013; de Moraes et al., 2019), Mediterranean (Koopmans \& Wijffels, 2008; Di Camillo et al., 2012) and Great Barrier Reef (Ramsby et al., 2017), but there have been no studies from the Indian Ocean. From these earlier studies, multiple biotic and abiotic factors, including macroalgal competition (Ávila et al., 2015; Ramsby et al., 2017), seawater temperature (Carballo et al., 2008; Kelmo et al., 2013), salinity (Corriero et al., 2007; Longo et al., 2015) and cyanobacterial blooms (Butler et al., 1995; Stevely et al., 2010), have been reported to correlate with sponge temporal variability. For example, the disappearance of sponges and the reduction of sponge biomass on the shallow reef of San Blas, Panama, over a 
14-year study were partially attributed to disease in keratose sponges, although other unknown local factors might have contributed to the decline (Wulff, 2006a). In the Mediterranean Sea, salinity and nutrients were negatively correlated with sponge growth (Koopmans \& Wijffels, 2008). However, while some studies report significant declines of sponge abundance due to thermal stress, other studies have reported sponge tolerance to extreme temperature events. For example, Kelmo et al. (2013) reported an increase in sponge population density with no significant changes in sponge assemblage composition from Bahia, Brazil, when the coral density in this region declined after the El-Niño Southern Oscillation of 1997-1998. The reduced spatial competition between corals and sponges provided sponges more space to proliferate. Furthermore, a six-year study on South Atlantic sponge reefs showed that the abundance of bioeroding sponges increased over time, which was correlated with elevated sea surface temperature (de Moraes et al., 2019). However, while multiple studies have been conducted on the temporal variability of reef sponges, few studies have explored temporal variation in lagoon-inhabiting sponges.

Butler et al. (1995) investigated the temporal variability of sponges in Florida Lagoons (Florida Bay, USA), with a decline in lagoon sponges being attributed to strong cyanobacterial blooms that lead to reduced light penetration and increased sedimentation affecting sponge filtration rates. However, signs of a gradual recovery of these populations after 10-15 years were reported by Stevely et al. (2010), demonstrating that sponge populations can be dynamic and may be able to recover from environmental disturbance. Other studies have reported much more stable lagoon sponge assemblages. For example, in the Mediterranean, the sponge assemblage of the Venice Lagoon (Italy) was found to be temporally stable due to the lack of competition with other benthic taxa (Corriero et al., 2007). Similarly, the sponge assemblages in southern Italian lagoons have persisted over decades, although the spatial distribution of these sponges is mainly driven by salinity fluctuations (Longo et al., 2015). While the temporal variability of both reef and lagoon sponges is often driven by local natural environmental fluctuations, in some regions, sponge temporal dynamics have also been associated with anthropogenic stressors. For example, Longo et al. (2015) reported that anthropogenic pressures have caused major temporal changes in patterns of sponge abundance in some Italian lagoons, although the nature of these stressors remains unknown.

The sponges Neopetrosia chaliniformis, Amphimedon navalis and Spheciospongia vagabunda are common species inhabiting the coastal lagoons of Mauritius in the Western Indian Ocean. 
These species are an important component of lagoon benthic communities in that region, which host diverse micro- and macrofaunal communities (Beepat et al., 2014, 2015, 2016), and are also known to produce bioactive compounds (Beedessee et al., 2012). In this chapter, the temporal changes of these lagoon-inhabiting sponges were investigated over a period of six to eight years (depending on species). Temporal changes in: (1) local distribution areas within lagoons (i.e. total benthic area where sponges are found); (2) sponge abundance (number of sponge patches); and (3) percentage cover of each species were specifically explored. Any possible correlations between sponge temporal changes and Sea Surface Temperature (SST) or Chl $a$ concentration, which have previously been correlated with sponge temporal variability were also explored. Therefore, this chapter aims to determine whether the temporal variability of lagoon sponges is influenced by SST and Chl $a$ concentration.

\subsection{Materials and Methods}

\subsubsection{Study lagoons and species}

This study was carried out in three sponge-inhabited lagoons, which are at least $25 \mathrm{~km}$ apart, bordering the island of Mauritius in the Western Indian Ocean (see Fig. 4.1).

\subsubsection{Trou aux Biches}

The lagoon of Trou aux Biches (TAB; $20^{\circ} 01^{\prime} \mathrm{S} ; 57^{\circ} 33^{\prime} \mathrm{E}$ ) is located to the north west of the island. This lagoon is approximately $2 \mathrm{~km}$ long with a depth range of 1 to $3 \mathrm{~m}$. It supports multiple seagrass (mostly Syringodium isoetifolium) patches (Daby, 2006) and six distinct areas where the sponge Neopetrosia chaliniformis occurs. N. chaliniformis is a branching species and in TAB is mostly found attached to dead corals, although some sponges also occur on live Acropora spp. (Appadoo et al., 2011).

\subsubsection{Trou D'eau Douce}

Trou D'eau Douce lagoon (TDD; $20^{\circ} 14^{\prime} \mathrm{S} ; 57^{\circ} 47^{\prime} \mathrm{E}$ ) is located on the east coast of Mauritius. It is one of the largest lagoons surrounding the island and extends approximately $4 \mathrm{~km}$ along the coast. The depth of this lagoon varies from $0.5 \mathrm{~m}$ to $3 \mathrm{~m}$, although the lagoon channels near the outlets are approximately $15 \mathrm{~m}$ deep. While reports on the biodiversity of this lagoon are limited, it has three distinct areas where the branching sponge Amphimedon navalis occurs, mostly on coral rubble, and live Pavona spp. and Acropora spp. patches (Beepat, 2015). 


\subsubsection{Albion}

Albion lagoon (ALB) is a shallow ( 0.5 to $1.5 \mathrm{~m}$ deep) body of water on the west coast of Mauritius $\left(20^{\circ} 12^{\prime} \mathrm{S} ; 57^{\circ} 24^{\prime} \mathrm{E}\right)$. The coastline of ALB is approximately $1.5 \mathrm{~km}$ long and the lagoon supports diverse benthic taxa including corals, seagrasses (Casareto et al., 2017) and two distinct areas containing the sponge Spheciospongia vagabunda (Beepat et al., 2013). S. vagabunda is a burrowing sponge species that predominately occurs on the soft-bottom substratum of the lagoon, although it sometimes occurs on dead coral and coral rubble.

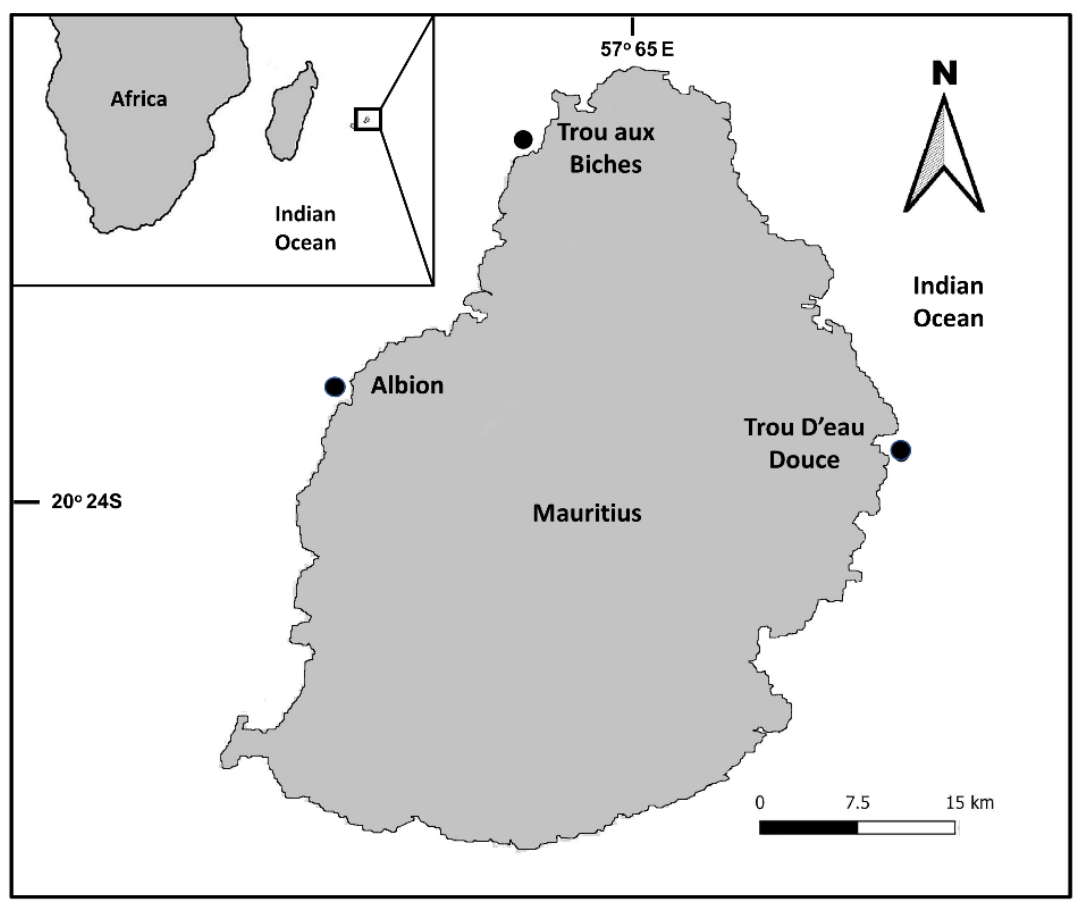

Fig. 4.1 The island of Mauritius (western Indian Ocean). Filled dots represent the study lagoons where sponge surveys were conducted. Map created in QGIS (QGIS Development Team, 2018).

\subsubsection{Field surveys}

\subsubsection{Local distribution area}

Sponge surveys in Mauritius were first conducted in January 2010 to assess the distribution of $N$. chaliniformis in TAB, with additional surveys initiated in 2012 to estimate the abundance of A. navalis and S. vagabunda in TDD and ALB, respectively, following the study of Beedessee et al. (2012). Field surveys were conducted at the three lagoons in January and December 2010 ( $N$. chaliniformis only), 2012, 2013, 2017 and 2018. The local distribution area of each species (i.e. the total benthic area where sponges could be found) within their respective lagoon was estimated by taking GPS coordinates $(10$ - 30 coordinates per distribution area) 
along the borders of each area where the sponges were found using a handheld GPS (GPS 72, Garmin, Kansas, USA) during each survey. GPS coordinates were used to construct sponge distribution maps (GIS maps) for each lagoon, which represented local sponge distribution areas at the start and end of the survey. GIS maps were constructed using Quantum GIS (QGIS Development Team, 2018) and the total local distribution areas within lagoons were estimated in $\mathrm{m}^{2}$ using the 'Ellipsoidal' tool from QGIS (see Appendix C - Table C4.1).

\subsubsection{Sponge abundance and percentage cover}

The sponge abundance (number of patches) in each lagoon was estimated by randomly placing $1 \mathrm{~m}^{2}$ quadrats $(\mathrm{n}=30)$ in the areas where sponges occurred. Sponge percentage cover within each local distribution area was estimated using $0.09 \mathrm{~m}^{2}(30 \mathrm{~cm} \times 30 \mathrm{~cm})$ photoquadrats $(\mathrm{n}=$ 30 per area), which were randomly placed on the benthos. Larger photoquadrats could not be used due to the shallow nature of the lagoons, limiting the distance between the camera lens and the benthos. Photoquadrats were acquired using a Canon G16 camera with an underwater housing and pictures were analysed using the NIH software ImageJ v.1.8.0 (Stokes \& Deane, 2009). Where sponges were seen to extend beyond the quadrat, only the sponge sub-section within the photoquadrat was considered for percentage cover measurements. The sponge abundance and percentage cover across all local sponge distribution areas within respective lagoons were then averaged to a yearly mean per lagoon (see Appendix C - Table C4.2).

\subsubsection{Data analysis}

\subsubsection{Temporal changes in abundance and percentage cover}

Temporal differences in sponge abundance and percentage cover for each species within local distribution areas (TAB, $\mathrm{n}=6$; $\mathrm{ALB}, \mathrm{n}=2$; TDD, $\mathrm{n}=3$ ) were estimated using generalized linear models (GLMs). Statistical analyses were conducted using R Statistical software v.3.6.1 (R Core Team, 2019). Negative binomial regression models (with logit link) were used from the R package 'MASS' (Venables \& Ripley, 2013) to explore temporal changes in sponge abundance (Ramsby et al., 2017). Negative binomial models were used to accommodate overdispersion of the sponge abundance data from Poisson regression models (Zeileis et al., 2008). A linear regression model from the $\mathrm{R}$ lme4 package (Bates et al., 2014) was used to investigate any temporal changes in sponge percentage cover (separately for each species). For both dependent variables, models were fitted with time (year) and distribution area as fixed factors. Model fits were evaluated by plotting residual and fitted values. 


\subsubsection{Effects of SST and Chl a}

For possible correlations between SST/Chl $a$ concentration and sponge temporal variability, daily SST and Chl $a$ concentration for the months of January and December corresponding with the field survey periods were retrieved from the level 3 MODIS-Aqua satellite products using a spatial resolution of $4 \mathrm{~km}$ (https://oceancolor.gsfc.nasa.gov/13/). Satellite data were extracted and averaged over a geographical box surrounding Mauritius using the following coordinates: $-19.5 \mathrm{~N}$ to $-21 \mathrm{~S} ; 56.5 \mathrm{~W}$ to $58.5 \mathrm{E}$ (see Fig. 4.2). Chl $a$ concentration data were used as a proxy for eutrophication, as this parameter has a strong relationship with phytoplankton biomass and nutrient levels in coastal waters (Taylor et al., 1995; Souchu et al., 2010; Ferreira et al., 2011). To account for satellite data variation over the survey period, bimonthly averaged SST and Chl $a$ concentration data corresponding to the survey periods (January and December) were used for statistical analysis. Generalized linear mixed models (GLMMs) were used to evaluate possible correlations between environmental variables (SST and Chl $a$ concentration) and changes in sponge abundance and percentage cover (see Table 4.1), with fixed effects being SST and Chl $a$ concentration and random effect being local distribution area. For sponge abundance data, GLMMs were fitted using a Poisson distribution since this variable was estimated through the 'counts' of sponges per $\mathrm{m}^{2}$ (Zeileis et al., 2008). The multicollinearity between both environmental variables was assessed using Pearson's correlation coefficients. Correlation coefficients between the variables were $<0.54$. Each model fit was evaluated by plotting residual and fitted values. Likelihood ratio tests (LRT) were also used to test the significance of individual terms. 


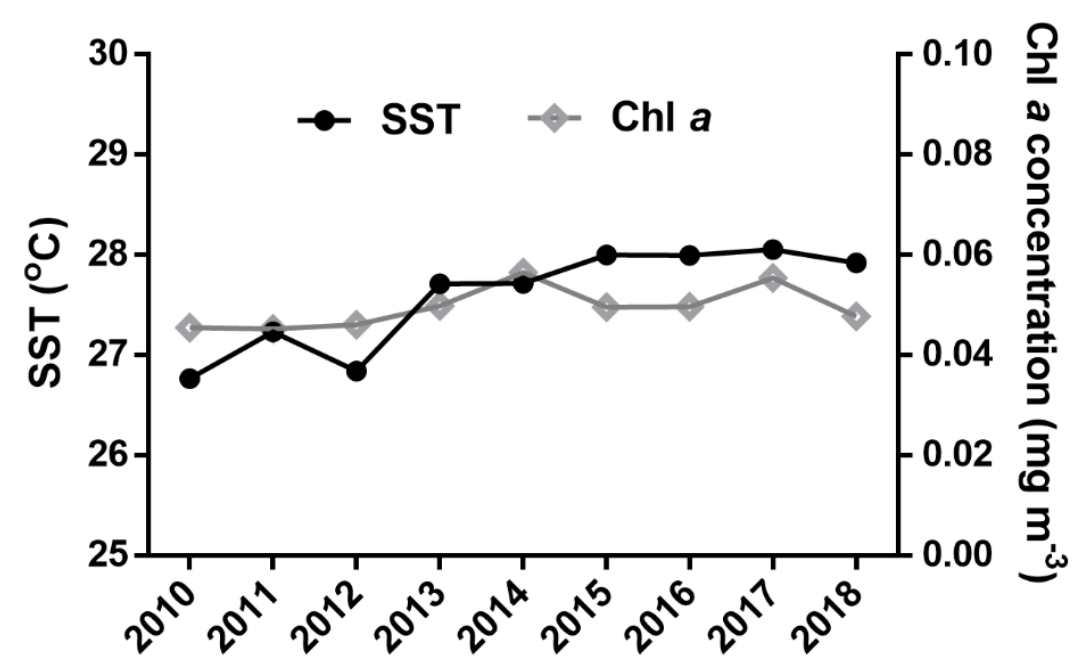

Fig. 4.2 Bimonthly SST and Chl $a$ concentration means from Mauritius during the survey period. Satellite data retrieved from MODIS-Aqua satellite, Ocean color. (Data available at: https://oceancolor.gsfc.nasa.gov/13/).

\subsection{Results}

\subsubsection{Local distribution area}

The total local distribution area of Neopetrosia chaliniformis in TAB steadily declined from $1.25 \times 10^{5} \mathrm{~m}^{2}$ in 2010 to $0.71 \times 10^{5} \mathrm{~m}^{2}$ by the end of the survey (Table C4.1; Fig. 4.3). From 2010 to 2013 , the total local distribution area of this species decreased from $1.20 \times 10^{5} \mathrm{~m}^{2}$ to $1.10 \times 10^{5} \mathrm{~m}^{2}$. From 2013 to 2017 , its local distribution area decreased to $0.83 \times 10^{5} \mathrm{~m}^{2}$ and in 2018 the total local distribution area of $N$. chaliniformis in TAB was $0.71 \times 10^{5} \mathrm{~m}^{2}$. Maximum local distribution area declines for this species were seen in areas B and F, where declines of $36.8 \%$ and $58.9 \%$ occurred respectively, from 2010 to 2018.

The local distribution areas of Amphimedon navalis in TDD remained relatively consistent throughout the survey (Table C4.1; Fig. 4.3). While a decline in total local distribution area was seen from $2012\left(0.37 \times 10^{5} \mathrm{~m}^{2}\right)$ to $2018\left(0.35 \times 10^{5} \mathrm{~m}^{2}\right)$, no change was seen from 2013 $\left(0.37 \times 10^{5} \mathrm{~m}^{2}\right)$ to $2017\left(0.36 \times 10^{5} \mathrm{~m}^{2}\right.$; Table $\left.\mathrm{S} 1\right)$. In contrast, the total local distribution area of Spheciospongia vagabunda in ALB increased from 2012 to 2018 (Table C4.1; Fig. 4.3). From 2012 to 2013, the total local distribution area of this species increased from $0.23 \times 10^{5}$ $\mathrm{m}^{2}$ to $0.30 \times 10^{5} \mathrm{~m}^{2}$, before reaching $0.44 \times 10^{5} \mathrm{~m}^{2}$ in 2017. In 2018, the total local distribution area of $S$. vagabunda in ALB was estimated at $0.55 \times 10^{5} \mathrm{~m}^{2}$, representing an increase in local distribution area of $239.1 \%$ from 2012 to 2018. 

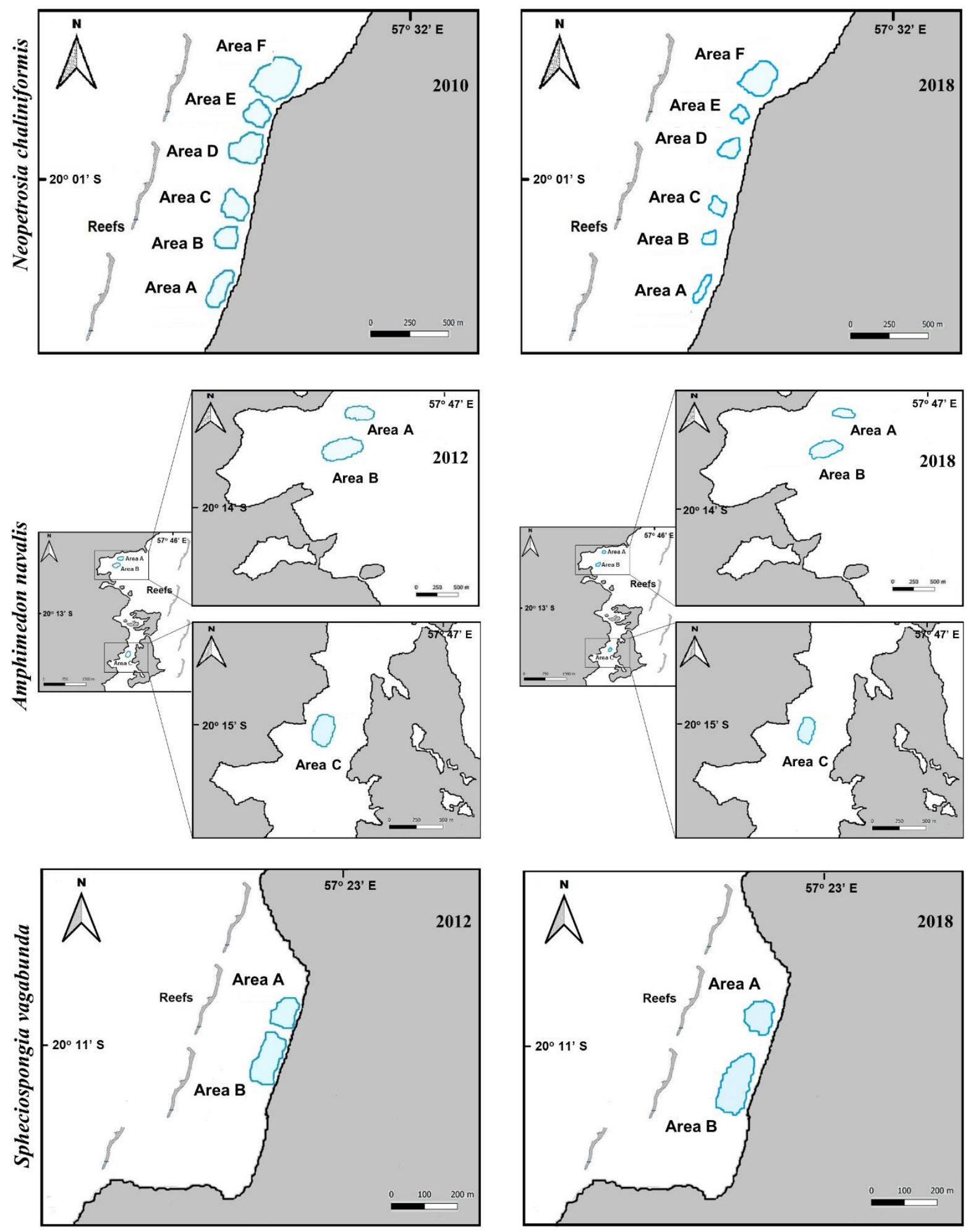

Fig. 4.3 The local distribution areas (within each lagoon) of Neopetrosia chaliniformis (TAB), Amphimedon navalis (TDD) and Spheciospongia vagabunda (ALB) during the sponge monitoring period. GIS maps were created in QGIS (QGIS Development Team, 2018). 


\subsubsection{Temporal changes in abundance (number of patches) and percentage cover}

The abundance of $N$. chaliniformis declined significantly over time $(\mathrm{z}=-2.04, \mathrm{p}=0.041)$ and was significantly different between the local distribution areas in TAB ( $p<0.001$; Table C4.3). From 2010 to 2018, the mean abundance for this species declined gradually from $4.58 \pm 0.36$ to $3.77 \pm 0.31$ sponges $\mathrm{m}^{-2}$ (mean $\pm \mathrm{SE}$ ), although $N$. chaliniformis abundance was generally lower in areas $\mathrm{A}$ and $\mathrm{C}$ compared to the other areas. $N$. chaliniformis abundance within TAB decreased from $4.39 \pm 0.36$ sponges $\mathrm{m}^{-2}$ in 2012 to $4.27 \pm 0.32$ sponges $\mathrm{m}^{-2}$ in 2013. In 2017, $N$. chaliniformis abundance was estimated at $3.99 \pm 0.30$ sponges $\mathrm{m}^{-2}$ (Table C4.2; Fig. 4.4A). The percentage cover of this species also declined significantly over time $(z=-2.14, p=0.032)$ and a significant difference was seen between the different local distribution areas $(\mathrm{p}<0.05$; Table C4.3), with mean percentage cover initially decreasing from $4.45 \pm 0.22 \%$ in 2010 to $4.18 \pm 0.20 \%$ in 2013. From 2017 to 2018 , percentage cover decreased further from $4.11 \pm$ $0.21 \%$ to $3.80 \pm 0.20 \%$. A consistent decline in percentage cover was observed in all distribution areas (Table C4.2; Fig. 4.4B).

For $A$. navalis, sponge abundance significantly decreased over time $(\mathrm{z}=-2.02, \mathrm{p}=0.042)$ and a significant difference was seen between the local distribution areas A and B in TDD $(\mathrm{z}=-$ 4.66, $\mathrm{p}<0.001)$, but not for area $\mathrm{C}(\mathrm{z}=-1.13, \mathrm{p}=0.255$; Table $\mathrm{C} 4.3)$ where the mean abundance of this specific area remained relatively unchanged over time. A. navalis abundance declined gradually from $9.53 \pm 0.55$ sponges $\mathrm{m}^{-2}$ in 2012 to $7.49 \pm 0.65$ sponges $\mathrm{m}^{-2}$ in 2013 . From 2013 to 2017 , A. navalis abundance declined to $7.43 \pm 0.66$ sponges $\mathrm{m}^{-2}$ and in 2018 the mean abundance in TDD was $7.26 \pm 0.65$ sponges $\mathrm{m}^{-2}$ (Table C4.2; Fig. 4.4C). In contrast, no significant change in A. navalis percentage cover was observed over time $(\mathrm{z}=1.39, \mathrm{p}=0.163)$ or between local distribution areas $(\mathrm{p}<0.05)$, apart from area $\mathrm{C}(\mathrm{z}=19.11, \mathrm{p}<0.001$; Table C4.3) where percentage cover initially declined from $8.61 \pm 1.48 \%$ to $7.53 \pm 0.86 \%$ between 2012 and 2013, before increasing again to $9.03 \pm 0.51 \%$ in 2017 (Table C4.2; Fig. 4.4D).

The abundance of $S$. vagabunda significantly increased over time $(\mathrm{z}=4.21, \mathrm{p}<0.001)$ and was significantly different between its local distribution areas in ALB ( $\mathrm{p}<0.001$; Table C4.3). From 2012 to 2013, mean abundance of $S$. vagabunda increased from $2.48 \pm 0.25$ to $3.77 \pm$ 0.35 sponges $\mathrm{m}^{-2}$, and in $2017 \mathrm{~S}$. vagabunda abundance increased to $4.30 \pm 0.38$ sponges $\mathrm{m}^{-2}$. In 2018, the mean abundance of this species in ALB was $4.62 \pm 0.42$ sponges $\mathrm{m}^{-2}$. The gradual increase in abundance for this species was relatively consistent between all local distribution 
areas within ALB (Table C4.2; Fig. 4.4E). Percentage cover for this species also significantly increased over time $(\mathrm{z}=2.23, \mathrm{p}=0.026)$ and a significant difference was seen between the different local distribution areas $(\mathrm{z}=-6.70, \mathrm{p}<0.001$; Table C4.3). From 2012 to 2013, S. vagabunda percentage cover increased from $5.81 \pm 0.45 \%$ to $6.21 \pm 0.43 \%$ and reached $6.86 \pm$ 0.60 in 2017\%. In 2018, the mean percentage cover of this sponge in ALB was $7.17 \pm 0.55 \%$ (Table C4.2; Fig. 4.4F).
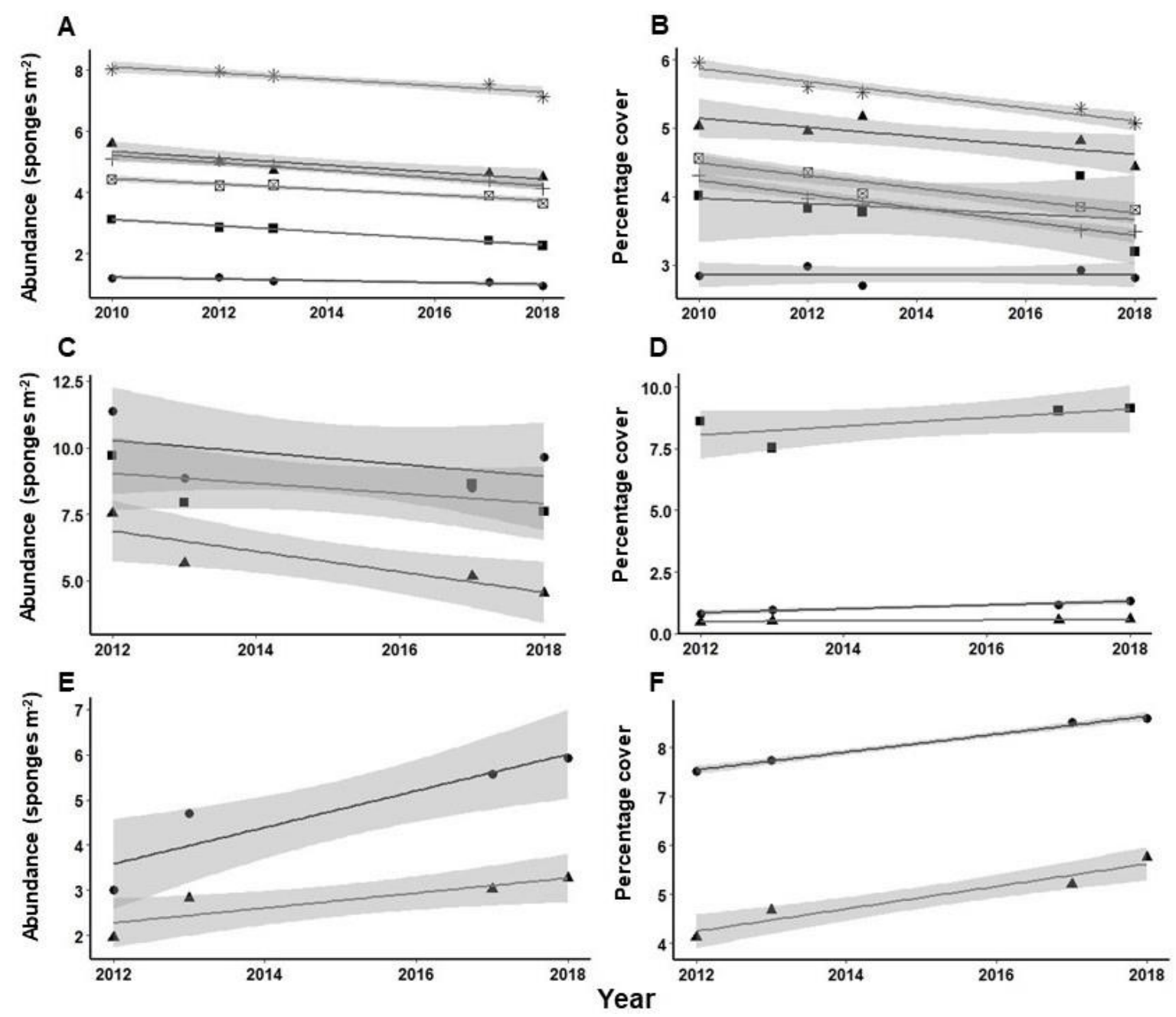

Fig. 4.4 General linear model (GLM) fits showing temporal trends in sponge abundance (left) and percentage cover (right) of Neopetrosia chaliniformis (A \& B), Amphimedon navalis (C \& D) and Spheciospongia vagabunda (E \& F). Lines are indicative of linear fit for each spongedominated area. Area A, $\triangle$ Area B, Area C, $\square$ Area D, + Area E, * Area F. Values are mean per area of occurrence \pm SE (grey shading) of the fit. $(n=30$ per area per year). Note: scales on the axes differ between species. 


\subsubsection{Effects of SST and Chl $a$ concentration}

$\operatorname{SST}(\mathrm{z}=-3.54, \mathrm{p}<0.001)$ and Chl $a$ concentration $(\mathrm{z}=-2.17, \mathrm{p}=0.030)$ were significantly correlated with the change in $N$. chaliniformis abundance in TAB. In contrast, no significant correlations were seen with the combination of both factors $(z=-0.50, p=0.614)$. The best model determined by AIC explaining the changes in abundance of this species was SST (Table 4.1). The change in $N$. chaliniformis percentage cover, however, was best explained by SST ( $\mathrm{t}$ $=-2.01, \mathrm{p}=0.044)$ only. No other significant correlations were seen with $N$. chaliniformis temporal percentage cover ( $\mathrm{p}>0.05$; Table $\mathrm{C} 4.4)$.

Changes in A. navalis abundance in TDD was significantly correlated with SST $(\mathrm{z}=-5.88, \mathrm{p}<$ $0.001)$ and Chl $a$ concentration $(\mathrm{z}=-3.55, \mathrm{p}<0.001)$, but not with the combination of both factors $(\mathrm{z}=-1.91, \mathrm{p}=0.055$; Table $\mathrm{C} 4.4)$. In contrast, A. navalis percentage cover was not significantly correlated with either environmental factor ( $p>0.05$; Table C4.4).

The change in $S$. vagabunda abundance in ALB was significantly correlated with SST (z= 5.78, $\mathrm{p}<0.001)$, Chl $a$ concentration $(\mathrm{z}=3.43, \mathrm{p}<0.001)$ and the combination of both factors ( $\mathrm{z}=2.47, \mathrm{p}=0.013$; Table C4.4). The temporal abundance of this species was best explained by the combination of both environmental factors (Table 4.1). S. vagabunda percentage cover was not significantly correlated with either environmental factor ( $p>0.05$; Table C4.4). 
Table 4.1 Model comparisons of the effects of SST and Chl $a$ concentration on the temporal abundance and percentage cover of Neopetrosia chaliniformis, Amphimedon navalis and Spheciospongia vagabunda. GLMMs were compared by the Akaike Information Criterion (AIC) scores. $\mathrm{n}=$ number of predictors. Models marked with an * represent the best model.

\begin{tabular}{|c|c|c|c|c|}
\hline Variable & $\mathbf{n}$ & Fixed Effects & AIC & $\Delta \mathrm{AIC}$ \\
\hline \multicolumn{5}{|c|}{ Neopetrosia chaliniformis } \\
\hline \multirow[t]{3}{*}{ Abundance } & 1 & $\mathrm{SST}^{*}$ & 5617.5 & 0 \\
\hline & 1 & Chl $a$ & 5625.3 & 7.8 \\
\hline & 2 & SST, Chl $a$ & 5619.3 & 1.8 \\
\hline \multirow{3}{*}{$\%$ Cover } & 1 & SST* & -3880 & 0 \\
\hline & 1 & Chl $a$ & -3876.4 & 3.6 \\
\hline & 2 & $\mathrm{SST}, \mathrm{Chl} a$ & -3878.1 & 1.9 \\
\hline \multicolumn{5}{|c|}{ Amphimedon navalis } \\
\hline \multirow{3}{*}{ Abundance } & 1 & SST & 2941 & 1.8 \\
\hline & 1 & Chl $a$ & 2962 & 22.8 \\
\hline & 2 & SST, Chl $a^{*}$ & 2939.2 & 0 \\
\hline \multirow{3}{*}{$\%$ Cover } & 1 & SST* & -1470.7 & 0 \\
\hline & 1 & Chl $a$ & -1467 & 3.7 \\
\hline & 2 & SST, Chl $a$ & -1468.9 & 1.8 \\
\hline \multicolumn{5}{|c|}{ Spheciospongia vagabunda } \\
\hline \multirow{3}{*}{ Abundance } & 1 & SST & 1143.2 & 4 \\
\hline & 1 & Chl $a$ & 1167.2 & 28 \\
\hline & 2 & SST, Chl $a^{*}$ & 1139.2 & 0 \\
\hline \multirow{3}{*}{$\%$ Cover } & 1 & SST* & -895 & 0 \\
\hline & 1 & Chl $a$ & -893.1 & 1.9 \\
\hline & 2 & SST, Chl $a$ & -891 & 4 \\
\hline
\end{tabular}

\subsection{Discussion}

Lagoon-inhabiting benthic communities are known to experience important temporal variations in abundance (Pérez-Ruzafa et al., 2007a). This study reports on the temporal changes in the local distribution areas, abundance and percentage cover of three lagooninhabiting sponge species occurring in three distinct coastal lagoons in the Western Indian Ocean. While the total local distribution area of Neopetrosia chaliniformis was considerably smaller after eight years, no change was apparent in the total local distribution area of Amphimedon navalis. In contrast, the total local distribution area of Spheciospongia vagabunda increased from $0.23 \times 10^{5} \mathrm{~m}^{2}$ to $0.55 \times 10^{5} \mathrm{~m}^{2}$. The temporal changes in abundance and percentage cover of tropical lagoon sponges appear species-specific. While the abundance of A. navalis and $N$. chaliniformis declined gradually over a period of six and eight years, respectively, the abundance of $S$. vagabunda increased significantly over six years. Significant declines in $N$. chaliniformis abundance and percentage cover within its local distribution areas indicated that $N$. chaliniformis populations are gradually decreasing. The local distribution areas and percentage cover of A. navalis were stable over time, but the decline in abundance of 
this species in TDD suggests that, although the number of A. navalis patches has decreased, the size of these patches has increased within its local distribution areas. These findings are consistent with Ávila et al. (2015), where species-specific inter-annual temporal dynamics of three shallow sponge species were observed in the Terminos Lagoon (Mexico). The abundance and biomass of Halichondria melanadocia, Haliclona implexiformis and Chondrilla caribensis showed high small-scale spatial variations but without a clear pattern of variation related with the distance from the shore. GLMMs also demonstrate that while SST had significant negative correlations with the abundance of $N$. chaliniformis and A. navalis, a positive correlation was seen with S. vagabunda abundance. A weak negative correlation was also seen between SST and $N$. chaliniformis percentage cover, but no correlations were seen for the other species. In contrast, Chl $a$ concentration was negatively correlated with the changes in abundance of $N$. chaliniformis and A. navalis, while a positive correlation was seen with $S$. vagabunda abundance and no correlations between $\mathrm{Chl} a$ concentration and percentage cover were seen for any species.

\subsubsection{Temporal changes}

Sponge population abundance often fluctuates considerably over time (Carballo et al., 2008; Ramsby et al., 2017; Rovellini et al., 2019). For example, during a 10-year study on the Great Barrier Reef, Ramsby et al. (2017) reported that the percentage cover of the sponge Cliona orientalis was highly variable most likely due to the influence of fine sediment and macroalgal competition. Similarly, the studies of Carballo et al. (2008) and Rovellini et al. (2019) showed high temporal variability in sponge assemblages in Mexico and Indonesia, respectively, although both studies also found that the populations of some species are relatively stable or only experience gradual changes, over time. Changes in abundance and percentage cover were gradual for $N$. chaliniformis and S. vagabunda, although the variability in both abundance and percentage cover was species-specific. The decline in $N$. chaliniformis abundance and percentage cover suggests that populations of this species might disappear in TAB, whereas for S. vagabunda significant increases in both abundance and percentage cover suggest that this species could dominate the benthos in ALB over the next few decades. The gradual decline in the abundance of $N$. chaliniformis within its local distribution areas and the decline in percentage cover suggest that the $N$. chaliniformis population in TAB is gradually becoming smaller. In contrast, the stable percentage cover but reduced abundance of A. navalis in TDD suggest that this species has experienced little temporal variability and that existing patches are becoming larger over time. Sponge populations can sometimes exhibit interannual and seasonal 
fluctuations (Koopmans \& Wijffels, 2008; Di Camillo et al., 2012). For example, the growth rate of the sponges Haliclona oculata (Koopmans \& Wijffels, 2008) and Xestospongia muta (McMurray et al., 2008) is correlated with seasonal variability. Here, since field surveys could only be conducted once a year, the interannual or seasonal population variability of each species could not be considered in the temporal models (McCain et al., 2016).

Changes in lagoon sponge populations have previously been correlated with environmental variables, for example salinity (Corriero et al., 2007; Longo et al., 2015) and excess cyanobacterial concentration (Butler et al., 1995). Here, the loss of coral cover in Mauritian lagoons is most likely a strong contributing factor to the temporal changes observed. While many sponges are known to compete and overgrow corals killing them (Rossi et al., 2015; Elliott et al., 2016a; Turicchia et al., 2018; Ashok et al., 2019, 2020), others grow on live corals that stay alive (Aerts, 1998; López-Victoria \& Zea, 2005). During recent years (1998 - 2016), coral cover within Mauritian lagoons has consistently declined, whereby approximately 20$50 \%$ of coral patches have been lost due to anthropogenic stressors (Obura et al., 2017; Elliott et al., 2018). For example, between 1998 and 2010, the live coral communities at both TAB and ALB have declined by approximately $25 \%$. N. chaliniformis in TAB is often attached to dead corals. However, almost $30 \%$ of this species also occurs on live Acropora spp. corals (Appadoo et al., 2011). Similarly, A. navalis in TDD is mostly found anchored on live Pavona spp. and Acropora spp. corals (Beepat, 2015). This decline in substrate availability might have been the principal cause for the decline of sponges at TAB and TDD (see Table C4.5). For example, in TDD it is likely that the decline of live corals has resulted in reduced availability of substratum for new A. navalis recruits, although recruits are also likely to settle on dead corals or coral rubble (Beepat, 2015). N. chaliniformis and A. navalis are both branching erect species and according to Aerts and Van Soest (1997), branching sponges are less destructive to corals as they can potentially avoid competition by escaping in height. Unlike $N$. chaliniformis and A. navalis, S. vagabunda is often found buried in soft sediment, although this species is also known to excavate coral rubble (Levi et al., 1998). In ALB, S. vagabunda is mostly found anchored in sand within the post-reef depression zone (Beepat et al., 2013) and therefore is not generally reliant on hard substratum. As a result, the loss of live coral communities (i.e. reduced spatial competition with corals) at ALB (Elliott et al., 2018) did not have any negative impacts on the temporal variability of this species, which supports the suggestion that the loss of hard coral cover may be responsible for the reduced abundance of $N$. chaliniformis and A. navalis at TAB and TDD, respectively. 


\subsubsection{Effects of SST and Chl $a$ concentration}

SST and Chl $a$ concentration are two potential drivers that may influence sponge distribution patterns (Butler et al., 1995; Cerrano et al., 2000; Wall et al., 2012). Here, the models show that both factors correlated with the patterns of variability of lagoon sponges although the degree and strength of the correlations differed between species. The effect of temperature on sponges is often species-specific (Bell et al., 2018) and therefore its impact on sponge populations is highly dependent on the species' thermal tolerance. For example, the sponges Ircinia fasciculata (Cebrian et al., 2011) and Cliona orientalis (Ramsby et al., 2018) are susceptible to elevated temperature. However, other species such as Cliona celata (Duckworth \& Peterson, 2013) and Aplysina cauliformis (Duckworth et al., 2012) appear more tolerant to increased temperature. As lagoon ecosystems are likely to retain more heat energy compared to the open sea (Anthony et al., 2009), elevated temperature could potentially have a significant impact on lagoon-inhabiting species. Some sponges, including $N$. chaliniformis and $S$. vagabunda, are at least partially energetically dependent on associated photo-symbionts, such as cyanobacteria and symbiotic dinoflagellates (Levi et al., 1998; Thacker, 2005). However, when exposed to thermal stress, a breakdown of the host-symbiont association may result in mortality and a more restricted population distribution. Reduced sponge abundance due to this symbiotic breakdown has previously been reported in the Mediterranean (Cebrian et al., 2011) and Caribbean (Rützler, 1988), although this is less likely the case for the studied species here because, no change in coloration were seen within $N$. chaliniformis and S. vagabunda populations during field surveys. However, the laboratory-based experiment conducted in Chapter 2 demonstrated that $N$. chaliniformis and A. navalis are sensitive to elevated temperatures of $+2{ }^{\circ} \mathrm{C}$ and $+4{ }^{\circ} \mathrm{C}$, respectively, whereas $S$. vagabunda is more thermally tolerant. These findings support the relationships described in the models suggesting that $N$. chaliniformis and A. navalis patches will likely continue to decline under future climate warming projections (IPCC, 2014), although it is important to note that there is the potential that these species are in a longer natural cycle than studied here. In contrast, S. vagabunda might become a dominant species under these same conditions unless the proliferation of this species in ALB is limited by competition with other dominant benthic organisms, such as seagrasses and macroalgae (Casareto et al., 2017), noting that there are no other sponge species in ALB which could spatially compete with S. vagabunda.

The impacts of Chl $a$ concentration on temporal sponge variability are not well understood, although previous studies have shown that cyanobacterial blooms can negatively impact lagoon 
sponges (Butler et al., 1995; Wall et al., 2012). Here, GLMMs demonstrate that in Mauritian lagoons, Chl $a$ concentration was negatively correlated with the abundance of $N$. chaliniformis and A. navalis, while a positive correlation was seen with $S$. vagabunda abundance. The interactions between sponges and $\mathrm{Chl} a$ from the water column is poorly understood, although recent reports suggest that these interactions are mostly species-specific (Morganti et al., 2017; Valentine \& Butler, 2019). Many sponges often feed on microorganisms such as picoplankton, and some sponges can sometimes satisfy their dietary requirements by filtration alone (Reiswig, 1971b; Maldonado et al., 2010), although shallow-water sponges including $N$. chaliniformis and S. vagabunda are at least partially energetically reliant on associated photosymbionts, such as cyanobacteria (Wilkinson, 1978, 1983; Cheshire \& Wilkinson, 1991). While the negative correlation between $N$. chaliniformis and A. navalis abundance and Chl $a$ concentration in TAB and TDD, respectively could not be explained, the positive correlation observed here between $S$. vagabunda abundance and Chl $a$ concentration is consistent with other studies (Rose \& Risk, 1985; Holmes, 2000), suggesting that this species may proliferate when exposed to elevated Chl $a$ concentration, most likely due to the availability of Chl $a$ containing microorganisms as source of food for the sponge. Rose and Risk (1985) and Holmes (2000) reported that the bioeroding capabilities of clionid sponges are generally enhanced across gradients of eutrophication. As for $N$. chaliniformis and A. navalis, it is likely that the yearly sampling strategy employed during this study has resulted in models lacking the representation of any short-term population variability that might be occurring between February to November. In addition, it is also possible that, in parallel to Chl $a$ fluctuations, other undetermined environmental factors, such as changes in salinity (Corriero et al., 2007; Longo et al., 2015) due to underground freshwater seepage (Povinec et al., 2012), might be influencing the abundance of $N$. chaliniformis and A. navalis, in TAB and TDD, respectively.

Changes in sponge distribution patterns might also be attributed to other factors such as predation (Dunlap \& Pawlik, 1996; Pawlik, 1998), physical disturbance from storms (Wulff, 1995) and disease outbreaks (Wulff, 2006a; Webster, 2007). For example, using videomonitoring, Dunlap and Pawlik (1996) demonstrated that mangrove sponge distribution patterns are likely controlled by multiple predatory reef fishes. Likewise, the study of Wulff (2006a) demonstrated that the steady decline of sponges in Panama was likely caused by disease. However, while these factors were not initially considered in the present study, in situ field observations did not indicate any signs of predation or disease on $N$. chaliniformis and A. navalis, suggesting that the temporal variability of lagoon-inhabiting sponges in the region is 
less likely to be driven by these factors. In contrast, the decline of $N$. chaliniformis and $A$. navalis in their respective lagoons where they occur could be attributed to the combined effects of reduced coral cover and elevated seawater temperature, although the statistical models presented here are not robust enough to determine the combined effects of these two factors on temporal sponge abundance and percentage cover. Habitat loss (loss of substratum) have previously been reported to greatly influence sponge distribution (Aerts, 1998; Duckworth \& Wolff, 2011). For example, Duckworth and Wolff (2011) suggested that changes in substrate composition of coral reefs could greatly influence the population dynamic and growth of the reef sponges Coscinoderma matthewsi and Hyrtios erectus. Therefore, the combination of reduced coral cover and elevated temperature could potentially result to a population decline of $N$. chaliniformis and A. navalis, since these species could physiologically strive to cope with thermal stress and reduced substrate availability, respectively. However, while $N$. chaliniformis and A. navalis are known to be thermally susceptible species, the correlations between the distribution of these sponges and changes in coral cover has not been thoroughly investigated in Mauritius. In addition, considering that no temporal data on N. chaliniformis and A. navalis substrate type were collected during this study, further field monitoring focusing on the temporal changes in coral cover and the sponges' substrate type would be required to confirm this hypothesis.

\subsection{Conclusions}

Tropical coastal lagoons experience dynamic environmental changes, which influence the temporal variability of lagoon-inhabiting benthic organisms. This study demonstrates that the local temporal variability of lagoon sponges and the potential drivers influencing these temporal dynamics are mostly species-specific. While there is increasing evidence that some reef sponges could potentially be tolerant of some anthropogenic stressors (Bell et al., 2013, 2018), the results presented in this chapter demonstrate that there is a negative relationship between the temporal abundance of some lagoon-inhabiting species and elevated SST, which is also likely related to the loss of live corals in their lagoon of residence. This study is the first to report on the temporal variability of sponges from the Indian Ocean. However, the results presented here are representative of only three lagoon-inhabiting sponge species and further combined short- and long-term investigations are necessary to enhance our understanding of the temporal variabilities of lagoon sponges. 


\section{Chapter 5:}

Effect of elevated temperature on bentho-pelagic interactions of the sponge Spheciospongia vagabunda in a coastal lagoon 


\begin{abstract}
Bentho-pelagic interactions are important nutrient pathways in shallow coastal lagoons, which are strongly influenced by anthropogenic stressors. Sponges are important suspension-feeding organisms occurring in many coastal lagoons. However, their bentho-pelagic roles in these ecosystems are poorly understood. The work presented in this chapter assesses the benthopelagic contribution of the lagoon-inhabiting sponge Spheciospongia vagabunda at three temperatures in a coastal lagoon in the Western Indian Ocean. Bacterial cell consumption, net organic matter [chlorophyll $a(\mathrm{Chl} a)$, a proxy for phytoplankton consumption and net dissolved organic carbon (DOC)] uptake, and the net release of inorganic nutrients, including nitrate + nitrite $\left(\mathrm{NO}_{3}{ }^{-}+\mathrm{NO}_{2}^{-}\right)$and phosphate $\left(\mathrm{PO}_{4}{ }^{3-}\right)$, were estimated. The bacterial cell consumption, net organic matter uptake and net inorganic nutrient release from this species were relatively low compared to other species reported from Caribbean shallow ecosystems. However, when exposed to an increase of $+2{ }^{\circ} \mathrm{C}$ and $+4{ }^{\circ} \mathrm{C}$ relative to the ambient temperature $\left(26{ }^{\circ} \mathrm{C}\right)$, net organic matter uptake and net inorganic nutrient release of the $S$. vagabunda population in the lagoon significantly increased, by approximately $115 \%$ and $142 \%$ respectively. The estimated bacterial consumption of the $S$. vagabunda population ranged from $0.85 \times 10^{-2}$ to $2.97 \times 10^{-2}$ cells $\mathrm{ml}^{-1} \mathrm{~h}^{-1}$. Estimated uptake of Chl $a$ and DOC by the $S$. vagabunda population in the lagoon ranged from $0.08 \times 10^{7}$ to $1.39 \times 10^{7} \mu \mathrm{g} \mathrm{h}^{-1}$ and $0.30 \times 10^{10}$ to $1.25 \mathrm{x}$ $10^{10} \mu \mathrm{mol} \mathrm{h}{ }^{-1}$, respectively, whereas the estimated production of $\mathrm{NO}_{2}{ }^{-}+\mathrm{NO}_{3}{ }^{-}$and $\mathrm{PO}_{4}{ }^{3-}$ ranged from $0.11-2.59 \times 10^{7} \mu \mathrm{mol} \mathrm{h} \mathrm{h}^{-1}$ and $0.75-5.24 \times 10^{6} \mu \mathrm{mol} \mathrm{h}{ }^{-1}$, respectively. These results indicate that the low bacterial cell consumption, and net organic matter uptake and net inorganic nutrient release of the $S$. vagabunda population in the lagoon are most likely small due to the low abundance of this sponge within the lagoon. However, despite the limited interaction of $S$. vagabunda with the water column, the bentho-pelagic interaction of this sponge will likely increase under future ocean-warming scenarios.
\end{abstract}




\subsection{Introduction}

Bentho-pelagic interactions are important in coastal lagoons and involve the exchange of organic matter and inorganic nutrients between the benthos and water column, which are often closely linked, as the water is shallow (Graf, 1992; Grenz et al., 2010; Kopp et al., 2015). These interactions in lagoon ecosystems are often maintained by physical processes such as diffusion i.e. sediment-water exchange (Rysgaard et al., 1996) and bioturbation, i.e. the displacement of organic and inorganic matter from the seafloor by living organisms (Kristensen et al., 2012). However, biological interactions, including the microbial loop (Azam et al., 1983), macrophyte nutrient uptake (Fox et al., 2010) and the activity of suspension feeding organisms (Nixon, 1988; Lauringson et al., 2009), are also major contributors in linking benthic and pelagic environments. Suspension-feeding organisms, particularly bivalves, have previously been reported to have important roles in regulating nutrient fluxes in coastal ecosystems (Norkko et al., 2001; Lonsdale et al., 2009; Alonso-Pérez et al., 2010). However, the benthic-pelagic roles of other suspension-feeders, such as sponges, have been largely overlooked (Folkers \& Rombouts, 2020).

In recent decades, multiple studies have highlighted the important roles of sponges in linking benthic and pelagic environments (Maldonado et al., 2012; de Goeij et al., 2017; Folkers \& Rombouts, 2020). For example, the recently-described 'sponge-loop' suggests that, through their filtering capabilities (Reiswig, 1971a), sponges actively contribute to the redistribution of nutrients to the water column (de Goeij et al., 2013; Rix et al., 2018). With the emergence of studies suggesting that some sponges may be potential winners in response to climate change (Bell et al., 2013, 2018), there is increasing evidence that sponges might have an enhanced ecosystem-engineering role in anthropogenically-impacted biological pathways (Pawlik et al., 2016). However, the persistence of heterotrophic sponges within an ecosystem would likely depend on the availability of food such as particulate and dissolved organic matter (Bell et al., 2018; Pawlik et al., 2018; Lesser \& Slattery, 2020). As a result, it is becoming increasingly important to understand the possible contribution of sponges to bentho-pelagic interactions, particularly in ecosystems such as coastal lagoons where human-induced impacts are usually high (Anthony et al., 2009).

Sponges are known to feed on a range of nano- and pico-phytoplankton, including the cyanobacteria Procholorococcus spp. and Synechoccus spp., and heterotrophic bacterial cells 
(Reiswig, 1971b, 1999). However, recent studies suggest that some sponge species can also obtain the bulk of their energy from the uptake of dissolved organic carbon (DOC) (Yahel et al., 2003; de Goeij et al., 2008; Mueller et al., 2014) and some sponges can feed on detritus too (McMurray et al., 2016; Pawlik et al., 2018). For example, the DOC uptake rates of the sponges Halisarca caerulea, Mycale microsigmatosa and Merlia normani in the Caribbean accounted for over $90 \%$ of the total organic carbon (TOC) consumed from coral reefs, and the sponge DOC uptake rates near the benthos are twice as much as bacterioplankton DOC uptake rates (de Goeij et al., 2008). Hoer et al. (2018) reported that the sponges Ircinia strobilina and Verongula gigantea take up $21 \%$ and $24 \%$ of the DOC at Conch Reef, Key Largo, Florida, respectively. However, not all DOC taken up is consumed by the sponge itself. According to de Goeij et al. (2008), 55-75\% of the DOC taken up by sponges is transformed and released back to the water column as detritus or particulate organic matter, whereas the remaining 15$25 \%$ is used for respiration, growth and reproduction (de Goeij et al., 2009; Alexander et al., 2014).

Nitrogenous inorganic compounds such as nitrate $\left(\mathrm{NO}_{3}^{-}\right)$, nitrite $\left(\mathrm{NO}_{2}^{-}\right)$and ammonium $\left(\mathrm{NH}_{4}{ }^{+}\right)$, are common inorganic nutrients released by sponges through the processes of nitrification (Corredor et al., 1988; Diaz \& Ward, 1997; Southwell et al., 2008), denitrification (Hoffmann et al., 2009) and remineralization (Ribes et al., 2005). For example, Corredor et al. (1988) reported that the sponge Chondrilla nucula can produce up to $4000 \mu \mathrm{mol} \mathrm{N} \mathrm{m} \mathrm{m}^{-2}$ and therefore contribute between 50-120\% of the nitrogen required by Puerto Rican reefs, although the sponge Cliona varians (previously known as Anthosigmella varians) contributed $<1 \%$ (20 $\mu \mathrm{mol} \mathrm{N} \mathrm{m}^{-2} \mathrm{~h}^{-1}$ ) of the nitrogen required for reef productivity. Southwell et al. (2008) also reported that sponges on Conch Reef can produce up to 270 and $230 \mu \mathrm{mol}$ net $\mathrm{NO}_{\mathrm{x}}^{-} \mathrm{L}^{-1} \mathrm{~h}^{-1}$. Recently, some studies have suggested that sponges can also contribute to phosphate $\left(\mathrm{PO}_{4}{ }^{3-}\right)$ fluxes in the water column (Sabarathnam et al., 2010; Maldonado et al., 2012). For example, studies from the Mediterranean have demonstrated that sponges such as Dysidea avara, Agelas oroides and Chondrosia reniformis can produce up to $0.06 \mu \mathrm{mol} \mathrm{PO}_{4}{ }^{3-} \mathrm{g} \mathrm{DW}^{-1} \mathrm{~h}^{-1}$ (Jiménez \& Ribes, 2007; Ribes et al., 2012) and López-Acosta et al. (2019) reported that the sponge Tethya citrina contributes $2.1 \%$ of the $\mathrm{PO}_{4}{ }^{3-}$ in the Bay of Brest (France), suggesting that sponges, via their microbial associations, may also have an important role in phosphorus production in the water column. So far, the bentho-pelagic roles of sponges have mostly been documented for reef sponges (Southwell et al., 2008; de Goeij et al., 2013), with the interactions for lagooninhabiting species being widely overlooked. Since some sponges are often important members 
of coastal lagoon communities (Levi et al., 1998; Longo et al., 2015), it is important to understand the bentho-pelagic interactions in these ecosystems and assess their potential contribution to nutrient fluxes under future climate change scenarios.

The sponge Spheciospongia vagabunda is an Indo-Pacific bioeroding species that often occurs in shallow coastal lagoons (Levi et al., 1998; Beepat et al., 2013). This species is ecologically important and, in addition to its bioeroding role (Marlow et al., 2018), it is an important substrate stabiliser (Beepat et al., 2013) and habitat provider for multiple micro- and macroinvertebrates (Beepat, 2015; Thomas et al., 2016). Recent laboratory-based thermal experiments suggest that $S$. vagabunda is likely physiologically tolerant to elevated seawater temperatures proposed for the end-of-century in Mauritian lagoons (see Chapter 3). The positive correlations between its temporal abundance/percentage cover and increasing sea surface temperature over a six-year period also suggest that this species could be a potential winner under future ocean warming scenarios (see Chapter 4).

In this chapter, I used a combination of the information from my thermal tolerance experiment in Chapter 3 and in situ data from Chapter 4 to estimate the potential bacterial cell consumption, net organic matter uptake and net inorganic nutrient release of $S$. vagabunda at three temperatures based on the IPCC (2014) Representative Concentration Pathways (RCP) for 2100 , i.e. ambient $\left(26^{\circ} \mathrm{C}\right)$, RCP6.0 $\left(28^{\circ} \mathrm{C}\right)$ and RCP8.5 $\left(30^{\circ} \mathrm{C}\right)$ in a shallow tropical lagoon in the Western Indian Ocean. Organic matter uptake from the seawater was measured as chlorophyll $a(\mathrm{Chl} a)$ removal, which was used as a proxy for phytoplankton consumption, and net DOC uptake. Net inorganic nutrient release into the seawater was measured with respect to nitrite + nitrate $\left(\mathrm{NO}_{2}{ }^{-}+\mathrm{NO}_{3}{ }^{-}\right)$and phosphate $\left(\mathrm{PO}_{4}{ }^{3-}\right)$. Since the feeding patterns and nutrientfluxes of $S$. vagabunda could not be directly quantified, bacterial cell consumption, net organic matter uptake and net inorganic nutrient release were modelled using existing estimates for the sponge Spheciospongia vesparium (Valentine \& Butler, 2019), which is known to occur in shallow tropical Caribbean lagoons (Wall et al., 2012).

\subsection{Materials and Methods}

\subsubsection{Study lagoon}

This study was conducted in the Albion Lagoon ( $\left.20^{\circ} 12^{\prime} \mathrm{S} ; 57^{\circ} 24^{\prime} \mathrm{E}\right)$, situated on the west coast of Mauritius in the Western Indian Ocean (Fig 5.1). The coastal shoreline of the Albion Lagoon 
extends to approximately $1.5 \mathrm{~km}$ and the lagoon topography (see Appendix D - Fig. D5.1) is generally shallow $(<0.5 \mathrm{~m})$ at both extremities (i.e. at the shore reef and the reef flat), resulting in the formation of a post-reef depression zone that is $1.5 \mathrm{~m}$ deep in the middle section of the lagoon (Moothien Pillay et al., 2002). The post-reef depression zone within the lagoon supports a suite of benthic communities, such as seagrasses, coralline algae (Casareto et al., 2017) and corals (Elliott et al., 2018). The sponge Spheciospongia vagabunda is the only sponge species occurring in this lagoon (Beepat et al., 2013) and is distributed among two distinct local distribution areas (see Chapter 4).

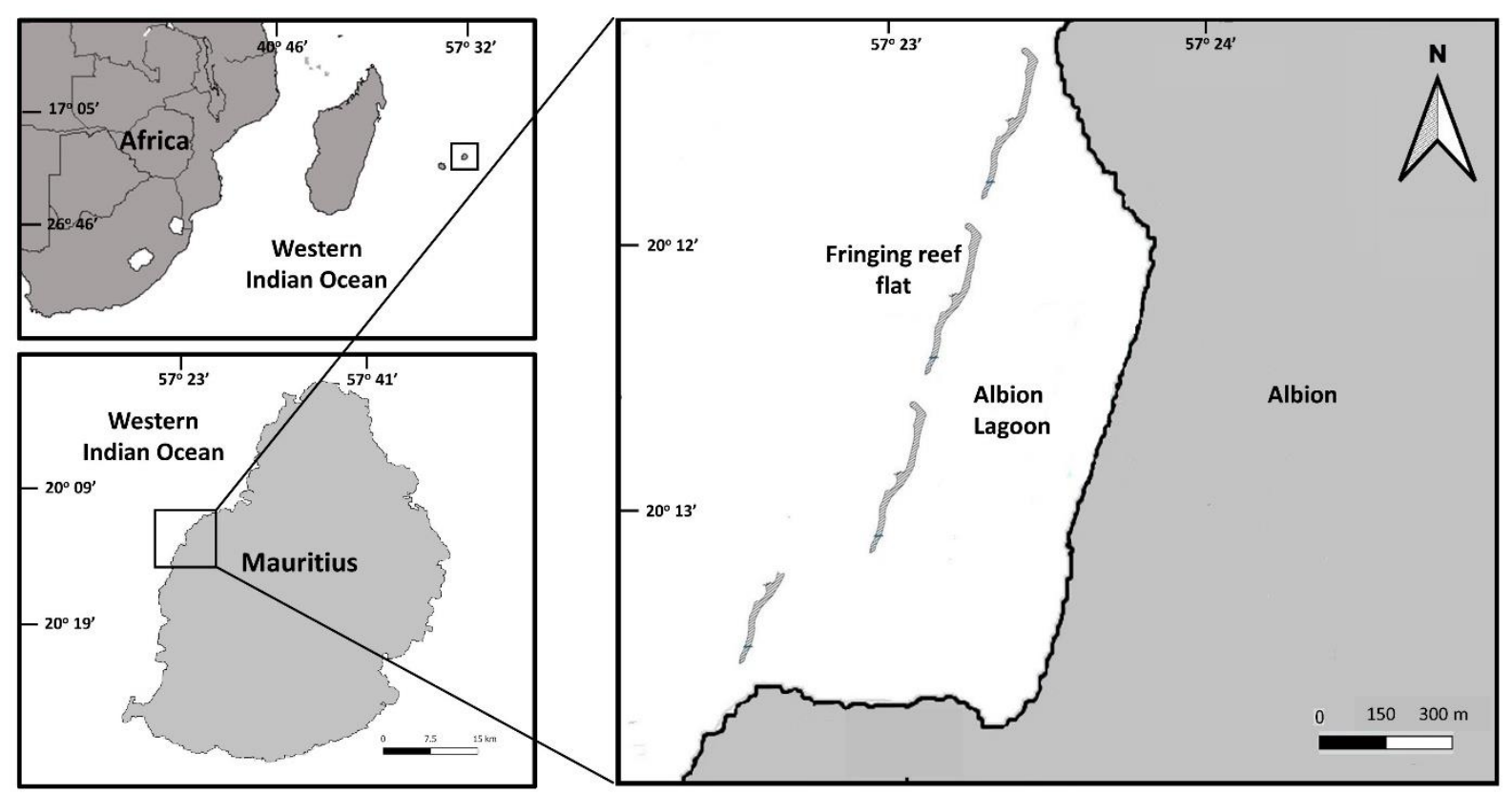

Fig. 5.1 Map of Albion Lagoon (right). Maps on the left indicate the geographical position of the study lagoon in the western Indian Ocean and on the west coast of Mauritius. Map created in QGIS (QGIS Development Team, 2018).

\subsubsection{Sponge volume}

Spheciospongia vagabunda volume was estimated using sponge percentage cover data conducted from field surveys in December 2018. A sponge volume to sponge percentage cover conversion factor of $3.89 \pm 0.13$ was used to convert the percentage cover of each quadrat into sponge volume data. This method was used to avoid the removal of multiple sponges from their substrate for volumetric measurements, which could result in physical/lethal damage to the sponges. Sponge volume data were preferred over sponge percentage cover data because sponges often have diverse, complex three-dimensional morphologies, and in such circumstances percentage cover data are often least informative (de Goeij et al., 2017). To 
estimate this conversion factor, the percentage cover of 25 random sponges from the lagoon was first measured using the method described in Chapter 4 (section 4.2.2.2). The sponges were then removed from their anchoring substrates, cleaned of any visible debris (coral rubble or dead coral) and their volumes (in ml) were estimated using the water displacement method (Osinga et al., 1999). The sponge percentage cover data $(\mathrm{n}=60)$ collected in Chapter 4 (i.e. from the two $S$. vagabunda LDA; 30 quadrats per LDA) were then transformed by applying the correction factor to each quadrat and the sponge volume within each quadrat was estimated as L of sponge $\mathrm{m}^{-2}$ (Appendix D - Table D5.1).

\subsubsection{Thermal experiment design and $S$. vagabunda pumping rate}

The thermal experiment design is described in detail in Chapter 3 and was conducted in a laboratory facility in Mauritius in December 2017. Briefly, distinct $S$. vagabunda sponges of sizes $4-10 \mathrm{~cm}$ were collected at a depth of $1.5 \mathrm{~m}$ from the Albion Lagoon. To avoid any damage to sponge tissues, only sponges attached to dead coral or coral rubble were collected. $S$. vagabunda ( $\mathrm{n}=9$ per thermal treatment) were then exposed to three temperature treatments based on the IPCC (2014) SST scenarios for 2100 at RCP6.0 $\left(+2{ }^{\circ} \mathrm{C}\right)$ and $\mathrm{RCP} 8.5\left(+4{ }^{\circ} \mathrm{C}\right)$ relative to the current ambient temperature $\left(26^{\circ} \mathrm{C}\right)$ for four weeks following seven days of acclimation. Three replicate tanks, each with a holding capacity of $10 \mathrm{~L}$, were used for each thermal treatment. Each treatment tank was supplied with an individual $100 \mathrm{~W}$ aquarium heater to maintain the temperature, and individual aquarium oxygen pumps were used to ensure oxygen supply and water circulation within the tanks. Three $20 \mathrm{~L}$ tanks were used to pre-heat seawater daily and pre-heated seawater was manually replaced at 12-h intervals.

Sponge pumping rate was measured following the methods of Massaro et al. (2012). Briefly, a ruler was vertically attached to the bottom of a transparent $2 \mathrm{~L}$ glass beaker and the targeted sponge was carefully transferred into the beaker with the osculum facing upwards. Approximately $1 \mathrm{ml}$ of fluorescein dye was carefully injected into the base of the sponge using a syringe and the exhaled dye movement from the sponge's osculum was recorded. In situations where the sponge's osculum could not be placed facing upwards in the beaker (e.g. the sponge osculum was horizontal), the glass beaker was placed on graph paper and the exhaled horizontal movement of the dye was recorded on video from the top of the beaker and analyzed. The pumping rate was calculated by measuring the time taken by the fluorescein dye to travel a known distance from the osculum opening to a specific distance on the ruler/graph paper. Pumping rate $\left(\mathrm{ml} \mathrm{s}^{-1}\right)$ was then multiplied with the cross-sectional area of the sponge's 
osculum. For sponges with multiple oscula, pumping rate was multiplied by the number of oscula. After four weeks of thermal exposure, the mean $S$. vagabunda pumping rates $( \pm \mathrm{SE})$ were $0.12 \pm 0.01 \mathrm{ml} \mathrm{s}^{-1}$ at $26^{\circ} \mathrm{C}, 0.26 \pm 0.02 \mathrm{ml} \mathrm{s}^{-1}$ at $28^{\circ} \mathrm{C}$ and $0.29 \pm 0.02 \mathrm{ml} \mathrm{s}^{-1}$ at $30^{\circ} \mathrm{C}$ (see Chapter 3 - section 3.3.2.4).

\subsubsection{S. vagabunda organic matter and inorganic nutrient fluxes}

S. vagabunda net organic matter and inorganic nutrient fluxes were estimated based on the mean estimate fluxes of the sponge Spheciospongia vesparium reported by Valentine and Butler (2019). Like S. vagabunda, S. vesparium is an excavating amorphous species bearing large oscula and clusters of pore sieves (Rützler, 2002), which also occurs on sand or sediment, though in shallow tropical Caribbean lagoons (Butler et al., 1995; Wall et al., 2012). I assumed that the rates of bacterial cell consumption, net organic matter uptake and net inorganic nutrient release of $S$. vagabunda pumping at $0.12 \mathrm{ml} \mathrm{s}^{-1}$ were relatively similar to those of $S$. vesparium pumping at $0.114 \mathrm{ml} \mathrm{s}^{-1}$ under normal conditions (Wall et al., 2012). In situ feeding, excretion and nutrient fluxes are reported to be dependent on sponges' pumping rates (Leys et al., 2011; Kahn et al., 2015; Morganti et al., 2019). Since the filtration rates of some sponges are known to increase when exposed to elevated temperature (Riisgård et al., 1993), it was assumed that sponge pumping rate was linearly correlated with bacterial cell consumption, net organic matter uptake and net inorganic nutrient release. Therefore, at $28{ }^{\circ} \mathrm{C}$ and $30{ }^{\circ} \mathrm{C}$ respectively, it was assumed that $S$. vagabunda bacterial cell consumption, and net organic matter and inorganic nutrient fluxes were 2.16 and 2.42 times higher relative to $26{ }^{\circ} \mathrm{C}$, respectively (Table 5.1). 
Table 5.1 Bacterial cell consumption, net organic matter uptake and net inorganic nutrient release estimates of $S$. vagabunda at $26{ }^{\circ} \mathrm{C}, 28{ }^{\circ} \mathrm{C}$ and $30{ }^{\circ} \mathrm{C}$ in Albion Lagoon. Values are range estimates $( \pm$ SE) per litre sponge per hour based on the mean estimate fluxes of Spheciospngia vesparium reported by Valentine and Butler (2019).

\begin{tabular}{ccccccc}
\cline { 3 - 6 } & & \multicolumn{2}{c}{ Organic matter uptake } & \multicolumn{2}{c}{ Nutrient release } \\
\hline $\begin{array}{c}\text { Temp } \\
\left({ }^{\circ} \mathbf{C}\right)\end{array}$ & $\begin{array}{c}\text { Pumping } \\
\text { rate }(\mathbf{m l}\end{array}$ & $\begin{array}{c}\text { Bacterial } \\
\text { cells }\left(\mathbf{x ~ 1 0} \mathbf{~ 1 0}^{-2}\right)\end{array}$ & $\mathbf{C h l} \boldsymbol{a}(\boldsymbol{\mu g})$ & $\begin{array}{c}\text { DOC }(\mathbf{x ~ 1 0}) \\
(\boldsymbol{\mu m o l})\end{array}$ & $\begin{array}{c}\mathbf{N O}^{-}{ }^{-}+\mathbf{N O}_{3}{ }^{-} \\
(\boldsymbol{\mu m o l})\end{array}$ & $\mathbf{P O}^{3-}(\boldsymbol{\mu m o l})$ \\
\hline \multirow{2}{*}{26} & 0.12 & $2.01-7.16$ & $50.56-337.07$ & $1.80-3.03$ & $67.41-643.59$ & $43.82-126.40$ \\
& $(0.01)$ & $(0.10-0.36)$ & $(2.53-16.85)$ & $(0.09-0.15)$ & $(3.37-32.18)$ & $(2.19-6.32)$ \\
\multirow{2}{*}{28} & 0.26 & $10.82-15.47$ & $108-728$ & $3.65-6.57$ & $145.61-1346.96$ & $94.65-273.03$ \\
& $(0.02)$ & $(0.54-0.77)$ & $(5.40-36.40)$ & $(0.18-0.33)$ & $(7.28-67.35)$ & $(4.73-13.65)$ \\
30 & 0.29 & $12.12-17.33$ & $122.36-815.73$ & $4.07-7.33$ & $163.14-1509.10$ & $106.04-305.89$ \\
& $(0.02)$ & $(0.61-0.87)$ & $(6.12-40.77)$ & $(0.20-0.37)$ & $(8.16-75.46)$ & $(5.30-15.29)$ \\
\hline
\end{tabular}

\subsubsection{Estimating lagoon volume}

Seawater volume within the Albion Lagoon was estimated using a trapezoid prism equation:

$$
1 / 2(a+w) d l
$$

where $a$ represents the post-reef depression zone width, $w$ lagoon width (i.e. the distance from shoreline to reef flat), $d$ lagoon depth and $l$ lagoon length (see Appendix D - Fig. D5.1). A trapezoid prism equation was used to estimate lagoon volume because a trapezoid is the nearest geometrical shape that corresponds to the topography of Mauritian lagoons (Moothien Pillay et al., 2002). Lagoon dimensions were estimated using a combination of existing literature (Chineah et al., 2001; Beepat et al., 2013) and Google Earth Pro (Google Earth Pro, 2019). Lagoon volume (in litres) was then estimated using mid-tide depth approximation (i.e. $1.5 \mathrm{~m}$ ) for Albion Lagoon. The volume of seawater in Albion Lagoon was estimated at $1.18 \times 10^{9} \mathrm{~L}$ of seawater. Since the coastal lagoons of Mauritius are generally characterized by variable water currents (Daby, 2006), and due to wave action on the near-shore and reef flat regions, it was assumed that there is enough seawater mixing within the lagoon and that there is a homogeneous distribution of nutrients within the lagoon.

\subsubsection{Seawater nutrient estimations}

$\mathrm{Chl} a, \mathrm{NO}_{2}{ }^{-}+\mathrm{NO}_{3}{ }^{-}$and $\mathrm{PO}_{4}{ }^{3-}$ levels within Albion Lagoon were estimated using existing longterm seawater quality monitoring data (see Table 5.2). For DOC estimations, approximately $100 \mathrm{ml}$ seawater $(\mathrm{n}=5)$ were collected from the lagoon in January 2020 and using sterile 
borosilicate glass vials (Yoshimura, 2013). Immediately after collection, a few drops of concentrated $\mathrm{HCl}$ were added to the samples to reduce their $\mathrm{pH}$. Seawater samples were stored in the dark at $4{ }^{\circ} \mathrm{C}$ during transportation, before being frozen at $-20{ }^{\circ} \mathrm{C}$. Seawater samples for DOC measurements were processed and analysed by SGS Laboratory (Mauritius) Ltd.

Table 5.2 Chl $a$, DOC, $\mathrm{NO}_{2}{ }^{-}+\mathrm{NO}_{3}{ }^{-}$and $\mathrm{PO}_{4}{ }^{3-}$ estimates in Albion Lagoon. Chl $a$ and $\mathrm{PO}_{4}{ }^{3-}$ estimations were taken from yearly concentrations reported in Ramessur et al. (2011) and Sadally et al. (2014) for the lagoon of Flic en Flac (i.e. nearest lagoon to Albion Lagoon) and $\mathrm{NO}_{2}{ }^{-}+\mathrm{NO}_{3}{ }^{-}$concentrations were estimated (yearly) from the study of Bissembur et al. (2012) for Albion Lagoon. Values are mean estimates $( \pm \mathrm{SE})$ per litre.

\begin{tabular}{ccc}
\hline Nutrient & Concentration $\left(\mathbf{L}^{-1}\right)$ & Source \\
\hline $\mathbf{C h l} \boldsymbol{a}(\boldsymbol{\mu g})$ & $0.356 \pm 0.07$ & Sadally et al. $(2014)$ \\
$\mathbf{D O C}(\boldsymbol{\mu m o l})$ & $816.6 \pm 40.83$ & This study \\
$\mathbf{N O}_{2}{ }^{-}+\mathbf{N O}_{3}{ }^{-}(\boldsymbol{\mu m o l})$ & $6.2 \pm 1.26$ & Bissembur et al. $(2012)$ \\
$\mathbf{P O}_{4}{ }^{3-}(\boldsymbol{\mu m o l})$ & $0.28 \pm 0.10$ & Ramessur et al. $(2011) ;$ Sadally et \\
& & al. $(2014)$ \\
\hline
\end{tabular}

\subsubsection{Data analysis}

Statistical analyses were performed using SPSS v.24 (SPSS Statistics for Windows, IBM Inc, NY, USA). Bacterial cell consumption data were square-root transformed whereas, organic matter and nutrient flux data were log transformed prior to statistical analyses. One-way ANOVA was used to assess the possible effects of temperature on $S$ vagabunda nutrient fluxes. Post hoc Tukey pairwise comparisons were conducted for significant organic matter and nutrient flux results. For bacterial cell consumption data, a Welch's one-way ANOVA $\left(\mathrm{F}_{(2,227)}\right.$ $=65.45 ; \mathrm{p}<0.001)$ was used to assess the possible effects of temperature, as variances among the groups were not equal and the Games-Howell post hoc test was used for pairwise comparisons.

\subsection{Results}

\subsubsection{Sponge volume}

The mean Spheciospongia vagabunda volume within the combined local distribution areas was estimated as $0.31 \pm 0.02 \mathrm{~L}$ sponge $\mathrm{m}^{-2}$, and therefore the total $S$. vagabunda volume in the lagoon (i.e. entire $S$. vagabunda population within $0.55 \times 10^{5} \mathrm{~m}^{2}$ LDAs - see Chapter 4) was estimated as $1.71 \times 10^{4} \mathrm{~L}$. 


\subsubsection{Bacterial cell consumption}

The bacterial cell consumption by the $S$. vagabunda population in the lagoon was estimated to increase significantly at elevated temperature $\left(\mathrm{F}_{(2,357)}=51.56, \mathrm{p}<0.001\right.$; Fig. 5.2; Table 5.3). The mean bacterial cell consumption at $26{ }^{\circ} \mathrm{C}$ was estimated as $0.85 \pm 0.06$ to $1.22 \pm 0.09 \times 10^{-}$ 2 cells $\mathrm{ml}^{-1} \mathrm{~h}^{-1}$. At $28{ }^{\circ} \mathrm{C}$ and $30{ }^{\circ} \mathrm{C}$, the estimated bacterial consumption of the $S$. vagabunda population ranged from $1.85 \pm 0.14$ to $2.65 \pm 0.20 \times 10^{-2}$ cells $\mathrm{ml}^{-1} \mathrm{~h}^{-1}$ and $2.07 \pm 0.16$ to 2.97 $\pm 0.23 \times 10^{-2}$ cells $\mathrm{ml}^{-1} \mathrm{~h}^{-1}$, respectively. Bacterial cell consumption was significantly higher at $28{ }^{\circ} \mathrm{C}$ and $30{ }^{\circ} \mathrm{C}$ than $26^{\circ} \mathrm{C}$ ( $\mathrm{p}<0.001$ for both comparisons), but no significant difference in bacterial cell consumption was noted between $28^{\circ} \mathrm{C}$ and $30^{\circ} \mathrm{C}(\mathrm{p}=0.291$; Table D5.2).

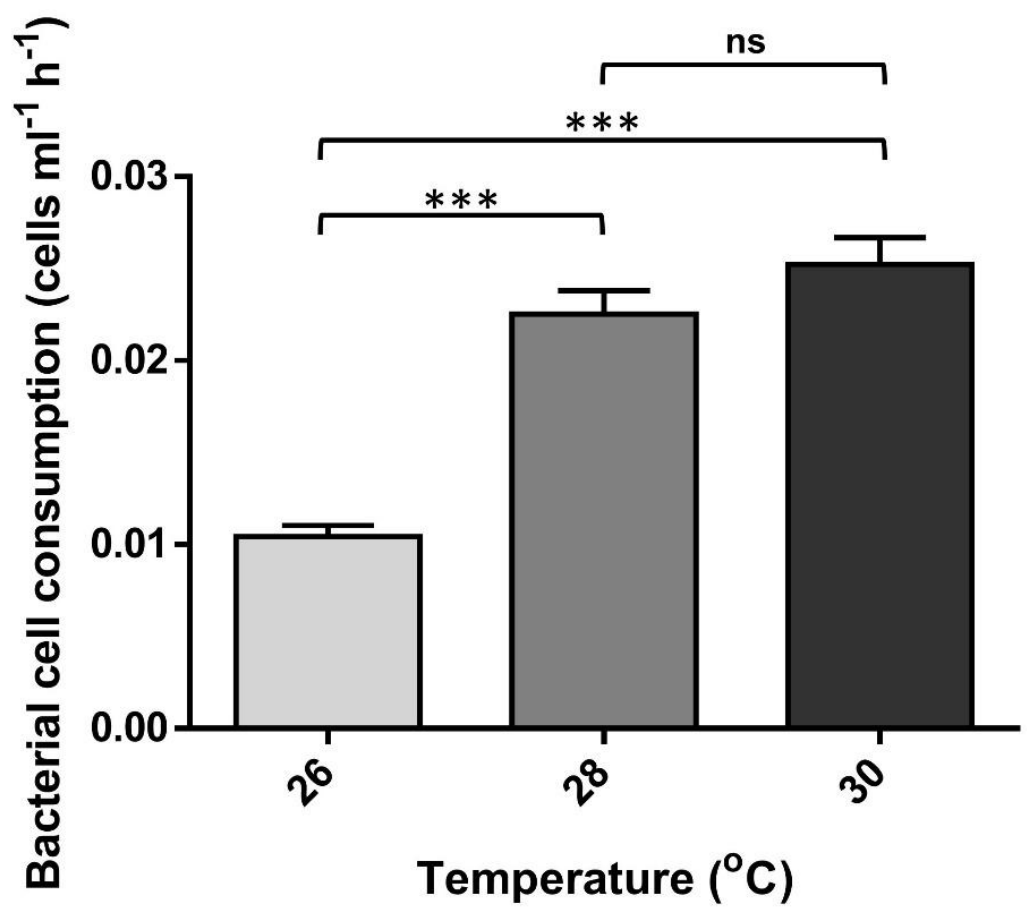

Fig. 5.2 Estimates of Spheciospongia vagabunda population bacterial cell consumption in Albion Lagoon at $26{ }^{\circ} \mathrm{C}, 28{ }^{\circ} \mathrm{C}$ and $30^{\circ} \mathrm{C}$. Values represent mean consumption rates per $\mathrm{ml}$ per hour.

\subsubsection{Organic matter uptake}

\subsubsection{Chlorophyll a}

The Chl $a$ uptake of the $S$. vagabunda population was estimated to be significantly higher at elevated temperatures $\left(\mathrm{F}_{(2,357)}=19.361, \mathrm{p}<0.001\right.$; Fig. 5.3A; Table 5.3). At $26{ }^{\circ} \mathrm{C}$, the mean Chl $a$ uptake by the lagoon sponge population was estimated as $0.08 \pm 0.01$ to $0.57 \pm 0.04 \mathrm{x}$ $10^{7} \mathrm{\mu g} \mathrm{h}^{-1}$ (i.e. $0.20-1.37 \%$ of the total $\mathrm{Chl} a$ available in the lagoon). At $28{ }^{\circ} \mathrm{C}$ and $30{ }^{\circ} \mathrm{C}$, the mean range of $\mathrm{Chl} a$ uptake was estimated at $0.18 \pm 0.01$ to $1.24 \pm 0.09 \times 10^{7} \mu \mathrm{g} \mathrm{h}^{-1}(0.44-$ 
$2.97 \%)$ and $0.20 \pm 0.02$ to $1.39 \pm 0.11 \times 10^{7} \mu \mathrm{g} \mathrm{h}^{-1}(0.50-3.33 \%)$, respectively. The mean Chl $a$ uptake was estimated to be significantly higher at $28{ }^{\circ} \mathrm{C}$ and $30{ }^{\circ} \mathrm{C}$ than $26{ }^{\circ} \mathrm{C}(\mathrm{p}<0.001$ for both comparisons). In contrast, the mean $S$. vagabunda population $\mathrm{Chl} a$ uptake between $28{ }^{\circ} \mathrm{C}$ and $30{ }^{\circ} \mathrm{C}$ was not significantly different ( $\mathrm{p}=0.998$; Table D5.2).

\subsubsection{Dissolved organic carbon}

The estimated net DOC uptake by the $S$. vagabunda population in Albion Lagoon was significantly higher at elevated temperatures $\left(\mathrm{F}_{(2,357)}=43.055, \mathrm{p}<0.001 ;\right.$ Fig. 5.3B; Table 5.3). At ambient temperature $\left(26^{\circ} \mathrm{C}\right)$, the estimated DOC uptake ranged from $0.30 \pm 0.02$ to $0.51 \pm$ $0.04 \times 10^{10} \mu \mathrm{mol} \mathrm{h}{ }^{-1}$, representing $0.32-0.54 \%$ of the total DOC in the lagoon. At $28{ }^{\circ} \mathrm{C}$, the range of DOC uptake was estimated as $0.62 \pm 0.05$ to $1.12 \pm 0.08 \times 10^{10} \mu \mathrm{mol} \mathrm{h}^{-1}(0.65-$ $1.17 \%$ ), and at $30^{\circ} \mathrm{C}$, the estimated DOC uptake ranged from $0.69 \pm 0.05$ to $1.25 \pm 0.09 \times 10^{10}$ $\mu \mathrm{mol} \mathrm{h} \mathrm{h}^{-1}(0.72-1.30 \%)$. At $28^{\circ} \mathrm{C}$ and $30{ }^{\circ} \mathrm{C}$, S. vagabunda population net DOC uptake in Albion Lagoon was estimated to be significantly higher than at $26{ }^{\circ} \mathrm{C}$ ( $\mathrm{p}<0.001$ for both comparisons), but the estimated DOC uptake between $28{ }^{\circ} \mathrm{C}$ and $30{ }^{\circ} \mathrm{C}$ was not significantly different ( $p=0.920$; Table D5.2).
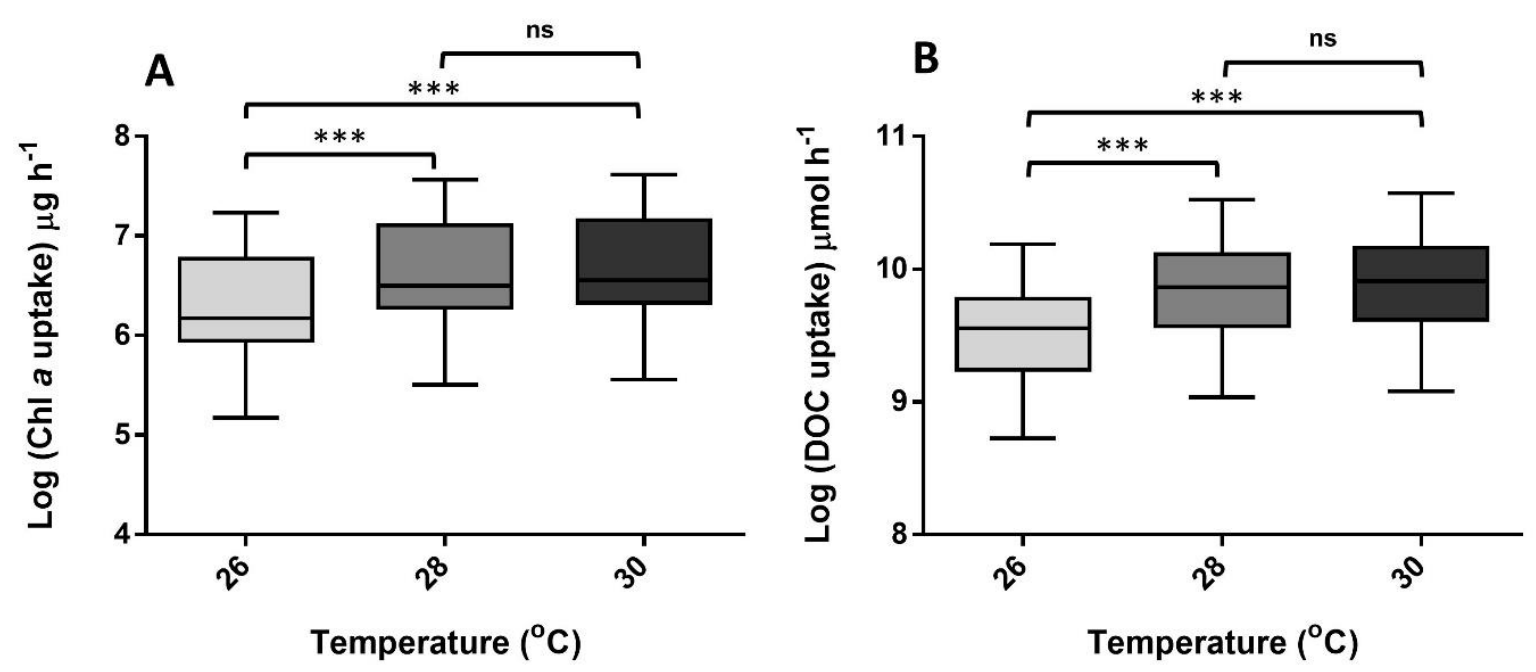

Fig. 5.3 The estimated range of A) Chl $a$ and B) net dissolved organic carbon (DOC) uptake by the Spheciospongia vagabunda population in Albion Lagoon at $26{ }^{\circ} \mathrm{C}, 28{ }^{\circ} \mathrm{C}$ and $30{ }^{\circ} \mathrm{C}$. Values represent log estimates of net organic matter uptake per hour. 


\subsubsection{Net inorganic nutrients release}

\subsubsection{Nitrite + Nitrate}

Net $\mathrm{NO}_{2}^{-}+\mathrm{NO}_{3}{ }^{-}$release by the $S$. vagabunda population in Albion Lagoon was estimated to be significantly higher at elevated temperature $\left(\mathrm{F}_{(2,357)}=15.744, \mathrm{p}<0.001\right.$; Fig. 5.4A; Table 5.3). The estimated $\mathrm{NO}_{2}{ }^{-}+\mathrm{NO}_{3}{ }^{-}$release at $26{ }^{\circ} \mathrm{C}$ ranged from $0.11 \pm 0.01$ to $1.06 \pm 0.08 \times 10^{7}$ $\mu \mathrm{mol} \mathrm{h}{ }^{-1}\left(0.02-0.15 \%\right.$ of the total $\mathrm{NO}_{2}{ }^{-}+\mathrm{NO}_{3}{ }^{-}$in the lagoon $)$. The estimated $\mathrm{NO}_{2}{ }^{-}+\mathrm{NO}_{3}{ }^{-}$ release at $28{ }^{\circ} \mathrm{C}$ ranged from $0.25 \pm 0.02$ to $2.31 \pm 0.08 \times 10^{7} \mu \mathrm{mol} \mathrm{h}^{-1}(0.03-0.32 \%)$, and at $30{ }^{\circ} \mathrm{C} \mathrm{NO}_{2}{ }^{-}+\mathrm{NO}_{3}{ }^{-}$release was estimated to range from $0.28 \pm 0.02$ to $2.59 \pm 0.19 \times 10^{7} \mu \mathrm{mol}$ $\mathrm{h}^{-1}(0.04-0.35 \%)$. Net $\mathrm{NO}_{2}{ }^{-}+\mathrm{NO}_{3}{ }^{-}$release estimates at $28{ }^{\circ} \mathrm{C}$ and $30{ }^{\circ} \mathrm{C}$ were significantly higher than at $26{ }^{\circ} \mathrm{C}$ ( $\mathrm{p}<0.001$ for both comparisons), but no significant difference was seen between $28{ }^{\circ} \mathrm{C}$ and $30^{\circ} \mathrm{C}(\mathrm{p}=0.441$; Table D5.2).

\subsubsection{Phosphate}

S. vagabunda population net $\mathrm{PO}_{4}{ }^{3-}$ release was estimated to increase significantly under elevated temperature $\left(\mathrm{F}_{(2,357)}=34.793, \mathrm{p}<0.001\right.$; Fig. 5.4B; Table 5.3). Estimates of $\mathrm{PO}_{4}{ }^{3-}$ released at $26{ }^{\circ} \mathrm{C}$ ranged from $0.75 \pm 0.06$ to $2.16 \pm 0.16 \times 10^{6} \mu \mathrm{mol} \mathrm{h}^{-1}$, representing $0.23-$ $0.66 \%$ of the total lagoon $\mathrm{PO}_{4}{ }^{3-}$ content. At $28{ }^{\circ} \mathrm{C}, \mathrm{PO}_{4}{ }^{3-}$ release was estimated as $1.62 \pm 0.12$ to $4.68 \pm 0.36 \times 10^{6} \mu \mathrm{mol} \mathrm{h}{ }^{-1}(0.49-1.42 \%)$, and at $30{ }^{\circ} \mathrm{C} \mathrm{PO}_{4}{ }^{3-}$ release ranged from $1.81 \pm$ 0.14 to $5.24 \pm 0.40 \times 10^{6} \mu \mathrm{mol} \mathrm{h}^{-1}(0.55-1.59 \%)$. S. vagabunda net $\mathrm{PO}_{4}{ }^{3-}$ release was estimated to be higher at $28{ }^{\circ} \mathrm{C}$ and $30{ }^{\circ} \mathrm{C}$ than at the ambient temperature $(\mathrm{p}<0.001$ for both comparisons), but no significant difference in $\mathrm{PO}_{4}{ }^{3-}$ release was seen between $28{ }^{\circ} \mathrm{C}$ and $30{ }^{\circ} \mathrm{C}$ $(\mathrm{p}=0.441$, Table D5.2). 

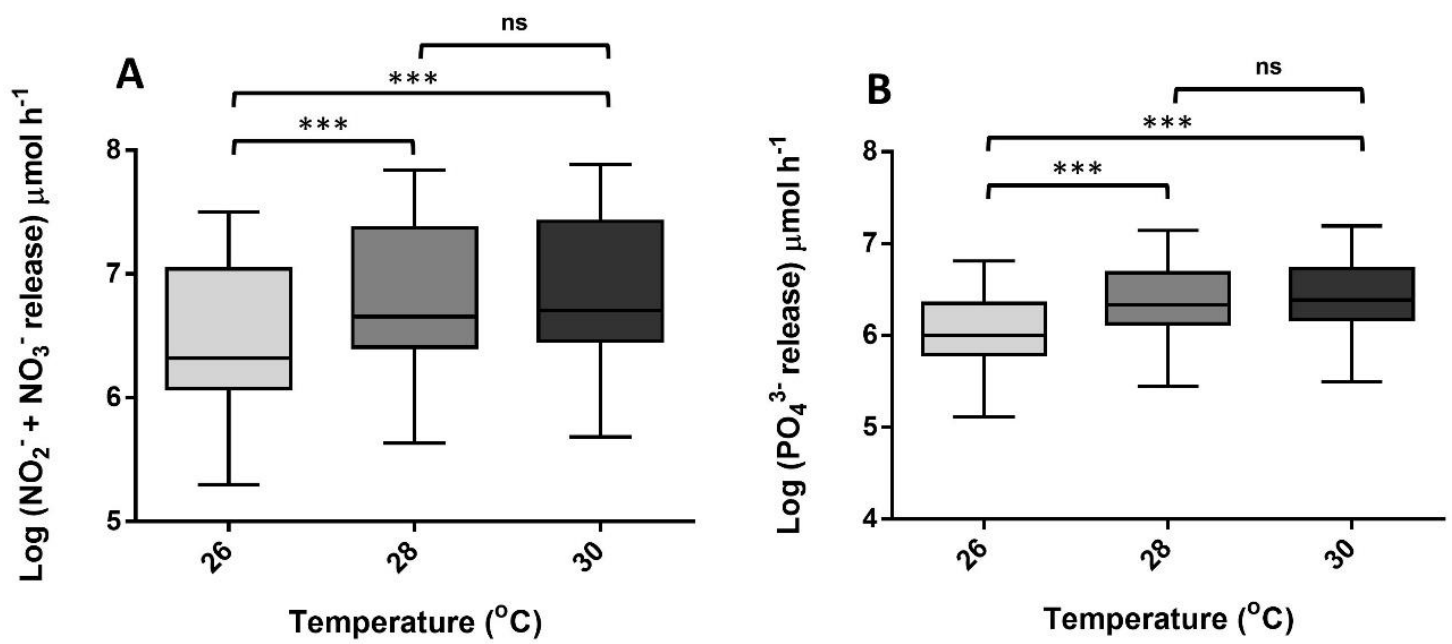

Fig. 5.4 The estimated range of net A) nitrite + nitrate and B) phosphate release by the Spheciospongia vagabunda population in Albion Lagoon at $26{ }^{\circ} \mathrm{C}, 28{ }^{\circ} \mathrm{C}$ and $30{ }^{\circ} \mathrm{C}$. Values represent log estimates of net inorganic nutrient release per hour.

Table 5.3. Organic matter and nutrient flux estimates of the Spheciospongia vagabunda population in Albion Lagoon at $26^{\circ} \mathrm{C}, 28{ }^{\circ} \mathrm{C}$ and $30^{\circ} \mathrm{C}$. Values are percentage range estimates $( \pm \mathrm{SE})$ for $S$. vagabunda population (total sponge volume) per hour.

\begin{tabular}{ccccc}
\cline { 2 - 5 } Temp $\left({ }^{\circ} \mathbf{C}\right)$ & Organic matter uptake & \multicolumn{2}{c}{ Nutrient release } \\
\hline \multirow{2}{*}{26} & $0.20-1.37$ & DOC $(\boldsymbol{\mu m o l})$ & $\begin{array}{c}\mathbf{N O}^{-}+\mathbf{N O}^{-} \\
(\boldsymbol{\mu m o l})\end{array}$ & $\mathbf{P O}^{-{ }^{3-}}(\boldsymbol{\mu m o l})$ \\
& $(0.01-0.11)$ & $(0.02-0.04)$ & $(0.005-0.01)$ & $(0.02-0.05)$ \\
\multirow{2}{*}{28} & $0.44-2.97$ & $0.65-1.17$ & $0.03-0.32$ & $0.49-1.42$ \\
& $(0.03-0.23)$ & $(0.05-0.09)$ & $(0.01-0.02)$ & $(0.04-0.12)$ \\
\multirow{2}{*}{30} & $0.50-3.33$ & $0.72-1.30$ & $0.04-0.35$ & $0.55-1.59$ \\
& $(0.04-0.26)$ & $(0.06-0.10)$ & $(0.01-0.02)$ & $(0.04-0.12)$
\end{tabular}

\subsection{Discussion}

Sponges have an important role in bentho-pelagic interactions (Maldonado et al., 2012; de Goeij et al., 2013) and are important producers of inorganic nutrients on some coral reefs (Diaz \& Ward, 1997; Pawlik et al., 2018). However, the bentho-pelagic interactions of sponges in semi-enclosed water bodies such as coastal lagoons are relatively unknown. This chapter reports on the bacterial cell consumption, net organic matter uptake and net inorganic nutrient release of the lagoon-inhabiting sponge Spheciospongia vagabunda population when exposed to elevated temperature. Net organic matter uptake and net inorganic nutrient release estimates 
indicate that the bentho-pelagic interactions of the S. vagabunda population in Albion Lagoon (Western Indian Ocean) are relatively limited when compared to other species inhabiting shallow Caribbean coastal ecosystems (Southwell et al., 2008; Valentine \& Butler, 2019), mainly because of its overall low abundance. S. vagabunda bacterial cell consumption, net organic matter uptake and net inorganic nutrient release also remained relatively low under elevated temperature scenarios. The Chl $a$ and net DOC uptake of this species' population ranged between $0.20-3.33 \%$ and $0.32-1.30 \%$ of the total Chl $a$ and DOC available in the lagoon, respectively. S. vagabunda net inorganic nutrient release (i.e. $\mathrm{NO}_{2}{ }^{-}+\mathrm{NO}_{3}{ }^{-}$and $\mathrm{PO}_{4}{ }^{3-}$ ) ranged between $0.02-0.35 \%$ and $0.23-1.59 \%$ of the total $\mathrm{NO}_{2}{ }^{-}+\mathrm{NO}_{3}{ }^{-}$and $\mathrm{PO}_{4}{ }^{3-}$ available in the lagoon, respectively. The S. vagabunda population in Albion Lagoon is estimated to consume $116 \%$ and $142 \%$ more bacterial cells when exposed to a thermal increase of $2{ }^{\circ} \mathrm{C}$ and $4{ }^{\circ} \mathrm{C}$, respectively, when compared to the ambient seawater temperature. Net organic matter uptake and net inorganic nutrient release of this population in Albion Lagoon were also predicted to increase, by approximately $115 \%$ at $28{ }^{\circ} \mathrm{C}$ and $142 \%$ at $30{ }^{\circ} \mathrm{C}$ respectively, when compared to ambient temperature $\left(26^{\circ} \mathrm{C}\right)$, suggesting that the contribution of $S$. vagabunda to bentho-pelagic interactions will likely increase under future ocean warming scenarios.

\subsubsection{Net organic matter uptake in Albion Lagoon}

Sponges are mostly heterotrophic organisms (Poppell et al., 2014) and feed on both photo- and autotrophic bacteria (Reiswig, 1971b), detritus (Pawlik et al., 2018), and DOC (Yahel et al., 2003; Hoer et al., 2018). For example, Mueller et al. (2014) reported that the sponges Cliona delitrix and Siphonodictyon sp. consume between $1.7-1.8 \times 10^{10}$ bacterial cells $\mathrm{h}^{-1}$ and take up between $354-461 \mu \mathrm{mol} \mathrm{DOC} \mathrm{h}^{-1}$. Here, it was estimated that the $S$. vagabunda population in Albion Lagoon consumed between $0.85-2.97 \times 10^{-2}$ bacterial cells $\mathrm{h}^{-1}$, and its Chl $a$ and net DOC uptake rates ranged between $0.08-1.39 \times 10^{7} \mu \mathrm{g} \mathrm{h}^{-1}$ and $0.23-1.25 \times 10^{10} \mu \mathrm{mol} \mathrm{h}^{-}$ 1 , respectively, suggesting that $S$. vagabunda is likely relying on both resources to meet its energetic demands. While the percentage contribution of the S. vagabunda population to bacterial cell consumption in the lagoon could not be estimated here, its net DOC uptake contribution in the lagoon was similar to other species such as Callyspongia vaginalis (3\%) and Mycale laxissima (1\%) reported by Hoer et al. (2018) on Caribbean reefs. Sponges such as Iricinia strobilina and Verongula gigantea have been reported to take up $21-24 \%$ of the DOC on Caribbean coral reefs (Hoer et al., 2018). However, their increased DOC uptake capabilities when compared to bioeroding species such as $S$. vagabunda might be related to their massive morphologies (i.e. the amount of space they occupy on the benthos) and their 
population abundance. For example, the mean sponge volume per unit area of the barrel sponge Xestospongia muta on Conch Reef, Florida, was estimated as $1.5 \mathrm{~L} \mathrm{~m}^{-2}$ and this species could consume up to $2910 \mu \mathrm{mol}$ DOC $\mathrm{h}^{-1}$ (Hoer et al., 2018). In comparison, in Albion Lagoon, $S$. vagabunda mean volume per unit area was estimated as $0.31 \mathrm{~L} \mathrm{~m}^{-2}$ and this species potentially consumes up to $2.27 \mu \mathrm{mol} \mathrm{DOC} \mathrm{h}{ }^{-1}$ at $30^{\circ} \mathrm{C}$. The feeding patterns of sponges are often speciesspecific (Reiswig, 1971b; Maldonado et al., 2010). Therefore, further in-depth investigations on $S$. vagabunda feeding patterns are required to fully understand the trophic ecology of this species and its interactions within the lagoon.

\subsubsection{Net inorganic nutrient contribution}

The percentage contribution of inorganic nitrogen from sponges on tropical coral reefs has previously been reported for the Caribbean (Corredor et al., 1988; Diaz \& Ward, 1997; Southwell et al., 2008) and Western Australia (Keesing et al., 2013). In Puerto Rico for example, the sponge Chondrilla nucula contributes 50 - 120\% of nitrate needed on the reef, and the sponge assemblage (15 species) along the Western Australian continental shelf contributes $10-18 \%$ of the total nitrogen required by the benthos. In this study, the net contribution of the $S$. vagabunda population in Albion Lagoon to environmental $\mathrm{NO}_{2}{ }^{-}+\mathrm{NO}_{3}{ }^{-}$ pools was relatively small compared to these previous studies, with an estimated maximum $\mathrm{NO}_{2}{ }^{-}+\mathrm{NO}_{3}{ }^{-}$contribution of $0.35 \%$ at $30{ }^{\circ} \mathrm{C}$. However, it is interesting to note that the results from S. vagabunda in Albion Lagoon are consistent with the findings of Corredor et al. (1988) for the sponge Cliona varians, which was reported to contribute $<1 \%$ of the total nitrate on Puerto Rican reefs, suggesting that some clionid sponges might be low $\mathrm{NO}_{2}^{-}+\mathrm{NO}_{3}^{-}$ contributors.

Net $\mathrm{PO}_{4}{ }^{3-}$ release by the $S$. vagabunda population in Albion Lagoon was estimated as 0.23 $1.59 \%$ of the total $\mathrm{PO}_{4}{ }^{3-}$ found in the lagoon's waters. These estimations are similar to those of López-Acosta et al. (2019), where the sponge Tethya citrina was reported to contribute $2.1 \%$ of the $\mathrm{PO}_{4}{ }^{3-}$ in the Bay of Brest (France), although the temperate Bay of Brest could potentially be richer in terms of nutrients compared to the tropical Albion Lagoon. There is currently a paucity of investigations on the contribution of $\mathrm{PO}_{4}{ }^{3-}$ from marine sponges within specific ecosystems and recent studies have mainly focused on estimating the net $\mathrm{PO}_{4}{ }^{3-}$ release from different sponge species (Ribes et al., 2012; Archer et al., 2017; Morganti et al., 2017). From existing studies however, there is a general indication that the amount of $\mathrm{PO}_{4}{ }^{3-}$ released by sponges is relatively small. For example, Ribes et al. (2012) showed that the sponges Dysidea 
avara, Agelas oroides and Chondrosia reniformis released very small amounts of $\mathrm{PO}_{4}^{3-}(0.10$ $\left.-0.12 \mu \mathrm{mol} \mathrm{min}{ }^{-1}\right)$ compared to $\mathrm{NO}_{\mathrm{x}}{ }^{-}\left(2.12-3.86 \mu \mathrm{mol} \mathrm{min}{ }^{-1}\right)$. A similar trend was also observed by Archer et al. (2017) and Morganti et al. (2017), suggesting that the amount of $\mathrm{PO}_{4}{ }^{3-}$ released by sponges is relatively small when compared to the release of other inorganic compounds, such as $\mathrm{NO}_{2}{ }^{-}+\mathrm{NO}_{3}{ }^{-}$and $\mathrm{NH}_{4}{ }^{+}$.

The low rates of bacterial cell consumption and net organic matter uptake reported here suggest that, in addition to feeding on bacterioplankton and DOC, S. vagabunda could possibly obtain energy from associated autotrophic microbial symbionts. While the microbiome of the species is dominated by gammaproteobacterial (Thomas et al., 2016), they also host symbiotic dinoflagellates (Levi et al., 1998) and cyanobacteria were detected (Appendix A - Section A2.1), suggesting that some energy could be provided by these symbionts. Feeding patterns and nutrient fluxes among sponges are usually species-specific (Jiménez \& Ribes, 2007; Southwell et al., 2008) and therefore between-species comparisons are more likely to be speculative. However, it is interesting to note that, in the three existing studies reporting nutrient fluxes of clionid sponges, i.e. C. varians (Corredor et al., 1988), C. delitrix (Mueller et al., 2014) and S. vesparium (Valentine \& Butler, 2019), the nutrient fluxes were relatively small. However, further investigations of other clinoid sponges are necessary to confirm this pattern. In the present study, the low rates of bacterial cell consumption, net organic matter uptake and net inorganic nutrient release are most likely related to the low abundance of $S$. vagabunda within the Albion lagoon. Currently, S. vagabunda occupies approximately $0.55 \mathrm{x}$ $10^{5} \mathrm{~m}^{2}$ of the total area of the lagoon $\left(0.65 \times 10^{6} \mathrm{~m}^{2}\right)$ post-reef benthos (see Chapter 4$)$. If the S. vagabunda population was more abundant and distributed across the total lagoon post-reef benthos, the rates of bacterial cell consumption, net organic matter uptake and net inorganic nutrient release by this sponge would have been approximately 10 times higher than the estimates reported here. However, variations in $S$. vagabunda bacterial cell consumption, and net organic matter and net inorganic nutrient flux, would likely depend on changes in environmental conditions such as the availability of food particles (e.g. bacterioplankton and DOC) in the water column (Archer et al., 2017; Bell et al., 2018; Lesser \& Slattery, 2020).

\subsubsection{Effects of elevated temperature}

The potential effects of climate change on the bentho-pelagic interactions of sponges have not been thoroughly investigated. However, since some sponges are likely to be more tolerant to global climate change than other benthic taxa such as corals (Bell et al., 2018), it is expected 
that sponges may have more prominent bentho-pelagic interactions in the future in anthropogenically-impacted ecosystems (de Goeij et al., 2017; Bell et al., 2018; Pawlik et al., 2018). For the estimates reported in this study, it is likely that the contribution of the $S$. vagabunda population to bentho-pelagic interactions in the Albion Lagoon will increase under future ocean warming scenarios. Some non-climatic models reported for the Caribbean (Archer et al., 2017) have indicated that changes to abiotic environmental conditions such as nutrient availability, irradiance and temperature could possibly result in changes to sponge nutrient processing. Achlatis et al. (2017), for example, demonstrated that DOC uptake by the sponge Cliona orientalis around Heron Island (Australia) is significantly reduced under future climate change scenarios. However, unlike other bioeroding sponges, including S. vagabunda (Schönberg et al., 2017), C. orientalis is physiologically less tolerant of environmental change (Ramsby et al., 2018). In this current study, the $S$. vagabunda bacterial cell consumption, and net organic matter uptake and net inorganic nutrient release, were estimated to increase under future ocean warming scenarios. However, it is important to note that the estimates here were based on changes to the $S$. vagabunda pumping rate at elevated temperature, and the assumption that changes in pumping rate correlate with changes in bacterial cell consumption and nutrient flux (Vogel, 1977; Weisz et al., 2008; Ludeman et al., 2017). Therefore, other factors, such as changes in existing population abundance/biomass, food availability (Bell et al., 2018; Pawlik et al., 2018; Lesser \& Slattery, 2020) and the host's microbial association (Zhang et al., 2019), which could not be incorporated in the estimates reported here could also influence the bentho-pelagic interactions of S. vagabunda within the Albion Lagoon. This is in addition to other undetermined functional changes such as sponge morphological traits (de Goeij et al., 2017) and sponge tissue density (Weisz et al., 2008), which might also be associated with sponges' nutrient flux variations and should be a focus of future study.

\subsection{Conclusions}

Sponges are important benthic components of many coastal lagoons (Levi et al., 1998; Cerrano et al., 2004). However, the roles and contributions of sponges in lagoonal bentho-pelagic interactions has been widely overlooked. Until now, investigations on the potential roles of sponges in organic matter and inorganic nutrient dynamics within the water column have mostly been conducted in the Caribbean (Southwell et al., 2008; Hoer et al., 2018) and Mediterranean (Yahel et al., 2003; Morganti et al., 2017), with limited information from the Indian Ocean. This study demonstrates that $S$. vagabunda has a relatively small bentho-pelagic 
contribution in a coastal lagoon in Western Indian Ocean, although the results presented here also indicate that this species, which is physiologically tolerant of elevated temperature, could potentially have an increased bentho-pelagic role under future ocean warming scenarios. However, the results reported in this study are indicative of a single lagoon-inhabiting sponge species. Since coastal lagoons often host multiple sponge species, it is important to determine the potential bentho-pelagic roles of other species to better understand the ecological roles of lagoon-inhabiting sponges in such interactions. 
Chapter 6:

General discussion 


\subsection{Summary of key findings}

The main aim of my thesis was to explore the responses of three lagoon-inhabiting sponges namely, Neopetrosia chaliniformis, Amphimedon navalis and Spheciospongia vagabunda when exposed to elevated seawater temperature projected by the IPCC (2014) Representative Concentration Pathways RCP6.0 $\left(+2{ }^{\circ} \mathrm{C}\right)$ and RCP $8.5\left(+4{ }^{\circ} \mathrm{C}\right)$ for the year 2100. In addition, I also aimed to determine whether the combined effects of elevated temperature and eutrophication might have deleterious impacts on these coastal lagoon sponges. The results from the short-term (two weeks) multifactorial experiment (chapter 2) demonstrated that lagoon-inhabiting sponges are more likely to be impacted by elevated temperature rather than an increase in nitrate concentration (used as a proxy for eutrophication). Results from chapter 3 showed that when exposed to elevated temperature alone, significant physiological changes appeared after the first week of thermal exposure for all species. However, after two weeks of thermal exposure, the bioeroding sponge $S$. vagabunda showed some evidence of acclimation to elevated temperature. This demonstrated that the physiological responses of lagooninhabiting sponges to elevated temperature are species-specific. The proteomic analysis from this chapter also revealed that, in the thermally-susceptible A. navalis sponge, disruption was also apparent at the cellular level, whereby proteins involved in oxidative stress, protein transport and cytoskeletal organisation were significantly enriched. In chapter 4, I described the temporal dynamics in the abundance and percentage cover of the three lagoon-inhabiting sponge species, and their correlation with sea surface temperature (SST) and chlorophyll $a$ (Chl a). The results from this chapter again showed species-specific responses of lagoon-inhabiting sponges to elevated temperature (Fig. 6.1), supporting earlier findings in chapter 3. While the distribution, abundance, and percentage cover of $N$. chaliniformis significantly declined over eight years, S. vagabunda significantly increased over six years. In contrast, no significant changes occurred to the distribution and percentage cover of A. navalis. Finally, in chapter 5, I estimated the bentho-pelagic interactions of the thermally tolerant sponge $S$. vagabunda. The results from this chapter demonstrated that this species has limited interactions with the water column in the lagoon where it occurs. However, my estimates showed that $S$. vagabunda bacterial cell consumption, net organic matter uptake and net inorganic nutrients release will likely increase, when exposed to an increase in seawater temperature of $+2{ }^{\circ} \mathrm{C}$ and $+4{ }^{\circ} \mathrm{C}$, respectively. 
Lagoon sponge

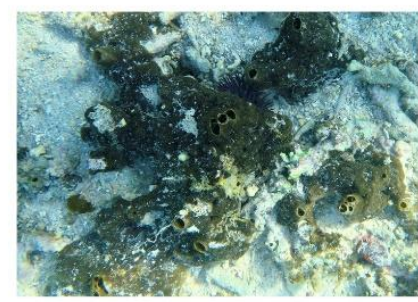

Spheciospongia vagabunda

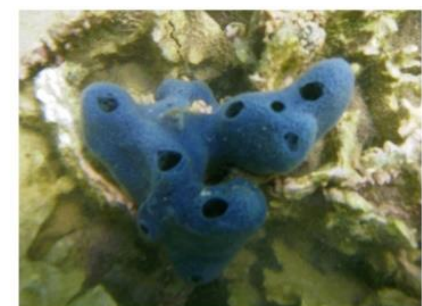

Amphimedon navalis

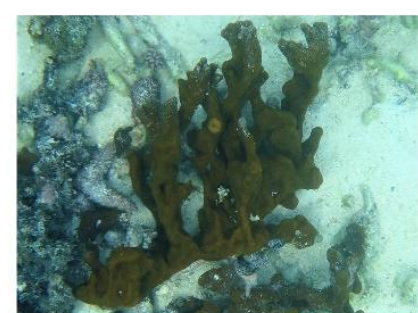

Neopetrosia chaliniformis

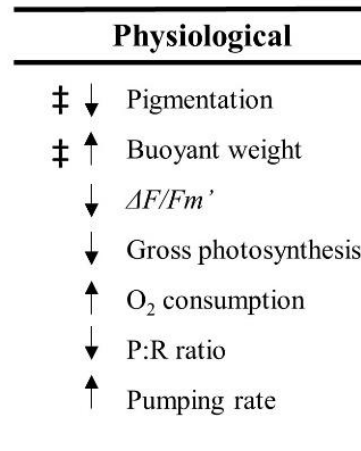

$\uparrow$ Oxidative stress

$\leftrightarrow$ Pigmentation

$\ddagger \downarrow$ Buoyant weight

$\uparrow \mathrm{O}_{2}$ consumption

$\uparrow$ Pumping rate
$\ddagger \downarrow$ Pigmentation
$\ddagger \downarrow$ Buoyant weight
$\downarrow \Delta F / F m^{\prime}$
$\downarrow$ Gross photosynthesis
- $\mathrm{O}_{2}$ consumption
$\downarrow$ P:R ratio
$\uparrow$ Pumping rate

Proteomic

Responses

Population level

Bentho-pelagic

$\uparrow$ Local Distribution Area (LDA)

Bacterial consumption

$+\uparrow$ Mean abundance

4 Net organic matter intake

$\uparrow$ Mean percentage cover

$\uparrow$ Net inorganic nutrients release

$\ddagger \downarrow$ Mean abundance

$\downarrow$ Mean percentage cover

Fig. 6.1 Physiological, proteomic and population level responses of the lagoon-inhabiting sponges Neopetrosia chaliniformis, Amphimedon navalis and Spheciospongia vagabunda to elevated temperature and eutrophication. Arrows represent significant $(\uparrow)$ increase, $(\downarrow)$ decrease and $(\leftrightarrow)$ no change in responses. $(\dagger)$ represent significant negative and $(\dagger)$ significant positive effect of eutrophication. Eutrophication data are based on 2 weeks lab-based experiments. Bentho-pelagic responses are based on S. vesparium estimates from Valentine and Butler (2019). 


\subsection{Lagoon-inhabiting sponges and thermal stress}

Lagoon-inhabiting organisms are regularly exposed to elevated temperature (Przeslawski et al., 2008). However, while motile organisms exposed to elevated temperature can migrate to other habitats, non-motile benthic organisms such as corals and sponges must either: (i) rely on phenotypic and physiological plasticity to tolerate thermal stress; or (ii) adapt to the new temperature thresholds through genetic change via the process of evolution (Hofmann \& Todgham, 2010). According to Pörtner (2012), the rate of all biochemical reactions, including physiological and cellular processes, are highly dependent on temperature. For example, multiple coral species are known to expel their endosymbiotic dinoflagellates when the holobiont coral is exposed to elevated temperature (Hoegh-Guldberg, 1999; Lesser, 2011). While, the effects of elevated temperature on sponges are likely to be species-specific (Bell et al., 2018), previous studies have shown that several species are vulnerable to ocean warming, which could result in mass mortalities, bleaching and disease (Cerrano et al., 2000; Cebrian et al., 2011; Ramsby et al., 2018). Results from chapters 2 and 3 revealed that for thermally susceptible $\mathrm{Chl} a$-containing lagoonal species, a reduced photosynthetic activity was seen and physiological functions such as respiration and pumping rates significantly increased for all species. These observations are consistent with prior thermal tolerance studies (Riisgård et al., 1993; Achlatis et al., 2017; Ramsby et al., 2018). Loss of sponge-associated photosymbionts or bleaching has previously been reported from multiple thermally-susceptible sponges such as Ircinia fasciculata (Cebrian et al., 2011) and Cliona orientalis (Ramsby et al., 2018). Similarly, increased respiration or pumping rates as a response to elevated temperature have been reported in Halichondria panicea (Riisgård et al., 1993) and Rhopaloides odorabile (Massaro et al., 2012). Achlatis et al. (2017) reported that the combination of high respiration rates and a reduction in photosymbiont populations in $C$. orientalis could potentially result in a resource drain to the sponge, where the holobiont's access to energy resources (mostly carbon from photosynthesis) are significantly reduced. As a result, it is possible that the increase in activity of primary physiological processes such as pumping may have negative repercussions on secondary aspects of the host's fitness such as tissue growth and reproduction.

It has been estimated that approximately $75 \%$ of the oxygen consumed by a sponge may be used for sponge maintenance and pumping, and the $25 \%$ remaining oxygen is allocated to growth (Hadas et al., 2008), indicating that pumping activity in some sponges could be an energetically costly process (Leys et al., 2011). Fang et al. (2014) demonstrated that, when 
exposed to elevated temperature, the energy balance of $C$. orientalis is strongly shifted and the high metabolic demand experienced by this sponge under these conditions significantly affected its growth and survival. Therefore, the reduced photosynthetic activity reported in the present study may possibly be impacting the ability of the sponge holobiont to acquire carbon from its associated photosymbionts. This might be more prominent in the thermally-susceptible photosynthetic sponge $N$. chaliniformis. As a result, the reduction in photosynthetic activity combined with the increase in respiration rates reported in chapters 2 and 3 may likely compromise sponge physiological functions such as growth, which was reflected in buoyant weight measurements.

The distribution and abundance of a species is often directly correlated with its physiological performance and tolerance to biotic/abiotic environmental factors (Miller \& Stillman, 2012). For example, adult $R$. odorabile and $C$. orientalis are both reported to have a strict thermal threshold of $32{ }^{\circ} \mathrm{C}$ (Pantile \& Webster, 2011; Ramsby et al., 2018). Therefore, negative impacts at the physiological level may likely be reflected at the population level and as a result, the distribution range of a thermally-susceptible species may likely reduce over time (Pörtner \& Farrell, 2008; Bell et al., 2017b). This observation has previously been reported in tropical scleractinian corals (Hoegh-Guldberg et al., 2007; D'Angelo \& Wiedenmann, 2014) and macroalgae (Bintz et al., 2003), when exposed to elevated temperature and eutrophication. Therefore, the reduced distribution of thermally-susceptible lagoon-inhabiting sponge species may be related to a combination of the following factors: (i) restricted growth and reproductive performance of these sponges because they are directly exposed to elevated temperatures; (ii) reduced physiological performance due to the loss or reduction of photosymbionts for photosynthetic species (e.g. N. chaliniformis); or (iii) the loss of live coral communities, which is often an important substratum on which these species may grow (e.g. A. navalis).

Physiological performance is also directly influenced by cellular metabolic pathways within an organism (DeBerardinis \& Thompson, 2012; Metallo \& Vander Heiden, 2013; Yoithapprabhunath et al., 2015). Changes in cellular functions originating from environmental stress directly impact the physiological behaviour of an organism. For example, elevated temperature has been found to induce oxidative stress and protein degradation in multiple coral (DeSalvo et al., 2010; Huang et al., 2018) and sponge (Webster et al., 2013; Guzman \& Conaco, 2016) species. However, the combination of physiological and molecular approaches to assess the responses of sponges to climate change or eutrophication has not been attempted 
to date. Recently, using a combined physiological-proteomic approach, Tisthammer et al. (2020) revealed potential adaptative underlying processes in Porites lobata corals. Results from chapter 3 , clearly demonstrate that some physiological responses such as increase in pumping rates and reduction in buoyant weight of A. navalis were directly correlated with specific changes at the proteome level. Therefore, a combined physiological-molecular approach would clearly enhance our understanding on the possible underlying mechanisms involved in sponge stress or adaptation responses. However, the high number of unidentified proteins recorded for sponges on proteome databases such as UniProtKB or InterPro highlights the current limitations and lack of proteome databases available for marine sponges.

\subsection{Spheciospongia vagabunda: a persistent lagoon-inhabiting species}

Results from chapters 2, 3 and 4 demonstrated that the bioeroding sponge $S$. vagabunda is a thermally tolerant species, which could also potentially thrive in eutrophication-impacted environments. Bioeroding clionid sponges are generally considered to be resilient to multiple environmental changes such as elevated temperature, excess nutrients and reduced $p \mathrm{CO}_{2}$ (Wisshak et al., 2014; Stubler et al., 2015; Schönberg et al., 2017). The occurrence of $S$. vagabunda in dynamic ecosystems such as coastal lagoons (Levi et al., 1998; Beepat et al., 2013), estuaries (S. S. Beepat, unpublished data) and harbours (Padovan et al., 2012), suggests that this species has evolved specific mechanisms to adapt to changing environmental conditions in shallow coastal waters, although the duration of the lab-based experiment reported in chapter 2 were based on two weeks.

The association of $S$. vagbaunda with zooxanthellae (Levi et al., 1998) might play an important role in the thermal tolerance of this species, supporting its persistence in coastal lagoons. According to Fang et al. (2016) some zooxanthellaed clionid sponges are able to protect their intracellular valuable symbionts, by shifting them into deeper tissues when exposed to environmental stress reducing the risk of losing them. It is possible that $S$. vagabunda may exhibit a similar mechanism, although further investigation would be required to confirm this hypothesis. Some symbionts such as the Symbiodinium $\mathrm{G}$ clade, which is often associated with clionid sponges (Schönberg \& Loh, 2005; Granados et al., 2008) are potentially more bleaching resistant compared to other Symbiodinium clades (Schönberg et al., 2017). These symbionts have recently been reported to be resistant to elevated temperatures in corals (Brener-Raffalli et al., 2018; Chakravarti \& van Oppen, 2018). As a result, it is likely that during prolonged 
thermal exposure, which initially result in the loss of some associated photosymbionts, $S$. vagabunda may shift its remaining Chl- $a$ containing photosymbionts into deeper tissues and photosynthetically rely on its associated zooxanthellae community for its energetic demands. Additionally, sponge-associated zooxanthellae have been reported to promote the growth and bioerosion rates of their hosts (Rosell \& Uriz, 1992; Hill, 1996). It is therefore possible that the association of $S$. vagabunda with zooxanthellae might be a contributing factor enhancing the growth (buoyant weight) of this sponge, when exposed to elevated temperature (see chapter 3). However, the rapid growth of this species during experimental manipulations in chapter 3 could not be explained and further in-depth investigations between $S$. vagabunda and its associated zooxanthellae are required to better understand the underlying adaptative mechanisms of this species to environmental stress.

The ability of $S$. vagabunda to attach to hard substratum but also to anchor in soft sediments might also be a factor contributing to its tolerance to environmental changes. While this anchoring ability gives $S$. vagabunda a strong advantage of not being fully reliable on one specific substrate type in the long term, endopsammic sponges are often more sheltered. This is because the embedded section of the sponge is less exposed to immediate environmental changes such as elevated temperature and pollution occurring in the water column (Schönberg \& Wisshak, 2012; Schönberg, 2016). As a result, these species are at least partially protected to immediate environmental changes (Schönberg, 2016, 2017). Endopsammic sponges including S. vagabunda also actively incorporate sediment or sand grains in the base of their body, mainly for anchoring stability and collagen production (Levi et al., 1998; Cerrano et al., 2007; Beepat et al., 2013). The incorporation of foreign materials also suggest that these species may invest less energy in spiculogenesis (i.e. the formation of spicules). As a result, the unused energy can be stored and utilized on other primary physiological functions such as respiration, pumping and growth when exposed to environmental stress, although our understanding of such mechanisms in sponges so far remains limited (Weisz et al., 2010).

\subsection{Implications for coastal lagoons}

Coastal lagoons occupy approximately $13 \%$ of the world's coastlines and provide numerous ecosystem services (Kjerfve, 1994; Pérez-Ruzafa et al., 2019). In the past two decades, the loss of lagoonal benthic taxa such as macroalgae (Bintz et al., 2003) and corals (Riegl et al., 2012; Elliott et al., 2018) has been reported from several regions. The results from my thesis suggest 
that some lagoon-inhabiting sponge species, such as $N$. chaliniformis could potentially disappear under future ocean warming scenarios and thus, support earlier studies reporting on the loss of lagoonal benthic taxa. However, as suggested for some coral reefs (López-Victoria \& Zea, 2005; Bell et al., 2013; Carballo et al., 2013), it is possible that some anthropogenicallyimpacted coastal lagoons could experience an increase in abundance of bioeroding sponges in the future. A possible shift from coral to sponge dominated lagoons has previously been reported in the lagoon of Palmyra Atoll in Central Pacific, although the lagoon at Palmyra is very different to coastal lagoons and, is mostly dominated by non-clionid species (Knapp et al., 2013). In some shallow coastal lagoons such as in Mauritius, a shift from thermallysusceptible lagoon benthic communities will likely feature an increase in bioeroding endopsammic sponge species, such as $S$. vagabunda and Spheciospongia inconstans (Beepat, 2015) because bioeroding sponges are potentially more tolerant to environmental changes (Schönberg et al., 2017) and often inhabit shallow coastal tropical lagoons (Illan \& Abelson, 1995; Levi et al., 1998; Ise et al., 2004; Beepat et al., 2013). Such a shift has previously been reported in the Caribbean, where clionid sponge assemblages were dominant on the coral framework in a northern Jamaican turbid lagoon (Macdonald \& Perry, 2003). Furthermore, spatial competition from these endopsammic species could further be enhanced. As coastal lagoons could experience significant loss of live corals under future climate change scenarios (López-Victoria et al., 2006), dead corals and coral rubble will most likely provide additional substate for bioeroding sponge species to proliferate. However, it should be noted that the magnitude of any lagoonal sponge shift will likely depend on few determining factors, such as the thermal tolerance and adaptation of other lagoon-inhabiting benthic species (McClanahan et al., 2005; Camp et al., 2017), the level of food availability (i.e. dissolve and particulate organic carbon) for the growing sponge populations (Bell et al., 2018; Lesser \& Slattery, 2020) as well as any other lagoon-specific ecosystem responses to global climate change and eutrophication.

\subsection{Future directions}

Given the exposure of coastal lagoons to anthropogentic stressors (Anthony et al., 2009; PérezRuzafa et al., 2019), it is becoming increasingly important to assess the vulnerability/tolerance of lagoon-inhabiting benthic fauna. While the present thesis reports the potential impacts of elevated temperature and eutrophication on lagoon-inhabiting sponges, it should be noted that these organisms are also exposed to other major environmental drivers such as salinity 
fluctuations originating freshwater input from land and ocean acidifcation. Unlike thermal effects, ocean acidifcation alone is known to have little negative impacts on sponges (Bennett et al., 2017; Bell et al., 2018) and some studies even demonstrated that reduced $p \mathrm{CO}_{2}$ (increase in seawater $\mathrm{pH}$ ) can potentially alleviate thermal stress on some reef sponges (Duckworth et al., 2012; Vicente et al., 2015; Bennett et al., 2017). As a result, multi-factorial investigations invovling the combined effects of ocean warming, eutrophication and ocean acidification are necessary to better understand the responses of lagoon-inhabiting sponges to anthropogenic stress. Sponges are often referred to as 'sponge holobiont' because of their association with a suite of microorganisms (Taylor et al., 2007; Thacker \& Freeman, 2012) and are also habitat providers for many macro-invetebrates (Wendt et al., 1985; Koukouras et al., 1996). Therefore, in addition to physiological and host-specific molecular responses, future sponge-climate change research should also consider investigating the effects of these anthropogenic stressors on lagoon-inhabiting sponge-associated microbial and macrofaunal community structure. Recently, Lesser and Slattery (2020) suggested that sponges are less likely to dominate shallow coastal waters under future climate change scenarios because anthropogenic stressors will likely increase the stratification of shallow waters, therefore preventing the distribution of nutrients such as dissolved organic carbon (DOC) and particulate organic carbon (POC) to the benthos. The bentho-pelagic interactions of coastal lagoons can often be limited, as the distance between lagoon-benthos and water column are considerably reduced, exacerbating any thermal stratification effects (Baustian et al., 2014; Griffiths et al., 2017). As such, future investigations should be focussed around the potential anthropogenic impacts on bentho-pelagic interactions and feeding patterns of lagoon-inhabiting sponges. In the last two decades, multiple studies have investigated the impacts of climate change (Massaro et al., 2012; Bennett et al., 2017; Ramsby et al., 2018) and eutrophication (Simister et al., 2012; Webb et al., 2017) on tropical sponges. While there have been multiple evidences indicating that sponges are more likely tolerant to other dominant calcifying benthic taxa such as corals (Bell et al., 2013; Kelmo et al., 2013; de Moraes et al., 2019), the mechanisms underlying the tolerance or acclimation of sponges (mostly bioeroding species) to climate change (Fang et al., 2014; Bell et al., 2018) and eutrophication (Simister et al., 2012; Luter et al., 2014) are relatively unknown. Future work should therefore be focussed on the understanding the specific physiological and cellular mechanisms, which enable sponges to acclimate to enviromental stress. Furthermore, given that sponges occur in all aquatic environments (Van Soest et al., 2012), there is a need to acquire additional information from sponges occuring in unexplored geographical locations 
such the southern African and west Indian Ocean regions (Bell et al., 2015) to better understand the ecology and impacts of climate of sponges on a global scale.

The western Indian Ocean (WIO) region, which make this region one of the richest sponge biodiversity hotspots across the globe (Van Soest et al., 2012). However, according to Bell et al. (2015), scientific research on marine sponges in the African ecoregion (including the western Indian Ocean) is poor compared to other tropical ecoregions such as the tropical Atlantic or Great Barrier Reef. Until 2015, no study has ever attempted to investigate the possible environmental impacts on marine sponges in this region (Bell et al., 2015). Therefore, future sponge research in the western Indian Ocean should be focused on: (i) the qualitative and quantitative description of coastal sponge species distribution and ecology; (ii) identify the ecological roles (i.e. contribution) of sponges within shallow water bodies; and (iii) investigating the potential impacts of anthropogenic stressors on existing sponge populations.

\subsection{Concluding remarks}

Climate change and eutrophication are known to have consequent negative impacts on multiple reef and lagoon-inhabiting benthic communities such as corals (Adjeroud et al., 2019) and magroalgae (Bintz et al., 2003). This thesis demonstrates that the effect elevated seawater temperature on lagoon-inahabiting sponges are species-dependent. While branching species were generally suceptible to elevated temperature, physiological measurements and temporal models showed that the bioeroding sponge $S$. vagabunda may have an acclimatory potential to increasing seawater temperature. Interstingly, this thesis also demonstrates that, similar to multiple reef sponge species (Simister et al., 2012; Luter et al., 2014), lagoon-inhabiting sponges are generally tolerant to excess nutrients. Coastal lagoons are naturally sensitive ecosystems (Badcock \& Barnes, 1981; Kjerfve, 1994), yet the impacts of anthropogenic stressors on lagoon-inhabiting benthic communties to date are poorly described (Pérez-Ruzafa et al., 2019) compared to reef benthic communities. Since coastal lagoons are directly connected to land masses, these ecosystems are becoming increasingly vulnerable to multiple anthropogenic stressors. Overall, this thesis enables us to understand the individual and combined effects of elevated temperature and eutrophication on the conspicious benthic taxon of sponges. The outcomes presented in this thesis may be used to implement future coastal lagoon conservation plans, most specifically in small island devleoping states, which are often heavily dependent on lagoonal natural resources. 
References 


\section{References}

Abraham, J. P., Baringer, M., Bindoff, N. L., Boyer, T., Cheng, L. J., Church, J. A., Conroy, J. L., Domingues, C. M., Fasullo, J. T., Gilson, J., Goni, G., Good, S. A., Gorman, J. M., Gouretski, V., Ishii, M., Johnson, G. C., Kizu, S., Lyman, J. M., Macdonald, A. M., Minkowycz, W. J., Moffitt, S. E., Palmer, M. D., Piola, A. R., Reseghetti, F., Schuckmann, K., Trenberth, K. E., Velicogna, I., \& Willis, J. K. (2013). A review of global ocean temperature observations: Implications for ocean heat content estimates and climate change. Reviews of Geophysics, 51(3), 450-483.

Achlatis, M., van der Zande, R. M., Schönberg, C. H. L., Fang, J. K. H., Hoegh-Guldberg, O., $\&$ Dove, S. (2017). Sponge bioerosion on changing reefs: ocean warming poses physiological constraints to the success of a photosymbiotic excavating sponge. Scientific Reports, 7(1), 10705.

Adjeroud, M., Poisson, E., Peignon, C., Penin, L., \& Kayal, M. (2019). Spatial patterns and short-term changes of coral assemblages along a cross-shelf gradient in the southwestern lagoon of New Caledonia. Diversity, 11(2), 21.

Aerts, L. A. M., \& Van Soest, R. W. M. (1997). Quantification of sponge/coral interactions in a physically stressed reef community, NE Colombia. Marine Ecology Progress Series, 148(13), 125-134.

Aerts, L. A. M. (1998). Sponge/coral interactions in Caribbean reefs: analysis of overgrowth patterns in relation to species identity and cover. Marine Ecology Progress Series, 175, 241249.

Alexander, B. E., Liebrand, K., Osinga, R., van der Geest, H. G., Admiraal, W., Cleutjens, J. P., Schutte, B., Verheyen, F., Ribes, M., \& van Loon, E. (2014). Cell turnover and detritus production in marine sponges from tropical and temperate benthic ecosystems. PLoS One, 9(10), e109486.

Alonso-Pérez, F., Ysebaert, T., \& Castro, C. G. (2010). Effects of suspended mussel culture on benthic-pelagic coupling in a coastal upwelling system (Ría de Vigo, NW Iberian Peninsula). Journal of Experimental Marine Biology and Ecology, 382(2), 96-107.

Anthony, A., Atwood, J., August, P., Byron, C., Cobb, S., Foster, C., Fry, C., Gold, A., Hagos, K., Heffner, L., Kellogg, D., Lellis-Dibble, K., Opaluch, J., \& Oviatt, C. (2009). Coastal lagoons and climate change: ecological and social ramifications in U.S. Atlantic and Gulf Coast ecosystems. Ecology and Society, 14(1), 8.

Appadoo, C., Beepat, S. S., \& Marie, D. E. P. (2011). Study of physico-chemical parameters affecting the distribution of sponge Xestospongia exigua (phylum Porifera, class Demospongiae) in a northern lagoon of Mauritius. Journal of Environmental Research and Development, 5(3A), 741-748.

Archer, S. K., Stevens, J. L., Rossi, R. E., Matterson, K. O., \& Layman, C. A. (2017). Abiotic conditions drive significant variability in nutrient processing by a common Caribbean sponge, Ircinia felix. Limnology and Oceanography, 62(4), 1783-1793. 
Ashok, A. M., Schönberg, C. H. L., Laju, R. L., \& Edward, J. K. P. (2019). Coral-killing sponge Terpios hoshinota in Southeast India-bested by Acropora muricata? Marine Biodiversity, 49(3), 1069-1070.

Ashok, A. M., Calcinai, B., \& Edward, J. K. P. (2020). The coral-killing red sponge Clathria (Microciona) aceratoobtusa (Porifera: Demosponigiae) invades various coral communities of Gulf of Mannar marine national park, southeast India. The European Zoological Journal, 87(1), 1-11.

Ávila, E., Ávila-García, A. K., \& Cruz-Barraza, J. A. (2015). Temporal and small-scale spatial variations in abundance and biomass of seagrass-dwelling sponges in a tropical estuarine system. Marine Ecology, 36(3), 623-636.

Azam, F., Fenchel, T., Field, J. G., Gray, J., Meyer-Reil, L., \& Thingstad, F. (1983). The ecological role of water-column microbes in the sea. Marine Ecology Progress Series, 10, 257263.

Bacescu, M. (1971). Les Spongiaires; un des plus intéressants biotopes benthiques marins. Rapport et procésverbaux des reunions. Conseil permanent international pour l'exploration scientifique de la Mer Méditerrané, 20, 239-241.

Bachinski, N., Koziol, C., Batel, R., Labura, Z., Schröder, H. C., \& Müller, W. E. G. (1997). Immediate early response of the marine sponge Suberites domuncula to heat stress: reduction of trehalose and glutathione concentrations and glutathione S-transferase activity. Journal of Experimental Marine Biology and Ecology, 210(1), 129-141.

Badcock, R., \& Barnes, R. (1981). Coastal lagoons: The natural history of a neglected habitat. The Journal of Ecology, 69, 1061.

Bannister, R. J., Battershill, C. N., \& de Nys, R. (2012). Suspended sediment grain size and mineralogy across the continental shelf of the Great Barrier Reef: Impacts on the physiology of a coral reef sponge. Continental Shelf Research, 32, 86-95.

Barnes, P. B. (2009). Environmental impacts and the ecology of sponges and ascidians in south-eastern Australian coastal lakes and lagoons. (PhD), University of Wollongong, Australia.

Bates, D., Mächler, M., Bolker, B., \& Walker, S. (2014). Package Lme4: linear mixed-effects models using Eigen and S4. Journal of Statistical Software, 67, 1-99.

Bates, T. E. M., \& Bell, J. J. (2018). Responses of two temperate sponge species to ocean acidification. New Zealand Journal of Marine and Freshwater Research, 52(2), 247-263.

Baustian, M., Hansen, G., De Kluijver, A., Robinson, K., Henry, E., Knoll, L., Rose, K., \& Carey, C. (2014). Linking the bottom to the top in aquatic ecosystems: mechanisms and stressors of benthic-pelagic coupling. In P. F. Kemp (Ed.), Eco-DAS X Symposium Proceedings (pp. 25-47). Texas, USA: Association for the Sciences of Limnology and Oceanography.

Beedessee, G., Ramanjooloo, A., Aubert, G., Eloy, L., Surnam-Boodhun, R., Van Soest, R. W., Cresteil, T., \& Marie, D. E. (2012). Cytotoxic activities of hexane, ethyl acetate and butanol extracts of marine sponges from Mauritian waters on human cancer cell lines. Environmental Toxicology and Pharmacology, 34(2), 397-408. 
Beedessee, G., Ramanjooloo, A., \& Marie, D. E. (2015). Marine natural products research in Mauritius: progress and challenges. Marine Chemistry, 170, 23-28.

Beepat, S. S., Appadoo, C., Marie, D. E., Paula, J., \& Sivakumar, K. (2013). Distribution, abundance and ecology of the sponge Spheciospongia vagabunda (phylum: Porifera, class: Demospongiae) in a shallow lagoon of Mauritius. Western Indian Ocean journal of marine science, 12(1), 15-23.

Beepat, S. S., Appadoo, C., Marie, D. E. P., Paula, J., Çinar, M., \& Sivakumar, K. (2014). Macrofauna associated with the sponge Neopetrosia exigua (Kirkpatrick, 1900) in Mauritius. Western Indian Ocean journal of marine science, 13(2), 133-142.

Beepat, S. S. (2015). Ecology, Diversity and Symbiotic Associates (with special reference to Actinobacteria) of Marine Sponges in the Coastal Lagoons of Mauritius. (MPhil), University of Mauritius, Mauritius.

Beepat, S. S., Appadoo, C., Marie, D., Sadally, S., Paula, J., Sivakumar, K., Rao, R., \& Salah, M. (2016). First records of sponge-associated actinomycetes from two coastal sponges from Mauritius. Western Indian Ocean journal of marine science, 15(1), 31-38.

Beer, S., \& Ilan, M. (1998). In situ measurements of photosynthetic irradiance responses of two Red Sea sponges growing under dim light conditions. Marine Biology, 131(4), 613-617.

Belhadj Slimen, I., Najar, T., Ghram, A., Dabbebi, H., Ben Mrad, M., \& Abdrabbah, M. (2014). Reactive oxygen species, heat stress and oxidative-induced mitochondrial damage. A review. International Journal of Hyperthermia, 30(7), 513-523.

Bell, J. J. (2007). The use of volunteers for conducting sponge biodiversity assessments and monitoring using a morphological approach on Indo-Pacific coral reefs. Aquatic Conservation: Marine and Freshwater Ecosystems, 17(2), 133-145.

Bell, J. J. (2008). The functional roles of marine sponges. Estuarine, Coastal and Shelf Science, 79(3), 341-353.

Bell, J. J., Davy, S. K., Jones, T., Taylor, M. W., \& Webster, N. S. (2013). Could some coral reefs become sponge reefs as our climate changes? Global Change Biology, 19(9), 2613-2624.

Bell, J. J., McGrath, E., Biggerstaff, A., Bates, T., Cárdenas, C. A., \& Bennett, H. (2015). Global conservation status of sponges. Conservation Biology, 29(1), $42-53$.

Bell, J. J., Biggerstaff, A., Bates, T., Bennett, H., Marlow, J., McGrath, E., \& Shaffer, M. (2017a). Sponge monitoring: Moving beyond diversity and abundance measures. Ecological Indicators, 78(Supplement C), 470-488.

Bell, J. J., \& Carballo, J. L. (2017). Future research directions and gaps in our knowledge. In J. L. Carballo \& J. J. Bell (Eds.), Climate Change, Ocean Acidification and Sponges: Impacts Across Multiple Levels of Organization (pp. 447-452). Cham: Springer International Publishing.

Bell, J. J., Shaffer, M., Bennett, H., McGrath, E., Mortimer, C., Rovellini, A., Marlow, J., Biggerstaff, A., \& Carballo, J. L. (2017b). Impacts of Short-Term Large-Scale Climatic Variation on Sponge Assemblages. In J. L. Carballo \& J. J. Bell (Eds.), Climate Change, Ocean 
Acidification and Sponges: Impacts Across Multiple Levels of Organization (pp. 143-177). Cham: Springer International Publishing.

Bell, J. J., Bennett, H. M., Rovellini, A., \& Webster, N. S. (2018). Sponges to be winners under near-future climate scenarios. Bioscience, 68(12), 955-968.

Bennett, H. M., Altenrath, C., Woods, L., Davy, S. K., Webster, N. S., \& Bell, J. J. (2017). Interactive effects of temperature and $p \mathrm{CO}_{2}$ on sponges: from the cradle to the grave. Global Change Biology, 23(5), 2031-2046.

Bennett, H. M., Bell, J. J., Davy, S. K., Webster, N. S., \& Francis, D. S. (2018). Elucidating the sponge stress response; lipids and fatty acids can facilitate survival under future climate scenarios. Global Change Biology, 24(7), 3130-3144.

Berchtold, M. W., \& Villalobo, A. (2014). The many faces of calmodulin in cell proliferation, programmed cell death, autophagy, and cancer. Biochimica et Biophysica Acta (BBA) Molecular Cell Research, 1843(2), 398-435.

Bergquist, P. R. (2001). Porifera (Sponges). In eLS: John Wiley \& Sons, Ltd.

Biggerstaff, A., Smith, D. J., Jompa, J., \& Bell, J. J. (2015). Photoacclimation supports environmental tolerance of a sponge to turbid low-light conditions. Coral Reefs, 34(4), 10491061.

Biggerstaff, A., Jompa, J., \& Bell, J. J. (2017). Increasing benthic dominance of the phototrophic sponge Lamellodysidea herbacea on a sedimented reef within the coral triangle. Marine Biology, 164(12), 220.

Binns, D., Dimmer, E., Huntley, R., Barrell, D., O'Donovan, C., \& Apweiler, R. (2009). QuickGO: a web-based tool for Gene Ontology searching. Bioinformatics (Oxford, England), 25(22), 3045-3046.

Bintz, J. C., Nixon, S. W., Buckley, B. A., \& Granger, S. L. (2003). Impacts of temperature and nutrients on coastal lagoon plant communities. Estuaries, 26(3), 765-776.

Bissembur, Z. B., Balgobin, J., Anjore, A., Ramessur, R. T., \& Boodhoo, K. (2012). Investigation of dissolved nutrients in tropical coastal waters in Mauritius. In M. Gupta Bhowon, S. Jhaumeer-Laulloo, H. Li Kam Wah, \& P. Ramasami (Eds.), Chemistry for Sustainable Development (pp. 1-10). Dordrecht: Springer Netherlands.

Boojhawon, R., Booneeady, P., \& Rughooputh, S. (2010). Global warming and changing temperature patterns over Mauritius. University of Mauritius Research Journal, 16(1), 472484.

Brener-Raffalli, K., Clerissi, C., Vidal-Dupiol, J., Adjeroud, M., Bonhomme, F., Pratlong, M., Aurelle, D., Mitta, G., \& Toulza, E. (2018). Thermal regime and host clade, rather than geography, drive Symbiodinium and bacterial assemblages in the scleractinian coral Pocillopora damicornis sensu lato. Microbiome, 6(1), 39.

Bridges, A. A., \& Gladfelter, A. S. (2015). Septin form and function at the cell cortex. The Journal of Biological Chemistry, 290(28), 17173-17180. 
Brito, A., Newton, A., Tett, P., \& Fernandes, T. (2011). How will shallow coastal lagoons respond to climate change? A modelling investigation. Estuarine, Coastal and Shelf Science, $112,98-104$.

Bruno, J. F., Selig, E. R., Casey, K. S., Page, C. A., Willis, B. L., Harvell, C. D., Sweatman, H., \& Melendy, A. M. (2007). Thermal stress and coral cover as drivers of coral disease outbreaks. PLoS Biology, 5(6), e124.

Buccitelli, C., \& Selbach, M. (2020). mRNAs, proteins and the emerging principles of gene expression control. Nature Reviews Genetics, 21(10), 630-644.

Butler, M. J., Hunt, J. H., Herrnkind, W. F., Childress, M., Bertelsen, R., Wc, S., Matthews, T., Field, J. M., \& Marshall, H. (1995). Cascading disturbances in Florida Bay, USA: cyanobacteria blooms, sponge mortality, and implications for juvenile spiny lobsters Panulirus argus. Marine Ecology Progress Series, 129, 119-125.

Calcinai, B., Azzini, F., Bavestrello, G., Gaggero, L., \& Cerrano, C. (2007). Excavating rates and boring pattern of Cliona albimarginata (Porifera: Clionaidae) in different substrata. Porifera Research: Biodiversity, Innovation \& Sustainability, 203-210.

Camp, E. F., Nitschke, M. R., Rodolfo-Metalpa, R., Houlbreque, F., Gardner, S. G., Smith, D. J., Zampighi, M., \& Suggett, D. J. (2017). Reef-building corals thrive within hot-acidified and deoxygenated waters. Scientific Reports, 7(1), 2434-2434.

Canadell, J. G., Le Quere, C., Raupach, M. R., Field, C. B., Buitenhuis, E. T., Ciais, P., Conway, T. J., Gillett, N. P., Houghton, R. A., \& Marland, G. (2007). Contributions to accelerating atmospheric $\mathrm{CO}_{2}$ growth from economic activity, carbon intensity, and efficiency of natural sinks. Proceedings of the Nationall Academy of Sciences of the USA, 104(47), 1886618870.

Canu, D. M., Solidoro, C., Cossarini, G., \& Giorgi, F. (2010). Effect of global change on bivalve rearing activity and the need for adaptive management. Climate Research, 42(1), 1326.

Cao, L., \& Zhang, H. (2017). The role of biological rates in the simulated warming effect on oceanic CO2 uptake. Journal of Geophysical Research: Biogeosciences, 122(5), 2016JG003756.

Carballo, J. L., Vega, C., Cruz-Barraza, J. A., Yáñez, B., Nava, H., Ávila, E., \& Wilson, M. (2008). Short- and long-term patterns of sponge diversity on a rocky tropical coast: evidence of large-scale structuring factors. Marine Ecology, 29(2), 216-236.

Carballo, J. L., Bautista, E., Nava, H., Cruz-Barraza, J. A., \& Chávez, J. A. (2013). Boring sponges, an increasing threat for coral reefs affected by bleaching events. Ecology and Evolution, 3(4), 872-886.

Casareto, B., Bhagooli, R., Fujimura, H., \& Yoshimi, S. (2017). Chemical and biological characteristics of Albion reef in the south-west of Mauritius island with special reference to primary production and $\mathrm{N}_{2}$ fixation of benthic substrata. Western Indian Ocean journal of marine science, Special issue 1, 85-93. 
Cathalot, C., Van Oevelen, D., Cox, T. J. S., Kutti, T., Lavaleye, M., Duineveld, G., \& Meysman, F. J. R. (2015). Cold-water coral reefs and adjacent sponge grounds: hotspots of benthic respiration and organic carbon cycling in the deep sea. Frontiers in Marine Science, 2(37).

Cebrian, E., Uriz, M. J., Garrabou, J., \& Ballesteros, E. (2011). Sponge mass mortalities in a warming Mediterranean Sea: are cyanobacteria-harboring species worse off? PLoS One, 6(6), e20211.

Cerrano, C., Bavestrello, G., Bianchi, C. N., Cattaneo-vietti, R., Bava, S., Morganti, C., Morri, C., Picco, P., Sara, G., Schiaparelli, S., Siccardi, A., \& Sponga, F. (2000). A catastrophic massmortality episode of gorgonians and other organisms in the Ligurian Sea (North-western Mediterranean), summer 1999. Ecology Letters, 3(4), 284-293.

Cerrano, C., Bavestrello, G., Boyer, M., Calcinai, B., Lalamentik, L. T. X., \& Pansini, M. (2002). Psammobiontic sponges from the Bunaken Marine Park (North Sulawesi, Indonesia): interactions with sediments. Paper presented at the Proceedings of the $9^{\text {th }}$ International Coral Reef Symposium.

Cerrano, C., Pansini, M., Valisano, L., Calcinai, B., Sarà, M., \& Bavestrello, G. (2004). Lagoon sponges from Carrie Bow Cay (Belize): ecological benefits of selective sediment incorporation. Bollettino dei Musei e degli Istituti Biologici dell'Univesita di Genova, 68, 239-252.

Cerrano, C., Calcinai, B., Di Camillo, C. G., Valisano, L., \& Bavestrello, G. (2007). How and why do sponges incorporate foreign material? Strategies in Porifera. Porifera Research: Biodiversity, Innovation and Sustainability. Série Livros, 28, 239-246.

Chaib De Mares, M., Jiménez, D. J., Palladino, G., Gutleben, J., Lebrun, L. A., Muller, E. E. L., Wilmes, P., Sipkema, D., \& van Elsas, J. D. (2018). Expressed protein profile of a Tectomicrobium and other microbial symbionts in the marine sponge Aplysina aerophoba as evidenced by metaproteomics. Scientific Reports, 8(1), 11795.

Chakravarti, L. J., \& van Oppen, M. J. H. (2018). Experimental evolution in coral photosymbionts as a tool to increase thermal tolerance. Frontiers in Marine Science, 5(227).

Chapman, P. M. (2012). Management of coastal lagoons under climate change. Estuarine, Coastal and Shelf Science, 110, 32-35.

Chaves-Fonnegra, A., Riegl, B., Zea, S., Lopez, J. V., Smith, T., Brandt, M., \& Gilliam, D. S. (2018). Bleaching events regulate shifts from corals to excavating sponges in algae-dominated reefs. Global Change Biology, 24(2), 773-785.

Cheshire, A. C., \& Wilkinson, C. R. (1991). Modelling the photosynthetic production by sponges on Davies Reef, Great Barrier Reef. Marine Biology, 109(1), 13-18.

Cheshire, A. C., Butler, A., Westphalen, G., Rowland, B., Stevenson, J., \& Wilkinson, C. (1995). Preliminary study of the distribution and photophysiology of the temperate phototrophic sponge Cymbastela sp. from South Australia. Marine and Freshwater Research, 46(8), 1211-1216. 
Chineah, V., Chooramun, V., Nallee, M., Basant Rai, Y., Moothien Pillay, R., Jayabalan, N., Terashima, H., \& Terai, A. (2001). Status of the marine environment of the Flic en Flac lagoon, Mauritius. Retrieved from Albion Fisheries Research Centre, Mauritius:

Cho, W. C. S. (2007). Proteomics technologies and challenges. Genomics, proteomics \& bioinformatics, 5(2), 77-85.

Christia, C., Giordani, G., \& Papastergiadou, E. (2018). Environmental variability and macrophyte assemblages in coastal lagoon types of western Greece (Mediterranean Sea). Water, 10(2), 151.

Chu, J. W. F., Maldonado, M., Yahel, G., \& Leys, S. P. (2011). Glass sponge reefs as a silicon sink. Marine Ecology Progress Series, 441, 1-14.

Clemente, S., Lorenzo-Morales, J., Mendoza, J. C., López, C., Sangil, C., Alves, F., Kaufmann, M., \& Hernández, J. C. (2014). Sea urchin Diadema africanum mass mortality in the subtropical eastern Atlantic: role of waterborne bacteria in a warming ocean. Marine Ecology Progress Series, 506, 1-14.

Coles, S. L., Jokiel, P. L., \& Lewis, C. R. (1976). Thermal tolerance in tropical versus subtropical Pacific reef corals. Pacific Science, 30(2), 159 - 166.

Colman, A. S. (2015). Sponge symbionts and the marine P cycle. Proceedings of the National Academy of Sciences, 112(14), 4191-4192.

Coma, R. (2002). Seasonality of in situ respiration rate in three temperate benthic suspension feeders. Limnology and Oceanography, 47(1), 324-331.

Corredor, J. E., Wilkinson, C. R., Vicente, V. P., Morell, J. M., \& Otero, E. (1988). Nitrate release by Caribbean reef sponges. Limnology and Oceanography, 33(1), 114-120.

Corriero, G., Longo, C., Mercurio, M., Marchini, A., \& Occhipinti-Ambrogi, A. (2007). Porifera and Bryozoa on artificial hard bottoms in the Venice lagoon: spatial distribution and temporal changes in the northern basin. Italian Journal of Zoology, 74(1), 21-29.

Cox, J., \& Mann, M. (2007). Is Proteomics the New Genomics? Cell, 130(3), 395-398.

Cox, J., Hein, M. Y., Luber, C. A., Paron, I., Nagaraj, N., \& Mann, M. (2014). Accurate proteome-wide label-free quantification by delayed normalization and maximal peptide ratio extraction, termed MaxLFQ. Molecular and Cellular Proteomics, 13(9), 2513-2526.

D’Angelo, C., \& Wiedenmann, J. (2014). Impacts of nutrient enrichment on coral reefs: new perspectives and implications for coastal management and reef survival. Current Opinion in Environmental Sustainability, 7, 82-93.

Daby, D. (1994). Possible implications of the oceanographic thermal effects in a landsat infrared imagery of Mauritius. Hydrobiologia, 277(1), 41-48.

Daby, D. (2003). Some quantitative aspects of seagrass ecology in a coastal lagoon of Mauritius. Marine Biology, 142(1), 193-203. 
Daby, D. (2006). Current patterns and the distribution of benthic habitats in a coastal lagoon of Mauritius. Hydrobiologia, 556(1), 47-60.

de Goeij, J. M., van den Berg, H., van Oostveen, M. M., Epping, E. H. G., \& van Duyl, F. C. (2008). Major bulk dissolved organic carbon (DOC) removal by encrusting coral reef cavity sponges. Marine Ecology Progress Series, 357, 139-151.

de Goeij, J. M., de Kluijver, A., Van Duyl, F., Vacelet, J., Wijffels, R., de Goeij, A., Cleutjens, J., \& Schutte, B. (2009). Cell kinetics of the marine sponge Halisarca caerulea reveal rapid cell turnover and shedding. Journal of Experimental Biology, 212(23), 3892-3900.

de Goeij, J. M., van Oevelen, D., Vermeij, M. J. A., Osinga, R., Middelburg, J. J., de Goeij, A. F. P. M., \& Admiraal, W. (2013). Surviving in a marine desert: The sponge loop retains resources within coral reefs. Science, 342(6154), 108-110.

de Goeij, J. M., Lesser, M. P., \& Pawlik, J. R. (2017). Nutrient fluxes and ecological functions of coral reef sponges in a changing ocean. In J. L. Carballo \& J. J. Bell (Eds.), Climate Change, Ocean Acidification and Sponges: Impacts Across Multiple Levels of Organization (pp. 373410). Cham: Springer International Publishing.

de Moraes, F. C., Cervi, F., Karez, C. S., Salgado, L. T., Moura, R. L., Leal, G. A., Bastos, A. C., \& Amado-Filho, G. M. (2019). Long-term temporal and spatial patterns in bioeroding sponge distribution at the Abrolhos Bank, Brazil, Southwestern Atlantic. Marine Ecology, $40(3)$, e12531.

DeBerardinis, R. J., \& Thompson, C. B. (2012). Cellular metabolism and disease: what do metabolic outliers teach us? Cell, 148(6), 1132-1144.

Decarlo, T. M., Cohen, A. L., Wong, G. T. F., Davis, K. A., Lohmann, P., \& Soong, K. (2017). Mass coral mortality under local amplification of $2{ }^{\circ} \mathrm{C}$ ocean warming. Scientific Reports, 7 , 44586.

DeSalvo, M. K., Sunagawa, S., Voolstra, C. R., \& Medina, M. (2010). Transcriptomic responses to heat stress and bleaching in the elkhorn coral Acropora palmata. Marine Ecology Progress Series, 402, 97-113.

Desrivières, S., Cooke, F. T., Morales-Johansson, H., Parker, P. J., \& Hall, M. N. (2002). Calmodulin controls organization of the actin cytoskeleton via regulation of phosphatidylinositol (4,5)-bisphosphate synthesis in Saccharomyces cerevisiae. Biochemical Journal, 366, 945-951.

Di Camillo, C. G., Coppari, M., Bartolucci, I., Bo, M., Betti, F., Bertolino, M., Calcinai, B., Cerrano, C., De Grandis, G., \& Bavestrello, G. (2012). Temporal variations in growth and reproduction of Tedania anhelans and Chondrosia reniformis in the North Adriatic Sea. Hydrobiologia, 687(1), 299-313.

Diaz, M. C., \& Ward, B. B. (1997). Sponge-mediated nitrification in tropical benthic communities. Marine Ecology Progress Series, 156, 97-107.

Diaz, M. C., \& Rützler, K. (2001). Sponges: an essential component of Caribbean coral reefs. Bulletin of Marine Science, 69(2), 535-546. 
Dillon, M. E., Wang, G., \& Huey, R. B. (2010). Global metabolic impacts of recent climate warming. Nature, 467, 704.

Downs, C. A., Mueller, E., Phillips, S., Fauth, J. E., \& Woodley, C. M. (2000). A molecular biomarker system for assessing the health of coral (Montastraea faveolata) during heat stress. Marine Biotechnology, 2(6), 533-544.

Duckworth, A. R., \& Wolff, C. W. (2011). Population dynamics and growth of two coral reef sponges on rock and rubble substrates. Journal of Experimental Marine Biology and Ecology, 402(1), 49-55.

Duckworth, A. R., West, L., Vansach, T., Stubler, A., \& Hardt, M. (2012). Effects of water temperature and $\mathrm{pH}$ on growth and metabolite biosynthesis of coral reef sponges. Marine Ecology Progress Series, 462, 67-77.

Duckworth, A. R., \& Peterson, B. J. (2013). Effects of seawater temperature and pH on the boring rates of the sponge Cliona celata in scallop shells. Marine Biology, 160(1), 27-35.

Dunlap, M., \& Pawlik, J. R. (1996). Video-monitored predation by Caribbean reef fishes on an array of mangrove and reef sponges. Marine Biology, 126(1), 117-123.

Eakin, C. M., Morgan, J. A., Heron, S. F., Smith, T. B., Gang, L., Alvarez-Filip, L., Baca, B., Bartels, E., Bastidas, C., Bouchon, C., Brandt, M., Bruckner, A. W., Bunkley-Williams, L., Cameron, A., Causey, B. D., Chiappone, M., Christensen, T. R. L., Crabbe, M. J. C., Day, O., $\&$ de la Guardia, E. (2010). Caribbean corals in crisis: Record thermal stress, bleaching, and mortality in 2005. PLoS ONE, 5(11), 1-9.

Elliott, J., Patterson, M., Summers, N., Miternique, C., Montocchio, E., \& Vitry, E. (2016a). How does the proliferation of the coral-killing sponge Terpios hoshinota affect benthic community structure on coral reefs? Coral Reefs, 35, 1083-1095.

Elliott, J., Patterson, M., Vitry, E., Summers, N., \& Miternique, C. (2016b). Morphological plasticity allows coral to actively overgrow the aggressive sponge Terpios hoshinota (Mauritius, Southwestern Indian Ocean). Marine Biodiversity, 46(2), 489-493.

Elliott, J. A., Patterson, M. R., Staub, C. G., Koonjul, M., \& Elliott, S. M. (2018). Decline in coral cover and flattening of the reefs around Mauritius (1998-2010). PeerJ, 6, e6014.

Elvin, D. W. (1976). Seasonal growth and reproduction of an intertidal sponge, Haliclona permollis (Bowerbank). Biological Bulletin, 151(1), 108-125.

Ezzat, L., Towle, E., Irisson, J. O., Langdon, C., \& Ferrier-Pagès, C. (2016). The relationship between heterotrophic feeding and inorganic nutrient availability in the scleractinian coral $T$. reniformis under a short-term temperature increase. Limnology and Oceanography, 61(1), 89102.

Fabricius, K. E. (2005). Effects of terrestrial runoff on the ecology of corals and coral reefs: review and synthesis. Marine Pollution Bulletin, 50(2), 125-146.

Fagoonee, I. (1990). Coastal marine ecosystems of Mauritius. International Journal of Aquatic Sciences, 208(1), 55-62. 
Fan, L., Liu, M., Simister, R., Webster, N. S., \& Thomas, T. (2013). Marine microbial symbiosis heats up: the phylogenetic and functional response of a sponge holobiont to thermal stress. The ISME Journal, 7(5), 991-1002.

Fang, J. K., Mello-Athayde, M. A., Schonberg, C. H., Kline, D. I., Hoegh-Guldberg, O., \& Dove, S. (2013). Sponge biomass and bioerosion rates increase under ocean warming and acidification. Global Change Biology, 19(12), 3581-3591.

Fang, J. K. H., Schönberg, C. H. L., Mello-Athayde, M. A., Hoegh-Guldberg, O., \& Dove, S. (2014). Effects of ocean warming and acidification on the energy budget of an excavating sponge. Global Change Biology, 20(4), 1043-1054.

Fang, J. K. H., Schönberg, C. H. L., Hoegh-Guldberg, O., \& Dove, S. (2016). Day-night ecophysiology of the photosymbiotic bioeroding sponge Cliona orientalis Thiele, 1900. Marine Biology, 163(5), 100.

Farmer, G. T., \& Cook, J. (2013). Carbon dioxide, other greenhouse gases, and the carbon cycle. In Climate Change Science: A Modern Synthesis: Volume 1 - The Physical Climate (pp. 199-215). Dordrecht: Springer Netherlands.

Ferrarin, C., Bajo, M., Bellafiore, D., Cucco, A., De Pascalis, F., Ghezzo, M., \& Umgiesser, G. (2014). Toward homogenization of Mediterranean lagoons and their loss of hydrodiversity. Geophysical Research Letters, 41(16), 5935-5941.

Ferreira, J. G., Andersen, J. H., Borja, A., Bricker, S. B., Camp, J., Cardoso da Silva, M., Garcés, E., Heiskanen, A.-S., Humborg, C., Ignatiades, L., Lancelot, C., Menesguen, A., Tett, P., Hoepffner, N., \& Claussen, U. (2011). Overview of eutrophication indicators to assess environmental status within the European Marine Strategy Framework Directive. Estuarine, Coastal and Shelf Science, 93(2), 117-131.

Fiore, C. L., Baker, D. M., \& Lesser, M. P. (2013). Nitrogen biogeochemistry in the Caribbean sponge, Xestospongia muta: A source or sink of dissolved inorganic nitrogen? PLoS ONE, 8(8), e72961.

Folkers, M., \& Rombouts, T. (2020). Sponges revealed: A synthesis of their overlooked ecological functions within aquatic ecosystems. In S. Jungblut, V. Liebich, \& M. Bode-Dalby (Eds.), YOUMARES 9 - The oceans: Our research, our future: Proceedings of the 2018 conference for YOUng MArine RESearcher in Oldenburg, Germany (pp. 181-193). Cham: Springer International Publishing.

Fox, S., Olsen, Y., Teichberg, M., \& Valiela, I. (2010). Controls acting on benthic macrophyte communities in a temperate and a tropical estuary. In M. J. Kennish \& H. W. Paerl (Eds.), Coastal Lagoons: Critical Habitats of Environmental Change (pp. 203-226): CRC Press.

Gatti, S., Brey, T., Müller, W., Heilmayer, O., \& Holst, G. (2002). Oxygen microoptodes: a new tool for oxygen measurements in aquatic animal ecology. Marine Biology, 140(6), 10751085 .

Glibert, P. M., Hinkle, D. C., Sturgis, B., \& Jesien, R. V. (2014). Eutrophication of a Maryland/Virginia coastal lagoon: A tipping point, ecosystem changes, and potential causes. Estuaries and Coasts, 37(1), 128-146. 
Gochfeld, D. J., Easson, C. G., Freeman, C. J., Thacker, R. W., \& Olson, J. B. (2012). Disease and nutrient enrichment as potential stressors on the Caribbean sponge Aplysina cauliformis and its bacterial symbionts. Marine Ecology Progress Series, 456, 101-111.

Gönenç, I. E., \& Wolflin, J. P. (2005). Coastal lagoons ecosystem processes and modeling for sustainable use and development / edited by I. Ethem Gonenc, John P. Wolflin. In. Boca Raton: Boca Raton : CRC Press.

Goodwin, C., Rodolfo-Metalpa, R., Picton, B., \& Hall-Spencer, J. M. (2014). Effects of ocean acidification on sponge communities. Marine Ecology, 35, 41-49.

Graf, G. (1992). Benthic-pelagic coupling: a benthic view. Oceanography and marine biology: an annual review, 30, 149-190.

Granados, C., Camargo, C., Zea, S., \& Sánchez, J. A. (2008). Phylogenetic relationships among zooxanthellae (Symbiodinium) associated to excavating sponges (Cliona spp.) reveal an unexpected lineage in the Caribbean. Molecular Phylogenetics and Evolution, 49(2), 554-560.

Green, L. L., \& Dove, W. F. (1984). Tubulin proteins and RNA during the myxamoebaflagellate transformation of Physarum polycephalum. Molecular and Cellular Biology, 4(9), 1706-1711.

Grenz, C., Denis, L., Pringault, O., \& Fichez, R. (2010). Spatial and seasonal variability of sediment oxygen consumption and nutrient fluxes at the sediment water interface in a subtropical lagoon (New Caledonia). Marine Pollution Bulletin, 61(7), 399-412.

Grenz, C., Fichez, R., Silva, C. Á., Benítez, L. C., Conan, P., Esparza, A. C. R., Denis, L., Ruiz, S. D., Douillet, P., Martinez, M. E. G., Ghiglione, J.-F., Mendieta, F. J. G., OrigelMoreno, M., Garcia, A. Z. M., Caravaca, A. M., Pujo-Pay, M., Alvarado, R. T., \& ZavalaHidalgo, J. (2017). Benthic ecology of tropical coastal lagoons: Environmental changes over the last decades in the Términos Lagoon, Mexico. Comptes Rendus Geoscience, 349(6), 319329.

Griffiths, J. R., Kadin, M., Nascimento, F. J. A., Tamelander, T., Törnroos, A., Bonaglia, S., Bonsdorff, E., Brüchert, V., Gårdmark, A., Järnström, M., Kotta, J., Lindegren, M., Nordström, M. C., Norkko, A., Olsson, J., Weigel, B., Žydelis, R., Blenckner, T., Niiranen, S., \& Winder, M. (2017). The importance of benthic-pelagic coupling for marine ecosystem functioning in a changing world. Global Change Biology, 23(6), 2179-2196.

Guzman, C., \& Conaco, C. (2016). Gene expression dynamics accompanying the sponge thermal stress response. PLoS ONE, 11(10), 1-15.

Hadas, E., Ilan, M., \& Shpigel, M. (2008). Oxygen consumption by a coral reef sponge. Journal of Experimental Biology, 211(13), 2185-2190.

Hardman, E. (1999). A rapid assessment of the extent of coral bleaching in Mauritius after the 1998 seawater warming event. (MSc), University of Wales, Bangor. 124p,

Harley, C. D. G., Randall Hughes, A., Hultgren, K. M., Miner, B. G., Sorte, C. J. B., Thornber, C. S., Rodriguez, L. F., Tomanek, L., \& Williams, S. L. (2006). The impacts of climate change in coastal marine systems. Ecology Letters, 9(2), 228-241. 
Heinze, C., Meyer, S., Goris, N., Anderson, L., Steinfeldt, R., Chang, N., Le Quéré, C., \& Bakker, D. C. E. (2015). The ocean carbon sink - impacts, vulnerabilities and challenges. Earth System Dynamics, 6(1), 327-358.

Hennemann, M. C., \& Petrucio, M. M. (2010). Seasonal phytoplankton response to increased temperature and phosphorus inputs in a freshwater coastal lagoon, Southern Brazil: a microcosm bioassay. Acta Limnologica Brasiliensia, 22(3), 295-305.

Herbert, R. A. (1999). Nitrogen cycling in coastal marine ecosystems. FEMS Microbiology Reviews, 23(5), 563-590.

Heron, S. F., Maynard, J. A., van Hooidonk, R., \& Eakin, C. M. (2016). Warming trends and bleaching stress of the world's coral reefs 1985-2012. Scientific Reports, 6, 38402.

Herrmann, H., Bär, H., Kreplak, L., Strelkov, S. V., \& Aebi, U. (2007). Intermediate filaments: from cell architecture to nanomechanics. Nature Reviews: Molecular Cell Biology, 8(7), 562573.

Hill, M. S. (1996). Symbiotic zooxanthellae enhance boring and growth rates of the tropical sponge Anthosigmella varians forma varians. Marine Biology, 125(4), 649-654.

Hill, M. S., Lopez, N. A., \& Young, K. A. (2005). Anti-predator defenses in western North Atlantic sponges with evidence of enhanced defense through interactions between spicules and chemicals. Marine Ecology Progress Series, 291, 93-102.

Hoegh-Guldberg, O. (1999). Climate change, coral bleaching and the future of the world's coral reefs. Marine and Freshwater Research, 50(8), 839-866.

Hoegh-Guldberg, O., Mumby, P. J., Hooten, A. J., Steneck, R. S., Greenfield, P., Gomez, E., Harvell, C. D., Sale, P. F., Edwards, A. J., Caldeira, K., Knowlton, N., Eakin, C. M., IglesiasPrieto, R., Muthiga, N., Bradbury, R. H., Dubi, A., \& Hatziolos, M. E. (2007). Coral reefs under rapid climate change and ocean acidification. Science, 318(5857), 1737-1742.

Hoegh-Guldberg, O., Andréfouët, S., Fabricius, K., Diaz-Pulido, G., Lough, J., Marshall, P., \& Pratchett, M. (2011). Vulnerability of coral reefs in the tropical Pacific to climate change. In J. Bell \& H. Alistair (Eds.), Vulnerability of tropical pacific fisheries and aquaculture to climate change (pp. 251-296). Noumea, New Caledonia: Secretariat of the Pacific Community.

Hoer, D. R., Gibson, P. J., Tommerdahl, J. P., Lindquist, N. L., \& Martens, C. S. (2018). Consumption of dissolved organic carbon by Caribbean reef sponges. Limnology and Oceanography, 63(1), 337-351.

Hoffmann, F., Radax, R., Woebken, D., Holtappels, M., Lavik, G., Rapp, H. T., Schläppy, M.L., Schleper, C., \& Kuypers, M. M. M. (2009). Complex nitrogen cycling in the sponge Geodia barretti. Environmental Microbiology, 11(9), 2228-2243.

Hofmann, G. E., \& Todgham, A. E. (2010). Living in the now: physiological mechanisms to tolerate a rapidly changing environment. Annual Review of Physiology, 72(1), 127-145.

Holmes, K. E. (2000). Effects of eutrophication on bioeroding sponge communities with the description of new West Indian sponges, Cliona spp. (Porifera: Hadromerida: Clionidae). Invertebrate Biology, 119(2), 125-138. 
Hooper, J. N. A., Soest, R. W. M. v., \& Willenz, P. (2002). Systema Porifera : a guide to the classification of sponges / edited by John N.A. Hooper and Rob W.M. Van Soest; bibliographic editor for recent taxa, Philippe Willenz. New York: New York : Kluwer Academic/Plenum Publishers.

Huang, Y., Yuan, J., Zhang, Y., Peng, H., \& Liu, L. (2018). Molecular cloning and characterization of calmodulin-like protein CaLP from the scleractinian coral Galaxea astreata. Cell Stress \& Chaperones, 23(6), 1329-1335.

Hughes, T. P., Baird, A. H., Bellwood, D. R., Card, M., Connolly, S. R., Folke, C., Grosberg, R., Hoegh-Guldberg, O., Jackson, J. B., Kleypas, J., Lough, J. M., Marshall, P., Nystrom, M., Palumbi, S. R., Pandolfi, J. M., Rosen, B., \& Roughgarden, J. (2003). Climate change, human impacts, and the resilience of coral reefs. Science, 301(5635), 929-933.

Hughes, T. P., Kerry, J. T., Álvarez-Noriega, M., Álvarez-Romero, J. G., Anderson, K. D., Baird, A. H., Babcock, R. C., Beger, M., Bellwood, D. R., Berkelmans, R., Bridge, T. C., Butler, I. R., Byrne, M., Cantin, N. E., Comeau, S., Connolly, S. R., Cumming, G. S., Dalton, S. J., Diaz-Pulido, G., Eakin, C. M., Figueira, W. F., Gilmour, J. P., Harrison, H. B., Heron, S. F., Hoey, A. S., Hobbs, J.-P. A., Hoogenboom, M. O., Kennedy, E. V., Kuo, C.-y., Lough, J. M., Lowe, R. J., Liu, G., McCulloch, M. T., Malcolm, H. A., McWilliam, M. J., Pandolfi, J. M., Pears, R. J., Pratchett, M. S., Schoepf, V., Simpson, T., Skirving, W. J., Sommer, B., Torda, G., Wachenfeld, D. R., Willis, B. L., \& Wilson, S. K. (2017). Global warming and recurrent mass bleaching of corals. Nature, 543(7645), 373-377.

Illan, M., \& Abelson, A. (1995). The life of a sponge in a sandy lagoon. The Biological Bulletin, 189(3), 363-369.

IPCC. (2014). Climate change 2014: synthesis report. Contribution of working groups I, II and III to the Fifth Assessment Report of the Intergovernmental Panel on Climate Change. Retrieved from Geneva, Switzerland:

Ise, Y., Takeda, M., \& Waranabe, Y. (2004). Psammobiontic Clionaidae (Demospongiae: Hadromerida) in lagoons of the Ryukyu Islands, southwestern Japan. BMIB-Bollettino dei Musei e degli Istituti Biologici, 68, 381-389.

Jakimavičius, D., Kriaučiūnienė, J., \& Šarauskienė, D. (2018). Impact of climate change on the Curonian Lagoon water balance components, salinity and water temperature in the $21^{\text {st }}$ century. Oceanologia, 60(3), 378-389.

Jiménez, E., \& Ribes, M. (2007). Sponges as a source of dissolved inorganic nitrogen: nitrification mediated by temperate sponges. Limnology and Oceanography, 52(3), 948-958.

Kahn, A. S., Yahel, G., Chu, J. W. F., Tunnicliffe, V., \& Leys, S. P. (2015). Benthic grazing and carbon sequestration by deep-water glass sponge reefs. Limnology and Oceanography, 60(1), 78-88.

Keesing, J. K., Strzelecki, J., Fromont, J., \& Thomson, D. (2013). Sponges as important sources of nitrate on an oligotrophic continental shelf. Limnology and Oceanography, 58(6), 19471958.

Keller, B. D., Gleason, D. F., McLeod, E., Woodley, C. M., Airamé, S., Causey, B. D., Friedlander, A. M., Grober-Dunsmore, R., Johnson, J. E., Miller, S. L., \& Steneck, R. S. (2009). 
Climate change, coral reef ecosystems, and management options for marine protected areas. Environmental Management, 44(6), 1069-1088.

Kelmo, F., Bell, J. J., \& Attrill, M. J. (2013). Tolerance of sponge assemblages to temperature anomalies: resilience and proliferation of sponges following the 1997-8 El-Niño Southern Oscillation. PLoS ONE, 8(10), e76441.

Kenneth, R. N. A. (2016). Coral reefs under climate change and ocean acidification: Challenges and opportunities for management and policy. Annual Review of Environment and Resources, 41(1), 59-81.

Kennish, M. J., \& Paerl, H. W. (2010). Coastal lagoons: critical habitats of environmental change: CRC Press.

Kennish, M. J. (2016). Coastal Lagoons. In M. J. Kennish (Ed.), Encyclopedia of Estuaries (pp. 140-143). Dordrecht: Springer Netherlands.

Kjerfve, B. r. (1994). Coastal lagoon processes. Amsterdam: New York : Elsevier.

Kleisner, K. M., Fogarty, M. J., McGee, S., Hare, J. A., Moret, S., Perretti, C. T., \& Saba, V. S. (2017). Marine species distribution shifts on the U.S. northeast continental shelf under continued ocean warming. Progress in Oceanography, 153, 24-36.

Klughhammer, C., \& Schreiber, U. (2008). Complementary PS II quantum yields calculated from simple fluorescence parameters measured by PAM fluorometry and the saturation pulse method. . PAM Application Notes(1), 27-35.

Knapp, I. S., Williams, G. J., Carballo, J. L., Cruz-Barraza, J. A., Gardner, J. P., \& Bell, J. J. (2013). Restriction of sponges to an atoll lagoon as a result of reduced environmental quality. Marine Pollution Bulletin, 66(1-2), 209-220.

Koga, T., \& Kawakami, A. (2018). The role of CaMK4 in immune responses. Modern Rheumatology, 28(2), 211-214.

Koopmans, M., \& Wijffels, R. H. (2008). Seasonal growth rate of the sponge Haliclona oculata (Demospongiae: Haplosclerida). Marine Biotechnology, 10(5), 502-510.

Kopp, D., Lefebvre, S., Cachera, M., Villanueva, M. C., \& Ernande, B. (2015). Reorganization of a marine trophic network along an inshore-offshore gradient due to stronger pelagic-benthic coupling in coastal areas. Progress in Oceanography, 130, 157-171.

Koukouras, A., Russo, A., Voultsiadou-Koukoura, E., Arvanitidis, C., \& Stefanidou, D. (1996). Macrofauna associated with sponge species of different morphology. Marine Ecology, 17(4), 569-582.

Krasko, A., Scheffer, U., Koziol, C., Pancer, Z., Batel, R., Badria, F. A., \& Müller, W. E. G. (1997). Diagnosis of sublethal stress in the marine sponge Geodia cydonium: application of the $70 \mathrm{kDa}$ heat-shock protein and a novel biomarker, the Rab GDP dissociation inhibitor, as probes. Aquatic Toxicology, 37(2), 157-168. 
Kristensen, E., Penha-Lopes, G., Delefosse, M., Valdemarsen, T., Quintana, C. O., \& Banta, G. T. (2012). What is bioturbation? The need for a precise definition for fauna in aquatic sciences. Marine Ecology Progress Series, 446, 285-302.

Lambert, F. H., Webb, M. J., \& Joshi, M. M. (2011). The relationship between land-ocean surface temperature contrast and radiative forcing. Journal of Climate, 24(13), 3239-3256.

Landschützer, P., Gruber, N., Bakker, D. C. E., \& Schuster, U. (2014). Recent variability of the global ocean carbon sink. Global Biogeochemical Cycles, 28(9), 927-949.

Lauringson, V., Kotta, J., Orav-Kotta, H., Kotta, I., Herkül, K., \& Põllumäe, A. (2009). Comparison of benthic and pelagic suspension feeding in shallow water habitats of the Northeastern Baltic Sea. Marine Ecology, 30(s1), 43-55.

Lemloh, M.-L., Fromont, J., Brümmer, F., \& Usher, K. M. (2009). Diversity and abundance of photosynthetic sponges in temperate Western Australia. BMC Ecology, 9, 4.

Lesser, M. P. (2006). Oxidative stress in marine environment: Biochemistry and physiological ecology. Annual Review of Physiology, 68(1), 253-278.

Lesser, M. P. (2011). Coral Bleaching: Causes and Mechanisms. In Z. Dubinsky \& N. Stambler (Eds.), Coral Reefs: An Ecosystem in Transition (pp. 405-419). Dordrecht: Springer Netherlands.

Lesser, M. P., \& Slattery, M. (2013). Ecology of Caribbean sponges: are top-down or bottomup processes more important? PLoS One, 8(11), e79799.

Lesser, M. P., \& Slattery, M. (2020). Will coral reef sponges be winners in the Anthropocene? Global Change Biology, 26(6), 3202-3211.

Levi, C., Laboute, P., Bargibant, G., \& Menou, J. (1998). Sponges from the New Caledonian lagoon (Orstom ed.). Paris, France.

Leys, S. P., Yahel, G., Reidenbach, M. A., Tunnicliffe, V., Shavit, U., \& Reiswig, H. M. (2011). The sponge pump: the role of current induced flow in the design of the sponge body plan. PLoS ONE, 6(12), e27787.

Lichtenthaler, H. K. (1987). Chlorophylls and carotenoids: Pigments of photosynthetic biomembranes. Methods in Enzymology, 148, 350-382.

Liu, M., Fan, L., Zhong, L., Kjelleberg, S., \& Thomas, T. (2012). Metaproteogenomic analysis of a community of sponge symbionts. The ISME Journal, 6(8), 1515-1525.

Lloret, J., Marín, A., \& Marín-Guirao, L. (2008). Is coastal lagoon eutrophication likely to be aggravated by global climate change? Estuarine, Coastal and Shelf Science, 78(2), 403-412.

Longo, C., Cardone, F., Mercurio, M., Nonnis Marzano, C., Pierri, C., \& Corriero, G. (2015). Spatial and temporal distributions of the sponge fauna insouthern Italian lagoon systems. Mediterranean marine science, 17(1), 174-189. 
Lonsdale, D. J., Cerrato, R. M., Holland, R., Mass, A., Holt, L., Schaffner, R. A., Pan, J., \& Caron, D. A. (2009). Influence of suspension-feeding bivalves on the pelagic food webs of shallow, coastal embayments. Aquatic Biology, 6, 263-279.

López-Acosta, M., Leynaert, A., Chavaud, L., Amice, E., Bihannic, I., Le Bec, T., \& Maldonado, M. (2019). In situ determination of Si, N, and P utilization by the demosponge Tethya citrina: A benthic-chamber approach. PLoS ONE, 14(7), e0218787.

Lopez-Legentil, S., Song, B., McMurray, S. E., \& Pawlik, J. R. (2008). Bleaching and stress in coral reef ecosystems: hsp70 expression by the giant barrel sponge Xestospongia muta. Molecular Ecology, 17(7), 1840-1849.

López-Victoria, M., \& Zea, S. (2005). Current trends of space occupation by encrusting excavating sponges on Colombian coral reefs. Marine Ecology, 26(1), 33-41.

López-Victoria, M., Zea, S., \& Weil, E. (2006). Competition for space between encrusting excavating Caribbean sponges and other coral reef organisms. Marine Ecology Progress Series, 312, 113-121.

Ludeman, D. A., Reidenbach, M. A., \& Leys, S. P. (2017). The energetic cost of filtration by demosponges and their behavioural response to ambient currents. The Journal of Experimental Biology, 220(6), 995-1007.

Luter, H. M., Gibb, K., \& Webster, N. S. (2014). Eutrophication has no short-term effect on the Cymbastela stipitata holobiont. Frontiers in Microbiology, 5, 216.

Macdonald, I. A., \& Perry, C. T. (2003). Biological degradation of coral framework in a turbid lagoon environment, Discovery Bay, north Jamaica. Coral Reefs, 22(4), 523-535.

Maldonado, M., \& Young, C. M. (1996). Effects of physical factors on larval behavior, settlement and recruitment of four tropical demosponges. Marine Ecology Progress Series, $138,169-180$.

Maldonado, M., Carmona, M. C., Velásquez, Z., Puig, A., Cruzado, A., López, A., \& Young, C. M. (2005). Siliceous sponges as a silicon sink: an overlooked aspect of benthopelagic coupling in the marine silicon cycle. Limnology and Oceanography, 50(3), 799-809.

Maldonado, M., \& Riesgo, A. (2008). Reproduction in the phylum Porifera: A synoptic overview. Treballs de la Societat Catalana de Biologia, 59, 29-49.

Maldonado, M., Zhang, X., Cao, X., Xue, L., Cao, H., \& Zhang, W. (2010). Selective feeding by sponges on pathogenic microbes: a reassessment of potential for abatement of microbial pollution. Marine Ecology Progress Series, 403, 75-89.

Maldonado, M., Ribes, M., \& van Duyl, F. C. (2012). Nutrient fluxes through sponges: biology, budgets, and ecological implications. Advances in Marine Biology, 62, 113-182.

Manucharyan, G. E., Brierley, C. M., \& Fedorov, A. V. (2011). Climate impacts of intermittent upper ocean mixing induced by tropical cyclones. Journal of Geophysical Research: Oceans (1978-2012), 116(C11038). 
Marbà, N., \& Duarte, C. M. (2010). Mediterranean warming triggers seagrass (Posidonia oceanica) shoot mortality. Global Change Biology, 16(8), 2366-2375.

Marlow, J., Smith, D., Werorilang, S., \& Bell, J. (2018). Sedimentation limits the erosion rate of a bioeroding sponge. Marine Ecology, 39(1), e12483.

Massaro, A. J., Weisz, J. B., Hill, M. S., \& Webster, N. S. (2012). Behavioral and morphological changes caused by thermal stress in the Great Barrier Reef sponge Rhopaloeides odorabile. Journal of Experimental Marine Biology and Ecology, 416(Supplement C), 55-60.

Mattan-Moorgawa, S., Poonet, G., Bhagooli, R., \& Rughooputh, S. (2014). Differential effects of thermal and chemical stressors on tissue balls from scleractinian corals. African Journal of Marine Science, 36(4), 439-447.

McCain, C., Szewczyk, T., \& Bracy Knight, K. (2016). Population variability complicates the accurate detection of climate change responses. Global Change Biology, 22(6), 2081-2093.

McClanahan, T. R., Maina, J., Moothien-Pillay, R., \& Baker, A. (2005). Effects of geography, taxa, water flow, and temperature variation on coral bleaching intensity in Mauritius. Marine Ecology Progress Series, 298, 131-142.

McClanahan, T. R., Maina, J. M., \& Muthiga, N. A. (2011). Associations between climate stress and coral reef diversity in the western Indian Ocean. Global Change Biology, 17(6), 2023-2032.

McClanahan, T. R., Ateweberhan, M., Darling, E. S., Graham, N. A. J., \& Muthiga, N. A. (2014). Biogeography and change among regional coral communities across the Western Indian Ocean. PLoS ONE, 9(4), e93385.

McMurray, S., Blum, J. E., \& Pawlik, J. R. (2008). Redwood of the reef: growth and age of the giant barrel sponge Xestospongia muta in the Florida Keys. Marine Biology, 155(2), 159-171.

McMurray, S. E., Johnson, Z. I., Hunt, D. E., Pawlik, J. R., \& Finelli, C. M. (2016). Selective feeding by the giant barrel sponge enhances foraging efficiency. Limnology and Oceanography, 61(4), 1271-1286.

McMurray, S. E., Stubler, A. D., Erwin, P. M., Finelli, C. M., \& Pawlik, J. R. (2018). A test of the sponge-loop hypothesis for emergent Caribbean reef sponges. Marine Ecology Progress Series, 588, 1-14.

Mercurio, M., Corriero, G., \& Gaino, E. (2006). Sessile and non-sessile morphs of Geodia cydonium (Jameson) (Porifera, Demospongiae) in two semi-enclosed Mediterranean bays. Marine Biology, 148(3), 489-501.

Metallo, C. M., \& Vander Heiden, M. G. (2013). Understanding metabolic regulation and its influence on cell physiology. Molecular Cell, 49(3), 388-398.

Miller, N., \& Stillman, J. (2012). Physiological optima and critical limits. Nature Education Knowledge, 3(10), 1.

Miller, N. A., Strychar, K., C. Shirley, T., \& Rützler, K. (2010). Effects of heat and salinity stress on the sponge Cliona Celata. International Journal of Biology, 2(2), 3-16. 
Mohri, H., Inaba, K., Ishijima, S., \& Baba, S. A. (2012). Tubulin-dynein system in flagellar and ciliary movement. Proceedings of the Japan Academy. Series B, Physical and biological sciences, 88(8), 397-415.

Moothien-Pillay, R., Terashima, H., \& Kawasaki, H. (2002). The extent and intensity of the 1998 mass bleaching event on the reefs of Mauritius, Indian Ocean. Journal of the Japanese Coral Reef Society, 2002(4), 43-52.

Moothien Pillay, R., Terashima, H., Venkatasami, A., \& Uchida, H. (2002). Field guide to corals of Mauritius: Albion Fisheries Research Centre (AFRC), Ministry of Fisheries, Mauritius \& Japan International Cooperation Agency (JICA).

Morganti, T., Coma, R., Yahel, G., \& Ribes, M. (2017). Trophic niche separation that facilitates co-existence of high and low microbial abundance sponges is revealed by in situ study of carbon and nitrogen fluxes. Limnology and Oceanography, 62(5), 1963-1983.

Morganti, T. M., Ribes, M., Yahel, G., \& Coma, R. (2019). Size ei the major determinant of pumping rates in marine sponges. Frontiers in Physiology, 10(1474).

Mueller, B., de Goeij, J. M., Vermeij, M. J. A., Mulders, Y., van der Ent, E., Ribes, M., \& van Duyl, F. C. (2014). Natural diet of coral-excavating sponges consists mainly of dissolved organic carbon (DOC). PLoS ONE, 9(2), e90152.

Muko, S., Suzuki, G., Saito, M., Nakamura, T., \& Nadaoka, K. (2019). Transitions in coral communities over 17 years in the Sekisei Lagoon and adjacent reef areas in Okinawa, Japan. Ecological Research, 34(4), 524-534.

Müller, W. E. G., Koziol, C., Müller, I. M., \& Wiens, M. (1999). Towards an understanding of the molecular basis of immune responses in sponges: The marine demosponge Geodia cydonium as a model. Microscopy Research and Technique, 44(4), 219-236.

Müller, W. E. G. (2003). The origin of metazoan complexity: Porifera as integrated animals. Integrative and Comparative Biology, 43(1), 3-10.

Narayana, B., \& Sunil, K. (2009). A spectrophotometric method for the determination of nitrite and nitrate. Eurasian Journal of Analytical Chemistry, 4(2), 204-214.

Nicolaidou, A., Reizopoulou, S., Koutsoubas, D., Orfranidis, S., \& Kevrekidis, T. (2005). Biological components of Greek lagoonal ecosystems: an overview. Mediterranean marine science, 6(2), 31-50.

Nixon, S. W. (1982). Nutrient dynamics, primary production and fisheries yields of lagoons. Oceanologica Acta(Special Issue), 357-372.

Nixon, S. W. (1988). Physical energy inputs and the comparative ecology of lake and marine ecosystems. Limnology and Oceanography, 33(4part2), 1005-1025.

Nixon, S. W. (1995). Coastal marine eutrophication: a definition, social causes, and future concerns. Ophelia, 41(1), 199-219. 
Norkko, A., Hewitt, J. E., Thrush, S. F., \& Funnell, T. (2001). Benthic-pelagic coupling and suspension-feeding bivalves: Linking site-specific sediment flux and biodeposition to benthic community structure. Limnology and Oceanography, 46(8), 2067-2072.

Oakley, C. A., Ameismeier, M. F., Peng, L., Weis, V. M., Grossman, A. R., \& Davy, S. K. (2016). Symbiosis induces widespread changes in the proteome of the model cnidarian Aiptasia. Cellular Microbiology, 18(7), 1009-1023.

Obura, D., Gudka, M., Rabi, F., Gian, S., Bijoux, J., Freed, S., Maharavo, J., Mwaura, J., Porter, S., Sola, E., Wickel, J., Yahya, S., \& Ahamada, S. (2017). Coral reef status report for the Western Indian Ocean (2017). Retrieved from Global Coral Reef Monitoring Network (GCRMN)/International Coral Reef Initiative (ICRI):

Osinga, R., Redeker, D., Beukelaar, \& Wijffels, R. (1999). Measurement of sponge growth by projected body area and underwater weight. Memoires of the Queensland Meusem, 44, 419 426.

Padedda, B. M., Pulina, S., Satta, C. T., Luglie, A., \& Magni, P. (2019). Eutrophication and nutrient fluxes in Mediterranean coastal lagoons. In P. Maurice (Ed.), Encyclopedia of Water (pp. 1-16).

Padovan, A., Munksgaard, N., Alvarez, B., McGuinness, K., Parry, D., \& Gibb, K. (2012). Trace metal concentrations in the tropical sponge Spheciospongia vagabunda at a sewage outfall: Synchrotron X-ray imaging reveals the micron-scale distribution of accumulated metals. Hydrobiologia, 687, 275-288 LA.

Pang, T.-L., Chen, F.-C., Weng, Y.-L., Liao, H.-C., Yi, Y.-H., Ho, C.-L., Lin, C.-H., \& Chen, M.-Y. (2010). Costars, a Dictyostelium protein similar to the C-terminal domain of STARS, regulates the actin cytoskeleton and motility. Journal of Cell Science, 123(21), 3745-3755.

Pantile, R., \& Webster, N. (2011). Strict thermal threshold identified by quantitative PCR in the sponge Rhopaloeides odorabile. Marine Ecology Progress Series, 431, 97-105.

Pawlik, J. R., Chanas, B., Toonen, R. J., \& Fenical, W. (1995). Defenses of Caribbean sponges against predatory reef fish. I. Chemical deterrency. Marine Ecology Progress Series, 127(1/3), 183-194.

Pawlik, J. R. (1998). Coral reef sponges: do predatory fishes affect their distribution? Limnology and Oceanography, 43(6), 1396-1399.

Pawlik, J. R., Loh, T. L., McMurray, S. E., \& Finelli, C. M. (2013). Sponge communities on Caribbean coral reefs are structured by factors that are top-down, not bottom-up. PLoS ONE, $8(5)$, e62573.

Pawlik, J. R., Burkepile, D. E., \& Thurber, R. V. (2016). A vicious circle? Altered carbon and nutrient cycling may explain the low resilience of Caribbean coral reefs. Bioscience, 66(6), 470-476.

Pawlik, J. R., Loh, T. L., \& McMurray, S. E. (2018). A review of bottom-up vs. top-down control of sponges on Caribbean fore-reefs: what's old, what's new, and future directions. PeerJ, 6, e4343. 
Pérez-Ruzafa, A., \& Marcos-Diego, C. (1992). Colonization rates and dispersal as essential parameters in the confinement theory to explain the structure and horizontal zonation of lagoon benthic assemblages. Retrieved from Technical Report Rapport Commission International Mer Mediterranean:

Pérez-Ruzafa, A., Gilabert, J., Gutiérrez, J. M., Fernández, A. I., Marcos, C., \& Sabah, S. (2002). Evidence of a planktonic food web response to changes in nutrient input dynamics in the Mar Menor coastal lagoon, Spain. Hydrobiologia, 475(1), 359-369.

Pérez-Ruzafa, A., Marcos, C., \& Gilabert, J. (2005). The ecology of the Mar Menor coastal lagoon: A fast changing ecosystem under human pressure. In I. E. Gönenç \& J. P. Wolflin (Eds.), Coastal lagoons: ecosystem processes and modeling for sustainable use and development (pp. 392-422). Boca Raton, FL: CRC Press.

Pérez-Ruzafa, A., Marcos, C., Pérez-Ruzafa, I. M., Barcala, E., Hegazi, M. I., \& Quispe, J. (2007a). Detecting changes resulting from human pressure in a naturally quick-changing and heterogeneous environment: Spatial and temporal scales of variability in coastal lagoons. Estuarine, Coastal and Shelf Science, 75(1), 175-188.

Pérez-Ruzafa, A., Mompeán, M. C., \& Marcos, C. (2007b). Hydrographic, geomorphologic and fish assemblage relationships in coastal lagoons. Hydrobiologia, 577(1), 107-125.

Pérez-Ruzafa, A., Hegazi, M. I., Perez-Ruzafa, I. M., \& Marcos, C. (2008). Differences in spatial and seasonal patterns of macrophyte assemblages between a coastal lagoon and the open sea. Marine Environmental Research, 65(4), 291-314.

Pérez-Ruzafa, A., Pérez-Ruzafa, I. M., Newton, A., \& Marcos, C. (2019). Coastal lagoons: environmental variability, ecosystem complexity, and goods and services uniformity. In J. W. D. Eric Wolanski, Michael Elliott, Ramesh Ramachandran (Ed.), Coasts and Estuaries (pp. 253-276): Elsevier.

Peterson, C. H. (1979). Predation, competitive exclusion, and diversity in the soft-sediment benthic communities of estuaries and lagoons. In R. J. Livingston (Ed.), Ecological Processes in Coastal and Marine Systems (pp. 233-264). Boston, MA: Springer US.

Petrosillo, G., Ruggiero, F. M., Pistolese, M., \& Paradies, G. (2001). Reactive oxygen species generated from the mitochondrial electron transport chain induce cytochrome c dissociation from beef-heart submitochondrial particles via cardiolipin peroxidation. Possible role in the apoptosis. FEBS Letters, 509(3), 435-438.

Picton, B. E. (1995). New perspectives in sponge biology. Journal of Experimental Marine Biology and Ecology, 193(1), 279-281.

Pineda, M. C., Duckworth, A., \& Webster, N. (2016). Appearance matters: sedimentation effects on different sponge morphologies. Journal of the Marine Biological Association of the United Kingdom, 96(2), 481-492.

Pita, L., Erwin, P. M., Turon, X., \& López-Legentil, S. (2013). Till death do us part: Stable sponge-bacteria associations under thermal and food shortage stresses. PLoS ONE, 8(11), e80307. 
Pomponi, S. A. (1979). Ultrastructure of cells associated with excavation of calcium carbonate substrates by boring sponges. Journal of the Marine Biological Association of the United Kingdom, 59(3), 777-790.

Ponti, M., Casselli, C., \& Abbiati, M. (2011). Anthropogenic disturbance and spatial heterogeneity of macrobenthic invertebrate assemblages in coastal lagoons: the study case of Pialassa Baiona (northern Adriatic Sea). Helgoland marine research, 65(1), 25-42.

Poppell, E., Weisz, J., Spicer, L., Massaro, A., Hill, A., \& Hill, M. (2014). Sponge heterotrophic capacity and bacterial community structure in high- and low-microbial abundance sponges. Marine Ecology, 35(4), 414-424.

Pörtner, H. O., \& Farrell, A. P. (2008). Physiology and Climate Change. Science, 322(5902), 690-692.

Pörtner, H. O. (2012). Integrating climate-related stressor effects on marine organisms: unifying principles linking molecule to ecosystem-level changes. Marine Ecology Progress Series, 470, 273-290.

Pörtner, H. O., \& Gutt, J. (2016). Impacts of climate variability and change on (marine) animals: Physiological underpinnings and evolutionary consequences. Integrative and Comparative Biology, 56(1), 31-44.

Povinec, P. P., Burnett, W. C., Beck, A., Bokuniewicz, H., Charette, M., Gonneea, M. E., Groening, M., Ishitobi, T., Kontar, E., Liong Wee Kwong, L., Marie, D. E. P., Moore, W. S., Oberdorfer, J. A., Peterson, R., Ramessur, R., Rapaglia, J., Stieglitz, T., \& Top, Z. (2012). Isotopic, geophysical and biogeochemical investigation of submarine groundwater discharge: IAEA-UNESCO intercomparison exercise at Mauritius Island. Journal of Environmental Radioactivity, 104, 24-45.

Przeslawski, R., Ahyong, S., Byrne, M., Wörheide, G., \& Hutchings, P. (2008). Beyond corals and fish: the effects of climate change on noncoral benthic invertebrates of tropical reefs. Global Change Biology, 14(12), 2773-2795.

Quéré, C. L., Takahashi, T., Buitenhuis, E. T., Rödenbeck, C., \& Sutherland, S. C. (2010). Impact of climate change and variability on the global oceanic sink of $\mathrm{CO}_{2}$. Global Biogeochemical Cycles, 24(4).

Ramessur, R. T., Boodhoo, K., Balgobin, J., Povinec, P., \& Burnett, W. C. (2011). Dissolved nutrients in submarine groundwater discharge in Flic en Flac lagoon, Mauritius. Western Indian Ocean journal of marine science, 10(2), 121-127.

Ramessur, R. T. (2013). A review of coastal zone management facing climate change and natural disasters in Mauritius. Journal of Geography and Natural Disasters, 3, 1-8.

Ramsby, B. D., Hoogenboom, M. O., Whalan, S., Webster, N. S., \& Thompson, A. (2017). A decadal analysis of bioeroding sponge cover on the inshore Great Barrier Reef. Scientific Reports, 7(1), 2706.

Ramsby, B. D., Hoogenboom, M. O., Smith, H. A., Whalan, S., \& Webster, N. S. (2018). The bioeroding sponge Cliona orientalis will not tolerate future projected ocean warming. Scientific Reports, 8(1), 8302. 
Rands, M., Loughman, B., \& Douglas, A. (1993). The symbiotic interface in an algainvertebrate symbiosis. Proceedings of The Royal Society of London. Series B, Biological Sciences (1934-1990), 253, 161-165.

Ray, P. D., Huang, B.-W., \& Tsuji, Y. (2012). Reactive oxygen species (ROS) homeostasis and redox regulation in cellular signaling. Cellular Signalling, 24(5), 981-990.

Reiswig, H. (1971a). In situ pumping activities of tropical Demospongiae. Marine Biology, 9(1), 38-50.

Reiswig, H. M. (1971b). Particle feeding in natural populations of three marine demosponges. The Biological Bulletin, 141(3), 568-591.

Repolho, T., Duarte, B., Dionísio, G., Paula, J. R., Lopes, A. R., Rosa, I. C., Grilo, T. F., Caçador, I., Calado, R., \& Rosa, R. (2017). Seagrass ecophysiological performance under ocean warming and acidification. Scientific Reports, 7, 41443.

Ribes, M., Coma, R., \& Gili, J. (1999). Natural diet and grazing rate of the temperate sponge Dysidea avara (Demospongiae, Dendroceratida) throughout an annual cycle. Marine Ecology Progress Series, 176, 179-190.

Ribes, M., Coma, R., Atkinson, M. J., \& Kinzie III, R. A. (2005). Sponges and ascidians control removal of particulate organic nitrogen from coral reef water. Limnology and Oceanography, 50(5), 1480-1489.

Ribes, M., Jiménez, E., Yahel, G., López-Sendino, P., Diez, B., Massana, R., Sharp, J. H., \& Coma, R. (2012). Functional convergence of microbes associated with temperate marine sponges. Environmental Microbiology, 14(5), 1224-1239.

Riegl, B. M., Sheppard, C. R. C., \& Purkis, S. J. (2012). Human impact on atolls leads to coral loss and community homogenisation: A modeling study. PLoS ONE, 7(6), e36921.

Riisgård, H. U., Thomassen, S., Jakobsen, H., Weeks, J. M., \& Larsen, P. S. (1993). Suspension feeding in marine sponges Halichondria panicea and Haliclona urceolus: effects of temperature on filtration rate and energy cost of pumping. Marine Ecology Progress Series, 96(2), 177-188.

Ritchie, R. J. (2008). Universal chlorophyll equations for estimating chlorophylls $a, b, c$, and $d$ and total chlorophylls in natural assemblages of photosynthetic organisms using acetone, methanol, or ethanol solvents. Photosynthetica, 46(1), 115-126.

Rix, L., de Goeij, J. M., Mueller, C. E., Struck, U., Middelburg, J. J., van Duyl, F. C., AlHorani, F. A., Wild, C., Naumann, M. S., \& van Oevelen, D. (2016). Coral mucus fuels the sponge loop in warm- and cold-water coral reef ecosystems. Scientific Reports, 6, 18715.

Rix, L., Goeij, J., Oevelen, D., Struck, U., Al-Horani, F. A., Wild, C., \& Naumann, M. S. (2018). Reef sponges facilitate the transfer of coral-derived organic matter to their associated fauna via the sponge loop. Marine Ecology Progress Series, 589, 85-96.

Roberts, D. E., Davis, A. R., \& Cummins, S. P. (2006). Experimental manipulation of shade, silt, nutrients and salinity on the temperate reef sponge Cymbastela concentrica. Marine Ecology Progress Series, 307, 143-154. 
Rohde, S., \& Schupp, P. J. (2011). Allocation of chemical and structural defenses in the sponge Melophlus sarasinorum. Journal of Experimental Marine Biology and Ecology, 399(1), 76-83.

Rose, C. S., \& Risk, M. J. (1985). Increase in Cliona delitrix Infestation of Montastrea cavernosa heads on an organically polluted portion of the Grand Cayman fringing reef. Marine Ecology, 6(4), 345-363.

Rosell, D., \& Uriz, M. J. (1992). Do associated zooxanthellae and the nature of the substratum affect survival, attachment and growth of Cliona viridis (Porifera: Hadromerida)? An experimental approach. Marine Biology, 114(3), 503-507.

Rossi, G., Montori, S., Cerrano, C., \& Calcinai, B. (2015). The coral killing sponge Chalinula nematifera (Porifera: Haplosclerida) along the eastern coast of Sulawesi Island (Indonesia). Italian Journal of Zoology, 82(1), 143-148.

Rovellini, A., Dunn, M. R., Fulton, E. A., Webster, N. S., Smith, D. J., Jompa, J., Haris, A., Berman, J., \& Bell, J. J. (2019). Decadal variability in sponge abundance and biodiversity on an Indo-Pacific coral reef. Marine Ecology Progress Series, 620, 63-76.

Rützler, K. (1975). The role of burrowing sponges in bioerosion. Oecologia, 19(3), 203-216.

Rützler, K. (1988). Mangrove sponge disease induced by cyanobacterial symbionts: Failure of a primitive immune system? Diseases of Aquatic Organisms, 5, 143-149.

Rützler, K. (2002). Family Clionaidae D’Orbigny, 1851. In Systema Porifera (pp. 173-185): Springer.

Rützler, K. (2012). The role of sponges in the Mesoamerican barrier-reef ecosystem, Belize. Advances in Marine Biology, 61, 211-271.

Rysgaard, S., Risgaard-Petersen, N., \& Sloth, N. P. (1996). Nitrification, denitrification, and nitrate ammonification in sediments of two coastal lagoons in Southern France. Hydrobiologia, 329(1), 133-141.

Saba, V. S., Griffies, S. M., Anderson, W. G., Winton, M., Alexander, M. A., Delworth, T. L., Hare, J. A., Harrison, M. J., Rosati, A., Vecchi, G. A., \& Zhang, R. (2016). Enhanced warming of the Northwest Atlantic Ocean under climate change. Journal of Geophysical Research: Oceans, 121(1), 118-132.

Sabarathnam, B., Manilal, A., Sujith, S., Kiran, G. S., Selvin, J., Thomas, A., \& Ravji, R. (2010). Role of sponge associated actinomycetes in the marine phosphorous biogeochemical cycles. American-Eurasian Journal of Agriculture and Environmental Sciences, 8(3), 253-256.

Sadally, S. B., Taleb-Hossenkhan, N., \& Bhagooli, R. (2014). Spatio-temporal variation in density of microphytoplankton genera in two tropical coral reefs of Mauritius. African Journal of Marine Science, 36(4), 423-438.

Saunders, M. I., Leon, J. X., Callaghan, D. P., Roelfsema, C. M., Hamylton, S., Brown, C. J., Baldock, T., Golshani, A., Phinn, S. R., Lovelock, C. E., Hoegh-Guldberg, O., Woodroffe, C. D., \& Mumby, P. J. (2014). Interdependency of tropical marine ecosystems in response to climate change. Nature Climate Change, 4(8), 724-729. 
Schönberg, C. H. L., \& Loh, W. K. W. (2005). Molecular identity of the unique symbiotic dinoflagellates found in the bioeroding demosponge Cliona orientalis. Marine Ecology Progress Series, 299, 157-166.

Schönberg, C. H. L., \& Suwa, R. (2007). Why bioeroding sponges may be better hosts for symbiotic dinoflagellates than many corals. Porifera Research: Biodiversity, Innovation and Sustainability, 569-580.

Schönberg, C. H. L., Suwa, R., Hidaka, M., \& Loh, W. K. W. (2008). Sponge and coral zooxanthellae in heat and light: preliminary results of photochemical efficiency monitored with pulse amplitude modulated fluorometry. Marine Ecology, 29(2), 247-258.

Schönberg, C. H. L., \& Wisshak, M. (2012). The perks of being endolithic. Aquatic Biology, $17(1), 1-5$.

Schönberg, C. H. L. (2016). Happy relationships between marine sponges and sediments - a review and some observations from Australia. Journal of the Marine Biological Association of the United Kingdom, 96(2), 493-514.

Schönberg, C. H. L., Fang, J. K.-H., \& Carballo, J. L. (2017). Bioeroding Sponges and the Future of Coral Reefs. In J. L. Carballo \& J. J. Bell (Eds.), Climate change, ocean acidification and sponges: impacts across multiple levels of organization (pp. 179-372). Cham: Springer International Publishing.

Schreiber, U., Hormann, H., Neubauer, C., \& Klughammer, C. (1995). Assessment of photosystem II photochemical quantum yield by chlorophyll fluorescence quenching analysis. Functional Plant Biology, 22(2), 209-220.

Schwämmle, V., Hagensen, C. E., Rogowska-Wrzesinska, A., \& Jensen, O. N. (2020). PolySTest: Robust statistical testing of proteomics data with missing values improves detection of biologically relevant features. Molecular \&amp; Cellular Proteomics, 19(8), 1396-1408.

Schwartz, A. L., \& Ciechanover, A. (2009). Targeting proteins for destruction by the ubiquitin system: implications for human pathobiology. Annual Review of Pharmacology and Toxicology, 49, 73-96.

Shaffer, G., Olsen, S. M., \& Pedersen, J. O. P. (2009). Long-term ocean oxygen depletion in response to carbon dioxide emissions from fossil fuels. Nature Geoscience, 2(2), 105-109.

Simister, R., Taylor, M. W., Tsai, P., \& Webster, N. (2012). Sponge-microbe associations survive high nutrients and temperatures. PLoS ONE, 7(12), e52220.

Simpson, T. (1984). The biology of sponges. In: Springer, Berlin Heidelberg New York.

Somero, G. N. (2010). The physiology of climate change: how potentials for acclimatization and genetic adaptation will determine 'winners' and 'losers'. The Journal of Experimental Biology, 213(6), 912-920.

Souchu, P., Bec, B., Smith, V. H., Laugier, T., Fiandrino, A., Benau, L., Orsoni, V., Collos, Y., \& Vaquer, A. (2010). Patterns in nutrient limitation and chlorophyll $a$ along an anthropogenic eutrophication gradient in French Mediterranean coastal lagoons. Canadian Journal of Fisheries and Aquatic Sciences, 67(4), 743-753. 
Southwell, M. W., Weisz, J. B., Martens, C. S., \& Lindquist, N. (2008). In situ fluxes of dissolved inorganic nitrogen from the sponge community on Conch Reef, Key Largo, Florida. Limnology and Oceanography, 53(3), 986-996.

Srivastava, M., Simakov, O., Chapman, J., Fahey, B., Gauthier, M. E. A., Mitros, T., Richards, G. S., Conaco, C., Dacre, M., Hellsten, U., Larroux, C., Putnam, N. H., Stanke, M., Adamska, M., Darling, A., Degnan, S. M., Oakley, T. H., Plachetzki, D. C., Zhai, Y., Adamski, M., Calcino, A., Cummins, S. F., Goodstein, D. M., Harris, C., Jackson, D. J., Leys, S. P., Shu, S., Woodcroft, B. J., Vervoort, M., Kosik, K. S., Manning, G., Degnan, B. M., \& Rokhsar, D. S. (2010). The Amphimedon queenslandica genome and the evolution of animal complexity. Nature, 466(7307), 720-726.

Stevely, J., Sweat, D., Bert, T., Sim-Smith, C., \& Kelly, M. (2010). Sponge mortality at Marathon and Long Key, Florida: patterns of species response and population recovery. Proceedings of the Gulf and Caribbean Fisheries Institute, 63, 384-400.

Stokes, M. D., \& Deane, G. B. (2009). Automated processing of coral reef benthic images. Limnology and Oceanography: Methods, 7(2), 157-168.

Strand, R., Whalan, S., Webster, N. S., Kutti, T., Fang, J. K. H., Luter, H. M., \& Bannister, R. J. (2017). The response of a boreal deep-sea sponge holobiont to acute thermal stress. Scientific Reports, 7(1), 1660.

Stubler, A. D., Furman, B. T., \& Peterson, B. J. (2015). Sponge erosion under acidification and warming scenarios: differential impacts on living and dead coral. Global Change Biology, 21(11), 4006-4020.

Tagliapietra, D., Bejaoui, N., Bellafiore, D., De Wit, R., C, F., Gamito, S., P, L., Magni, P., Mistri, M., Perez-Ruzafa, A., Pranovi, F., Reizopoulou, S., Rilov, G., Solidoro, C., B, T., Valiela, I., \& P, V. (2011). The Ecological Implications of Climate Change on the Lagoon of Venice. In: The future of Venice and its lagoon in the context of global change (E. Ruoss Ed.): UNESCO, Venice, Italy.

Taylor, D., Nixon, S., Granger, S., \& Buckley, B. (1995). Nutrient limitation and the eutrophication of coastal lagoons. Marine Ecology Progress Series, 127, 235-244.

Taylor, M. W., Radax, R., Steger, D., \& Wagner, M. (2007). Sponge-associated microorganisms: evolution, ecology, and biotechnological potential. Microbiology and Molecular Biology Reviews, 71(2), 295-347.

Thacker, R. W. (2005). Impacts of shading on sponge-cyanobacteria symbioses: a comparison between host-specific and generalist associations. Integrative and Comparative Biology, 45(2), 369-376.

Thacker, R. W., \& Freeman, C. J. (2012). Sponge-microbe symbioses: recent advances and new directions. In M. A. Becerro, M. J. Uriz, M. Maldonado, \& X. Turon (Eds.), Advances in Marine Biology (Vol. 62, pp. 57-111): Academic Press.

Thomas, T., Moitinho-Silva, L., Lurgi, M., Björk, J. R., Easson, C., Astudillo-García, C., Olson, J. B., Erwin, P. M., López-Legentil, S., Luter, H., Chaves-Fonnegra, A., Costa, R., Schupp, P. J., Steindler, L., Erpenbeck, D., Gilbert, J., Knight, R., Ackermann, G., Victor Lopez, J., Taylor, M. W., Thacker, R. W., Montoya, J. M., Hentschel, U., \& Webster, N. S. 
(2016). Diversity, structure and convergent evolution of the global sponge microbiome. Nature Communications, 7, 11870.

Thomassen, S., \& Riisgård, H. U. (1995). Growth and energetics of the sponge Halichondria panicea. Marine Ecology Progress Series, 128, 239-246.

Thomassin, B. A., Gourbesville, P., Gout, P., \& Arnoux, A. (1998, 28 Sept.-1 Oct. 1998). Impact of an industrial and urban sewage off a coral fringing reef at Mauritius (Indian Ocean): modeling of plumes, distribution of trace metals in sediments and effects of the eutrophisation on coral reef communities. Paper presented at the IEEE Oceanic Engineering Society. OCEANS'98. Conference Proceedings (Cat. No.98CH36259).

Tisthammer, K. H., Timmins-Schiffman, E., Seneca, F. O., Nunn, B. L., \& Richmond, R. H. (2020). Surviving in high stress environments: Physiological and molecular responses of lobe coral indicate nearshore adaptations to anthropogenic stressors. bioRxiv, 786673.

Tomanek, L., \& Somero, G. N. (1999). Evolutionary and acclimation-induced variation in the heat-shock responses of congeneric marine snails (genus Tegula) from different thermal habitats: implications for limits of thermotolerance and biogeography. The Journal of Experimental Biology, 202(21), 2925.

Turicchia, E., Hoeksema, B. W., \& Ponti, M. (2018). The coral-killing sponge Chalinula nematifera as a common substrate generalist in Komodo National Park, Indonesia. Marine Biology Research, 14(8), 827-833.

Turner, J., Hardman, E., Klaus, R., Fagoonee, I., Daby, D., Baghooli, R., \& Persands, S. (2000). The reefs of Mauritius. Coral reef degradation in the Indian Ocean: status report.

Turner, J., \& Klaus, R. (2005). Coral Reefs of the Mascarenes, Western Indian Ocean. Philosophical Transactions: Mathematical, Physical and Engineering Sciences, 363(1826), 229-250.

Tyanova, S., \& Cox, J. (2018). Perseus: A bioinformatics platform for integrative analysis of proteomics data in cancer research. In L. von Stechow (Ed.), Cancer Systems Biology: Methods and Protocols (pp. 133-148). New York, NY: Springer New York.

Tyers, M., \& Mann, M. (2003). From genomics to proteomics. Nature, 422(6928), 193-197.

UniProt Consortium, T. (2018). UniProt: the universal protein knowledgebase. Nucleic Acids Research, 46(5), 2699-2699.

Valentine, M., \& Butler, M. J. (2019). Sponges structure water column characteristics in shallow, tropical coastal ecosystems. Marine Ecology Progress Series, 608, 133-147.

Van Soest, R. W. M., Boury-Esnault, N., Vacelet, J., Dohrmann, M., Erpenbeck, D., De Voogd, N. J., Santodomingo, N., Vanhoorne, B., Kelly, M., \& Hooper, J. N. A. (2012). Global diversity of sponges (Porifera). PLoS ONE, 7(4), e35105.

Venables, W. N., \& Ripley, B. D. (2013). Modern Applied Statistics with S-plus. New York: Springer. 
Vernberg, F. (1982). Environmental adaptation to lagoon systems. Oceanologia Acta, 5(Special Issue), 407-716.

Vicente, J. (2015). Impact of high pCO 2 and warmer temperatures on the process of silica biomineralization in the sponge Mycale grandis. (PhD), University of Maryland, USA.

Vicente, J., Silbiger, N. J., Beckley, B. A., Raczkowski, C. W., \& Hill, R. T. (2015). Impact of high $p \mathrm{CO}_{2}$ and warmer temperatures on the process of silica biomineralization in the sponge Mycale grandis. ICES Journal of Marine Science, 73(3), 704-714.

Vogel, S. (1977). Current-induced flow through living sponges in nature. Proceedings of the National Academy of Sciences of the United States of America, 74(5), 2069-2071.

Wah, H. L. K., Jhuameer-Laulloo, S., Yive, R., Bonnard, I., \& Banigs, B. (2006). Biological and chemical study of some soft corals and sponges collected in Mauritian waters. Western Indian Ocean journal of marine science, 5(2), 115-122.

Wall, C., Rodgers, B., Gobler, C., \& Peterson, B. (2012). Responses of loggerhead sponges Spheciospongia vesparium during harmful cyanobacterial blooms in a sub-tropical lagoon. Marine Ecology Progress Series, 451, 31-43.

Warren, C. R. (2008). Rapid measurement of chlorophylls with a microplate reader. Journal of Plant Nutrition, 31(7), 1321-1332.

Webb, A. E., van Heuven, S. M. A. C., de Bakker, D. M., van Duyl, F. C., Reichart, G.-J., \& de Nooijer, L. J. (2017). Combined effects of experimental acidification and eutrophication on reef sponge bioerosion rates. Frontiers in Marine Science, 4(311), 1-15.

Webster, N. S. (2007). Sponge disease: a global threat? Environmental Microbiology, 9(6), $1363-1375$.

Webster, N. S., Cobb, R. E., \& Negri, A. P. (2008). Temperature thresholds for bacterial symbiosis with a sponge. The ISME Journal, 2(8), 830-842.

Webster, N. S., \& Taylor, M. W. (2012). Marine sponges and their microbial symbionts: love and other relationships. Environmental Microbiology, 14(2), 335-346.

Webster, N. S., Pantile, R., Botté, E., Abdo, D., Andreakis, N., \& Whalan, S. (2013). A complex life cycle in a warming planet: gene expression in thermally stressed sponges. Molecular Ecology, 22(7), 1854-1868.

Weisz, J. B., Lindquist, N., \& Martens, C. S. (2008). Do associated microbial abundances impact marine demosponge pumping rates and tissue densities? Oecologia, 155(2), 367-376.

Weisz, J. B., Massaro, A. J., Ramsby, B. D., \& Hill, M. S. (2010). Zooxanthellar symbionts shape host sponge trophic status through translocation of carbon. Biology Bulletin, 219(3), 189197.

Wendt, P. H., Van Dolah, R. F., \& O'rourke, C. B. (1985). A comparative study of the invertebrate macrofauna associated with seven sponge and coral species collected from the South Atlantic Bight. Journal of the Elisha Mitchell Scientific Society, 101(3), 187-203. 
Wiedenmann, J., D’Angelo, C., Smith, E. G., Hunt, A. N., Legiret, F.-E., Postle, A. D., \& Achterberg, E. P. (2012). Nutrient enrichment can increase the susceptibility of reef corals to bleaching. Nature Climate Change, 3, 160-164.

Wilkinson, C. (1978). Microbial associations in sponges. I. Ecology, physiology and microbial populations of coral reef sponges. Marine Biology, 49(2), 161-167.

Wilkinson, C. R. (1983). Net primary productivity in coral reef sponges. Science, 219(4583), 410-412.

Winton, M., Griffies, S. M., Samuels, B. L., Sarmiento, J. L., \& Frölicher, T. L. (2013). Connecting changing ocean circulation with changing climate. Journal of Climate, 26(7), 2268-2278.

Wiśniewski, J. R., Zougman, A., Nagaraj, N., \& Mann, M. (2009). Universal sample preparation method for proteome analysis. Nature Methods, 6(5), 359-362.

Wisshak, M., Schönberg, C. H. L., Form, A., \& Freiwald, A. (2014). Sponge bioerosion accelerated by ocean acidification across species and latitudes? Helgoland marine research, 68(2), 253-262.

Wulff, J. L. (1991). Asexual fragmentation, genotype success, and population dynamics of erect branching sponges. Journal of Experimental Marine Biology and Ecology, 149(2), 227247.

Wulff, J. L. (1995). Effects of a hurricane on survival and orientation of large erect coral reef sponges. Coral Reefs, 14(1), 55-61.

Wulff, J. L. (2001). Assessing and monitoring coral reef sponges: Why and how? Bulletin of Marine Science, 69(2), 831-846.

Wulff, J. L. (2006a). Rapid diversity and abundance decline in a Caribbean coral reef sponge community. Biological Conservation, 127(2), 167-176.

Wulff, J. L. (2006b). Ecological interactions of marine sponges. Canadian Journal of Zoology, 84(2), 146-166.

Yahel, G., Sharp, J. H., Marie, D., Häse, C., \& Genin, A. (2003). In situ feeding and element removal in the symbiont-bearing sponge Theonella swinhoei: Bulk DOC is the major source for carbon. Limnology and Oceanography, 48(1), 141-149.

Yahel, G., Marie, D., \& Genin, A. (2005). InEx - a direct in situ method to measure filtration rates, nutrition, and metabolism of active suspension feeders. Limnology and Oceanography: Methods, 3(2), 46-58.

Yamashiro, S., Yamakita, Y., Ono, S., \& Matsumura, F. (1998). Fascin, an actin-bundling protein, induces membrane protrusions and increases cell motility of epithelial cells. Molecular biology of the cell, 9(5), 993-1006.

Yeung, Y.-G., \& Stanley, E. R. (2010). Rapid detergent removal from peptide samples with ethyl acetate for mass spectrometry analysis. Current protocols in protein science, Chapter 16, Unit-16.12. 
Yoithapprabhunath, T. R., Nirmal, R. M., Santhadevy, A., Anusushanth, A., Charanya, D., Rojiluke, Sri Chinthu, K. K., \& Yamunadevi, A. (2015). Role of proteomics in physiologic and pathologic conditions of dentistry: Overview. Journal of pharmacy \& bioallied sciences, 7(2), S344-S349.

Yoshimura, T. (2013). Appropriate bottles for storing seawater samples for dissolved organic phosphorus (DOP) analysis: A step toward the development of DOP reference materials. Limnology and Oceanography: Methods, 11(4), 239-246.

Zaneveld, J. R., Burkepile, D. E., Shantz, A. A., Pritchard, C. E., McMinds, R., Payet, J. P., Welsh, R., Correa, A. M. S., Lemoine, N. P., Rosales, S., Fuchs, C., Maynard, J. A., \& Thurber, R. V. (2016). Overfishing and nutrient pollution interact with temperature to disrupt coral reefs down to microbial scales. Nature communications, 7, 11833-11833.

Zea, S. (1994). Patterns of sponge and coral abundance in stressed coral reefs at Santa Marta, Colombian Caribbean. In VanSoest (Ed.), Sponges in time and space: biology, chemistry, paleontology (pp. 257-264). Rotterdam: Balkema.

Zeileis, A., Kleiber, C., \& Jackman, S. (2008). Regression Models for Count Data in R. 2008, 27(8), 25.

Zhang, F., Jonas, L., Lin, H., \& Hill, R. T. (2019). Microbially mediated nutrient cycles in marine sponges. FEMS Microbiology Ecology, 95(11).

Zhang, X., \& Pratt, B. R. (1994). New and extraordinary early cambrian sponge spicule assemblage from China. Geology, 22(1), 43-46. 
Appendices 


\section{Appendix A}

A2.1 - Test for associated cyanobacteria

Sponge samples from each species $(\mathrm{n}=2)$ were collected and stored in $99 \%$ ethanol. DNA extraction was performed using the Qiagen DNeasy Blood \& Tissue kit (Qiagen Group) following the manufacturer's instructions. 16S rRNA of sponge-associated cyanobacteria were amplified by polymerase chain reaction (PCR) using the cyanobacterial-specific primers $\begin{array}{llll}\text { CYA361F (GGAATTTTCCGCAATGGG) } & \text { CYA785R }\end{array}$ (GACTACWGGGGTATCTAATCC) as described by Bayer et al. (2014). The PCR mixture was composed of $0.5 \mu 1$ of both forward and reverse primers, $12.5 \mu 1$ of MyTaq Red Mix, 10.5 $\mu 1$ of DNA/RNA free ultra-pure water and $1 \mu 1$ of template DNA. The PCR conditions were as follows: denaturation at $94{ }^{\circ} \mathrm{C}$ followed by 40 cycles of denaturation at $95{ }^{\circ} \mathrm{C}$ for $10 \mathrm{~min}$ and annealing at $59^{\circ} \mathrm{C}$ for $30 \mathrm{~min}$. PCR was conducted in an ABI 2700 (Applied Biosystems Inc, USA). The DNA quality was tested with a Nanodrop (Implen NP80, Germany) and the PCR products were separated by $1.5 \%$ agarose gel. The gel was stained and visualized under a UV transilluminator (see figure below).

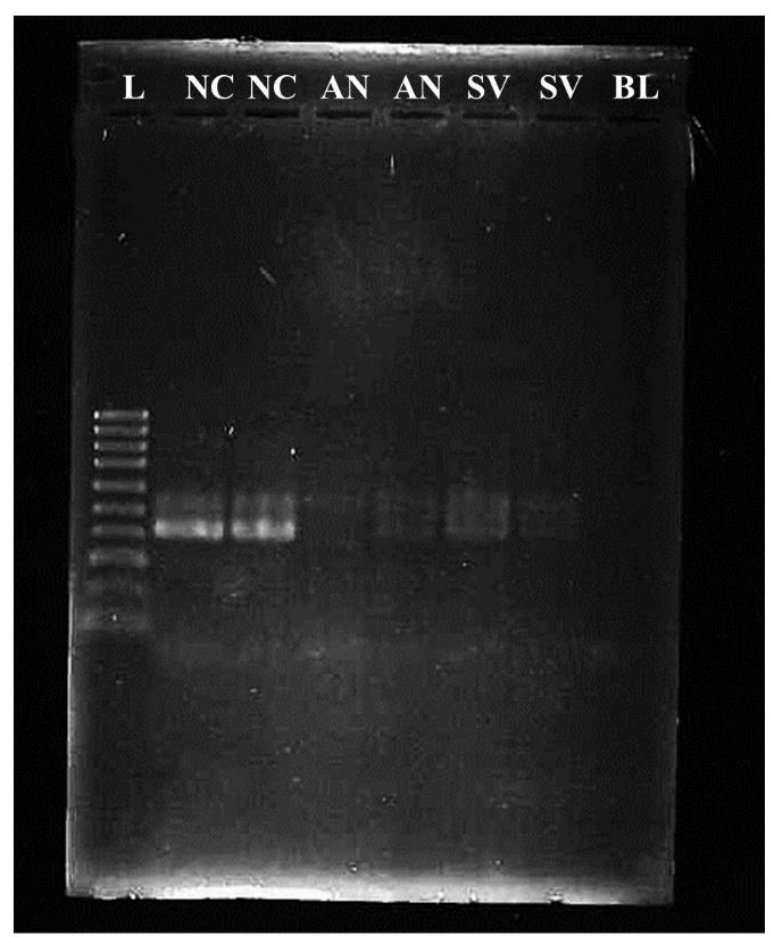

Fig. A2.1. Gel electrophoresis showing PCR products for cyanobacteria from Neopetrosia chaliniformis (NE), Amphimedon navalis (AN) and Spheciospongia vagabunda (SV). L = Standard Ladder, BL = Blank (negative control). 
A2.2 - Sponge pumping rate measurements

Prior to the start of the experiment, the pumping rate was measured for 5 sponges from each species to ensure that sponges had enough food during the experiment. Pumping rate of sponges were measured according to the methods of Massaro et al. (2012) with some minor modifications. A ruler was vertically attached to the bottom of a transparent $2 \mathrm{~L}$ glass beaker. The targeted sponge was carefully transferred into the beaker with the osculum facing upward. Approximately $1 \mathrm{ml}$ of fluorescein dye was carefully injected at the base of the sponge using a syringe and a needle and the distance travelled by the dye was videotaped. In situations where the sponge's osculum was not faced upward in the beaker, the sponge was placed with its osculum facing horizontally. The glass beaker was placed on graph paper and the exhaled horizontal movement of the dye was recorded on video. The $1 \mathrm{~cm}$ squares of the graph paper were used to assess distance travelled by the dye and the exhalation (pumping) rates of the sponges were calculated. The fluorescein dye motion rate $\left(\mathrm{cm} \mathrm{s}^{-1}\right)$ was first calculated by measuring the time taken and distance travelled by the fluorescein dye from the osculum opening to a specific distance on the ruler/graph paper. For sponge pumping rate, the diameter of the oscula of the sponge was measured with a Vernier caliper and the pumping rate was calculated $\left(\mathrm{ml} \mathrm{s}^{-1}\right)$ by multiplying the fluorescein dye motion rates of the sponge by the crosssectional area of the oscula. This number was then extrapolated to the total number of oscula of the sponge (see table below).

Table AS2. Pumping rate estimates of each sponge species calculated prior to the experiment. Values are mean \pm SD.

\begin{tabular}{cc}
\hline Sponge & Estimated pumping rate $\left(\mathbf{m l ~ s}^{-\mathbf{1}}\right)$ \\
\hline Neopetrosia chaliniformis & $0.045(0.02)$ \\
Amphimedon navalis & $0.089(0.04)$ \\
Spheciospongia vagabunda & $0.039(0.01)$ \\
\hline
\end{tabular}


A2.3 - Preliminary experiment trials

The soluble plant fertilizer Thrive (Yates, NPK: 27-5-5-TE) was used as nutrient enrichment agent in the studies of Simister et al. (2012) and Luter et al. (2014). As for Webb et al. (2017), the cell culture medium RPMI 1640 (Roswell Park Memorial Institute) was used as nutrient enrichment agent. However, as none of these enrichment agents were available in Mauritius, experimental trials were conducted prior to the start of the experiment using the sponge Neopetrosia chaliniformis as a proxy to (i) determine the type of fertilizer to be used for the experiment and (ii) estimate the survival tolerance of sponges to increased fertilizer concentrations. Eighteen $N$. chaliniformis sponges were collected, acclimated for approximately one week at $26^{\circ} \mathrm{C}$ and subjected to nitrate treatment (duplicate treatment tanks each containing 3 sponges) of approximately $16 \mu \mathrm{mol}\left(1 \mathrm{mg} \mathrm{l}^{-1}\right)$ for 1 week using three types of nitrate-enriched fertilizers commonly used in Mauritius: granular Agroleaf Power High N (NPK: 31-11-11-TE), Fairway Master mini High N (NPK: 24-05-11- TE) and liquid CAN-17 (NPK:17-0-0-TE). A nitrate concentration of $16 \mu \mathrm{mol}$ was used as this is approximately the maximum nitrate concentration level allowed in Mauritian lagoons based on the coastal water quality guidelines (The Environment Protection Act 2002 of Mauritius). Each aquarium was equipped with an individual oxygen pump and kept at $26^{\circ} \mathrm{C}$ (ambient temperature) using $100 \mathrm{~W}$ aquarium heaters. The sponge survival rates were monitored daily for 8 days. Nitrate-treated (approximately $16 \mu \mathrm{mol}$ ) seawater was regularly replaced at 12 hours interval. Nitrate concentration in the tanks were monitored using a digital pinpoint nitrate monitor (American Marine Inc) and temperature were monitored using a Hobo temperature logger. The survival rates of the sponges with respect to type of fertilizer varied with granular Agroleaf Power High $\mathrm{N}$ being more lethal to the sponges followed by granular Fairway Master mini High N (see Fig. S3.). In contrast, the liquid fertilizer $\mathrm{CAN}-17$ provided a more stable results with no mortalities after 8 day and was therefore used as source of nitrate for the experiment. 


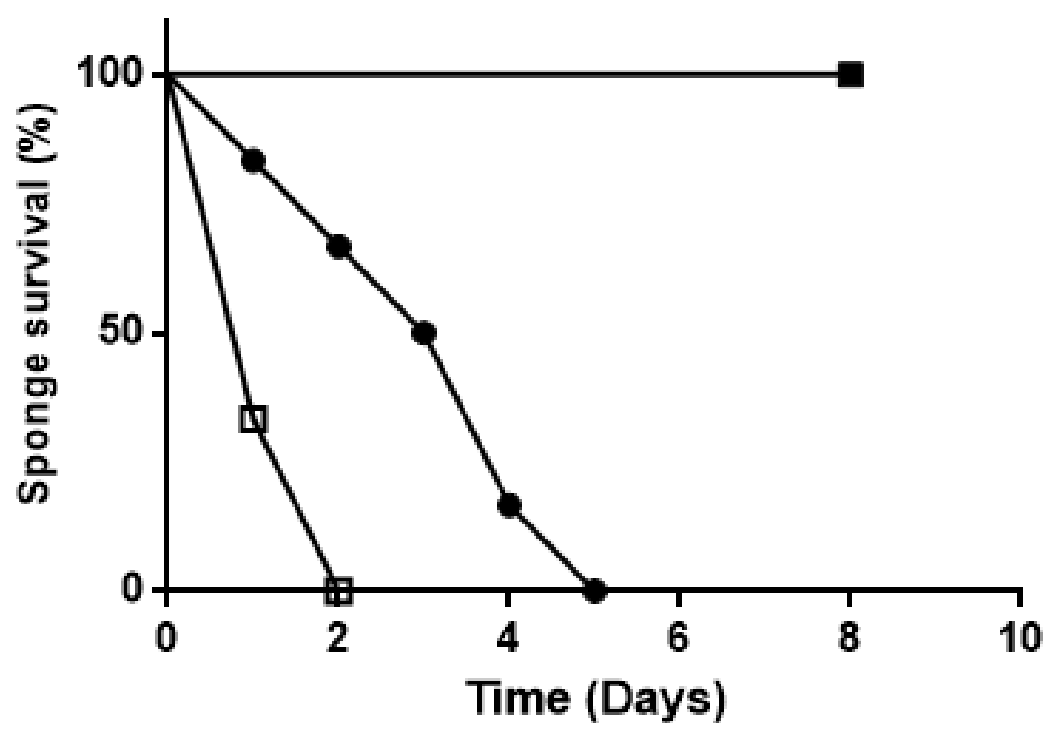

Fig. A2.3 Percentage sponge survival when subjected to granular Agroleaf High Power N (open squares), granular Fairway Master mini High N (filled circles) and soluble liquid CAN17 (filled squares) during experimental trials. 
A

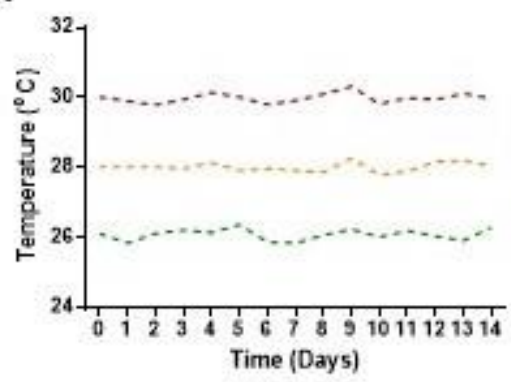

C

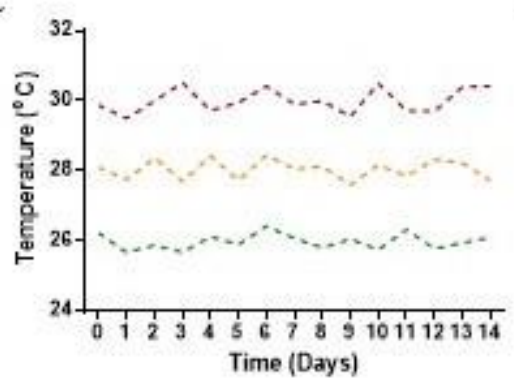

E

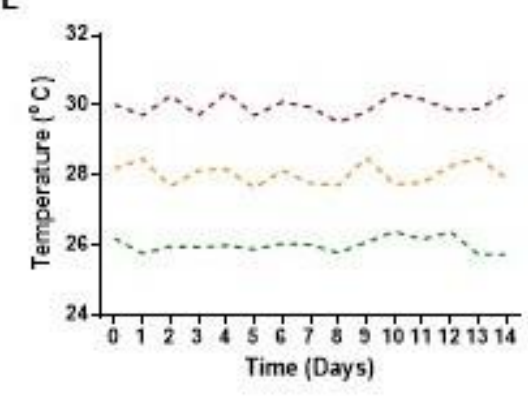

B

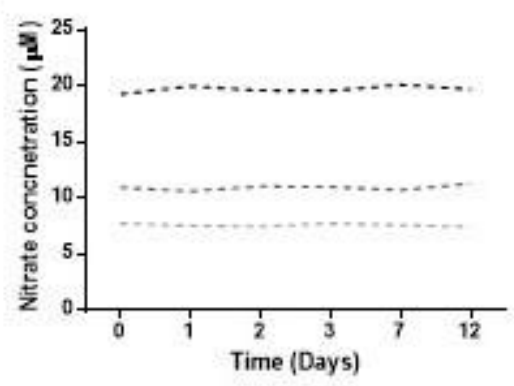

D

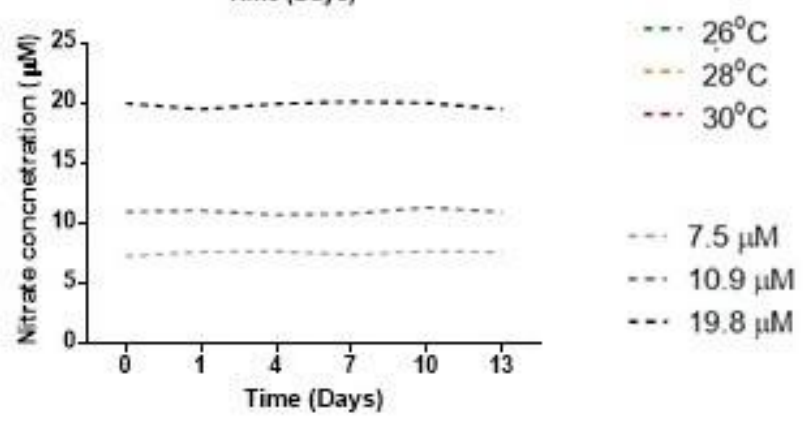

$\mathrm{F}$

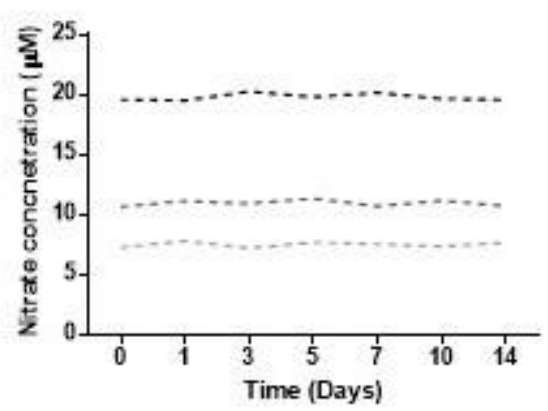

Fig. A2.4. Temperature and Nitrate fluctuations in treatment tanks over time during the experiment for Neopetrosia chaliniformis (A \& B), Amphimedon navalis (C \& D) and Spheciospongia vagabunda (E \& F). Note: Scale on $\mathrm{x}$-axis differ between species. 
Table A2.5a Results of PERMANOVA analysis; the individual and interactive effects of temperature and nitrate on pigment concentrations at T-end. Chl $a=$ Chlorophyll $a$, Chl $b=$ Chlorophyll $b, \mathrm{Chl} c=$ Chlorophyll $c$, Carotenoids $=$ Total Carotenoids. $\mathrm{F}=$ Pseudo-F and $\mathrm{p}=$ p-value from permutational comparisons. Significant p-values are listed in bold.

\begin{tabular}{|c|c|c|c|c|c|c|c|c|c|}
\hline & \multicolumn{3}{|c|}{ Neopetrosia chaliniformis } & \multicolumn{3}{|c|}{ Amphimedon navalis } & \multicolumn{3}{|c|}{ Spheciospongia vagabunda } \\
\hline & $\mathrm{df}$ & Pseudo-F & $\mathrm{p}$ & $\mathrm{df}$ & Pseudo-F & $\mathrm{p}$ & $\mathrm{df}$ & Pseudo-F & $\mathrm{p}$ \\
\hline \multicolumn{10}{|l|}{ Chl $a$} \\
\hline Temp & 2 & 3.656 & 0.038 & 2 & 2.088 & 0.079 & 2 & 11.104 & 0.001 \\
\hline Nitrate & 2 & 0.801 & 0.452 & 2 & 8.059 & 0.052 & 2 & 9.104 & 0.001 \\
\hline Temp x & 4 & 4.567 & 0.001 & 4 & 1.113 & 0.354 & 4 & 11.664 & 0.001 \\
\hline Nitrate & & & & & & & & & \\
\hline \multicolumn{10}{|l|}{ Chl $b$} \\
\hline Temp & 2 & 3.836 & 0.021 & 2 & 0.962 & 0.43 & 2 & 2.491 & 0.047 \\
\hline Nitrate & 2 & 2.108 & 0.132 & 2 & 4.439 & 0.064 & 2 & 0.594 & 0.69 \\
\hline Temp x & 4 & 1.351 & 0.261 & 4 & 0.889 & 0.498 & 4 & 3.464 & 0.002 \\
\hline Nitrate & & & & & & & & & \\
\hline \multicolumn{10}{|l|}{ Chl $c$} \\
\hline Temp & - & - & - & 2 & 1.806 & 0.141 & 2 & 0.722 & 0.64 \\
\hline Nitrate & - & - & - & 2 & 6.300 & 0.062 & 2 & 0.773 & 0.601 \\
\hline Temp x & - & - & - & 4 & 0.457 & 0.847 & 4 & 0.998 & 0.462 \\
\hline Nitrate & & & & & & & & & \\
\hline \multicolumn{10}{|c|}{ Carotenoids } \\
\hline Temp & 2 & 11.677 & 0.001 & 2 & 0.038 & 0.978 & 2 & 18.65 & 0.001 \\
\hline Nitrate & 2 & 8.061 & 0.002 & 2 & 2.235 & 0.116 & 2 & 6.37 & 0.002 \\
\hline Temp x & 4 & 14.687 & 0.001 & 4 & 0.667 & 0.616 & 4 & 14.692 & 0.001 \\
\hline Nitrate & & & & & & & & & \\
\hline
\end{tabular}


Table A2.5b-d Results of permutational post hoc tests for significant PERMANOVA analysis on the combined effects of temperature and nitrate on each species (Table S2a). Chl $a=$ Chlorophyll $a, \mathrm{Chl} b=$ Chlorophyll $b, \mathrm{Chl} c=$ Chlorophyll $c$, Carotenoids = Total Carotenoids. $\mathrm{t}=$ pairwise $\mathrm{t}$-test $; \mathrm{p}=\mathrm{p}$-value. Significant $\mathrm{p}$-values are listed in bold.

b. Neopetrosia chaliniformis

\begin{tabular}{|c|c|c|c|c|}
\hline Chl $a$ & \multicolumn{2}{|c|}{ Temp } & $\mathbf{t}$ & p \\
\hline \multirow{3}{*}{$7.5 \mu \mathrm{mol}$} & $26^{\circ} \mathrm{C}$ & $28^{\circ} \mathrm{C}$ & 0.191 & 0.855 \\
\hline & $26^{\circ} \mathrm{C}$ & $30^{\circ} \mathrm{C}$ & 4.151 & 0.003 \\
\hline & $28^{\circ} \mathrm{C}$ & $30^{\circ} \mathrm{C}$ & 4.891 & 0.004 \\
\hline \multirow{3}{*}{$10.9 \mu \mathrm{mol}$} & $26^{\circ} \mathrm{C}$ & $28^{\circ} \mathrm{C}$ & 1.644 & 0.148 \\
\hline & $26^{\circ} \mathrm{C}$ & $30^{\circ} \mathrm{C}$ & 0.706 & 0.491 \\
\hline & $28^{\circ} \mathrm{C}$ & $30^{\circ} \mathrm{C}$ & 1.648 & 0.131 \\
\hline \multirow{3}{*}{$19.8 \mu \mathrm{mol}$} & $26^{\circ} \mathrm{C}$ & $28^{\circ} \mathrm{C}$ & 2.092 & 0.031 \\
\hline & $26^{\circ} \mathrm{C}$ & $30^{\circ} \mathrm{C}$ & 0.777 & 0.456 \\
\hline & $28^{\circ} \mathrm{C}$ & $30^{\circ} \mathrm{C}$ & 0.533 & 0.596 \\
\hline Chl $b$ & \multicolumn{2}{|c|}{ Temp } & $\mathbf{t}$ & p \\
\hline \multirow{3}{*}{$7.5 \mu \mathrm{mol}$} & $26^{\circ} \mathrm{C}$ & $28^{\circ} \mathrm{C}$ & 0.620 & 0.567 \\
\hline & $26^{\circ} \mathrm{C}$ & $30^{\circ} \mathrm{C}$ & 0.370 & 0.774 \\
\hline & $28^{\circ} \mathrm{C}$ & $30^{\circ} \mathrm{C}$ & 0.421 & 0.671 \\
\hline \multirow{3}{*}{$10.9 \mu \mathrm{mol}$} & $26^{\circ} \mathrm{C}$ & $28^{\circ} \mathrm{C}$ & 4.507 & 0.003 \\
\hline & $26^{\circ} \mathrm{C}$ & $30^{\circ} \mathrm{C}$ & 1.057 & 0.319 \\
\hline & $28^{\circ} \mathrm{C}$ & $30^{\circ} \mathrm{C}$ & 2.415 & 0.031 \\
\hline \multirow{3}{*}{$19.8 \mu \mathrm{mol}$} & $26^{\circ} \mathrm{C}$ & $28^{\circ} \mathrm{C}$ & 1.733 & 0.105 \\
\hline & $26^{\circ} \mathrm{C}$ & $30^{\circ} \mathrm{C}$ & 0.787 & 0.428 \\
\hline & $28^{\circ} \mathrm{C}$ & $30^{\circ} \mathrm{C}$ & 0.792 & 0.431 \\
\hline T Carotenoids & \multicolumn{2}{|c|}{ Temp } & $\mathbf{t}$ & $\mathbf{p}$ \\
\hline \multirow{3}{*}{$7.5 \mu \mathrm{mol}$} & $26^{\circ} \mathrm{C}$ & $28^{\circ} \mathrm{C}$ & 1.725 & 0.105 \\
\hline & $26^{\circ} \mathrm{C}$ & $30^{\circ} \mathrm{C}$ & 3.659 & 0.004 \\
\hline & $28^{\circ} \mathrm{C}$ & $30^{\circ} \mathrm{C}$ & 9.809 & 0.001 \\
\hline \multirow{3}{*}{$10.9 \mu \mathrm{mol}$} & $26^{\circ} \mathrm{C}$ & $28^{\circ} \mathrm{C}$ & 3.416 & 0.003 \\
\hline & $26^{\circ} \mathrm{C}$ & $30^{\circ} \mathrm{C}$ & 3.436 & 0.003 \\
\hline & $28^{\circ} \mathrm{C}$ & $30^{\circ} \mathrm{C}$ & 0.178 & 0.87 \\
\hline \multirow{3}{*}{$19.8 \mu \mathrm{mol}$} & $26^{\circ} \mathrm{C}$ & $28^{\circ} \mathrm{C}$ & 2.937 & 0.016 \\
\hline & $26^{\circ} \mathrm{C}$ & $30^{\circ} \mathrm{C}$ & 4.852 & 0.003 \\
\hline & $28^{\circ} \mathrm{C}$ & $30^{\circ} \mathrm{C}$ & 1.243 & 0.257 \\
\hline
\end{tabular}


c. Amphimedon navalis

\begin{tabular}{|c|c|c|c|c|}
\hline Chl $a$ & \multicolumn{2}{|c|}{ Temp } & $\mathbf{t}$ & $\mathbf{p}$ \\
\hline \multirow{3}{*}{$7.5 \mu \mathrm{mol}$} & $26^{\circ} \mathrm{C}$ & $28^{\circ} \mathrm{C}$ & 0.718 & 0.655 \\
\hline & $26^{\circ} \mathrm{C}$ & $30^{\circ} \mathrm{C}$ & 0.697 & 0.706 \\
\hline & $28^{\circ} \mathrm{C}$ & $30^{\circ} \mathrm{C}$ & 1.093 & 0.286 \\
\hline \multirow{3}{*}{$10.9 \mu \mathrm{mol}$} & $26^{\circ} \mathrm{C}$ & $28^{\circ} \mathrm{C}$ & 1.311 & 0.131 \\
\hline & $26^{\circ} \mathrm{C}$ & $30^{\circ} \mathrm{C}$ & 1.771 & 0.052 \\
\hline & $28^{\circ} \mathrm{C}$ & $30^{\circ} \mathrm{C}$ & 0.510 & 0.824 \\
\hline \multirow{3}{*}{$19.8 \mu \mathrm{mol}$} & $26^{\circ} \mathrm{C}$ & $28^{\circ} \mathrm{C}$ & 1.734 & 0.069 \\
\hline & $26^{\circ} \mathrm{C}$ & $30^{\circ} \mathrm{C}$ & 1.368 & 0.154 \\
\hline & $28^{\circ} \mathrm{C}$ & $30^{\circ} \mathrm{C}$ & 1.004 & 0.332 \\
\hline Chl $b$ & \multicolumn{2}{|c|}{ Temp } & $\mathbf{t}$ & p \\
\hline \multirow{3}{*}{$7.5 \mu \mathrm{mol}$} & $26^{\circ} \mathrm{C}$ & $28^{\circ} \mathrm{C}$ & 1.253 & 0.252 \\
\hline & $26^{\circ} \mathrm{C}$ & $30^{\circ} \mathrm{C}$ & 0.462 & 0.707 \\
\hline & $28^{\circ} \mathrm{C}$ & $30^{\circ} \mathrm{C}$ & 1.208 & 0.29 \\
\hline \multirow{3}{*}{$10.9 \mu \mathrm{mol}$} & $26^{\circ} \mathrm{C}$ & $28^{\circ} \mathrm{C}$ & 0.689 & 0.479 \\
\hline & $26^{\circ} \mathrm{C}$ & $30^{\circ} \mathrm{C}$ & 1.521 & 0.099 \\
\hline & $28^{\circ} \mathrm{C}$ & $30^{\circ} \mathrm{C}$ & 0.807 & 0.566 \\
\hline \multirow{3}{*}{$19.8 \mu \mathrm{mol}$} & $26^{\circ} \mathrm{C}$ & $28^{\circ} \mathrm{C}$ & 0.383 & 0.911 \\
\hline & $26^{\circ} \mathrm{C}$ & $30^{\circ} \mathrm{C}$ & 0.149 & 0.979 \\
\hline & $28^{\circ} \mathrm{C}$ & $30^{\circ} \mathrm{C}$ & 0.470 & 0.84 \\
\hline Chl c & \multicolumn{2}{|c|}{ Temp } & $\mathbf{t}$ & $\mathbf{p}$ \\
\hline \multirow{3}{*}{$7.5 \mu \mathrm{mol}$} & $26^{\circ} \mathrm{C}$ & $28^{\circ} \mathrm{C}$ & 1.233 & 0.215 \\
\hline & $26^{\circ} \mathrm{C}$ & $30^{\circ} \mathrm{C}$ & 0.131 & 0.996 \\
\hline & $28^{\circ} \mathrm{C}$ & $30^{\circ} \mathrm{C}$ & 1.133 & 0.252 \\
\hline \multirow{3}{*}{$10.9 \mu \mathrm{mol}$} & $26^{\circ} \mathrm{C}$ & $28^{\circ} \mathrm{C}$ & 0.468 & 0.74 \\
\hline & $26^{\circ} \mathrm{C}$ & $30^{\circ} \mathrm{C}$ & 0.706 & 0.464 \\
\hline & $28^{\circ} \mathrm{C}$ & $30^{\circ} \mathrm{C}$ & 0.570 & 0.69 \\
\hline \multirow{3}{*}{$19.8 \mu \mathrm{mol}$} & $26^{\circ} \mathrm{C}$ & $28^{\circ} \mathrm{C}$ & 1.274 & 0.184 \\
\hline & $26^{\circ} \mathrm{C}$ & $30^{\circ} \mathrm{C}$ & 0.411 & 0.836 \\
\hline & $28^{\circ} \mathrm{C}$ & $30^{\circ} \mathrm{C}$ & 0.904 & 0.419 \\
\hline T Carotenoids & \multicolumn{2}{|c|}{ Temp } & $\mathbf{t}$ & p \\
\hline \multirow{3}{*}{$7.5 \mu \mathrm{mol}$} & $26^{\circ} \mathrm{C}$ & $28^{\circ} \mathrm{C}$ & 0.675 & 0.51 \\
\hline & $26^{\circ} \mathrm{C}$ & $30^{\circ} \mathrm{C}$ & 0.434 & 0.672 \\
\hline & $28^{\circ} \mathrm{C}$ & $30^{\circ} \mathrm{C}$ & 1.402 & 0.196 \\
\hline \multirow{3}{*}{$10.9 \mu \mathrm{mol}$} & $26^{\circ} \mathrm{C}$ & $28^{\circ} \mathrm{C}$ & 0.649 & 0.529 \\
\hline & $26^{\circ} \mathrm{C}$ & $30^{\circ} \mathrm{C}$ & 0.092 & 0.937 \\
\hline & $28^{\circ} \mathrm{C}$ & $30^{\circ} \mathrm{C}$ & 0.773 & 0.429 \\
\hline \multirow{3}{*}{$19.8 \mu \mathrm{mol}$} & $26^{\circ} \mathrm{C}$ & $28^{\circ} \mathrm{C}$ & 0.176 & 0.878 \\
\hline & $26^{\circ} \mathrm{C}$ & $30^{\circ} \mathrm{C}$ & 0.814 & 0.416 \\
\hline & $28^{\circ} \mathrm{C}$ & $30^{\circ} \mathrm{C}$ & 0.575 & 0.545 \\
\hline
\end{tabular}


d. Spheciospongia vagabunda

\begin{tabular}{|c|c|c|c|c|}
\hline Chl $a$ & \multicolumn{2}{|c|}{ Temp } & $\mathbf{t}$ & $\mathbf{p}$ \\
\hline \multirow{3}{*}{$7.5 \mu \mathrm{mol}$} & $26^{\circ} \mathrm{C}$ & $28^{\circ} \mathrm{C}$ & 2.994 & 0.019 \\
\hline & $26^{\circ} \mathrm{C}$ & $30^{\circ} \mathrm{C}$ & 2.357 & 0.039 \\
\hline & $28^{\circ} \mathrm{C}$ & $30^{\circ} \mathrm{C}$ & 2.800 & 0.028 \\
\hline \multirow{3}{*}{$10.9 \mu \mathrm{mol}$} & $26^{\circ} \mathrm{C}$ & $28^{\circ} \mathrm{C}$ & 1.199 & 0.41 \\
\hline & $26^{\circ} \mathrm{C}$ & $30^{\circ} \mathrm{C}$ & 1.456 & 0.172 \\
\hline & $28^{\circ} \mathrm{C}$ & $30^{\circ} \mathrm{C}$ & 1.379 & 0.454 \\
\hline \multirow{3}{*}{$19.8 \mu \mathrm{mol}$} & $26^{\circ} \mathrm{C}$ & $28^{\circ} \mathrm{C}$ & 0.655 & 0.604 \\
\hline & $26^{\circ} \mathrm{C}$ & $30^{\circ} \mathrm{C}$ & 4.333 & 0.029 \\
\hline & $28^{\circ} \mathrm{C}$ & $30^{\circ} \mathrm{C}$ & 4.155 & 0.028 \\
\hline Chl $b$ & \multicolumn{2}{|c|}{ Temp } & $\mathbf{t}$ & p \\
\hline \multirow{3}{*}{$7.5 \mu \mathrm{mol}$} & $26^{\circ} \mathrm{C}$ & $28^{\circ} \mathrm{C}$ & 1.331 & 0.174 \\
\hline & $26^{\circ} \mathrm{C}$ & $30^{\circ} \mathrm{C}$ & 1.126 & 0.327 \\
\hline & $28^{\circ} \mathrm{C}$ & $30^{\circ} \mathrm{C}$ & 2.752 & 0.122 \\
\hline \multirow{3}{*}{$10.9 \mu \mathrm{mol}$} & $26^{\circ} \mathrm{C}$ & $28^{\circ} \mathrm{C}$ & 0.778 & 0.54 \\
\hline & $26^{\circ} \mathrm{C}$ & $30^{\circ} \mathrm{C}$ & 1.570 & 0.23 \\
\hline & $28^{\circ} \mathrm{C}$ & $30^{\circ} \mathrm{C}$ & 0.966 & 0.394 \\
\hline \multirow{3}{*}{$19.8 \mu \mathrm{mol}$} & $26^{\circ} \mathrm{C}$ & $28^{\circ} \mathrm{C}$ & 2.691 & 0.015 \\
\hline & $26^{\circ} \mathrm{C}$ & $30^{\circ} \mathrm{C}$ & 3.557 & 0.031 \\
\hline & $28^{\circ} \mathrm{C}$ & $30^{\circ} \mathrm{C}$ & 3.022 & 0.035 \\
\hline Chl $c$ & \multicolumn{2}{|c|}{ Temp } & $\mathbf{t}$ & p \\
\hline \multirow{3}{*}{$7.5 \mu \mathrm{mol}$} & $26^{\circ} \mathrm{C}$ & $28^{\circ} \mathrm{C}$ & 1.362 & 0.06 \\
\hline & $26^{\circ} \mathrm{C}$ & $30^{\circ} \mathrm{C}$ & 0.675 & 0.932 \\
\hline & $28^{\circ} \mathrm{C}$ & $30^{\circ} \mathrm{C}$ & 2.025 & 0.056 \\
\hline \multirow{3}{*}{$10.9 \mu \mathrm{mol}$} & $26^{\circ} \mathrm{C}$ & $28^{\circ} \mathrm{C}$ & 0.603 & 0.634 \\
\hline & $26^{\circ} \mathrm{C}$ & $30^{\circ} \mathrm{C}$ & 7.654 & 0.022 \\
\hline & $28^{\circ} \mathrm{C}$ & $30^{\circ} \mathrm{C}$ & 1.315 & 0.421 \\
\hline \multirow{3}{*}{$19.8 \mu \mathrm{mol}$} & $26^{\circ} \mathrm{C}$ & $28^{\circ} \mathrm{C}$ & 0.158 & 0.909 \\
\hline & $26^{\circ} \mathrm{C}$ & $30^{\circ} \mathrm{C}$ & 0.999 & 0.385 \\
\hline & $28^{\circ} \mathrm{C}$ & $30^{\circ} \mathrm{C}$ & 0.990 & 0.486 \\
\hline T Carotenoids & \multicolumn{2}{|c|}{ Temp } & $\mathbf{t}$ & p \\
\hline \multirow{3}{*}{$7.5 \mu \mathrm{mol}$} & $26^{\circ} \mathrm{C}$ & $28^{\circ} \mathrm{C}$ & 5.026 & 0.004 \\
\hline & $26^{\circ} \mathrm{C}$ & $30^{\circ} \mathrm{C}$ & 1.959 & 0.065 \\
\hline & $28^{\circ} \mathrm{C}$ & $30^{\circ} \mathrm{C}$ & 2.917 & 0.028 \\
\hline \multirow{3}{*}{$10.9 \mu \mathrm{mol}$} & $26^{\circ} \mathrm{C}$ & $28^{\circ} \mathrm{C}$ & 0.839 & 0.423 \\
\hline & $26^{\circ} \mathrm{C}$ & $30^{\circ} \mathrm{C}$ & 0.636 & 0.546 \\
\hline & $28^{\circ} \mathrm{C}$ & $30^{\circ} \mathrm{C}$ & 1.023 & 0.439 \\
\hline \multirow{3}{*}{$19.8 \mu \mathrm{mol}$} & $26^{\circ} \mathrm{C}$ & $28^{\circ} \mathrm{C}$ & 0.357 & 0.722 \\
\hline & $26^{\circ} \mathrm{C}$ & $30^{\circ} \mathrm{C}$ & 15.686 & 0.029 \\
\hline & $28^{\circ} \mathrm{C}$ & $30^{\circ} \mathrm{C}$ & 7.678 & $\mathbf{0 . 0 2 7}$ \\
\hline
\end{tabular}


Table A2.6a Results of temperature * nitrate post hoc pairwise comparisons test (with the sequential Sidak correction applied) from General Linear Mixed Models for change in buoyant weight. Note: Only significant effects of treatments at T-end are reported. Significant p-values are reported in bold.

\begin{tabular}{|c|c|c|c|c|c|c|c|c|c|}
\hline Nitrate & \multicolumn{2}{|c|}{ Temp } & $\begin{array}{l}\text { Contrast } \\
\text { Estimate }\end{array}$ & $\begin{array}{c}\text { Std. } \\
\text { Error }\end{array}$ & $\mathbf{t}$ & df & $P$ & $\begin{array}{c}\text { CI } \\
\text { (lower) }\end{array}$ & $\begin{array}{c}\text { CI } \\
\text { (upper) }\end{array}$ \\
\hline \multicolumn{10}{|c|}{ Neopetrosia chaliniformis } \\
\hline \multirow{3}{*}{7.5} & $28^{\circ} \mathrm{C}$ & $26^{\circ} \mathrm{C}$ & 0.001 & 0.002 & 0.764 & 180 & 0.446 & -0.002 & 0.004 \\
\hline & $30^{\circ} \mathrm{C}$ & $26^{\circ} \mathrm{C}$ & 0.014 & 0.002 & 8.705 & 180 & $<0.001$ & 0.01 & 0.017 \\
\hline & $30^{\circ} \mathrm{C}$ & $28^{\circ} \mathrm{C}$ & 0.012 & 0.002 & 7.942 & 180 & $<0.001$ & 0.009 & 0.016 \\
\hline \multirow{3}{*}{10.9} & $28^{\circ} \mathrm{C}$ & $26^{\circ} \mathrm{C}$ & 0.007 & 0.002 & 4.582 & 180 & $<0.001$ & 0.004 & 0.011 \\
\hline & $30^{\circ} \mathrm{C}$ & $26^{\circ} \mathrm{C}$ & 0.009 & 0.002 & 5.804 & 180 & $<0.001$ & -0.001 & 0.005 \\
\hline & $30^{\circ} \mathrm{C}$ & $28^{\circ} \mathrm{C}$ & 0.002 & 0.002 & 1.222 & 180 & 0.223 & -0.001 & 0.005 \\
\hline \multirow{3}{*}{19.8} & $28^{\circ} \mathrm{C}$ & $26^{\circ} \mathrm{C}$ & 0.008 & 0.002 & 5.193 & 180 & $<0.001$ & 0.005 & 0.011 \\
\hline & $30^{\circ} \mathrm{C}$ & $26^{\circ} \mathrm{C}$ & 0.016 & 0.002 & 10.53 & 180 & $<0.001$ & 0.013 & 0.02 \\
\hline & $30^{\circ} \mathrm{C}$ & $28^{\circ} \mathrm{C}$ & 0.008 & 0.002 & 5.345 & 180 & $<0.001$ & 0.005 & 0.012 \\
\hline \multicolumn{10}{|c|}{ Amphimedon navalis } \\
\hline \multirow{3}{*}{7.5} & $28^{\circ} \mathrm{C}$ & $26^{\circ} \mathrm{C}$ & 0.33 & 0.061 & 0.546 & 205 & 0.586 & -0.087 & 0.154 \\
\hline & $30^{\circ} \mathrm{C}$ & $26^{\circ} \mathrm{C}$ & 0.25 & 0.061 & 4.093 & 205 & $<0.001$ & 0.103 & 0.397 \\
\hline & $30^{\circ} \mathrm{C}$ & $28^{\circ} \mathrm{C}$ & 0.217 & 0.061 & 3.547 & 205 & 0.001 & 0.079 & 0.354 \\
\hline \multirow{3}{*}{10.9} & $28^{\circ} \mathrm{C}$ & $26^{\circ} \mathrm{C}$ & 0.283 & 0.061 & 4.639 & 205 & $<0.001$ & 0.146 & 0.421 \\
\hline & $30^{\circ} \mathrm{C}$ & $26^{\circ} \mathrm{C}$ & 0.367 & 0.061 & 6.003 & 205 & $<0.001$ & 0.22 & 0.514 \\
\hline & $30^{\circ} \mathrm{C}$ & $28^{\circ} \mathrm{C}$ & 0.083 & 0.061 & 1.364 & 205 & 0.174 & -0.037 & 0.204 \\
\hline \multirow{3}{*}{19.8} & $28^{\circ} \mathrm{C}$ & $26^{\circ} \mathrm{C}$ & 0.25 & 0.061 & 4.093 & 205 & $<0.001$ & 0.112 & 0.388 \\
\hline & $30^{\circ} \mathrm{C}$ & $26^{\circ} \mathrm{C}$ & 0.367 & 0.061 & 6.003 & 205 & $<0.001$ & 0.22 & 0.514 \\
\hline & $30^{\circ} \mathrm{C}$ & $28^{\circ} \mathrm{C}$ & 0.117 & 0.061 & 1.910 & 205 & 0.058 & -0.004 & 0.237 \\
\hline \multicolumn{10}{|c|}{ Spheciospongia vagabunda } \\
\hline \multirow{3}{*}{7.5} & $28^{\circ} \mathrm{C}$ & $26^{\circ} \mathrm{C}$ & 0.042 & 0.005 & 7.577 & 85 & $<0.001$ & 0.028 & 0.055 \\
\hline & $30^{\circ} \mathrm{C}$ & $26^{\circ} \mathrm{C}$ & 0.026 & 0.005 & 4.677 & 85 & $<0.001$ & 0.013 & 0.038 \\
\hline & $30^{\circ} \mathrm{C}$ & $28^{\circ} \mathrm{C}$ & -0.016 & 0.005 & -2.9 & 85 & 0.005 & -0.027 & -0.005 \\
\hline \multirow[t]{3}{*}{10.9} & $28^{\circ} \mathrm{C}$ & $26^{\circ} \mathrm{C}$ & -0.016 & 0.005 & -2.835 & 85 & 0.017 & -0.029 & -0.002 \\
\hline & $30^{\circ} \mathrm{C}$ & $26^{\circ} \mathrm{C}$ & -0.005 & 0.005 & -0.861 & 85 & 0.392 & -0.016 & 0.006 \\
\hline & $30^{\circ} \mathrm{C}$ & $28^{\circ} \mathrm{C}$ & 0.011 & 0.005 & 1.974 & 85 & 0.101 & -0.002 & 0.023 \\
\hline 19.8 & $28^{\circ} \mathrm{C}$ & $26^{\circ} \mathrm{C}$ & 0.036 & 0.005 & 6.637 & 85 & $<0.001$ & 0.026 & 0.047 \\
\hline
\end{tabular}


Table A2.6b Results of temperature * nitrate post hoc pairwise comparisons test (with the sequential Sidak correction applied) from General Linear Mixed Models for effective quantum yield. Note: Only significant effects of treatments at T-end are reported. Significant p-values are reported in bold.

\begin{tabular}{|c|c|c|c|c|c|c|c|c|c|}
\hline Nitrate & \multicolumn{2}{|c|}{ Temp } & $\begin{array}{l}\text { Contrast } \\
\text { Estimate }\end{array}$ & $\begin{array}{l}\text { Std. } \\
\text { Error }\end{array}$ & $\mathbf{t}$ & df & $P$ & $\underset{\text { (lower) }}{\text { CI }}$ & $\begin{array}{c}\text { CI } \\
\text { (upper } \\
\text { ) }\end{array}$ \\
\hline \multicolumn{10}{|c|}{ Neopetrosia chaliniformis } \\
\hline \multirow{3}{*}{7.5} & $28^{\circ} \mathrm{C}$ & $26^{\circ} \mathrm{C}$ & -0.03 & 0.013 & -2.372 & 81 & 0.04 & -0.06 & -0.001 \\
\hline & $30^{\circ} \mathrm{C}$ & $26^{\circ} \mathrm{C}$ & -0.061 & 0.013 & -4.724 & 81 & $<0.001$ & -0.092 & -0.029 \\
\hline & $30^{\circ} \mathrm{C}$ & $28^{\circ} \mathrm{C}$ & -0.03 & 0.013 & -2.352 & 81 & 0.04 & -0.059 & -0.001 \\
\hline \multirow{3}{*}{10.9} & $28^{\circ} \mathrm{C}$ & $26^{\circ} \mathrm{C}$ & -0.04 & 0.013 & -3.102 & 81 & 0.005 & -0.069 & -0.011 \\
\hline & $30^{\circ} \mathrm{C}$ & $26^{\circ} \mathrm{C}$ & -0.073 & 0.013 & -5.725 & 81 & $<0.001$ & -0.105 & -0.042 \\
\hline & $30^{\circ} \mathrm{C}$ & $28^{\circ} \mathrm{C}$ & -0.034 & 0.013 & -2.622 & 81 & 0.01 & -0.059 & -0.008 \\
\hline \multirow{3}{*}{19.8} & $28^{\circ} \mathrm{C}$ & $26^{\circ} \mathrm{C}$ & -0.06 & 0.013 & -4.674 & 81 & $<0.001$ & -0.089 & -0.031 \\
\hline & $30^{\circ} \mathrm{C}$ & $26^{\circ} \mathrm{C}$ & -0.089 & 0.013 & -6.922 & 81 & $<0.001$ & -0.12 & -0.058 \\
\hline & $30^{\circ} \mathrm{C}$ & $28^{\circ} \mathrm{C}$ & -0.029 & 0.013 & -2.247 & 81 & 0.027 & -0.054 & -0.003 \\
\hline \multicolumn{10}{|c|}{ Spheciospongia vagabunda } \\
\hline \multirow{3}{*}{7.5} & $28^{\circ} \mathrm{C}$ & $26^{\circ} \mathrm{C}$ & -0.009 & 0.008 & -1.107 & 240 & 0.270 & -0.026 & 0.007 \\
\hline & $30^{\circ} \mathrm{C}$ & $26^{\circ} \mathrm{C}$ & -0.095 & 0.008 & -11.41 & 240 & $<0.001$ & -0.115 & -0.075 \\
\hline & $30^{\circ} \mathrm{C}$ & $28^{\circ} \mathrm{C}$ & -0.086 & 0.008 & -10.31 & 240 & $<0.001$ & -0.104 & -0.067 \\
\hline \multirow[t]{3}{*}{10.9} & $28^{\circ} \mathrm{C}$ & $26^{\circ} \mathrm{C}$ & -0.023 & 0.008 & -2.744 & 240 & 0.007 & -0.039 & -0.006 \\
\hline & $30^{\circ} \mathrm{C}$ & $26^{\circ} \mathrm{C}$ & -0.102 & 0.008 & -12.27 & 240 & $<0.001$ & -0.122 & -0.082 \\
\hline & $30^{\circ} \mathrm{C}$ & $28^{\circ} \mathrm{C}$ & -0.079 & 0.008 & -9.527 & 240 & $<0.001$ & -0.098 & -0.06 \\
\hline 19.8 & $28^{\circ} \mathrm{C}$ & $26^{\circ} \mathrm{C}$ & -0.033 & 0.008 & -4.007 & 240 & $<0.001$ & -0.05 & -0.017 \\
\hline
\end{tabular}


Table A2.6c Results of temperature * nitrate post hoc pairwise comparisons test (with the sequential Sidak correction applied) from General Linear Mixed Models for gross photosynthesis rate. Note: Only significant effects of treatments at T-end are reported. Significant p-values are reported in bold.

\begin{tabular}{|c|c|c|c|c|c|c|c|c|c|}
\hline Nitrate & Temp & & $\begin{array}{l}\text { Contrast } \\
\text { Estimate } \\
\end{array}$ & $\begin{array}{l}\text { Std. } \\
\text { Error }\end{array}$ & $\mathbf{t}$ & df & $P$ & $\begin{array}{l}\text { CI } \\
\text { (lower) }\end{array}$ & $\begin{array}{l}\text { CI } \\
\text { (upper) }\end{array}$ \\
\hline \multicolumn{10}{|c|}{ Neopetrosia chaliniformis } \\
\hline \multirow{3}{*}{7.5} & $28^{\circ} \mathrm{C}$ & $26^{\circ} \mathrm{C}$ & -0.001 & 0.003 & -0.079 & 45 & 0.937 & -0.006 & 0.006 \\
\hline & $30^{\circ} \mathrm{C}$ & $26^{\circ} \mathrm{C}$ & 0.002 & 0.003 & 0.545 & 45 & 0.900 & -0.005 & 0.009 \\
\hline & $30^{\circ} \mathrm{C}$ & $28^{\circ} \mathrm{C}$ & 0.002 & 0.003 & 0.624 & 45 & 0.900 & -0.005 & 0.009 \\
\hline \multirow{3}{*}{10.9} & $28^{\circ} \mathrm{C}$ & $26^{\circ} \mathrm{C}$ & 0.004 & 0.003 & 1.471 & 45 & 0.382 & -0.003 & 0.012 \\
\hline & $30^{\circ} \mathrm{C}$ & $26^{\circ} \mathrm{C}$ & 0.004 & 0.003 & 1.305 & 45 & 0.382 & -0.003 & 0.011 \\
\hline & $30^{\circ} \mathrm{C}$ & $28^{\circ} \mathrm{C}$ & -0.001 & 0.003 & -0.166 & 45 & 0.869 & -0.006 & 0.005 \\
\hline \multirow{3}{*}{19.8} & $28^{\circ} \mathrm{C}$ & $26^{\circ} \mathrm{C}$ & 0.009 & 0.003 & 3.141 & 45 & 0.009 & 0.002 & 0.016 \\
\hline & $30^{\circ} \mathrm{C}$ & $26^{\circ} \mathrm{C}$ & 0.008 & 0.003 & 2.582 & 45 & 0.026 & 0.001 & 0.014 \\
\hline & $30^{\circ} \mathrm{C}$ & $28^{\circ} \mathrm{C}$ & -0.002 & 0.003 & -0.559 & 45 & 0.579 & -0.008 & 0.004 \\
\hline \multicolumn{10}{|c|}{ Spheciospongia vagabunda } \\
\hline \multirow{3}{*}{7.5} & $28^{\circ} \mathrm{C}$ & $26^{\circ} \mathrm{C}$ & 0.002 & 0.003 & 0.716 & 240 & 0.475 & -0.003 & 0.007 \\
\hline & $30^{\circ} \mathrm{C}$ & $26^{\circ} \mathrm{C}$ & -0.010 & 0.003 & -3.830 & 240 & $<0.001$ & -0.016 & -0.004 \\
\hline & $30^{\circ} \mathrm{C}$ & $28^{\circ} \mathrm{C}$ & -0.008 & 0.003 & -3.114 & 240 & 0.004 & -0.014 & -0.002 \\
\hline \multirow{3}{*}{10.9} & $28^{\circ} \mathrm{C}$ & $26^{\circ} \mathrm{C}$ & -0.005 & 0.003 & -1.789 & 240 & 0.144 & -0.010 & 0.001 \\
\hline & $30^{\circ} \mathrm{C}$ & $26^{\circ} \mathrm{C}$ & -0.009 & 0.003 & -3.427 & 240 & $<0.001$ & -0.015 & -0.003 \\
\hline & $30^{\circ} \mathrm{C}$ & $28^{\circ} \mathrm{C}$ & -0.004 & 0.003 & -1.638 & 240 & 0.144 & -0.010 & 0.001 \\
\hline 19.8 & $28^{\circ} \mathrm{C}$ & $26^{\circ} \mathrm{C}$ & -0.008 & 0.003 & -3.115 & 240 & 0.002 & -0.013 & -0.003 \\
\hline
\end{tabular}


Table A2.6d Results of temperature * nitrate post hoc pairwise comparisons test (with the sequential Sidak correction applied) from General Linear Mixed Models for respiration rate. Note: Only significant effects of treatments at T-end are reported. Significant p-values are reported in bold.

\begin{tabular}{|c|c|c|c|c|c|c|c|c|c|}
\hline Nitrate & \multicolumn{2}{|c|}{ Temp } & $\begin{array}{l}\text { Contrast } \\
\text { Estimate }\end{array}$ & $\begin{array}{l}\text { Std. } \\
\text { Error }\end{array}$ & $\mathbf{t}$ & df & $\boldsymbol{P}$ & $\begin{array}{c}\text { CI } \\
\text { (lower) }\end{array}$ & $\begin{array}{c}\text { CI } \\
\text { (upper) }\end{array}$ \\
\hline \multicolumn{10}{|c|}{ Neopetrosia chaliniformis } \\
\hline \multirow{3}{*}{7.5} & $28^{\circ} \mathrm{C}$ & $26^{\circ} \mathrm{C}$ & 0.003 & 0.002 & 1.081 & 40 & 0.286 & -0.002 & 0.008 \\
\hline & $30^{\circ} \mathrm{C}$ & $26^{\circ} \mathrm{C}$ & 0.009 & 0.002 & 3.582 & 40 & 0.003 & 0.003 & 0.015 \\
\hline & $30^{\circ} \mathrm{C}$ & $28^{\circ} \mathrm{C}$ & 0.006 & 0.002 & 2.501 & 40 & 0.033 & 0.001 & 0.012 \\
\hline \multirow{3}{*}{10.9} & $28^{\circ} \mathrm{C}$ & $26^{\circ} \mathrm{C}$ & 0.009 & 0.002 & 3.496 & 40 & 0.002 & 0.003 & 0.014 \\
\hline & $30^{\circ} \mathrm{C}$ & $26^{\circ} \mathrm{C}$ & 0.014 & 0.002 & 5.568 & 40 & $<0.001$ & 0.008 & 0.02 \\
\hline & $30^{\circ} \mathrm{C}$ & $28^{\circ} \mathrm{C}$ & 0.005 & 0.002 & 2.072 & 40 & 0.045 & 0.001 & 0.01 \\
\hline \multirow{3}{*}{19.8} & $28^{\circ} \mathrm{C}$ & $26^{\circ} \mathrm{C}$ & 0.012 & 0.002 & 4.685 & 40 & $<0.001$ & 0.005 & 0.018 \\
\hline & $30^{\circ} \mathrm{C}$ & $26^{\circ} \mathrm{C}$ & 0.01 & 0.002 & 4.1 & 40 & $<0.001$ & 0.004 & 0.016 \\
\hline & $30^{\circ} \mathrm{C}$ & $28^{\circ} \mathrm{C}$ & -0.001 & 0.002 & -0.586 & 40 & 0.561 & -0.004 & 0.006 \\
\hline \multicolumn{10}{|c|}{ Amphimedon navalis } \\
\hline \multirow{3}{*}{7.5} & $28^{\circ} \mathrm{C}$ & $26^{\circ} \mathrm{C}$ & 0.004 & 0.014 & 0291 & 18 & 0.774 & -0.025 & 0.033 \\
\hline & $30^{\circ} \mathrm{C}$ & $26^{\circ} \mathrm{C}$ & 0.027 & 0.014 & 1.950 & 18 & 0.187 & -0.009 & 0.064 \\
\hline & $30^{\circ} \mathrm{C}$ & $28^{\circ} \mathrm{C}$ & 0.023 & 0.014 & 1.658 & 18 & 0.216 & -0.011 & 0.057 \\
\hline \multirow{3}{*}{10.9} & $28^{\circ} \mathrm{C}$ & $26^{\circ} \mathrm{C}$ & 0.057 & 0.014 & 4.099 & 18 & 0.001 & 0.023 & 0.091 \\
\hline & $30^{\circ} \mathrm{C}$ & $26^{\circ} \mathrm{C}$ & 0.071 & 0.014 & 5.1 & 18 & $<0.001$ & 0.034 & 0.108 \\
\hline & $30^{\circ} \mathrm{C}$ & $28^{\circ} \mathrm{C}$ & 0.014 & 0.012 & 1.001 & 18 & 0.330 & -0.015 & 0.043 \\
\hline \multirow{3}{*}{19.8} & $28^{\circ} \mathrm{C}$ & $26^{\circ} \mathrm{C}$ & 0.045 & 0.014 & 3.24 & 18 & 0.009 & 0.011 & 0.079 \\
\hline & $30^{\circ} \mathrm{C}$ & $26^{\circ} \mathrm{C}$ & 0.057 & 0.014 & 4.096 & 18 & 0.002 & 0.02 & 0.094 \\
\hline & $30^{\circ} \mathrm{C}$ & $28^{\circ} \mathrm{C}$ & 0.012 & 0.014 & 0.856 & 18 & 0.403 & -0.017 & 0.041 \\
\hline \multicolumn{10}{|c|}{ Spheciospongia vagabunda } \\
\hline \multirow{3}{*}{7.5} & $28^{\circ} \mathrm{C}$ & $26^{\circ} \mathrm{C}$ & 0.003 & 0.002 & 2.222 & 240 & 0.027 & 0.001 & 0.007 \\
\hline & $30^{\circ} \mathrm{C}$ & $26^{\circ} \mathrm{C}$ & 0.008 & 0.002 & 5.373 & 240 & $<0.001$ & 0.005 & 0.012 \\
\hline & $30^{\circ} \mathrm{C}$ & $28^{\circ} \mathrm{C}$ & 0.005 & 0.002 & 3.152 & 240 & 0.004 & 0.001 & 0.008 \\
\hline \multirow{3}{*}{10.9} & $28^{\circ} \mathrm{C}$ & $26^{\circ} \mathrm{C}$ & 0.005 & 0.002 & 2.982 & 240 & 0.006 & 0.001 & 0.008 \\
\hline & $30^{\circ} \mathrm{C}$ & $26^{\circ} \mathrm{C}$ & 0.009 & 0.002 & 5.687 & 240 & $<0.001$ & 0.005 & 0.013 \\
\hline & $30^{\circ} \mathrm{C}$ & $28^{\circ} \mathrm{C}$ & 0.004 & 0.002 & 2.706 & 240 & 0.007 & 0.001 & 0.007 \\
\hline 19.8 & $28^{\circ} \mathrm{C}$ & $26^{\circ} \mathrm{C}$ & 0.004 & 0.002 & 2.727 & 240 & 0.007 & 0.001 & 0.007 \\
\hline
\end{tabular}


Table A2.6e Results of temperature * nitrate post hoc pairwise comparisons test (with the sequential Sidak correction applied) from General Linear Mixed Models for P:R ratio. Note: Only significant effects of treatments at T-end are reported. Significant p-values are reported in bold.

\begin{tabular}{|c|c|c|c|c|c|c|c|c|c|}
\hline Nitrate & \multicolumn{2}{|c|}{ Temp } & $\begin{array}{l}\text { Contrast } \\
\text { Estimate }\end{array}$ & $\begin{array}{l}\text { Std. } \\
\text { Error }\end{array}$ & $\mathbf{t}$ & df & $P$ & $\begin{array}{c}\text { CI } \\
\text { (lower) }\end{array}$ & $\begin{array}{c}\text { CI } \\
\text { (upper) }\end{array}$ \\
\hline \multicolumn{10}{|c|}{ Neopetrosia chaliniformis } \\
\hline \multirow{3}{*}{7.5} & $28^{\circ} \mathrm{C}$ & $26^{\circ} \mathrm{C}$ & -0.005 & 0.022 & -0.237 & 23 & 0.815 & -0.050 & 0.040 \\
\hline & $30^{\circ} \mathrm{C}$ & $26^{\circ} \mathrm{C}$ & -0.084 & 0.022 & -3.888 & 23 & 0.002 & -0.140 & -0.029 \\
\hline & $30^{\circ} \mathrm{C}$ & $28^{\circ} \mathrm{C}$ & -0.079 & 0.022 & -3.652 & 23 & 0.003 & -0.131 & -0.027 \\
\hline \multirow{3}{*}{10.9} & $28^{\circ} \mathrm{C}$ & $26^{\circ} \mathrm{C}$ & -0.089 & 0.022 & -4.099 & 23 & 0.001 & -0.141 & -0.037 \\
\hline & $30^{\circ} \mathrm{C}$ & $26^{\circ} \mathrm{C}$ & -0.141 & 0.022 & -6.490 & 23 & $<0.001$ & -0.197 & -0.085 \\
\hline & $30^{\circ} \mathrm{C}$ & $28^{\circ} \mathrm{C}$ & -0.052 & 0.022 & -2.391 & 23 & 0.025 & -0.097 & -0.007 \\
\hline \multirow{3}{*}{19.8} & $28^{\circ} \mathrm{C}$ & $26^{\circ} \mathrm{C}$ & -0.081 & 0.022 & -3.709 & 23 & 0.002 & -0.132 & -0.029 \\
\hline & $30^{\circ} \mathrm{C}$ & $26^{\circ} \mathrm{C}$ & -0.087 & 0.022 & -3.988 & 23 & 0.002 & -0.142 & -0.031 \\
\hline & $30^{\circ} \mathrm{C}$ & $28^{\circ} \mathrm{C}$ & -0.006 & 0.022 & -0.279 & 23 & 0.783 & -0.051 & 0.039 \\
\hline \multicolumn{10}{|c|}{ Spheciospongia vagabunda } \\
\hline \multirow{3}{*}{7.5} & $28^{\circ} \mathrm{C}$ & $26^{\circ} \mathrm{C}$ & -0.019 & 0.007 & -2.888 & 240 & 0.004 & -0.032 & -0.006 \\
\hline & $30^{\circ} \mathrm{C}$ & $26^{\circ} \mathrm{C}$ & -0.058 & 0.007 & -8.750 & 240 & $<0.001$ & -0.075 & -0.042 \\
\hline & $30^{\circ} \mathrm{C}$ & $28^{\circ} \mathrm{C}$ & -0.039 & 0.007 & -5.862 & 240 & $<0.001$ & -0.054 & -0.024 \\
\hline \multirow{3}{*}{10.9} & $28^{\circ} \mathrm{C}$ & $26^{\circ} \mathrm{C}$ & -0.032 & 0.007 & -4.719 & 240 & $<0.001$ & -0.047 & -0.017 \\
\hline & $30^{\circ} \mathrm{C}$ & $26^{\circ} \mathrm{C}$ & -0.058 & 0.007 & -8.738 & 240 & $<0.001$ & -0.074 & -0.042 \\
\hline & $30^{\circ} \mathrm{C}$ & $28^{\circ} \mathrm{C}$ & -0.027 & 0.007 & -4.019 & 240 & $<0.001$ & -0.040 & -0.014 \\
\hline 19.8 & $28^{\circ} \mathrm{C}$ & $26^{\circ} \mathrm{C}$ & -0.038 & 0.007 & -5.718 & 240 & $<0.001$ & -0.051 & -0.025 \\
\hline
\end{tabular}

\section{References}

Bayer, K., Kamke, J., Hentschel, U., 2014. Quantification of bacterial and archaeal symbionts in high and low microbial abundance sponges using real-time PCR. FEMS Microbiol. Ecol. 89, 679-690. doi:10.1111/1574-6941.12369.

Luter, H.M., Gibb, K., Webster, N.S., 2014. Eutrophication has no short-term effect on the Cymbastela stipitata holobiont. Front. Microbiol. 5, doi:216.10.3389/fmicb.2014.00216.

Massaro, A.J., Weisz, J.B., Hill, M.S., Webster, N.S., 2012. Behavioral and morphological changes caused by thermal stress in the Great Barrier Reef sponge Rhopaloeides odorabile. J. Exp. Mar. Biol. Ecol. 416, 55-60. doi.org/10.1016/j.jembe.2012.02.008.

Simister, R., Taylor, M.W., Tsai, P., Webster, N., 2012. Sponge-Microbe Associations Survive High Nutrients and Temperatures. PLoS One. 7, doi: e52220.10.1371/journal.pone.0052220.

Webb, A.E., van Heuven, S.M.A.C., de Bakker, D.M., van Duyl, F.C., Reichart, G.-J., de Nooijer, L.J., 2017. Combined Effects of Experimental Acidification and Eutrophication on Reef Sponge Bioerosion Rates. Front. Mar. Sci. doi:4.10.3389/fmars.2017.00311. 


\section{Appendix B}

Table B3.1a Results of time * temperature post hoc pairwise comparisons test (with the sequential Sidak correction applied) from General Linear Mixed Models for percentage change in buoyant weight. Significant p-values are reported in bold.

\begin{tabular}{|c|c|c|c|c|c|c|c|c|c|}
\hline $\begin{array}{c}\text { Time } \\
\text { (Weeks) }\end{array}$ & \multicolumn{2}{|c|}{ Temp } & $\begin{array}{l}\text { Contrast } \\
\text { Estimate }\end{array}$ & $\begin{array}{l}\text { Std. } \\
\text { Error }\end{array}$ & $\mathbf{t}$ & df & $P$ & $\begin{array}{c}\text { CI } \\
\text { (lower) }\end{array}$ & $\begin{array}{c}\text { CI } \\
\text { (upper) }\end{array}$ \\
\hline \multicolumn{10}{|c|}{ Neopetrosia chaliniformis } \\
\hline \multirow{3}{*}{$\mathbf{0}$} & $28^{\circ} \mathrm{C}$ & $26^{\circ} \mathrm{C}$ & - & - & - & - & - & - & - \\
\hline & $30^{\circ} \mathrm{C}$ & $26^{\circ} \mathrm{C}$ & - & - & - & - & - & - & - \\
\hline & $30^{\circ} \mathrm{C}$ & $28^{\circ} \mathrm{C}$ & - & - & - & - & - & - & - \\
\hline \multirow{3}{*}{1} & $28^{\circ} \mathrm{C}$ & $26^{\circ} \mathrm{C}$ & 0.033 & 0.010 & 3.354 & 59 & 0.003 & 0.010 & 0.055 \\
\hline & $30^{\circ} \mathrm{C}$ & $26^{\circ} \mathrm{C}$ & 0.040 & 0.010 & 4.124 & 59 & $<0.001$ & 0.016 & 0.065 \\
\hline & $30^{\circ} \mathrm{C}$ & $28^{\circ} \mathrm{C}$ & 0.008 & 0.010 & 0.770 & 59 & 0.444 & -0.012 & 0.027 \\
\hline \multirow{3}{*}{2} & $28^{\circ} \mathrm{C}$ & $26^{\circ} \mathrm{C}$ & 0.054 & 0.010 & 5.517 & 59 & $<0.001$ & 0.032 & 0.077 \\
\hline & $30^{\circ} \mathrm{C}$ & $26^{\circ} \mathrm{C}$ & 0.063 & 0.010 & 6.475 & 59 & $<0.001$ & 0.039 & 0.088 \\
\hline & $30^{\circ} \mathrm{C}$ & $28^{\circ} \mathrm{C}$ & 0.009 & 0.010 & 0.958 & 59 & 0.342 & -0.010 & 0.029 \\
\hline \multirow{3}{*}{3} & $28^{\circ} \mathrm{C}$ & $26^{\circ} \mathrm{C}$ & 0.109 & 0.010 & 11.084 & 59 & $<0.001$ & 0.086 & 0.131 \\
\hline & $30^{\circ} \mathrm{C}$ & $26^{\circ} \mathrm{C}$ & 0.117 & 0.010 & 11.655 & 59 & $<0.001$ & 0.092 & 0.141 \\
\hline & $30^{\circ} \mathrm{C}$ & $28^{\circ} \mathrm{C}$ & 0.008 & 0.010 & 0.797 & 59 & 0.429 & -0.012 & 0.028 \\
\hline \multicolumn{10}{|c|}{ Amphimedon navalis } \\
\hline \multirow{3}{*}{$\mathbf{0}$} & $28^{\circ} \mathrm{C}$ & $26^{\circ} \mathrm{C}$ & - & - & - & - & - & - & - \\
\hline & $30^{\circ} \mathrm{C}$ & $26^{\circ} \mathrm{C}$ & - & - & - & - & - & - & - \\
\hline & $30^{\circ} \mathrm{C}$ & $28^{\circ} \mathrm{C}$ & - & - & - & - & - & - & - \\
\hline \multirow{3}{*}{1} & $28^{\circ} \mathrm{C}$ & $26^{\circ} \mathrm{C}$ & -0.007 & 0.002 & -2.830 & 60 & 0.013 & -0.013 & -0.001 \\
\hline & $30^{\circ} \mathrm{C}$ & $26^{\circ} \mathrm{C}$ & -0.009 & 0.002 & -3.620 & 60 & 0.002 & -0.015 & -0.003 \\
\hline & $30^{\circ} \mathrm{C}$ & $28^{\circ} \mathrm{C}$ & -0.002 & 0.002 & -0.790 & 60 & 0.433 & -0.007 & 0.003 \\
\hline \multirow{3}{*}{2} & $28^{\circ} \mathrm{C}$ & $26^{\circ} \mathrm{C}$ & -0.012 & 0.002 & -4.783 & 60 & $<0.001$ & -0.017 & -0.006 \\
\hline & $30^{\circ} \mathrm{C}$ & $26^{\circ} \mathrm{C}$ & -0.018 & 0.002 & -7.280 & 60 & $<0.001$ & -0.024 & -0.012 \\
\hline & $30^{\circ} \mathrm{C}$ & $28^{\circ} \mathrm{C}$ & -0.006 & 0.002 & -2.497 & 60 & 0.015 & -0.011 & -0.001 \\
\hline \multirow{3}{*}{3} & $28^{\circ} \mathrm{C}$ & $26^{\circ} \mathrm{C}$ & -0.016 & 0.002 & -6.537 & 60 & $<0.001$ & -0.022 & -0.010 \\
\hline & $30^{\circ} \mathrm{C}$ & $26^{\circ} \mathrm{C}$ & -0.026 & 0.002 & -10.396 & 60 & $<0.001$ & -0.032 & -0.020 \\
\hline & $30^{\circ} \mathrm{C}$ & $28^{\circ} \mathrm{C}$ & -0.010 & 0.002 & -3.859 & 60 & $<0.001$ & -0.014 & -0.005 \\
\hline \multirow{3}{*}{4} & $28^{\circ} \mathrm{C}$ & $26^{\circ} \mathrm{C}$ & -0.020 & 0.002 & -8.209 & 60 & $<0.001$ & -0.026 & -0.015 \\
\hline & $30^{\circ} \mathrm{C}$ & $26^{\circ} \mathrm{C}$ & -0.034 & 0.002 & -13.751 & 60 & $<0.001$ & -0.040 & -0.028 \\
\hline & $30^{\circ} \mathrm{C}$ & $28^{\circ} \mathrm{C}$ & -0.014 & 0.002 & -5.542 & 60 & $<0.001$ & -0.019 & -0.009 \\
\hline
\end{tabular}


Table 3.1b Results of time * temperature post hoc pairwise comparisons test (with the sequential Sidak correction applied) from General Linear Mixed Models for $\Delta F / F$ '. Significant $\mathrm{p}$-values are reported in bold.

\begin{tabular}{|c|c|c|c|c|c|c|c|c|c|}
\hline $\begin{array}{c}\text { Time } \\
\text { (Weeks) }\end{array}$ & \multicolumn{2}{|c|}{ Temp } & $\begin{array}{l}\text { Contrast } \\
\text { Estimate }\end{array}$ & $\begin{array}{l}\text { Std. } \\
\text { Error }\end{array}$ & $\mathbf{t}$ & df & $P$ & $\begin{array}{c}\text { CI } \\
\text { (lower) }\end{array}$ & $\begin{array}{c}\text { CI } \\
\text { (upper) }\end{array}$ \\
\hline \multicolumn{10}{|c|}{ Neopetrosia chaliniformis } \\
\hline \multirow{3}{*}{$\mathbf{0}$} & $28^{\circ} \mathrm{C}$ & $26^{\circ} \mathrm{C}$ & 0.002 & 0.005 & 0.435 & 93 & 0.888 & -0.012 & 0.008 \\
\hline & $30^{\circ} \mathrm{C}$ & $26^{\circ} \mathrm{C}$ & 0.003 & 0.005 & 0.708 & 93 & 0.860 & -0.008 & 0.012 \\
\hline & $30^{\circ} \mathrm{C}$ & $28^{\circ} \mathrm{C}$ & 0.001 & 0.005 & 0.273 & 93 & 0.888 & -0.009 & 0.011 \\
\hline \multirow{3}{*}{1} & $28^{\circ} \mathrm{C}$ & $26^{\circ} \mathrm{C}$ & -0.010 & 0.005 & -2.079 & 93 & 0.040 & 0.001 & 0.019 \\
\hline & $30^{\circ} \mathrm{C}$ & $26^{\circ} \mathrm{C}$ & -0.022 & 0.005 & -4.862 & 93 & $<0.001$ & -0.033 & -0.011 \\
\hline & $30^{\circ} \mathrm{C}$ & $28^{\circ} \mathrm{C}$ & -0.013 & 0.005 & -2.783 & 93 & 0.013 & -0.023 & -0.011 \\
\hline \multirow{3}{*}{2} & $28^{\circ} \mathrm{C}$ & $26^{\circ} \mathrm{C}$ & -0.030 & 0.005 & -6.516 & 93 & $<0.001$ & -0.040 & -0.019 \\
\hline & $30^{\circ} \mathrm{C}$ & $26^{\circ} \mathrm{C}$ & -0.038 & 0.005 & -8.242 & 93 & $<0.001$ & -0.049 & -0.027 \\
\hline & $30^{\circ} \mathrm{C}$ & $28^{\circ} \mathrm{C}$ & -0.008 & 0.005 & -1.726 & 93 & 0.088 & -0.017 & 0.001 \\
\hline \multirow{3}{*}{3} & $28^{\circ} \mathrm{C}$ & $26^{\circ} \mathrm{C}$ & -0.034 & 0.005 & -7.332 & 93 & $<0.001$ & -0.044 & -0.023 \\
\hline & $30^{\circ} \mathrm{C}$ & $26^{\circ} \mathrm{C}$ & -0.065 & 0.005 & -14.135 & 93 & $<0.001$ & -0.076 & -0.054 \\
\hline & $30^{\circ} \mathrm{C}$ & $28^{\circ} \mathrm{C}$ & -0.031 & 0.005 & -6.804 & 93 & $<0.001$ & -0.040 & -0.022 \\
\hline \multicolumn{10}{|c|}{ Spheciospongia vagabunda } \\
\hline \multirow{3}{*}{$\mathbf{0}$} & $28^{\circ} \mathrm{C}$ & $26^{\circ} \mathrm{C}$ & -0.002 & 0.003 & -0.662 & 120 & 0.878 & -0.008 & 0.005 \\
\hline & $30^{\circ} \mathrm{C}$ & $26^{\circ} \mathrm{C}$ & 0.001 & 0.003 & 0.009 & 120 & 0.993 & -0.005 & 0.005 \\
\hline & $30^{\circ} \mathrm{C}$ & $28^{\circ} \mathrm{C}$ & 0.002 & 0.003 & 0.671 & 120 & 0.878 & -0.005 & 0.008 \\
\hline \multirow{3}{*}{1} & $28^{\circ} \mathrm{C}$ & $26^{\circ} \mathrm{C}$ & -0.008 & 0.003 & -2.782 & 120 & 0.006 & -0.013 & -0.002 \\
\hline & $30^{\circ} \mathrm{C}$ & $26^{\circ} \mathrm{C}$ & -0.016 & 0.003 & -5.861 & 120 & $<0.001$ & -0.023 & -0.009 \\
\hline & $30^{\circ} \mathrm{C}$ & $28^{\circ} \mathrm{C}$ & -0.008 & 0.003 & -3.079 & 120 & 0.005 & -0.015 & -0.002 \\
\hline \multirow{3}{*}{2} & $28^{\circ} \mathrm{C}$ & $26^{\circ} \mathrm{C}$ & -0.022 & 0.003 & -7.998 & 120 & $<0.001$ & -0.028 & -0.016 \\
\hline & $30^{\circ} \mathrm{C}$ & $26^{\circ} \mathrm{C}$ & -0.043 & 0.003 & -15.603 & 120 & $<0.001$ & -0.049 & -0.036 \\
\hline & $30^{\circ} \mathrm{C}$ & $28^{\circ} \mathrm{C}$ & -0.021 & 0.003 & -7.606 & 120 & $<0.001$ & -0.026 & -0.015 \\
\hline \multirow{3}{*}{3} & $28^{\circ} \mathrm{C}$ & $26^{\circ} \mathrm{C}$ & -0.032 & 0.003 & -11.582 & 120 & $<0.001$ & -0.038 & -0.025 \\
\hline & $30^{\circ} \mathrm{C}$ & $26^{\circ} \mathrm{C}$ & -0.046 & 0.003 & -16.629 & 120 & $<0.001$ & -0.052 & -0.039 \\
\hline & $30^{\circ} \mathrm{C}$ & $28^{\circ} \mathrm{C}$ & -0.014 & 0.003 & -5.046 & 120 & $<0.001$ & -0.019 & -0.008 \\
\hline \multirow{3}{*}{4} & $28^{\circ} \mathrm{C}$ & $26^{\circ} \mathrm{C}$ & -0.036 & 0.003 & -12.963 & 120 & $<0.001$ & -0.042 & -0.029 \\
\hline & $30^{\circ} \mathrm{C}$ & $26^{\circ} \mathrm{C}$ & -0.042 & 0.003 & -15.288 & 120 & $<0.001$ & -0.048 & -0.036 \\
\hline & $30^{\circ} \mathrm{C}$ & $28^{\circ} \mathrm{C}$ & -0.006 & 0.003 & -2.325 & 120 & $\mathbf{0 . 0 2 2}$ & -0.012 & -0.001 \\
\hline
\end{tabular}


Table B3.1c Results of time * temperature post hoc pairwise comparisons test (with the sequential Sidak correction applied) from General Linear Mixed Models for holobiont oxygen consumption. Significant p-values are reported in bold.

\begin{tabular}{|c|c|c|c|c|c|c|c|c|c|}
\hline $\begin{array}{c}\text { Time } \\
\text { (Weeks) }\end{array}$ & \multicolumn{2}{|c|}{ Temp } & $\begin{array}{l}\text { Contrast } \\
\text { Estimate }\end{array}$ & $\begin{array}{l}\text { Std. } \\
\text { Error }\end{array}$ & $\mathbf{t}$ & df & $\boldsymbol{P}$ & $\begin{array}{c}\text { CI } \\
\text { (lower) }\end{array}$ & $\begin{array}{c}\text { CI } \\
\text { (upper) }\end{array}$ \\
\hline \multicolumn{10}{|c|}{ Neopetrosia chaliniformis } \\
\hline \multirow{3}{*}{$\mathbf{0}$} & $28^{\circ} \mathrm{C}$ & $26^{\circ} \mathrm{C}$ & -0.004 & 0.004 & -0.995 & 49 & 0.544 & -0.012 & 0.005 \\
\hline & $30^{\circ} \mathrm{C}$ & $26^{\circ} \mathrm{C}$ & 0.002 & 0.004 & 0.516 & 49 & 0.608 & -0.006 & 0.009 \\
\hline & $30^{\circ} \mathrm{C}$ & $28^{\circ} \mathrm{C}$ & 0.006 & 0.004 & 1.510 & 49 & 0.358 & -0.004 & 0.015 \\
\hline \multirow{3}{*}{1} & $28^{\circ} \mathrm{C}$ & $26^{\circ} \mathrm{C}$ & 0.006 & 0.004 & 1.674 & 49 & 0.191 & -0.002 & -0.001 \\
\hline & $30^{\circ} \mathrm{C}$ & $26^{\circ} \mathrm{C}$ & 0.011 & 0.004 & 2.873 & 49 & 0.018 & 0.001 & 0.020 \\
\hline & $30^{\circ} \mathrm{C}$ & $28^{\circ} \mathrm{C}$ & 0.004 & 0.004 & 1.200 & 49 & 0.236 & -0.003 & 0.012 \\
\hline \multirow{3}{*}{2} & $28^{\circ} \mathrm{C}$ & $26^{\circ} \mathrm{C}$ & 0.009 & 0.004 & 2.506 & 49 & 0.016 & 0.002 & 0.017 \\
\hline & $30^{\circ} \mathrm{C}$ & $26^{\circ} \mathrm{C}$ & 0.021 & 0.004 & 5.576 & 49 & $<0.001$ & 0.011 & 0.030 \\
\hline & $30^{\circ} \mathrm{C}$ & $28^{\circ} \mathrm{C}$ & 0.011 & 0.004 & 3.070 & 49 & 0.007 & 0.003 & 0.020 \\
\hline \multirow{3}{*}{3} & $28^{\circ} \mathrm{C}$ & $26^{\circ} \mathrm{C}$ & 0.008 & 0.004 & 2.267 & 49 & 0.028 & 0.001 & 0.016 \\
\hline & $30^{\circ} \mathrm{C}$ & $26^{\circ} \mathrm{C}$ & 0.037 & 0.004 & 10.061 & 49 & $<0.001$ & 0.028 & 0.046 \\
\hline & $30^{\circ} \mathrm{C}$ & $28^{\circ} \mathrm{C}$ & 0.029 & 0.004 & 7.794 & 49 & $<0.001$ & 0.020 & 0.037 \\
\hline \multicolumn{10}{|c|}{ Amphimedon navalis } \\
\hline \multirow{3}{*}{$\mathbf{0}$} & $28^{\circ} \mathrm{C}$ & $26^{\circ} \mathrm{C}$ & -0.001 & 0.003 & -0.247 & 27 & 0.993 & -0.009 & 0.007 \\
\hline & $30^{\circ} \mathrm{C}$ & $26^{\circ} \mathrm{C}$ & -0.001 & 0.003 & -0.003 & 27 & 0.998 & -0.007 & 0.006 \\
\hline & $30^{\circ} \mathrm{C}$ & $28^{\circ} \mathrm{C}$ & 0.001 & 0.003 & 0.245 & 27 & 0.993 & -0.007 & 0.009 \\
\hline \multirow{3}{*}{1} & $28^{\circ} \mathrm{C}$ & $26^{\circ} \mathrm{C}$ & 0.003 & 0.003 & 1.066 & 27 & 0.504 & -0.004 & 0.011 \\
\hline & $30^{\circ} \mathrm{C}$ & $26^{\circ} \mathrm{C}$ & 0.005 & 0.003 & 1.687 & 27 & 0.279 & -0.003 & 0.013 \\
\hline & $30^{\circ} \mathrm{C}$ & $28^{\circ} \mathrm{C}$ & 0.002 & 0.003 & 0.621 & 27 & 0.540 & -0.005 & 0.008 \\
\hline \multirow{3}{*}{2} & $28^{\circ} \mathrm{C}$ & $26^{\circ} \mathrm{C}$ & 0.005 & 0.003 & 1.539 & 27 & 0.135 & -0.002 & -0.004 \\
\hline & $30^{\circ} \mathrm{C}$ & $26^{\circ} \mathrm{C}$ & 0.012 & 0.003 & 3.670 & 27 & 0.003 & 0.004 & 0.020 \\
\hline & $30^{\circ} \mathrm{C}$ & $28^{\circ} \mathrm{C}$ & 0.007 & 0.003 & 2.131 & 27 & 0.083 & -0.001 & 0.014 \\
\hline \multirow{3}{*}{3} & $28^{\circ} \mathrm{C}$ & $26^{\circ} \mathrm{C}$ & 0.007 & 0.003 & 2.224 & 27 & 0.035 & 0.001 & 0.014 \\
\hline & $30^{\circ} \mathrm{C}$ & $26^{\circ} \mathrm{C}$ & 0.016 & 0.003 & 5.159 & 27 & $<0.001$ & 0.008 & 0.024 \\
\hline & $30^{\circ} \mathrm{C}$ & $28^{\circ} \mathrm{C}$ & 0.009 & 0.003 & 2.935 & 27 & 0.014 & 0.002 & 0.017 \\
\hline \multirow{3}{*}{4} & $28^{\circ} \mathrm{C}$ & $26^{\circ} \mathrm{C}$ & 0.009 & 0.003 & 2.690 & 27 & 0.012 & 0.002 & 0.015 \\
\hline & $30^{\circ} \mathrm{C}$ & $26^{\circ} \mathrm{C}$ & 0.020 & 0.003 & 6.224 & 27 & $<0.001$ & 0.012 & 0.028 \\
\hline & $30^{\circ} \mathrm{C}$ & $28^{\circ} \mathrm{C}$ & 0.011 & 0.003 & 3.534 & 27 & 0.003 & 0.004 & 0.019 \\
\hline
\end{tabular}


Table B3.1d Results of time * temperature post hoc pairwise comparisons test (with the sequential Sidak correction applied) from General Linear Mixed Models for change in sponge pumping rate. Significant $\mathrm{p}$-values are reported in bold.

\begin{tabular}{|c|c|c|c|c|c|c|c|c|c|}
\hline $\begin{array}{c}\text { Time } \\
\text { (Weeks) }\end{array}$ & \multicolumn{2}{|c|}{ Temp } & $\begin{array}{l}\text { Contrast } \\
\text { Estimate }\end{array}$ & $\begin{array}{c}\text { Std. } \\
\text { Error }\end{array}$ & $\mathbf{t}$ & df & $P$ & $\begin{array}{c}\text { CI } \\
\text { (lower) }\end{array}$ & $\begin{array}{c}\text { CI } \\
\text { (upper) }\end{array}$ \\
\hline \multicolumn{10}{|c|}{ Neopetrosia chaliniformis } \\
\hline \multirow{3}{*}{$\mathbf{0}$} & $28^{\circ} \mathrm{C}$ & $26^{\circ} \mathrm{C}$ & -0.008 & 0.014 & -0.545 & 96 & 0.673 & -0.037 & 0.022 \\
\hline & $30^{\circ} \mathrm{C}$ & $26^{\circ} \mathrm{C}$ & 0.011 & 0.014 & 0.796 & 96 & 0.673 & -0.021 & 0.044 \\
\hline & $30^{\circ} \mathrm{C}$ & $28^{\circ} \mathrm{C}$ & 0.019 & 0.014 & 1.341 & 96 & 0.455 & -0.015 & 0.054 \\
\hline \multirow{3}{*}{1} & $28^{\circ} \mathrm{C}$ & $26^{\circ} \mathrm{C}$ & 0.041 & 0.014 & 2.878 & 96 & 0.015 & 0.006 & 0.075 \\
\hline & $30^{\circ} \mathrm{C}$ & $26^{\circ} \mathrm{C}$ & 0.019 & 0.014 & 1.339 & 96 & 0.238 & -0.010 & 0.054 \\
\hline & $30^{\circ} \mathrm{C}$ & $28^{\circ} \mathrm{C}$ & -0.022 & 0.014 & -1.539 & 96 & 0.238 & -0.054 & 0.010 \\
\hline \multirow{3}{*}{2} & $28^{\circ} \mathrm{C}$ & $26^{\circ} \mathrm{C}$ & 0.035 & 0.014 & 2.455 & 96 & 0.032 & 0.003 & 0.067 \\
\hline & $30^{\circ} \mathrm{C}$ & $26^{\circ} \mathrm{C}$ & 0.040 & 0.014 & 2.785 & 96 & 0.019 & 0.005 & 0.074 \\
\hline & $30^{\circ} \mathrm{C}$ & $28^{\circ} \mathrm{C}$ & 0.005 & 0.014 & 0.330 & 96 & 0.742 & -0.023 & 0.033 \\
\hline \multirow{3}{*}{3} & $28^{\circ} \mathrm{C}$ & $26^{\circ} \mathrm{C}$ & 0.056 & 0.014 & 3.921 & 96 & $<0.001$ & 0.023 & 0.088 \\
\hline & $30^{\circ} \mathrm{C}$ & $26^{\circ} \mathrm{C}$ & 0.089 & 0.014 & 6.295 & 96 & $<0.001$ & 0.055 & 0.124 \\
\hline & $30^{\circ} \mathrm{C}$ & $28^{\circ} \mathrm{C}$ & 0.034 & 0.014 & 2.374 & 96 & $\mathbf{0 . 0 2 0}$ & 0.006 & 0.062 \\
\hline \multicolumn{10}{|c|}{ Amphimedon navalis } \\
\hline \multirow{3}{*}{ o } & $28^{\circ} \mathrm{C}$ & $26^{\circ} \mathrm{C}$ & 0.008 & 0.003 & 2.801 & 38 & 0.024 & 0.001 & 0.015 \\
\hline & $30^{\circ} \mathrm{C}$ & $26^{\circ} \mathrm{C}$ & 0.006 & 0.003 & 2.032 & 38 & 0.096 & -0.001 & 0.013 \\
\hline & $30^{\circ} \mathrm{C}$ & $28^{\circ} \mathrm{C}$ & -0.002 & 0.003 & -0.769 & 38 & 0.447 & -0.008 & 0.004 \\
\hline \multirow{3}{*}{1} & $28^{\circ} \mathrm{C}$ & $26^{\circ} \mathrm{C}$ & 0.009 & 0.003 & 3.273 & 38 & 0.005 & 0.003 & 0.016 \\
\hline & $30^{\circ} \mathrm{C}$ & $26^{\circ} \mathrm{C}$ & 0.013 & 0.003 & 4.404 & 38 & $<0.001$ & 0.005 & 0.020 \\
\hline & $30^{\circ} \mathrm{C}$ & $28^{\circ} \mathrm{C}$ & 0.003 & 0.003 & 1.131 & 38 & 0.265 & -0.003 & 0.009 \\
\hline \multirow{3}{*}{2} & $28^{\circ} \mathrm{C}$ & $26^{\circ} \mathrm{C}$ & 0.010 & 0.003 & 3.338 & 38 & 0.004 & 0.003 & 0.016 \\
\hline & $30^{\circ} \mathrm{C}$ & $26^{\circ} \mathrm{C}$ & 0.018 & 0.003 & 6.431 & 38 & $<0.001$ & 0.011 & 0.026 \\
\hline & $30^{\circ} \mathrm{C}$ & $28^{\circ} \mathrm{C}$ & 0.009 & 0.003 & 3.094 & 38 & 0.004 & 0.003 & 0.015 \\
\hline \multirow{3}{*}{3} & $28^{\circ} \mathrm{C}$ & $26^{\circ} \mathrm{C}$ & 0.020 & 0.003 & 6.999 & 38 & $<0.001$ & 0.013 & 0.027 \\
\hline & $30^{\circ} \mathrm{C}$ & $26^{\circ} \mathrm{C}$ & 0.033 & 0.003 & 11.401 & 38 & $<0.001$ & 0.026 & 0.040 \\
\hline & $30^{\circ} \mathrm{C}$ & $28^{\circ} \mathrm{C}$ & 0.013 & 0.003 & 4.402 & 38 & $<0.001$ & 0.007 & 0.018 \\
\hline \multirow{3}{*}{4} & $28^{\circ} \mathrm{C}$ & $26^{\circ} \mathrm{C}$ & 0.022 & 0.003 & 7.743 & 38 & $<0.001$ & 0.016 & 0.029 \\
\hline & $30^{\circ} \mathrm{C}$ & $26^{\circ} \mathrm{C}$ & 0.040 & 0.003 & 13.980 & 38 & $<0.001$ & 0.003 & 0.047 \\
\hline & $30^{\circ} \mathrm{C}$ & $28^{\circ} \mathrm{C}$ & 0.018 & 0.003 & 6.237 & 38 & $<0.001$ & 0.012 & 0.024 \\
\hline
\end{tabular}

*Table continues on next page 


\begin{tabular}{|c|c|c|c|c|c|c|c|c|c|}
\hline $\begin{array}{c}\text { Time } \\
\text { (Weeks) }\end{array}$ & \multicolumn{2}{|c|}{ Temp } & $\begin{array}{l}\text { Contrast } \\
\text { Estimate }\end{array}$ & $\begin{array}{c}\text { Std. } \\
\text { Error }\end{array}$ & $\mathbf{t}$ & df & $P$ & $\begin{array}{c}\text { CI } \\
\text { (lower) }\end{array}$ & $\begin{array}{c}\text { CI } \\
\text { (upper) }\end{array}$ \\
\hline \multicolumn{10}{|c|}{ Spheciospongia vagabunda } \\
\hline \multirow{3}{*}{$\mathbf{0}$} & $28^{\circ} \mathrm{C}$ & $26^{\circ} \mathrm{C}$ & -0.005 & 0.009 & -0.520 & 94 & 0.917 & -0.025 & 0.016 \\
\hline & $30^{\circ} \mathrm{C}$ & $26^{\circ} \mathrm{C}$ & 0.001 & 0.009 & 0.059 & 94 & 0.953 & -0.017 & 0.018 \\
\hline & $30^{\circ} \mathrm{C}$ & $28^{\circ} \mathrm{C}$ & 0.005 & 0.009 & 0.580 & 94 & 0.917 & -0.016 & 0.026 \\
\hline \multirow{3}{*}{1} & $28^{\circ} \mathrm{C}$ & $26^{\circ} \mathrm{C}$ & 0.030 & 0.009 & 3.379 & 94 & 0.002 & 0.010 & 0.050 \\
\hline & $30^{\circ} \mathrm{C}$ & $26^{\circ} \mathrm{C}$ & 0.045 & 0.009 & 5.130 & 94 & $<0.001$ & 0.024 & 0.066 \\
\hline & $30^{\circ} \mathrm{C}$ & $28^{\circ} \mathrm{C}$ & 0.015 & 0.009 & 1.751 & 94 & 0.083 & -0.002 & 0.033 \\
\hline \multirow{3}{*}{2} & $28^{\circ} \mathrm{C}$ & $26^{\circ} \mathrm{C}$ & 0.043 & 0.009 & 4.907 & 94 & $<0.001$ & 0.022 & 0.064 \\
\hline & $30^{\circ} \mathrm{C}$ & $26^{\circ} \mathrm{C}$ & 0.043 & 0.009 & 4.907 & 94 & $<0.001$ & 0.022 & 0.064 \\
\hline & $30^{\circ} \mathrm{C}$ & $28^{\circ} \mathrm{C}$ & 0.001 & 0.009 & 0.001 & 94 & 0.999 & -0.017 & 0.017 \\
\hline \multirow{3}{*}{3} & $28^{\circ} \mathrm{C}$ & $26^{\circ} \mathrm{C}$ & 0.040 & 0.009 & 4.545 & 94 & $<0.001$ & 0.020 & 0.060 \\
\hline & $30^{\circ} \mathrm{C}$ & $26^{\circ} \mathrm{C}$ & 0.058 & 0.009 & 6.627 & 94 & $<0.001$ & 0.037 & 0.079 \\
\hline & $30^{\circ} \mathrm{C}$ & $28^{\circ} \mathrm{C}$ & 0.018 & 0.009 & 2.081 & 94 & 0.040 & 0.001 & 0.036 \\
\hline \multirow{3}{*}{4} & $28^{\circ} \mathrm{C}$ & $26^{\circ} \mathrm{C}$ & 0.051 & 0.009 & 5.865 & 94 & $<0.001$ & 0.031 & 0.071 \\
\hline & $30^{\circ} \mathrm{C}$ & $26^{\circ} \mathrm{C}$ & 0.061 & 0.009 & 6.918 & 94 & $<0.001$ & 0.039 & 0.082 \\
\hline & $30^{\circ} \mathrm{C}$ & $28^{\circ} \mathrm{C}$ & 0.009 & 0.009 & 1.052 & 94 & 0.295 & -0.008 & 0.027 \\
\hline
\end{tabular}

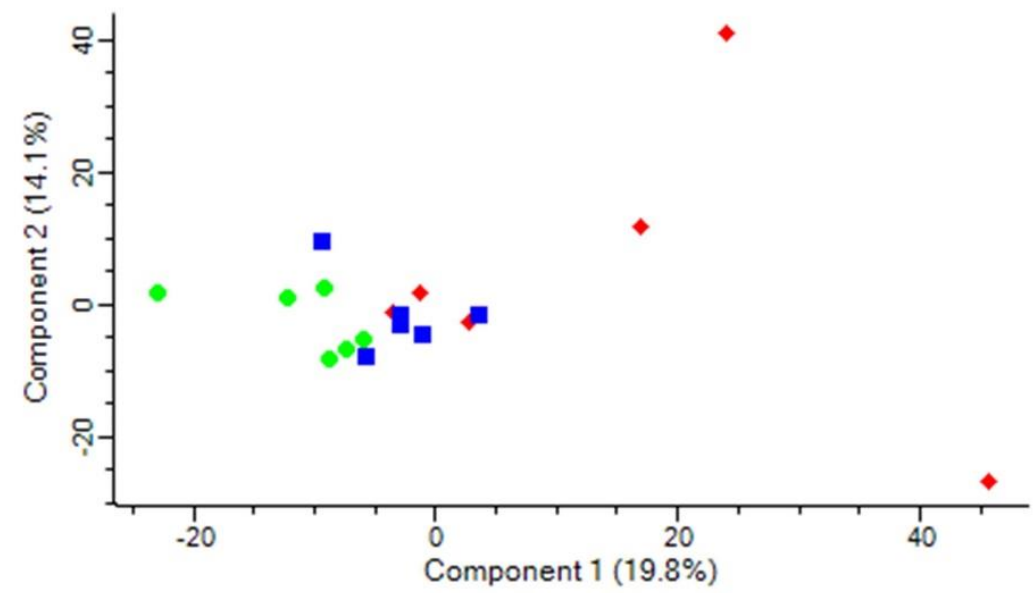

Fig. B3.1 Principal Component Analysis (PCA) plot of proteins expressed in Amphimedon navalis at $26{ }^{\circ} \mathrm{C}$ (filled circles), $28{ }^{\circ} \mathrm{C}$ (filled squares) and $30{ }^{\circ} \mathrm{C}$ (filled diamonds). PCA was constructed using all detected proteins. Each point represents a biological sponge replicate ( $n=6$ for each treatment). 
Table B3.2 Results of pairwise comparisons between temperature treatments for differentially expressed proteins from Amphimedon navalis from Miss test using an FDR threshold of 0.1 and log-ratio (fold-change) of \pm 0.25 . Significant $p$-values are reported in bold.

\begin{tabular}{|c|c|c|c|c|c|}
\hline $\begin{array}{c}\begin{array}{c}\text { Uniprot Accession } \\
\text { number }\end{array} \\
\end{array}$ & Protein annotation & $\begin{array}{l}\text { Proteins } \\
\text { in cluster }\end{array}$ & $\begin{array}{c}26^{\circ} \mathrm{C} \text { vs } \\
28^{\circ} \mathrm{C} \\
\end{array}$ & $\begin{array}{c}26^{\circ} \mathrm{C} \text { vs } \\
30^{\circ} \mathrm{C} \\
\end{array}$ & $\begin{array}{c}28^{\circ} \mathrm{C} \text { vs } \\
30^{\circ} \mathrm{C} \\
\end{array}$ \\
\hline \multicolumn{6}{|c|}{ Oxidation-reduction process (Oxidative stress) } \\
\hline A0A1X7V4C4 & Aldedh domain-containing protein & 2 & 1.22E-05 & 5.24E-06 & 0.980313 \\
\hline I1GFQ7 & Ferritin & 2 & 3.53E-06 & 5.24E-06 & 1 \\
\hline A0A1X7SUN1 & VOC domain-containing protein & 2 & 0.831446 & 0.054828 & 1 \\
\hline A0A1X7VNW3 & Catalase (Heme cofactor) & 2 & 0.311372 & 0.001572 & 0.090423 \\
\hline A0A1X7VQL2 & $\begin{array}{c}\text { Uncharacterized (Thioredoxin-like } \\
\text { superfamily) }\end{array}$ & 1 & 1 & 0.012566 & 0.090423 \\
\hline A0A1X7UNX4 & $\begin{array}{l}\text { Uncharacterized (Glutathione S-transferase } \\
\text { superfamily) }\end{array}$ & 1 & 1 & 0.192653 & 0.050264 \\
\hline A0A1X7T3Q9 & E1_dh domain-containing protein & 2 & 1 & 0.000314 & 0.003458 \\
\hline A0A1X7VJL6 & Peroxiredoxin & 1 & 0.83146 & 0.049142 & 1 \\
\hline A0A1X7U633 & Cytochrome $\mathrm{c}$ domain-containing protein & 2 & 0.795518 & 0.000314 & 0.035267 \\
\hline A0A1X7V4Y0 & $\begin{array}{l}\text { Proton-translocating NAD }(\mathrm{P})(+) \\
\text { transhydrogenase }\end{array}$ & 1 & 0.071665 & 0.063899 & 0.683634 \\
\hline \multicolumn{6}{|c|}{ Protein transport } \\
\hline A0A1X7U4A4 & Protein kinase domain-containing protein & 1 & 0.023796 & $\mathbf{0 . 0 4 7 8 8 5}$ & 1 \\
\hline A0A1X7UVI1 & Protein kinase domain-containing protein & 1 & 0.559622 & 0.042849 & 0.683634 \\
\hline A0A1X7VH72 & $\begin{array}{c}\text { Uncharacterized (inositol phosphokinase } \\
\text { family) }\end{array}$ & 1 & 0.066834 & 0.012566 & 1 \\
\hline A0A1X7V114 & $\begin{array}{l}\text { Vacuolar protein sorting-associated protein } \\
11 \text { homolog }\end{array}$ & 1 & 0.63163 & $\mathbf{0 . 0 0 1 9 3 7}$ & 0.115427 \\
\hline A0A1X7UHM1 & Ras-related protein Rab-14 & 1 & 1 & 0.055495 & 0.40943 \\
\hline A0A1X7VLI5 & Protein kinase domain-containing protein & 1 & 1 & 0.005623 & 0.03029 \\
\hline A0A1X7VL10 & ATP synthase subunit beta & 1 & 0.023366 & 0.207581 & 1 \\
\hline A0A1X7VVN1 & $\begin{array}{l}\text { Uncharacterized (ABC transporter-like } \\
\text { family) }\end{array}$ & 1 & 0.066834 & 0.001133 & 0.079628 \\
\hline A0A1X7VJC1 & Uncharacterized (DUOXA family) & 1 & 0.024449 & 0.222406 & 0.683634 \\
\hline A0A1X7VXP7 & Uncharacterized (SNF7 family) & 1 & 0.015008 & 0.003536 & 0.61806 \\
\hline \multicolumn{6}{|c|}{$\begin{array}{c}\text { Cytoskeletal organization } \\
\end{array}$} \\
\hline A0A1X7UKK7 & Costars domain-containing protein & 1 & 0.066834 & 0.001937 & 0.61806 \\
\hline A0A1X7VU79 & Fascin & 1 & 0.066834 & 0.2606 & 0.40943 \\
\hline A0A1X7UPB4 & Tubulin alpha chain & 1 & 0.066834 & 0.000171 & 0.393734 \\
\hline A0A1X7UIF6 & F-actin-capping protein subunit beta & 1 & 1 & 0.680671 & 0.079628 \\
\hline A0A1X7V1D4 & Tubulin alpha chain & 1 & 0.024449 & $5.24 \mathrm{E}-06$ & 0.005016 \\
\hline A0A1X7U6V8 & Septin-type G domain-containing protein & 2 & 0.047777 & 1 & 0.005016 \\
\hline A0A1X7VTE3 & Uncharacterized (small GTPase family) & 1 & 0.232523 & 0.005506 & 0.269237 \\
\hline A0A1X7UXJ8 & Uncharacterized (alpha-actinin family) & 1 & 0.023366 & 0.008162 & 1 \\
\hline A0A1X7V9U2 & $\begin{array}{c}\text { Uncharacterized (WASH complex, subunit } \\
\text { strumpellin) }\end{array}$ & 1 & 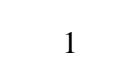 & 0.033781 & 0.090423 \\
\hline A0A1X7U0F7 & PDZ domain-containing protein & 1 & 1 & 0.092884 & 0.954823 \\
\hline \multicolumn{6}{|c|}{$\begin{array}{l}\text { Signal transduction } \\
\end{array}$} \\
\hline A0A1X7VAN2 & Calmodulin & 3 & 0.004717 & 6.59E-07 & 0.090423 \\
\hline A0A1X7UI48 & Histidine-tRNA ligase & 1 & 0.024449 & 5.24E-06 & 0.182332 \\
\hline A0A1X7VIG0 & ADP-ribosylation factor 6 (Arf family) & 1 & 0.318505 & 0.054828 & 0.683634 \\
\hline \multicolumn{6}{|c|}{$\begin{array}{l}\text { Protein translation } \\
\end{array}$} \\
\hline A0A1X7VB92 & Aspartate-tRNA ligase, cytoplasmic & 1 & 0.047777 & 0.009516 & 0.303402 \\
\hline A0A1X7V8E5 & $\begin{array}{l}\text { Uncharacterized (Universal ribosomal } \\
\text { protein S8 family) }\end{array}$ & 1 & 1 & 0.000838 & 0.244596 \\
\hline A0A1X7V0I1 & Ubiquitin - 60S ribosomal protein L40 & 6 & $\mathbf{0 . 0 2 3 3 6 6}$ & 0.008763 & 0.090423 \\
\hline \multicolumn{6}{|c|}{ Protein catabolism } \\
\hline A0A1X7VN30 & Proteasome subunit beta & 2 & 0.061227 & 0.001937 & 0.090423 \\
\hline A0A1X7VGM8 & Palmitoyl-protein hydrolase 1 & 1 & 0.089645 & 0.680671 & 1 \\
\hline A0A1X7VV07 & $\begin{array}{c}\text { Sulfatase domain-containing protein }\left(\mathrm{Ca}^{2+}\right. \\
\text { Cofactor })\end{array}$ & 1 & 0.003762 & $5.24 \mathrm{E}-06$ & 0.090423 \\
\hline
\end{tabular}




\begin{tabular}{|c|c|c|c|c|c|}
\hline $\begin{array}{l}\text { Uniprot Accession } \\
\text { number }\end{array}$ & Protein annotation & $\begin{array}{l}\text { Proteins } \\
\text { in cluster }\end{array}$ & $\begin{array}{l}26^{\circ} \mathrm{C} \text { vs } \\
28^{\circ} \mathrm{C}\end{array}$ & $\begin{array}{l}26^{\circ} \mathrm{C} \text { vs } \\
30^{\circ} \mathrm{C}\end{array}$ & $\begin{array}{l}28^{\circ} \mathrm{C} \text { vs } \\
30^{\circ} \mathrm{C}\end{array}$ \\
\hline \multicolumn{6}{|c|}{$\begin{array}{l}\text { Metabolic process } \\
\end{array}$} \\
\hline A0A1X7VEB3 & Adenosylhomocysteinase ( $\mathrm{NAD}^{+}$cofactor) & 1 & 0.089645 & 0.000314 & 0.016798 \\
\hline \multicolumn{6}{|c|}{ Others } \\
\hline A0A1X7SVR6 & Uncharacterized & 4 & 3.53E-06 & 5.24E-06 & 0.40943 \\
\hline A0A1X7VMX7 & Septin-type $\mathrm{G}$ domain containing protein & 1 & 0.831446 & 0.001133 & 0.576949 \\
\hline A0A1X7SMT9 & Uncharacterized & 1 & 0.066834 & 0.012566 & 1 \\
\hline A0A1X7VLW9 & $\begin{array}{l}\text { Transket_pyr domain-containing protein } \\
\left(\mathrm{Co}^{2+} \text { and } \mathrm{Mg}^{2+} \text { cofactor }\right)\end{array}$ & 1 & 1 & 0.055495 & 0.40943 \\
\hline A0A1X7V015 & DUF3504 domain-containing protein & 1 & 1 & 0.040336 & 0.269237 \\
\hline A0A1X7SJZ1 & Uncharacterized & 3 & 1 & 0.054828 & 0.683634 \\
\hline A0A1X7SYB4 & Uncharacterized & 1 & 0.398718 & 0.054828 & 0.153691 \\
\hline A0A1X7U869 & $\begin{array}{l}\text { Store-operated calcium entry-associated } \\
\text { regulatory factor }\end{array}$ & 1 & 1 & 0.054143 & 0.393734 \\
\hline A0A1X7VNC8 & Uncharacterized (RNA helicase family) & 1 & 1 & 0.042849 & 0.116539 \\
\hline A0A1X7T7Q1 & Uncharacterized & 2 & 0.24654 & 0.049142 & 0.393734 \\
\hline
\end{tabular}




\section{Appendix C}

Table C4.1 Local distribution areas $\left(\mathrm{m}^{2}\right)$ of Neopetrosia chaliniformis, Amphimedon navalis and Spheciospongia vagabunda in TAB, TDD and ALB. Values are estimations from QGIS (QGIS Development Team, 2018). Numbers in bracket represent percentage (-) decrease and (+) increase of LDA over time.

\begin{tabular}{|c|c|c|c|c|c|c|c|}
\hline \multicolumn{8}{|c|}{ Local distribution area $\left(\mathrm{m}^{2}\right)$} \\
\hline \multicolumn{8}{|c|}{ Neopetrosia chaliniformis } \\
\hline & Area A & Area B & Area C & Area D & Area E & Area F & Total Area \\
\hline 2010 & 13967 & 8512 & 10362 & 14659 & 17456 & 52089 & 120045 \\
\hline 2012 & $13251(-5.12)$ & $8026(-5.70)$ & $10421(0.56)$ & $14256(-2.74)$ & $17595(0.79)$ & $50265(-3.50)$ & $113814(-5.19)$ \\
\hline 2013 & $12985(-7.03)$ & $7985(-6.19)$ & $10125(-2.28)$ & $13861(-5.44)$ & $17045(-2.35)$ & $48561(-6.77)$ & $110562(-7.89)$ \\
\hline 2017 & $12056(-13.68)$ & $6346(-25.44)$ & $9751(-5.89)$ & $11895(-18.85)$ & $14223(-18.52)$ & $29365(-43.62)$ & $83636(-30.32)$ \\
\hline 2018 & $11502(-17.64)$ & $5378(-36.81)$ & $9609(-7.26)$ & $10850(-25.98)$ & $13067(-25.14)$ & $21358(-58.99)$ & $71764(-40.21)$ \\
\hline \multicolumn{8}{|c|}{ Amphimedon navalis } \\
\hline 2012 & 5778 & 14289 & 17368 & - & - & - & 37435 \\
\hline 2013 & $5687(-1.57)$ & $14365(0.53)$ & $17259(-0.61)$ & - & - & - & $37311(-0.33)$ \\
\hline 2017 & $5456(-5.57)$ & $13895(-2.75)$ & $16856(-2.93)$ & - & - & - & $36207(-3.28)$ \\
\hline 2018 & $5216(-9.72)$ & $13546(-5.19)$ & $16560(-4.13)$ & - & - & - & $35322(-5.64)$ \\
\hline \multicolumn{8}{|c|}{ Spheciospongia vagabunda } \\
\hline 2012 & 19200 & 4286 & - & - & - & - & 23486 \\
\hline 2013 & $25351(32.03)$ & $5326(24.26)$ & - & - & - & - & 30677 (30.61) \\
\hline 2017 & $35621(85.52)$ & $9365(118.50)$ & - & - & - & - & $44986(91.46)$ \\
\hline 2018 & 41423 (115.74) & $13799(221.95)$ & - & - & - & - & $55222(135.12)$ \\
\hline
\end{tabular}


Table C4.2 Abundance and percentage cover of Neopetrosia chaliniformis, Amphimedon navalis and Spheciospongia vagabunda per local distribution area per year. Values are mean \pm SE.

\begin{tabular}{|c|c|c|c|c|c|c|c|c|c|c|}
\hline \multicolumn{7}{|c|}{ Abundance (sponge $\mathbf{m}^{-2}$ ) } & \multicolumn{4}{|c|}{ Percentage Cover (\%) } \\
\hline \multicolumn{11}{|c|}{ Neopetrosia chaliniformis } \\
\hline & 2010 & 2012 & 2013 & 2017 & 2018 & 2010 & 2012 & 2013 & 2017 & 2018 \\
\hline Area A & $1.20 \pm 0.41$ & $1.23 \pm 0.27$ & $1.10 \pm 0.42$ & $1.07 \pm 0.24$ & $0.96 \pm 0.20$ & $2.84 \pm 0.41$ & $2.98 \pm 0.51$ & $2.70 \pm 0.39$ & $2.93 \pm 0.49$ & $2.81 \pm 0.45$ \\
\hline Area B & $5.6 \pm 1.10$ & $5.0 \pm 0.89$ & $4.73 \pm 0.73$ & $4.63 \pm 0.65$ & $4.50 \pm 0.79$ & $5.03 \pm 0.55$ & $4.95 \pm 0.58$ & $5.17 \pm 0.54$ & $4.81 \pm 0.51$ & $4.43 \pm 0.46$ \\
\hline Area C & $3.13 \pm 0.64$ & $2.86 \pm 0.50$ & $2.83 \pm 0.56$ & $2.43 \pm 0.48$ & $2.26 \pm 0.43$ & $4.01 \pm 0.51$ & $3.82 \pm 0.43$ & $3.77 \pm 0.47$ & $4.30 \pm 0.53$ & $3.19 \pm 0.39$ \\
\hline Area D & $5.10 \pm 0.86$ & $5.06 \pm 0.94$ & $4.90 \pm 0.66$ & $4.40 \pm 0.68$ & $4.13 \pm 0.66$ & $4.31 \pm 0.57$ & $3.97 \pm 0.52$ & $3.89 \pm 0.46$ & $3.50 \pm 0.51$ & $3.49 \pm 0.47$ \\
\hline Area $\mathbf{E}$ & $4.43 \pm 0.58$ & $4.23 \pm 0.81$ & $4.26 \pm 0.73$ & $3.9 \pm 0.71$ & $3.66 \pm 0.71$ & $4.56 \pm 0.52$ & $4.35 \pm 0.54$ & $4.05 \pm 0.49$ & $3.85 \pm 0.53$ & $3.81 \pm 0.53$ \\
\hline Area F & $8.03 \pm 0.98$ & $7.96 \pm 1.07$ & $7.83 \pm 1.04$ & $7.53 \pm 0.96$ & $7.13 \pm 1.03$ & $5.96 \pm 0.58$ & $5.60 \pm 0.66$ & $5.52 \pm 0.49$ & $5.28 \pm 0.56$ & $5.07 \pm 0.55$ \\
\hline \multicolumn{11}{|c|}{ Amphimedon navalis } \\
\hline Area $\mathbf{A}$ & - & $11.36 \pm 0.87$ & $8.86 \pm 1.22$ & $8.5 \pm 1.33$ & $9.66 \pm 1.42$ & - & $0.81 \pm 0.11$ & $0.98 \pm 0.11$ & $1.16 \pm 0.13$ & $1.35 \pm 0.14$ \\
\hline Area B & - & $7.53 \pm 0.96$ & $5.66 \pm 0.79$ & $5.16 \pm 0.89$ & $4.53 \pm 0.77$ & - & $0.48 \pm 0.05$ & $0.51 \pm 0.05$ & $0.55 \pm 0.04$ & $0.57 \pm 0.06$ \\
\hline Area C & - & $9.70 \pm 0.95$ & $7.93 \pm 1.25$ & $8.63 \pm 1.09$ & $7.6 \pm 0.95$ & - & $8.61 \pm 1.48$ & $7.53 \pm 0.86$ & $9.03 \pm 0.51$ & $9.12 \pm 0.96$ \\
\hline \multicolumn{11}{|c|}{ Spheciospongia vagabunda } \\
\hline Area A & - & $3.00 \pm 0.36$ & & $5.56 \pm 0.57$ & $5.93 \pm 0.64$ & - & $7.51 \pm 0.67$ & $7.75 \pm 0.63$ & $8.51 \pm 0.95$ & $8.59 \pm 0.84$ \\
\hline Area B & - & $1.96 \pm 0.33$ & $2.83 \pm 0.35$ & $3.03 \pm 0.39$ & $3.26 \pm 0.45$ & - & $4.12 \pm 0.44$ & $4.67 \pm 0.47$ & $5.21 \pm 0.6$ & $5.75 \pm 0.62$ \\
\hline
\end{tabular}


Table C4.3 Results from Generalised Linear Models indicating the temporal differences of sponge abundance (negative binomial regression) and percentage cover (linear model) per area of occurrence. $S$. Error $=$ Standard error, $z=z$-value, $p=p$-value. Significant results $(p<0.05)$ are highlighted in bold.

\begin{tabular}{|c|c|c|c|c|c|}
\hline Variable & Coefficient & Estimate & S. Error & $\mathbf{z}$ & $\mathbf{p}$ \\
\hline \multicolumn{6}{|c|}{ Neopetrosia chaliniformis } \\
\hline \multirow{7}{*}{ Abundance } & Intercept & 49.177 & 24.017 & 2.048 & 0.040 \\
\hline & Time & -0.024 & 0.011 & -2.043 & 0.041 \\
\hline & Area B & 1.480 & 0.137 & 10.741 & $<0.001$ \\
\hline & Area $\mathrm{C}$ & 0.886 & 0.141 & 6.249 & $<0.001$ \\
\hline & Area D & 1.444 & 0.138 & 10.461 & $<0.001$ \\
\hline & Area E & 1.304 & 0.138 & 9.395 & $<0.001$ \\
\hline & Area F & 1.936 & 0.136 & 14.232 & $<0.001$ \\
\hline \multirow{7}{*}{$\%$ Cover } & Intercept & 1.343 & 0.612 & 2.194 & 0.028 \\
\hline & Time & -0.001 & 0.001 & -2.148 & 0.032 \\
\hline & Area B & 0.020 & 0.003 & 6.353 & $<0.001$ \\
\hline & Area C & 0.009 & 0.003 & 3.033 & 0.002 \\
\hline & Area D & 0.009 & 0.003 & 3.076 & 0.002 \\
\hline & Area E & 0.012 & 0.003 & 3.992 & $<0.001$ \\
\hline & Area F & 0.026 & 0.003 & 8.251 & $<0.001$ \\
\hline \multicolumn{6}{|c|}{ Amphimedon navalis } \\
\hline \multirow{4}{*}{ Abundance } & Intercept & 2.369 & 0.094 & 25.150 & $<0.001$ \\
\hline & Time & -0.036 & 0.017 & -2.025 & 0.042 \\
\hline & Area B & -0.525 & 0.112 & -4.664 & $<0.001$ \\
\hline & Area C & -0.125 & 0.110 & -1.136 & 0.255 \\
\hline \multirow{4}{*}{$\%$ Cover } & Intercept & 0.008 & 0.003 & 2.415 & 0.016 \\
\hline & Time & 0.001 & 0.001 & 1.397 & 0.163 \\
\hline & Area B & -0.005 & 0.003 & -1.390 & 0.165 \\
\hline & Area C & 0.075 & 0.003 & 19.111 & $<0.001$ \\
\hline \multicolumn{6}{|c|}{ Spheciospongia vagabunda } \\
\hline \multirow{3}{*}{ Abundance } & Intercept & 1.320 & 0.083 & 15.801 & $<0.001$ \\
\hline & Time & 0.075 & 0.017 & 4.219 & $<0.001$ \\
\hline & Area B & -0.542 & 0.092 & -5.897 & $<0.001$ \\
\hline \multirow{3}{*}{ \% Cover } & Intercept & 0.074 & 0.004 & 17.258 & $<0.001$ \\
\hline & Time & 0.002 & 0.001 & 2.236 & 0.026 \\
\hline & Area B & -0.031 & 0.004 & -6.700 & $<0.001$ \\
\hline
\end{tabular}


Table C4.4 Coefficients of Generalised Linear Mixed Models with fixed effects, coefficient estimate, standard error, $\mathrm{z}$ or $\mathrm{t}$-values and $\mathrm{p}$-values for all dependent variables (abundance and percentage cover). Significant results $(\mathrm{p}<0.05)$ are highlighted in bold.

\begin{tabular}{|c|c|c|c|c|c|}
\hline Variable & Fixed Effects & Estimate & S. Error & z/t-value & p value \\
\hline \multicolumn{6}{|c|}{ Neopetrosia chaliniformis } \\
\hline \multirow{3}{*}{ Abundance } & SST & -0.124 & 0.035 & -3.544 & $<0.001$ \\
\hline & Chl $a$ & -0.099 & 0.046 & -2.170 & $\mathbf{0 . 0 3 0}$ \\
\hline & SST, Chl $a$ & -0.026 & 0.052 & -0.504 & 0.614 \\
\hline \multirow{3}{*}{$\%$ Cover } & SST & -0.004 & 0.001 & -2.013 & 0.044 \\
\hline & Chl $a$ & -0.001 & 0.002 & -0.654 & 0.513 \\
\hline & SST, Chl $a$ & 0.001 & 0.002 & 0.344 & 0.730 \\
\hline \multicolumn{6}{|c|}{ Amphimedon navalis } \\
\hline \multirow{3}{*}{ Abundance } & SST & -0.263 & 0.044 & -5.881 & $<0.001$ \\
\hline & Chl $a$ & -0.194 & 0.054 & -3.555 & $<0.001$ \\
\hline & SST, Chl $a$ & -0.107 & 0.056 & -1.917 & 0.055 \\
\hline \multirow{3}{*}{ \% Cover } & SST & 0.031 & 0.026 & 1.193 & 0.345 \\
\hline & Chl $a$ & 0.001 & 0.004 & 0.358 & 0.720 \\
\hline & SST, Chl $a$ & 0.002 & 0.004 & 0.273 & 0.785 \\
\hline \multicolumn{6}{|c|}{ Spheciospongia vagabunda } \\
\hline \multirow{3}{*}{ Abundance } & SST & 0.515 & 0.089 & 5.783 & $<0.001$ \\
\hline & Chl $a$ & 0.313 & 0.091 & 3.438 & $<0.001$ \\
\hline & SST, Chl $a$ & 0.237 & 0.095 & 2.478 & 0.013 \\
\hline \multirow{3}{*}{$\%$ Cover } & SST & 0.010 & 0.005 & 1.728 & 0.084 \\
\hline & Chl $a$ & 0.006 & 0.006 & 0.966 & 0.335 \\
\hline & SST, Chl $a$ & 0.003 & 0.006 & 0.545 & 0.586 \\
\hline
\end{tabular}


Table C4.5 Immediate habitats of Neopetrosia chaliniformis, Amphimedon navalis and Spheciospongia vagabunda in their respective lagoons of occurrence. Data extracted from Appadoo et al. (2011), Beepat (2015) and Beepat et al. (2013), respectively.

\begin{tabular}{cccc}
\hline Habitat & \multicolumn{3}{c}{ Percentage cover (\%) } \\
\hline & Neopetrosia chaliniformis & Amphimedon navalis & Spheciospongia vagabunda \\
\hline Dead corals/coral & $49.16 \pm 9.23$ & $25.10 \pm 6.27$ & $31.90 \pm 8.91$ \\
rubble & $29.57 \pm 4.56$ & $39.66 \pm 5.14$ & - \\
Live corals & $10.50 \pm 3.81$ & $4.50 \pm 1.49$ & $43.33 \pm 8.01$ \\
Sand & $10.77 \pm 2.10$ & $30.74 \pm 5.23$ & $24.77 \pm 4.95$ \\
Others & & & \\
\hline
\end{tabular}

\section{References}

Appadoo C, Beepat SS, Marie DEP (2011) Study of physico-chemical parameters affecting the distribution of sponge Xestospongia exigua (Phylum Porifera, Class Demospongiae) in a northern lagoon of mauritius. J Environ Res Develop 5: 741-748

Beepat SS, Appadoo C, Marie DE, Paula J, Sivakumar K (2013) Distribution, abundance and ecology of the sponge Spheciospongia vagabunda (Phylum: Porifera, Class: Demospongiae) in a shallow lagoon of Mauritius. West Indian Ocean J Mar Sci 12: 1523

Beepat SS (2015) Ecology, diversity and symbiotic associates (with special reference to Actinobacteria) of marine sponges in the coastal lagoons of Mauritius. Dissertation, University of Mauritius 


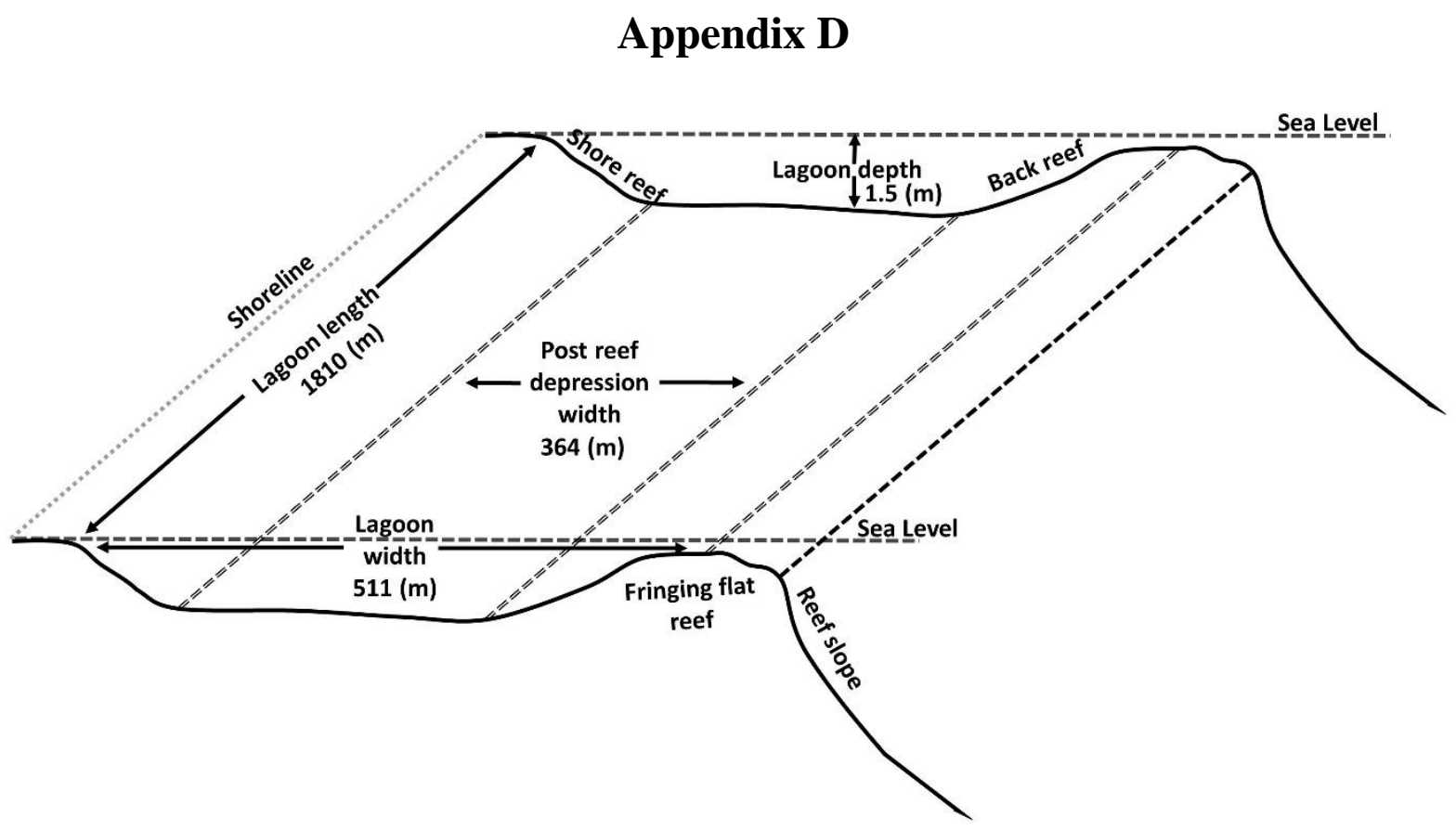

Fig. D5.1 Topographical features of the Albion lagoon. 
Table D5.1 Dataset used to estimate the sponge volume to sponge percentage cover conversion factor $(3.89 \pm 0.13)$.

\begin{tabular}{ccccc}
\hline Quadrat No & $\begin{array}{c}\text { Sponge } \\
\text { percentage cover }\end{array}$ & $\begin{array}{c}\text { Sponge volume } \\
(\mathbf{m l})\end{array}$ & $\begin{array}{c}\text { Conversion } \\
\text { factor }\end{array}$ \\
\hline 1 & 63.7455 & 16.539 & 3.854253582 \\
2 & 78.456 & 20.946 & 3.745631624 \\
3 & 61.7841 & 16.285 & 3.793926927 \\
4 & 76.4946 & 20.163 & 3.793810445 \\
5 & 50.0157 & 13.183 & 3.793954335 \\
6 & 31.3824 & 8.272 & 3.793810445 \\
7 & 10.7877 & 8.637 & 1.249010073 \\
8 & 53.9385 & 14.549 & 3.707368204 \\
9 & 87.2823 & 16.927 & 5.156395108 \\
& 11.7684 & 3.182 & 3.698428661 \\
& 10 & 55.8999 & 15.116 & 3.698061657 \\
11 & 34.3245 & 9.282 & 3.697963801 \\
& 12 & 83.3595 & 22.542 & 3.697963801 \\
13 & 73.5525 & 15.856 & 4.638780272 \\
14 & 69.6297 & 22.059 & 3.156521148 \\
15 & 116.7033 & 22.281 & 5.237794533 \\
16 & 58.842 & 13.644 & 4.312664908 \\
& 17 & 71.5911 & 16.6 & 4.312716867 \\
Standard Error & 93.1665 & 21.603 & 4.312664908 \\
& 18 & 62.7648 & 15.147 & 4.143711626 \\
& 19 & 77.4753 & 20.84 & 3.71762476 \\
& 20 & 60.8034 & 15.602 & 3.897154211 \\
& 21 & 77.4753 & 19.881 & 3.896951864 \\
& 22 & 49.035 & 12.582 & 3.897234144 \\
& 23 & 30.4017 & 7.801 & 3.897154211 \\
\hline 24 & 61.627188 & 15.58076 & 3.886062085 \\
& & & & \\
& & & &
\end{tabular}


Table D5.2 Results of Games-Howell and Tukey post hoc pairwise comparisons from Oneway ANOVA for the effects of temperature on the consumption of bacterial cells and nutrient fluxes of S. vagabunda in Albion lagoon. Significant p-values are reported in bold.

\begin{tabular}{|c|c|c|c|c|c|c|c|}
\hline \multicolumn{2}{|c|}{ Temp } & $\begin{array}{c}\text { Mean } \\
\text { Difference }\end{array}$ & $\begin{array}{l}\text { Std. } \\
\text { Error }\end{array}$ & df & $\boldsymbol{P}$ & $\begin{array}{c}\text { CI } \\
\text { (lower) }\end{array}$ & $\begin{array}{c}\text { CI } \\
\text { (upper) }\end{array}$ \\
\hline \multicolumn{8}{|c|}{ Bacterial cells consumption } \\
\hline $26^{\circ} \mathrm{C}$ & $28^{\circ} \mathrm{C}$ & -0.045 & 0.005 & 357 & $<0.001$ & -0.057 & -0.033 \\
\hline $26^{\circ} \mathrm{C}$ & $30^{\circ} \mathrm{C}$ & -0.053 & 0.005 & 357 & $<0.001$ & -0.066 & -0.040 \\
\hline $28^{\circ} \mathrm{C}$ & $30^{\circ} \mathrm{C}$ & -0.008 & 0.006 & 357 & 0.390 & -0.023 & 0.006 \\
\hline \multicolumn{8}{|c|}{ Chl $a$ uptake } \\
\hline $26^{\circ} \mathrm{C}$ & $28^{\circ} \mathrm{C}$ & -0.332 & 0.066 & 357 & $<0.001$ & -0.489 & -0.174 \\
\hline $26^{\circ} \mathrm{C}$ & $30^{\circ} \mathrm{C}$ & -0.383 & 0.066 & 357 & $<0.001$ & -0.541 & -0.226 \\
\hline $28^{\circ} \mathrm{C}$ & $30^{\circ} \mathrm{C}$ & -0.051 & 0.066 & 357 & 0.719 & -0.209 & 0.105 \\
\hline \multicolumn{8}{|c|}{ DOC uptake } \\
\hline $26^{\circ} \mathrm{C}$ & $28^{\circ} \mathrm{C}$ & -0.321 & 0.043 & 357 & $<0.001$ & -0.423 & -0.219 \\
\hline $26^{\circ} \mathrm{C}$ & $30^{\circ} \mathrm{C}$ & -0.368 & 0.043 & 357 & $<0.001$ & -0.470 & -0.267 \\
\hline $28^{\circ} \mathrm{C}$ & $30^{\circ} \mathrm{C}$ & -0.047 & 0.043 & 357 & 0.517 & -0.149 & 0.054 \\
\hline \multicolumn{8}{|c|}{$\mathrm{NO}_{2}^{-}+\mathrm{NO}_{3}^{-}$production } \\
\hline $26^{\circ} \mathrm{C}$ & $28^{\circ} \mathrm{C}$ & -0.334 & 0.074 & 357 & $<0.001$ & -0.509 & -0.159 \\
\hline $26^{\circ} \mathrm{C}$ & $30^{\circ} \mathrm{C}$ & -0.383 & 0.074 & 357 & $<0.001$ & -0.558 & -0.208 \\
\hline $28^{\circ} \mathrm{C}$ & $30^{\circ} \mathrm{C}$ & -0.049 & 0.074 & 357 & 0.785 & -0.224 & 0.125 \\
\hline \multicolumn{8}{|c|}{$\mathrm{PO}_{4}{ }^{3-}$ production } \\
\hline $26^{\circ} \mathrm{C}$ & $28^{\circ} \mathrm{C}$ & -0.334 & 0.050 & 357 & $<0.001$ & -0.452 & -0.216 \\
\hline $26^{\circ} \mathrm{C}$ & $30^{\circ} \mathrm{C}$ & -0.383 & 0.050 & 357 & $<0.001$ & -0.501 & -0.265 \\
\hline $28^{\circ} \mathrm{C}$ & $30^{\circ} \mathrm{C}$ & -0.049 & 0.050 & 357 & 0.586 & -0.167 & 0.068 \\
\hline
\end{tabular}

